\title{
I. Beratungsgegenstand:
}

\section{Die staatliche Intervention im Bereich der Wirtschaft ${ }^{\mathbf{}}$ )}

\author{
Rechtsformen und Rechtsschutz
}

\author{
1. Bericht von Professor Dr. Ulrich Scheuner, Bonn
}

I. Im Jahre I83I wandten sich die Gemeindebevollmächtigten der Haupt- und Residenzstadt München mit einer Vorstellung an die Kammer der Abgeordneten ${ }^{2}$ ), in der sie sich gegen die in dem Gesetze vom II. 9. I825, die Grundbestimmungen des Gewerbewesens betr., enthaltenen Bestimmungen wandten, die beim Vorliegen der Voraussetzung der persönlichen Fähigkeit des Bewerbers zu dem Gewerbe und der Erfüllung der Bedingungen für die Ansässigmachung festlegten, daB die Konzession nicht versagt werden dürfe, und die nur eine offenbar wenig benutzte Bestimmung enthielten, wonach bei in ihrem Absatz ortsgebundenen Gewerben der Nahrungsstand, d.h. die vorhandenen Stellen, berücksichtigt werden könnten $\%$. Stattdessen, so forderte die Eingabe, solle man im Hinblick auf die eingetretene schädliche und übermäßige Vermehrung des Gewerbes als fernere Erfordernisse aufstellen: „Die Concession wird mit besonderer Berücksichtigung des Nahrungsstandes sowohl der bereits Berechtigten als des Bewerbers verliehen. Bey den unproductiven örtlichen Gewerben findet eine neue Concessionsverleihung nur im Falle des Bedarfes Statt $)^{\prime \prime}$.

1) Derm Bericht ist in den Anmerkungen ergănzendes Material beigegeben, auch soweit es - durch die dem I. Berichterstatter zur Last fallende verspātete Erscheinung bedingt - spãtere Vorgānge nach der Erstattung des Berichtes betrifft.

1) Vorstellung der Gemeindebevollmächtigten der konigl. Haupt- und Residenzstadt München an die im Jahre 1831 versammelte Kammer der Abgeordneten, die gegenwärtige Gewerbs-Gesetrgebung betreffend, München 1831. Dieselben Grundgedanken mit eingehender statistischer Grundlage findet man schon bei J oh. Nep. Frhr. v. Pelkhoven, Uber die Gewerbe in Bayern aus einem hőheren Standpunkte betrachtet, oder über die Folgen einer unbeschrănkten Gewerbe- und Handelsfreyheit, München 1818.

2) Art. 2' des Gesetzes. Zum bayerischen Rechtszustand im Vormărx siehe Ernst v. Moy, Das Staatsrecht des Kgr. Bayern II, I, Regensburg I843. S. $404 \mathrm{ff}$.

4) Vorstellung S. 4I. Āhnliche Tendenzen in preuBischen Eingaben gegen die dort eingeführte Gewerbefreiheit siehe bei Kurt v. Rohrscheid, Vom Zunftzwange zur Gewerbefreiheit 1898 , S. $55^{8} \mathrm{ff}$ (z. B. Eingabe des Berliner Magistrats vom 18. 3. 1817). Es ist bekannt, wie noch $1848 \mathrm{Be}-$ strebungen zur Begrenzung der Gewerbefreiheit für handwerkliche Kreise auftraten. Vgl. dazu Herbert Arthur Strau B, Staat, Bürger, Mensch. Die Debatten der Dt. Nationalversammlung $1848 / 49$ über die Grundrechte, 
Die Schrift der Gemeindebevollmächtigten stellt ihren Ausführungen den Gedanken voran, da $B$ der Staat über die Entwicklung der Gewerbe bestimme:

„Wie auf fast alle Verhältnisse im Staate, so wirkt auch auf den Wohlstand der Gewerbetreibenden die Gesetzgebung bald fördernd bald hemmend ein, je nachdem sie ihre Aufgabe richtig erfaßt, oder durch Truggebilde sich täuschen läBt, sie ist es, die die Grundlage dauernder kräftiger Blüte der Gewerbe bildet, in ihr findet sich aber auch die Ursache, wenn diese immer mehr verwelkend dahin siechen" 5 ).

Ich führe diesen für die damalige Zeit keineswegs seltenen Vorgang nicht deshalb an, um die Konstanz gewisser mittelständischer Wünsche und Forderungen zu beleuchten - geht es doch heute um die Merkmale der Zuverlässigkeit und Sachkunde im Einzelhandel ${ }^{6}$ ) oder um den großen Befähigungsnachweis im Handwerk ${ }^{7}$ )oder um darzutun, welche Bedeutung der Staatsintervention in jener noch präliberalen Anschauung eingeräumt wurde. Es sind vielmehr einige andere Züge, die an diesem Vorgang bezeichnend erscheinen. Hier gilt die aus Handwerkerkreisen stammende Bitte an den Staat nicht dem Schutze von Freiheitsrechten und der Abwehr von Staatseingriffen, sondern es wird umgekehrt ein Eingreifen des Staates zur Lenkung der wirtschaftlichen Entwicklung verlangt. Diese Wünsche wurden auch nicht von Individuen vorgetragen, sondern von einer Gruppe, zu deren Sprecherin sich eine kommunale Versammlung machte. Und nicht die staatliche Verwaltung ist es, an die man sich wendet, sondern der Gesetzgeber, die Kammer. Das Gruppeninteresse ist es, daß nnan geschützt wissen möchte, wenn nach österreichischem Vorbild die vorherige Einvernehmung der Gewerbetreibenden vor Erteilung einer neuen Konzession und die Gewährung eines Rekurses der Gewerbetreibenden gegen eine Erlaubniserteilung begehrt wird ${ }^{\text {\%). }}$

In diesem Gesuche - und wie viele ähnliche aus alter und neuer Zeit könnte man anführen - treten deutlich die besonderen Probleme und Schwierigkeiten hervor, die das Gebiet der staatlichen Wirtschaftsregulierung von anderen Zweigen des Verwaltungsrechtes unterscheiden. Unser Verwaltungsrecht ist. jedenfalls in

\footnotetext{
Aarau 1947, S. 59ff.; Stadelmann, Soziale und politische Geschichte der Revolntion von 1848 , München 1948, S. IIf., 61 f., I66ff. Für das Denken in handwerklichen Positionen ein bezeichnendes Beispiel jetzt bei Smend, Die Gottinger Universität und ihre Umwelt, 1953, S. 6: 1848 glaubte der städtische Kapellmeister und Inhaber des gewerblichen Musikmonopols der Stadt, jetzt seine Stellung gegen die bisher den Professoren freistehende Zuziehung auswărtiger Musik endgültig gesichert.

5) Vorstellung S. $1 / 2$.

9 Vl. hierzu die Entscheidung des OVC. Münster v. 16. 10. 1952 DVBH. $r 953$ S. 474.

7 Handwerksordnung vom 17.9. 1953 (BGBl. S. I4II) \$7

o) Vorstellung a. a. O. S. 43.
} 
dem an dem glänzenden Bau des französischen droit administratif orientierten Gebäude, das es seit dem Durchdringen der juristischen Schule Ot to Mayers darstellt, ausgerichtet an dem Bilde, wie es die europäischen Staaten in der hochliberalen Epoche etwa zwischen I860 bis I880 darboten. Denn in diesem Zeitraum sind die Werke von Aucoc und Laferrièrt entstanden, die den Ruhm der französischen Theorie erneut begründeten und die über Otto Mayer hinweg auch die deutsche Entwicklung so tief beeinflußt haben. Im Mittelpunkte dieses Verwaltungsrechtes steht der Staat als bloße Ordnungsmacht, nicht als Gestaltungskraft, die die sozialen Verhältnisse formt und leitet. Daher wird zur entscheidenden Rechtsfigur der hoheitliche Eingriff des Staates in die Freiheiten des Bürgers mit dem Kern im Polizeirecht. Die wirtschaftlichen Fragen treten nur in der Gestalt einer überwachenden, polizeilich aufgefaßten Kontrolle des Staates über die Gewerbe und eines Sonderrechtes der öffentlichen Betriebe und Anstalten in Erscheinung, das uns in den Monopolen, der Gestalt des beliehenen Unternehmers und dem Begriffe der Anstalten und Körperschaften begegnet. Die Enteignung, deren Zusammenhang mit der staatlichen Intervention zugunsten bestimmter geförderter Wirtschaftsbetriebe wie der Eisenbahnen oder gewisser Industriezweige heute kaum mehr bewuBt ist - dankenswerterweise hat in den vorjährigen Beratungen Herr Ipsen auf den Zusammenhang von Staatsintervention und Inhaltsbestimmung des Eigentums aufmerksam gemacht ${ }^{9}$ ) - wird gesondert beim Recht der öffentlichen Sachen behandelt. Das Gesetz erscheint in dieser Lehre noch in seiner vollen Autorität als Ausdruck des nationalen Gesamtwillens und damit als souveräne Entscheidung. Es steckt die Grenzen des Eigentums ab, es befindet endgültig darüber, ob für einen verändernden Eingriff - z. B. die Aufhebung überalterter wirtschaftlicher Vorrechte - eine Entschädigung zu gewähren ist, und es kann gewissen Betrieben und Gewerbezweigen durch Konzessionierung als öffentliche Unternehmen erhöhte rechtliche Möglichkeiten verleihen.

Für gewisse Gebiete des wirtschaftlichen Lebens ist dies Bild auch heute noch teilweise gültig, oder man bemüht sich, es wieder zur Geltung zu bringen. Kann man aber heute noch das Verhältnis des Staates zur Wirtschaft in dem Rahmen der Gewerbeordnung - so wichtig ihr Recht bleibt - einfangen? Um wenigstens alsbald einige Stichworte zu nennen: Wo der Staat unmittelbar mit Gebot und Verbot, mit Erlaubnissen, Auflagen und Inhaltsbestimmung von Rechtsverhältnissen in den Bereich des Eigentums, der Vertrags- und Gewerbefreiheit eingreift, da bleiben, soweit die Einwirkungen auf allgemeinen Normen beruhen und im Einzelfall

ๆ VDStRL. to S. 75, 83 . 
von Verwaltungsbehörden ausgeführt werden, die alten Formen anwendbar. Schwierig wird es aber bereits, wo es sich um die gesetzliche Absteckung der Grenzen des Eigentums oder von rechtlichen Freiheiten handelt, etwa um die Bestimmung des Mißbrauchs wirtschaftlicher Machtstellungen (Art. 74 Ziff. I6 GG.), und vollends dort, wo der Gesetzgeber selbst unmittelbare rechtliche und wirtschaftliche Verfügungen trifft, im Einzelfall enteignet, bestimmte soziale Gruppen begünstigt, andere benachteiligt, überhaupt eine gestaltende und verändernde Aktivität entfaltet. Und wie steht es ferner, wenn der Staat ganze Wirtschaftszweige regulierend ordnet - Zulassung, Ausübung des Berufes, Preise, Qualitäten, Betriebsart und-größe, Subventionenoder umgestaltend die soziale Ordnung auf ganzen Gebieten durch Vergesellschaftung oder durch Uberführung von Tätigkeiten in seine eigene Hand oder durch Aufrichtung von Kontrollen und Lenkungsmaßnahmen verwandelt? Die ältere Anschauung ließ hier dem Gesetzgeber freie Hand. Heute ist es die Verfassung oder sind es die aus dem ungeschriebenen Recht - in den angelsächsischen Ländern dem Common Law, in Frankreich den libertés publiques - entwickelten allgemeinen Grundsätze, an denen nun auch die Tätigkeit des Gesetzgebers rechtlich gemessen wird, und in denen das wirtschaftliche Leben in der Gegenwart eine festere, konstante Rechtsbasis sucht. Uberall geht es um das Problem, wie die zahlreichen indirekten Einwirkungen des Staates - von der Steuer über die Subventionen bis zur Manipulation der Währung und der Einflußnahme durch das Kreditwesen und die Devisenkontrolle - erfaßt und den Grundsätzen rechtsstaatlicher Gestaltung und einem ausreichenden Rechtsschutz unterstellt werden.

2. Ein weiterer wichtiger Gesichtspunkt tritt hinzu: Es handelt sich heute im wirtschaftlich-sozialen Bereich nicht mehr allein um eine Auseinandersetzung Individuum-Staat. Das wirtschaftliche und gesellschaftliche Leben unseres Zeitalters ist von den sozialen Gruppen und Zusammenschlüssen durchformt und teilweise beherrscht. Damit aber gewinnen alle Beziehungen neue Seiten. Auch die Verbände begehren Sicherung ihrer Sphäre gegenüber dem Staate. Sie streben aber auf der anderen Seite auch nach Einflub auf sein Handeln, um ihre Zwecke mit staatlicher Hilfe zu fördern oder den Staat in eine bestimmte Richtung zu lenken ${ }^{10}$ ). Wiederum aber wird das Individuurm sich nicht selten an den Staat

19 Zum Aufstieg der Gruppen siehe K. Mannheim, Freedom, Power and Democratic Planning, 1950, S. I I ff., 56 ff. (Power Concentration in Groups); Earl Latham, The Group Basis of Politics in American Pol. Science Review 46, 1952, S. 37rff.; Eichenberger, Die oberste Gewalt im Bunde, Zürich 1949, S. 215 ff.; Hans Georg Giger, Die Mitwirkung privatrechtlicher Verbände bei der Durchführung offentlicher Aufgaben (Berner Rechts- und Wirtschaftswiss. Abh. 6o) I95I S. 32 ff., I92 ff. 
mit dem Wunsche nach Schutz vor der übermächtig gewordenen Verbandsgewalt wenden. Individuelle Freiheitsrechte, die auf die Figur und den Machtbereich der Einzelperson abgestellt sind - Vertragsfreiheit, Meinungsfreiheit, Unterrichtsfreiheit - können in der Hand großer Organisationen eine tiefe Umwandlung erfahren. Sie werden hier zur Grundlage planmäBig gelenkten Verbandseinflusses und damit zu einem Mittel sozialer Machtbildungi1). Denn die individuellen Freiheitsrechte, von denen das Recht zwar einzelne persönliche Gewährleistungen wie Glaubensfreiheit, Berufsfreiheit (Art. I2 GG.) oder Freiheit der Wohnung den Verbänden vorenthält, stehen in erheblichem Umfang - ich denke an Eigentum und wirtschaftliche Betätigung (Art. 2 GG.), Gleichheit und gewerbliche Freiheit - auch den Organisationen gemä $B$ Art. I9 Abs. III GG. 2u ${ }^{12}$ ).

3. Ich habe in diesen einleitenden Bemerkungen die Probleme umrissen, von denen aus sich das Recht der staatlichen Intervention

11) Die Abhăngigkeit des einzelnen von den sozialen Gruppen und Verbānden liegt entweder in dem Umstand begründet, daB der Verband tatsächlich den Anteil des einzelnen in einem bestimmten Wirtschaftszweige sichert oder kontrolliert, oder darin, daß der Verband in Ausübung der Vertragsfreiheit sich die Möglichkeit zur Ergreifung von Sanktionen gegen den einzelnen verschafft hat. Ein lehrreiches Beispiel hierfür bietet der kanadische Fall White v. Kuzych, der zur Entscheidung des Privy Council gelangte (I95I) 2 All E. R. 435. Die Gewerkschaft der Kesselmacher und Schiffbauer schlieBt ein Mitglied aus, das sich in einer Versammlung gegen das System des „closed shop" (Vereinbarung mit den Arbeitgebern, nur Organisierte dieser Gewerkschaft einzustellen) aussprach. Nach der Satzung der Gewerkschaft mußte der Betroffene, ehe er die Gerichte anrufen durfte, zuerst den Exekutivausschu $\beta$ der Shipbuilders Federation anrufen. Das war unterblieben. Die beiden ersten Instanzen wollten die Ausschließung für ungültig halten, weil das Verfahren parteiisch gewesen sei und ein Spruch solcher Bedeutung dem ordentlichen Richter vorbehalten sein müsse: „The civil liberties of the subject cannot be decided by a trial committee set up by a labour union". Sie betonten die schwerwiegende Natur des Ausschlusses: „A man has a right to work at his trade. If membership in a union is a condition attached to working in hus trade, then he has an indefeasible right to belong to that union. It must be so or else the union can have no right to agitate for a closed shop." Der Privy Council dagegen weist die Ansprüche des Ausgeschlossenen zurück. Er sieht in dem AusschluBverfahren keine Grundsãtze der „,natural justice“ (der grundlegenden Regeln eines geordneten Verfahrens) verletzt und bleibt daher dabei, der Betroffene hātte zuerst das verbandsinterne Verfahren durchführen müssen. Dagegen hat das Schweizer Bundesgericht die Verdrängung eines Arbeiters aus einer Fabrik durch die dort herrschende Gewerkschaftsrichtung wegen anderweiter Zugehorigkeit zu einem Berufsverbande für unzulässig erklärt, BGE. 5 I II 525 ff.

19) Daß die „Entfaltung der Persönlichkeit“ im eigentlichen vollen Sinn nur für den Menschen, nicht für einen Verband denkbar ist, folgt aus der Menschenauffassung des Grundgesetzes. Vgl. Dürig, JRdschau 1952 S. 259ff.; ders. AOOR. 79, 1953 S. 60 Anm. 19. Es bleibt jedoch richtig, daB hinsichtlich der Entfaltung im wirtschaftlichen Bereich - und nur in dieser Begrenzung - auch die Verbände sich wohl auf Art. 2 Abs. I stützen mógen. Vgl. Nip perdey, BB. I95I S. $593 \mathrm{ff}$. 
betrachten läßt. Es handelt sich wesentlich um die verfassungsrechtlichen Grundfragen, denen der schweizerische Gelehrte Hans Huber in seiner Arbeit über „Das Staatsrecht des Interventionismus" nachgegangen ist ${ }^{13}$ ), und die in Deutschland früher von Nipperdey ${ }^{14}$ ) und Ballerstedt ${ }^{15}$ ) erörtert worden sind. Zunächst: Ist der staatliche Interventionismus überhaupt mit den Grundlagen der demokratischen Freiheit und des Rechtsstaates vereinbar, und wenn man dies bejaht, in welchem Umfang?

Sodann die zweite Frage:

Wieweit lassen sich die Vorgänge des staatlichen Interventionismus mit unserer herkömmlichen Begriffsbildung erfassen, und in welcher Hinsicht bedarf unser rechtliches Denken einer Ergänzung und Fortbildung?

Als dritte Frage erhebt sich endlich das Problem des Rechtsschutzes gegenüber einer in ihren Formen und rechtlichen Gestaltungen so schwer übersehbaren und faßbaren Staatstätigkeit.

Ehe wir aber in zwei Abschnitten die Auswirkungen der Intervention auf das Verfassungs- und Verwaltungsrecht und die Probleme des Rechtsschutzes gegen Maßnahmen des interventionistischen Staatshandelns betrachten, werden wir zuvor in zwei anderen Abschnitten untersuchen müssen, was überhaupt unter der Intervention des Staates und unter interventionistischer Wirtschaftspolitik $z u$ verstehen ist, und ein Bild der auBerordentlichen Vielfalt der Formen staatlicher Einwirkung auf das Wirtschaftsleben zu zeichnen haben. Dabei bin ich mir bewußt, daß der Gegenstand unvermeidliche Beschränkungen auferlegt. Ich muB mich mit einer Auswahl von Fragen aus dem Gesamtgebiet unseres Themas begnügen, zumal ich auf eine so sehr auf praktische Erfahrung und große Lebensnähe gestützte Ergänzung und Bereicherung meiner Ausführungen durch meinen Mitberichterstatter hoffen darf. Ich greife daher bewußt mehr die grundsätzlichen und die verfassungsrechtlichen Gesichtspunkte als praktische Einzelfragen auf. $\mathrm{Zu}$ meinem Bedauern kann ich aber auch manche wichtige Fragen nur am Rande berühren, so das Verhältnis des Staates zu den wirtschaftlich-sozialen Verbänden, die Monopole und die Formen öffentlicher Unternehmungen $\left.{ }^{16}\right)$. Verzichten muB

\footnotetext{
18) Ztschr. für schweizer. Recht, N. F., 70, I95I, S. I74-r99.

14) Nipperdey, Grundprinzipien des Wirtschaftsverfassungsrechts. DRZ 1950 S. 193 ff.

15) Ballerstedt, Rechtsstaat und Wirtschaftslenkang, AÖR. 74 S. 130 ff. (1948).

10) Zum Problem der Formen offentlicher Unternehmen siehe etwa Walter HeuBer, Die Flucht des Gemeinwesens in die privatrechtliche Unternehmung als Rechtsproblem, Zürich r949; Dénéréaz, Les entreprises d'économie mixte et de droit public organistes selon le droit privt, Ztschr. f. Schweiz. Recht, N. F. 72 (1953)S. I aff.; Schürmann, Das Recht der gemischtwirtschaftlichen und offentlichen Unternehmungen mit privatrechtlicher Organisation, dort S. 65 aff.; E. R. Huber, Wirtschaftsver-
} 
ich auch ebenso auf historische Ausblicke wie auf eine systematische Darlegung des geltenden Rechts, die den Rahmen eines Vortrages sprengen würde. Schließlich habe ich auch - da jedes Ausgreifen auf die Formen und Fragen der totalitären Rechtssysteme auf einen völlig anders gearteten Boden führen würde und daher eine umfangreiche Vorklärung der abweichenden Voraussetzungen erforderte - auf eine Darstellung dieses Gebietes, in das uns neuerdings das lehrreiche Buch von Eckart Krömer ${ }^{17}$ ) einführt und das jedes Studium der ostzonalen Literatur und Rechtsprechung so eindrücklich erschließt, verzichten müssen und mich auf den Ausblick auf andere europäische Länder beschränkt. Ich vertraue dabei darauf, daß wir hier glücklicherweise durch unsere Schweizer Gäste auf eine Ergänzung hoffen dürfen. Bei der außerordentlichen Weite und Fülle des Stoffes können solche vergleichenden Ausblicke zum fremden Recht nur beispielshafte Einzelanführungen sein.

\section{Abschnitt}

\section{Begriff und Wesen der staatlichen Intervention}

I. Die staatliche Intervention im Bereiche der Wirtschaft bezeichnet eine Gestaltung der staatlichen Wirtschaftspolitik und demzufolge des staatlichen Rechts der Wirtschaft, die sich nicht im Sinne der älteren liberalen Lehre mit einer lediglich polizeilich überwachenden Ordnung begnügt, sondern die eine aktivere Lenkung und Beeinflussung des Wirtschaftsablaufes erstrebt. Die staatliche Intervention greift nach bestimmten politisch-sozialen Zielen in Erzeugung und Verteilung ein, sie schreitet mitunter sogar zu umformenden und auch die rechtlichen und sozialen Grundlagen der Wirtschaft verändernden Eingriffen fort. Auf der anderen Seite aber ist es nicht ihr Ziel, eine umfassende Planung und Leitung des gesamten Wirtschaftsablaufes in einem geschlossenen System zentraler, zwangsweise durchgesetzter Anordnungen zu erreichen. Es handelt sich bei dem Regime der staatlichen Intervention um eine zwischen der freien, den Staat auf Ordnungsfunktionen beschränkenden Wirtschaft und einer umfassenden Planwirtschaft in der Mitte liegende Wirtschaftsordnung.

In der volkswirtschaftlichen Theorie ist für unsere Frage nicht sehr viel Hilfe zu finden. Sie wird in der Gegenwart, jedenfalls in Deutschland, durch einen tiefgehenden Meinungs- und Richtungsgegensatz der neoliberalen Theorie auf der einen, der stärker

waltungsrecht, Bd. I 1953 S. ro4ff.; R. Stodter, Rechtsfragen des Zündholzmonopols, Hamburg 1953 S. 50 ff.

17) Eckart Kromer, Die Sozialisierung in der sowjetischen Besatzungszone Deutschlands als Rechtsproblem (Gottinger rechtswiss. Studien H. 4) 1952. 
von den Ideen der Keynes'schen Richtung abgeleiteten Auffassungen auf der anderen Seite bewegt. In einem streng dogmatischen Zweige der neoliberalen Theorie, wie er in den letzten Jahren gerade in Deutschland viel Boden gewonnen hat - ich nenne hier den Namen Walter Euckens - werden nur zwei Modelltypen, die Marktwirtschaft und die Zentralverwaltungswirtschaft, anerkannt, und von dieser Sicht her erscheint dann bereits ein Regime staatlicher Intervention als auf der breiten Straße zu immer mehr fortschreitender Planung und Lenkung befindlich, sobald einmal der schmale Pfad der theoretischen Tugend einer idealen Wettbewerbswirtschaft verlassen wird. Ich teile nicht den Glauben dieser Richtung an die natürliche und unfehlbare Harmonie des freien Wettbewerbs, wiewohl ich - aber erfahrungsmäßig und undogmatisch - davon überzeugt bin, daß eine freie wirtschaftliche Ordnung, die der Initiative des einzelnen und der Entfaltung und dem Sichmessen der Kräfte genügenden Spielraum läBt, einem Regime des $Z$ wanges und der umfassenden Planung überlegen ist. Ich grenze mich deshalb ausdrücklich von den Anschauungen der neoliberalen Schule ab, weil ich den Begriff der Intervention nicht mit einer diskriminierenden Note versehen möchte, als handele es sich um störende, nicht marktkonforme Eingriffe $\left.{ }^{172}\right)$. Ebensowenig teile ich die Anschauung dieser Schule, daB es im Grunde keine anderen Wirtschaftssysteme als die beiden extremen Modelltypen geben könne. Ich sehe daher auch im staatlichen Interventionismus nicht etwa eine Mischform, die als solche schon eine Schwäche in sich trüge, sondern eine durchaus selbständige, in unserer Zeit entstandene und eigenen besonderen Grundsätzen folgende Wirtschaftsordnung.

Ich muß es mir hier versagen, auf volkswirtschaftliche Systemfragen einzugehen. Ich bin von einer juristischen Sicht her jedenfalls der Meinung, daß jedes Wirtschaftssystem, auch das der freien Markt- und Wettbewerbswirtschaft mit seiner vermeintlichen harmonischen Automatik ${ }^{18}$ ) der Wirtschaftsabläufe, viel stärker von der staatlichen Gestaltung des sozialen Lebens und von der Rechtsordnung abhängt, als dies manchmal von volkswirtschaftlicher Seite erkannt wird. Es ist nicht so, daB das klassische liberale System allein auf dem Gedanken der Freiheit Vertragsfreiheit, Gewerbefreiheit, Wettbewerbsfreiheit - und des

17a) Zur Kritik der neoliberalen Wirtschaftstheorie siehe Hans Ritschl, Weltw. Archiv 65 (1950) S. 218 ff.; Kröll, ZgesStWiss. 108 (1952) S. 470 ff., der richtig auf die Möglichkeit eintr Verbindung planender Elemente mit Gebieten der freien Entwicklung hinweist, wie sie die heutige Lage charakterisieren (S. $488 \mathrm{ff}$.).

19) Zum Glauben an eine "prästabilisierte Harmonie" in der liberalen Vorstellungswelt vgl. Otto Tautscher, ZgesStWiss. I08 (1952) S. 80 f. Die geistesgeschichtliche Herkunft dieses Glaubens beleuchtet C. Schmitt, Die geistesgeschichtliche Lage des Parlamentarismus, 2. Aufl. 1926 S. 5of. 
Eigentums geruht hat. Wenn wir seine historische Erscheinung genauer betrachten, so werden wir eine Reihe ergänzender Voraussetzungen erkennen, auf denen jenes System beruhte und die sämtlich ganz bestimmte politisch-soziale Stellungnahmen der Rechtsordnung enthalten: Dazu gehört die volle Disposition über das Eigentum, auch in der Gestalt des großen, wirtschaftlichsoziale Macht gewährenden Eigentums ${ }^{19}$ ), lange Zeit hindurch gehörte hierher auch noch eine Begrenzung der Vertragsfreiheit und Vereinigungsfreiheit der Arbeitnehmer ${ }^{20}$ ), das Fehlen einer Steuerprogression, geringe Eigenbetätigung der öffentlichen Hand,

19) Mit der Einfügung dieses Eigentums in die einheitliche Privatrechtsordnung wird für das r9. Jahrhundert eine verschiedene Behandlung des personlichen Gebrauchseigentums und gewisser großer Eigentumsbereiche abgewiesen. Das ist auch die Lösung unseres heutigen Rechts, wiewohl in der Zulassung einer Sozialisierung für bestimmte Wirtschaftsgüter und in der Vorstellung des Mitbestimmungsrechts (Ges. vom 21. 5. 195 I GBBl. I S. 347) sich Wandlungen abzeichnen, die gewisse Eigentumsbereiche stärker unter besondere Kontrolle stellen. Im Ausland ist dieser Vorgang der offentlichen Aufsicht über Bereiche des Eigentums oder der Überführung in Formen offentlicher Verfügung weiter ausgebaut. Vgl. für England W. Friedmann, Law and Social Change in Contemporary Britain I95I S. 28 ff.; Edward Goodman, Forms of Public Control and Ownership r95r.

so) Sie ist auch ein Bestandteil des deutschen Rechts im 19. Jahrhundert, das den Arbeitnehmern die Koalitionsfreiheit vorenthält und ländliche Arbeiter wie Gesinde einer Sonderreglung mit Beschränkung der Vertragsfreiheit unterwirft. Vgl. Franz Wieacker, Das Sozialmodell der klassischen Privatrechtsgesetzbücher and die Entwicklung der modernen Gesellschaft (Schriftenreihe der Jurist. Studiengesellschaft Karlsrube Heft 3) 1953 S. I I, I4, der hier mit Recht von einem ,Zeugnis elementarer Ungerechtigkeit" spricht. An diesem Punkte lag indes nicht nur ein Zurückbleiben in der Ausbildung der individuellen Freiheiten vor. Der Bereich der Arbeit trug vielmehr in der modernen Entwicklung in sich die Tendenz, über den Rahmen einer auf den individuellen Wettbewerb aufgebauten Ordnung hinauszuwachsen. Mit der Gewāhrung der vollen Koalitionsfreiheit beginnt auf diesem Felde alsbald die Umwandlung der individuellen Vertragsfreiheit zum kollektiven Arbeitsvertrag und zur disziplinierten Kontrolle sozialer Gruppen. Das heutige Arbeitsrecht wird nicht durch den individuellen freien Vertrag, sondern durch die Verhandlung und den Ausgleich fest organisierter Gruppen gekennzeichnet, denen der Staat durch die Anerkennung der Verbindlichkeit kollektiver Vereinbarungen und die Gewăhrung des Streikrechts einen Raum freien Machtkampfes und freier Gestaltung bestimmter sozialer Verhältnisse überläbt. Die vom Staate den Sozialpartnern eingerăumte Autonomie und Bewegungsfreiheit ist kein Bestandteil einer Ordnung individuellen Wettbewerbes mehr, sondern sie gehört schon der modernen sozialen Erscheinung des Gruppenlebens an, die das Recht erst unvollkommen erfaBt. Vgl. zu diesen Problemen Dietrich Schindler, Recht, Staat, Volkergemeinschaft 1948 S. 299 ff. (,,Werdende Rechte"); Wieacker, Privatrechtsgeschichte der Neuzeit, 1952 S. 318f. Uber die Umwandlung der individuellen Vertragsfreiheit zum "collective bargaining" und die verschiedenartige Behandlung der kollektiven Arbeitsvertråge im angelsächsischen Bereich siehe W. Friedmann a. a. O. S. $48 \mathrm{ff}$, $130 \mathrm{ff}$. Die in allen Staaten zu beobachtende Zurückhaltung des Staates im Gebiet des Arbeitsrechts ist keine vollständige. Abgesehen von Făllen der Intervention im Wege der Schlichtung und der Verbindlich- 
ein freier Außenhandel, die Goldwährung und - wenn wir unsere Blicke über den europäischen Raum hinauslenken - die Beschaffung der wichtigsten kolonialen Rohstoffe durch die besonderen wirtschaftlichen Gegebenheiten und billigen Produktionsbedingungen der kolonialen Expansion ${ }^{n}$ ). Auch das liberale Wirtschaftssystem des rg. Jahrhunderts war - wenn auch in geringerem Gesamtumfange - von einer staatlichen Grundvorstellung getragen und stand unter Einfluß des Staates. Der Staat răumte die erhaltenen Reste älterer wirtschaftlicher Systeme - die Zünfte wie die feudalen Bindungen des lănd-

erklärung tritt das Problem der Begrenzung der Bewegungsfreiheit der Sozialpartner im Problem des politischen Streiks auf. Vgl. Ernst Forsthoff und Alfred Hueck, Die politischen Streikaktionen des Deutschen Gewerkschaftsbundes anläßlich der parlamentarischen Beratung des Betriebsverfassungsgesetzes in ihrer verfassungs- und zivilrechtlichen Bedeutung (Schriftenreihe der Bundesvereinigung der Deutschen Arbeitgeberverbände, Heft 6) Köln r952; C. H. Nipperdey, Die Ersatzansprüche für die Schäden, die durch den von den Gewerkschaften gegen das geplante Betriebsverfassungsgesetz geführten Zeitungsstreik vom 27.-29.5. 1952 entstanden sind (Schriftenreihe der Bundesvereinigung der Deutschen Arbeitgeberverbãnde Heft 9) 1953 S. 18ff. Zur Begrenzung des Streikrechts im englischen Recht anf eigentliche Arbeitskämpfe siehe die Trade Disputes and Trade Unions Act (1927) 17 \& 18 Geo 5 c. 22 und dazu O. Hood Philips, The Constitutional Law of Great Britain 1952 S. 573. Zu den Grenzen des Streiks in Frankreich Pierre Mimin, La grève encadrée Dalloz Hebd. 1952 S. 125 ff. Das Arbeitsverhaltnis wird durch faute lourde imputable au salarié gelöst; dahin rechnet Teilnahme an einem grève extraprofessional, also einem politischen Streik.

21) Steuerprogression: Als Joseph Chamberlain im Jannar 1885 in einer Rede in Birmingham forderte, ,that the burden of taxation is distributed according to the ability of the taxpayer", erregte dies Verlangen lebhaften Unwillen. Vgl. J. L. Garvin, The Life of Joseph Chamberlain, Bd. I 1935 S. 556ff. - Freier AuBenhandel: Die Prinzipien der inneren Wirtschaftsordnung der Staaten und des internationalen Handels stehen in nahem $\mathrm{Zn-}$ sammenhang. Die liberale Freiheit im innerstantlichen Recht war im 19. Jahrhundert auf drei grundlegende tatsächlich vorhandene Freiheiten des internationalen Verkehrs gegründet: Freiheit des Austauschs von Waren, des Kapital- und Geldverkehrs und der Bevolkerungswanderung. Die Einwanderung ist heute fast überall erschwert. Der Kapitalverkehr ist angesichts der Währungsschranken und der allenthalben wachsenden Unsicherbeit der Kapitalanlagen (Nationalisierung, Devisenschranken für Zinstransfer) relativ viel geringer als früher. Vgl. den nicht ermntigenden Bericht über die Aussichten eines investment abroad in: „Factors limiting U. S. Investment abroad, Part I: Survey of Factors in Foreign Conntries". Heransgegeben vom U. S. Department of Commerce unter sect. 516 (c) der Mutual Security Act. I953 und ,,Study of Factors limiting American private Foreign Investment" herausgegeben vom Department of Commerce Jnli 1953. Die Kapitalbewegung erscheint vor allem erschüttert durch die Gefahr der Nationalisierangen. Hier wird vereinzelt die These vertreten, daB bei groBen sozialen Umwandlungen entgegen der bisherigen befestigten Lehre vom Recht des Ausländers auf angemessene und prompte Entschãdigung auch der Fremde Opfer zu bringen habe, d. h. seine Entschadigang gemindert werden konne: vgl. schon Sir John Fischer Williams, Br. Yearbook of Intern. Law 1928 S. Iff. und heute A. de La Pradelle, An- 
lichen Bodens - hinweg, er sicherte den Raum der bürgerlichen Freiheit und damit die Grundlage der liberalen Wirtschaftsweise; auch Subventionen und Garantien fehlen in diesem Bilde ebensowenig, wie Ansätze sozialer Einwirkung " ${ }^{2}$ ).

Von diesem Standpunkt aus vermag ich in der heutigen Entwicklung der Staatsintervention nicht den Vorgang einer Abweichung von einem klassischen und sozusagen ",natürlichen" Ordnungsbilde $2 u$ sehen, sondern ich betrachte sie als den Ausdruck einer anderen, aber durchaus selbständigen wirtschaftlichen Konzeption der modernen Staaten, wie sie tatsächlich in

nuaire de l'Institut de droit international 43 (1950) S. 42 ff., 113 ff. Am 21. I2. I952 faBte die Generalversammlung der Ver. Nationen eine Resolution, die das Recht der Volker zur freien Ausbeutung ihrer Reichtümer als Bestandteil ihrer Souveränităt erklärte and gegenūber dieser Anerkennung von Nationalisierungen nur einen Hinweis auf die Erhaltung des "flow of capital" enthielt. Vgl. hiergegen die Stellungnahme der Association of the Bar of the City of New York Counittee on International Law v. 30. 3. 1953 (Record of the Association vol. 8 number 5). Ferner die nenesten Behandlungen dieser Frage bei Schwarzen berger. The Protection of British Property abroad in 5 Current Legal Problems 1952 S. 295ff.; Werner Niederer, Festschrift Hans Lewald, Basel r953 S. 547 ff. (Der volkerr. Schutz des Privateigentums) und Ernst J. Cohn, das. S. 459ff. Handelsfreiheit. Es genügt, auf den namentlich von den Ver. Staaten seit 1945 geführten Kampf für die Wiederherstellung freier Handelsbexiehungen hinzuweisen, die in multilateralen Abkommen (OEEC, GATT, Havana Charter) grobere Freiheit zu sichern strebt, aber nur Teilerfolge gegen die Schranken der nationalen Kontingente und die Währungsfesseln erringen konnte. Vgl hierza William Adam Brown. The Un. States and the Restoration of World Trade Washington 1950: Schwarzenberger. The Province and Standard of International Economic Law 2 Int. Law Quarterly 1948 S. 402 ff.; William R. Allen, The International Trade Philosophy of Cordell Hull Am. Economic Review 48 (1953) S. ror ff. Einen eindrucksvollen Uberblick über die Wandlungen des internationalen 8konomischen Feldes gibt Felix Somary. Krise and Zukunft der Demoluratie 1952 mit eindringlicher Darlegung der Zersetrung der Basis einer freien 2wischenstaatlichen Wirtschaft. Dort insbesondere eine schlagende Beleuchtung der Wirkungen der ,Monolisierung der Geldbeschaffung durch den Staat und der planmäBigen Geldverschlechterung" S. 59 ff.

m) Es gehörte der ganze Weitblick eines Lorenz von Stein daxu, um inmitten der liberalen Epoche an dem Begriff einer wirtschaftlichen Verwaltung festzuhalten und ihr gegenüber dem individuellen Interesse mehr als eine Aufsicht, nämlich das selbständige Tätigwerden des Gesamtinteresses zuxuweisen (Handbuch der Verwaltungslehre 3. Aufl. Bd. II S, 605ff.). Klarer noch hat als liberaler Radikaler der englische Staatsmann Joseph Chamberbin die Zeichen der Zeit gesehen. In der von ihm gebilligten Vorrede des Verlegers $2 u$ einer Aufsatzsammlung "The Radical Programme“" 1885 heibt es von den dort niedergelegten Vorschlagen: „They sond the death-knell of the laissez-faire system ... The goal towards which the advance will probably be made at an accelerated pace is that in the direction of which the legislation of the last quarter of the century has been tending - the intervention, in other words, of the State in behalf of the weak against the strong, in the interests of labour against capital, of want and suffering against luxury and ease" (Garvin, Chamberlain Br. II 1933 S. 57). 
den meisten europäischen Ländern, wenigstens ansatzweise aber auch in den Vereinigten Staaten, gehandhabt wird. Herr Ipsen hat uns im vergangenen Jahre eindringlich auf die grundlegende Bedeutung des Leitsatzes vom sozialen Rechtsstaat hingewiesen, die mittlerweile auch in der Rechtsprechung seine Anerkennung als ein grundlegender verbindlicher Rechtssatz der Verfassung gefunden hat ${ }^{23}$ ). Der Staat der Gegenwart, das gilt in besonderem $\mathrm{MaBe}$ für GroBbritannien und Frankreich wie die skandinavischen Länder, aber auch trotz einer stärker bewahrten liberalen Grundhaltung für die Schweiz mit ihren Wirtschaftsartikeln und ihrer wachsenden Neigung zur Aufrichtung eingehender Ordnungen für ganze Erwerbszweige ${ }^{24}$ ), tritt von grundsätzlichen politischen Zielsetzungen und bei uns in Deutschland auch von verfassungsrechtlichen Normierungen her mit dem Willen auf, über eine korrigierende und ergänzende Funktion hinaus einen gestaltenden Einfluß auf die wirtschaftliche Entwicklung auszuüben. Er beschränkt sich nicht mehr auf eine Aufgabe der bloßen Beaufsichtigung wirtschaftlicher Vorgänge in den Formen des Gewerberechts und der Gefahrenabwehr, sondern er möchte auch wenigstens teilweise formend und planend oder gar umgestaltend eingreifen, um die ihm vorschwebenden Ziele sozialer Gerechtigkeit zu verwirklichen.

Gewiß, in manchen Fällen ist die staatliche Intervention in der Tat nur Aushilfe und Übergang. Insoweit bleibt sie eine vorübergehende Erscheinung, die in freiheitlichen Staaten in Kriegs- und Notzeiten auftritt, wenn schwerwiegende Beschränkungen und Eingriffe in den freien Ablauf des Wirtschaftslebens nötig werden. Auch in Krisenzeiten - etwa in der Epoche der großen Weltwirtschaftskrise von I929-I934 - kann die Lenkung des Staates diesen Charakter tragen. Aber die staatliche Intervention ist doch längst über den Stand von Notmaßnahmen hinaus zu einem für unsere Zeit bezeichnenden System des staatlichen Handelns in wirtschaftlichen Fragen geworden, das mit der Entfaltung des Verwaltungsstaates in unmittelbarem Zusammenhang steht. Als solches müssen wir es hier auch würdigen. Der Interventionismus oder Dirigismus, wie man ihn auch nennt, ist zu einer eigenen Form staatlicher Wirtschaftspolitik geworden.

2. Vom autoritären Staatsbilde unterscheidet sich der Interventionismus dadurch, daB er nicht einem vorgefaßten ideologischen Bilde nachgeht, das er in umfassender Umgestaltung des sozialen

28) Urteil des BVerfG. Entsch. Bd. I S. 105; Urt. des BGH. Entsch. Bd. 9 S. 89 .

24) Vgl. zum Schutz der Hotellerie BB. vom 19. 6. 1953 (BB1. 1953 II 648), das Uhrenstatut BB. vom 22.6. I95I (AS. I95I S. I231), die Regelung des Milchhandels und der Getreideversorgung. Vgl. dazu Giger, Die Mitwirkung privater Verbände I95I S. IIzff. (seither zahlreiche neue Entwürfe). 
Lebens zwangsweise zu verwirklichen trachtet. Er sucht vielmehr begrenzte wirtschaftlich-soziale Ziele mit aktuell wechselnden Mitteln zu erreichen. Als System trägt er - soweit sich nicht teilweise in seinem Rahmen in einzelnen Ländern Elemente der sozialistischen von Marx stammenden Theorie geltend machen realistische Züge. Das Regime interventionistischer Wirtschaftspolitik steht also, in einer Abkehr von der Beschränkung des Staates auf bloße Ordnungsfunktionen, zwischen dem System der individuellen Wettbewerbsfreiheit und dem einer kollektivistischen Planung, die in ihrer normativen Starrheit die Elemente persönlicher Leistung und Verantwortung lähmt ${ }^{25}$ ).

Je nach der ideologischen oder verfassungsrechtlichen Grundlage kann der Interventionismus verschiedene Formen gewinnen. Bald stellt er sich - das gilt etwa für die Schweiz oder für den gegenwärtigen tatsächlichen Kurs der Bundesrepublik ${ }^{26}$ ) - als Korrektur der grundsätzlich anerkannten freien Wirtschaftsordnung dar, die mehr punktförmig von jeweiligen Anstößen her (Krisen, notleidenden Gewerbezweigen usw.) eingreift. So hat vorübergehend im Gebiete der Bundesrepublik während der im Gefolge der Koreakrise entstandenen Rohstoffknappheit eine Regelung in der Verteilung von Eisen und anderen Metallen, von Holz und Leder Platz gegriffen, die nunmehr mit der Freigabe des Eisenpreises im August 1952 und dem Sinken der Holzpreise wieder abgebaut wird. Auf der anderen Seite kann sich die Intervention $z u$ einem bewußt gehandhabten dauerhaften System entwickeln, in dem eine gewisse Kontrolle wichtiger Grundindustrien aufgerichtet wird und in gewissem Umfang gestaltende und planende Eingriffe erfolgen. Diesen Zug trägt die Entwicklung in Großbritannien unter der Labourregierung ${ }^{27}$ ), in den

इ) Eine wirtschaftliche Theorie der Intervention als Wirtschaftsform siehe bei Theod or Pütz, Theorie der allgem. Wirtschaftspolitik und Wirtschaftslenkring, Wien i948 S. $\mathbf{r}_{4} 8 \mathrm{ff}$. Er betont die unsystematische partielle Natur ihrer Eingriffe und ihren Gegensatz zu einer Form totaler Lenkung. Uber die Selbständigkeit dieser Wirtschaftsform ferner NellBreuning, FinanzArch., N. F. 13 (1952) S. 4 I Iff., der die Einzeleingriffe und punktuellen Maßnahmen hervorhebt und die Vorstellung eines machtfreien Wettbewerbssystems abweist, da jede Wirtschaftsform notwendig ein teleologisches Ziel habe. Zur Finanz- und Steuerpolitik des Interventionismus siehe Ritschl, FinanzArch., N. F. I2 (1950/5I) S. $596 \mathrm{ff}$.

4) DaB zwischen den faktischen Maßnahmen der Wirtschaftspolitik des Bundes und der starken Betonung der Prinzipien der freien Marktwirtschaft durch ihre Leiter ein gewisser Abstand besteht, sei hier angemerkt. Geht auch die Tendenz auf weitere Liberalisierung (Mietenbildung, Zins), so bleiben unauflosbare. Bindungen bestehen: Arbeit, Kreditwesen, Einkommensverteilung, Teile der landwirtschaftlichen Erzeugung und Verarbeitung werden vom Staate kontrolliert, und konjunkturelle Schwankungen können - wie in der Koreaperiode 1950/52 - jederzeit die Neigungen zu offentlicher Regulierung verstärken.

ar) Seither ist sie durch die Reprivatisierung des Transportwesens und der Stahlindustrie rücklăufig, obwohl Kohlenbergbau, Elektrixităt und Gas 
skandinavischen Ländern und in schwächerem Maße in Frankreich. In erheblichem Umfang werden diese beiden Formen interventionistischer Staatspolitik sich decken mit dem Gegensatz einer grundsätzlich die marktwirtschaftliche Freiheit bejahenden Anschauung auf der einen und eines halbsozialistischen Systems des Wohlfahrtsstaates und der Vollbeschäftigung, der Kontrolle der Grundindustrien und des billigen Geldes auf der anderen Seite ${ }^{28}$ ). Auch in dem ersten Typus aber legt sich, wie Röpke richtig bemerkt hat ${ }^{29}$ ), um den freien Kern der Wirtschaft ein Ring von Staats wegen regulierter Bereiche: Devisenbewirtschaftung, festgelegte Mieten, manipulierte Preise und Absatzverhältnisse bei landwirtschaftlichen Erzeugnissen, Beaufsichtigung gewisser Grundstoffe wie Kohle und Stahl ${ }^{30}$ ), extreme Steuerprogressionen und daher staatlich beeinflußte Kapitalbildung und Investitionsprogramme.

\section{Abschnitt}

\section{Demokratische Verfassung und Staatsintervention}

r. Ist ein solches System begrenzter Wirtschaftslenkung, das ein Feld partieller staatlicher Einwirkungen direkter oder indirekter Art mit der Anerkennung und Achtung eines weiten Bereiches freier wirtschaftlicher Bewegung verbindet, mit einem demokratischen und rechtsstaatlichen Verfassungssystem vereinbar? Das ist eine Kernfrage unseres heutigen Themas. Man kann sie etwa

sowie Luftfahrt im öffentlichen Sektor verbleiben. Vgl. Herbert Heldam. The Economic Problem of Denationalization, Pol. Science Quarterly 66 (195r) S. $576 \mathrm{ff}$.

28) $\mathrm{Zu}$ den Kennzeichen dieses letzteren Regimes siehe B. Ohlin, The Problem of Employment Stabilisation $195^{\circ}$ S. $96 \mathrm{ff}$.

${ }^{29}$ ) In seiner Würdigung der deutschen Marktwirtschaft: Wirtschaft und soziale Ordnung als Aufgabe der freien Welt (Schriften der Wirtschaftl. Gesellschaft für Westfalen und Lippe XIII) 1952 S. 9 ff. hat Ropke diese Unvollkommenheiten der Markwirtschaft im heutigen Deutschland von seinem Standpunkt aus kritisch beleuchtet.

s0) Es macht in diesem Sinne nur einen graduellen Unterschied, wenn dirigistische Möglichkeiten etwa im Bereiche von Kohle und Stahl aus dem Bereich des Einzelstaates auf die Ebene supranationaler Gemeinschaften verlagert werden. In der ausländischen Literatur sind von Anfang an die in der Montanunion - neben ihren Zielsetzungen für einen freien Marktverkehr - liegenden Ansätze lenkender Maßnahmen stärker betont worden als in Deutschland. Vgl. R. G. Hawtrey, Economic Aspects of Sovereignty 2. Aufl. 1952 S. I68; Reuter, La Communauté Européenne du Charbon et de l'Acier r953 S. 223 ff.; Rolin, La Communauté Européenne du Charbon et de l'Acier, Brüssei r 953 S. $296 \mathrm{ff}$, der die „pouvoirs considérables d'initiative et de gestion" der Organe der MU hervorhebt (S. 298, 303), freilich ein gewisses Element der Begrenzung in ihrem „caractère suppletif" findet (S. 24). Vielleicht rühren gewisse Spannungen zwischen dirigistischen und marktwirtschaftlichen Momenten in der MU daher, daB Kohle und Eisen schon lange Gebiete darstellten, in denen die Regein individuellen Wettbewerbes nur beschränkt noch Geltung besaßen. 
mit Hayek dahin beantworten, daß schon die Anfänge einer dirigistischen Politik die Freiheitsrechte der Person verkümmern, die Sicherheit des Rechtsstaats administrativ aushöhlen, das Gefühl für Recht und Sicherheit beeinträchtigen und schließlich unteigraben $^{\text {32}}$ ). Man kann umgekehrt darauf verweisen, da $\beta$ im Zeitalter der Massen, im Angesicht der aufsteigenden Macht sozialer Gruppen und auf der Basis einer ungewissen internationalen Wirtschaftsentwicklung die Möglichkeit einer Rückkehr zu Formen einer vollen individuellen Freiheit gar nicht mehr gegeben ist, da $B$ die Forderung eines Systems freien Wettbewerbs selbst von ihren Anhängern nur mehr als eine unter ständiger Staatseinwirkung aufrechtzuerhaltende Lebensform verstanden wird ${ }^{\text {s2 }}$. Man kann die Eingriffe und Kontrollen des Staates als den Weg auffassen, auf dem mit gewissen Schranken grundsätzlich ein System der Freiheit erhalten und ein Umschlag in eine strikt regulierte Wirtschaft vermieden werden kann $\left.{ }^{38}\right)$. Man kann auch tiefer greifend die staatliche Intervention aus den sozialen Aufgaben und Zielsetzungen des Staates begründen ${ }^{34}$ ). Wenn der moderne Staat dem Verlangen nach einem gewissen Maße sozialer Sicherheit, nach Schutz im Alter, nach Ausgleich für die Schäden und Umwälzungen des Krieges und der Nachkriegszeit nachkommen will, kann er nicht darauf verzichten, in einem begrenzten Umfang auch gestaltend in den Lauf des wirtschaftlichen und sozialen Prozesses einzugreifen. Der heutige Staat ist auch nicht mehr bereit, die Risiken und Gefahren wirtschaftlicher Rück-

31) Hayek, The road to serfdom. r944; siehe auch Franz Böhm, Wirtschaftsordnung und Staatsverfassung I950 S. $56 \mathrm{ff}$.

a) In der Tat erwartet die heutige neoliberale Lehre gar nicht mehr einen Ausgleich der Wirtschaftskräfte allein vom freien ,natürlichen“ Wettbewerb, sondern sie lehrt eine "verfeinerte" Wettbewerbswirtschaft, in der der Staat die ordnungspolitische Gesamtentscheidung (Eucken, Unser Zeitalter der Mißerfolge 195I S. 72) fällt und dies wirtschaftliche Ziel mit Hilfe der Rechtsordnung sichert und steuert, indem er das Konkurrenzsystem durch Bekämpfung von Machtpositionen und „vermeidbaren" Großbetrieben erhält unter Aufwendung eines ,ungewohnlichen Maßes an Anstrengung" und einer „Ballung von Macht" (B $6 \mathrm{hm}$, Wirtschaftsordnung und Staatsverfassung 1950 S. 27 ff. bes. S. 37; Ordo, Bd. IV S. 73 ff.). In Wirklichkeit enthält diese Ordnung also auch interventionistische Elemente. Wie sehr man sich vielfach darüber tăuscht, zeigt die amtliche Begründnng zum Entwurf eines Gesetzes über Wettbewerbsbeschränkungen (Bundestag I. Wahlp., Drucks. Nr. 3462 S. 15), wo die Steuerung der Wirtschaft durch Steuern, Geld und Kredit - also drei der heute wirksamsten, und in ihrer indirekten Unkontrollierbarkeit gefăhrlichsten Mittel des Interventionismos - als "marktkonform" bezeichnet wird.

\#) Vgl. Ohlin a. a. O. S. Io7f.

M) Auf diese sozialethische Seite weist namentlich die sozialistische Theorie hin, die in moderner Form etwa dargelegt ist bei R. H. S. Cross man, Socialist Values in a Changing Civilisation (Fabian Tract No. 286) 1950 S. 9ff. Hier wird die Sicherung des Arbeitsplatzes und die Sorge für das Alter ans dem Schutz der "human dignity" abgeleitet. 
schläge ohne eigenes aktives Eingreifen auszuhalten. Dafür ist die Lektion der Jahre der Weltkrise nach 1929 zu hart gewesen, als man mit traditionellen Mitteln, dem Festhalten an der Währung, der Wirkung der Konkurrenz und der Zinshöhe vergeblich Lösungen zu finden suchte. Was es hier festzuhalten gilt, ist, daß der Interventionismus eine Mischform darstellt, in der Momente einer wirtschaftlichen Freiheit mit begrenzten kontrollierenden und leitenden Einwirkungen des Staates verbunden werden ${ }^{35}$ ). Von diesem Boden aus muß auch seine Vereinbarkeit mit den verfassungsrechtlichen Grundlagen der Demokratie und des Rechtsstaates beurteilt werden.

Sicher ist, daß mit einem Utbergange zu voller zentraler Lenkung und umfassendem Zwange des Staates der Punkt erreicht wird, wo durch das $\mathrm{MaB}$ an Beschränkungen der individuellen Freiheiten und das Uberwiegen der Planung, die ihrem Wesen nach kurzfristig, daher nicht echte Rechtsetzung, sondern Regierungsakt ist ${ }^{36}$ ), die demokratischen Freiheiten und der Rechtsstaat gefährdet und schließlich erstickt oder beseitigt werden. Vielleicht gehen schon die Maßnahmen des norwegischen Entwurfes zu

36) Die hier gegebene Analyse geht von der Möglichkeit einer solchen Mischform mit Verbindung gelenkter und freier Bereiche der Wirtschaft aus. Sie wird auch anerkannt bei K. Mannheim, Freedom, Power and Democratic Planning 1950 S. 124f.; Marbach, Zur Frage der wirtschaftlichen Staatsintervention I95I S. 37; E. R. Huber, Wirtschaftsverwaltungsrecht 2. Aufl. Bd. I I953 S. II, 24 ff., 34 ff., der die verschiedenen zum Interventionismus führenden Motivationen betont (S. $34 \mathrm{f}$.) und verschiedene Typen interventionistischer Marktwirtschaft sowie noch der nicht total planenden gelenkten Wirtschaft unterscheidet. Zur Einteilung der gemischten, d.h. dualistisch aus marktwirtschaftlichen und kontrollierten Elementen aufgebauten Formen siehe auch Ritschl, Archiv f. Weltwirtschaft 65 (1950) S. 27 Iff.

36) Zeitbegrenzte Planakte, auch wenn sie genereller Natur sind, wie das Haushaltsgesetzoder ein Wirtschaftsplan, sind ihrem Wesen nach nicht echte Rechtssätze, weil ihnen das Moment des Dauerhaften und Grundlegenden fehlt. Ich stimme hier überein mit Hans $\mathrm{Huber,} \mathrm{Festgabe} \mathrm{für} \mathrm{Z.} \mathrm{Giaco-}$ metti r953 S. 74/75, und darf auf meine Ausführungen in ,Die Ubertragung rechtsetzender Gewalt im Rechtsstaat" ${ }^{\prime \prime} 952$ S. 138 ff. verweisen. Der heutige formalisierte Gesetzesbegriff, der nicht mehr Dauer, Gerechtigkeit und innere Bedeutung, sondern allein die generelle Tragweite zum Merkmal erhebt, geht an diesem Problem vorüber. Daher erscheint ein Wirtschaftsplan wie die jährlichen Gesetze über Preise für Getreide inländischer Erzeugung für das Getreidewirtschaftsjahr I95 I und über besondere MaBnahmen in der Getreide- und Futtermittelwirtschaft (z. B. Ges. vom 21. 7 . I95I BGBl. I S. 45I; Ges. vom 9. 7. I952 BGBl. I S. 369) oder das Gesetz über die Verteilung des erzielten Reingewinns der Bank deutscher Länder in den Geschäftsjahren 1950 und I95I vom Io. 8. I95I (BGBl. I S. 499) heute als formelles Gesetz. Wieder anders liegt der Fall in dem Recht der Deutschen Demokratischen Republik. Hier trägt das Gesetz an sich bereits administrativen Charakter und mag daher auch Wirtschaftspläne einschließen. Vgl. hierzu Krömer a. a. O. S. 6r ff., I55ff.; Otto Walther, Verwaltung, Lenkung und Planung der Wirtschaft in der sowjetischen Besatzungszone, Bonner Berichte aus Mittel- und Ostdeutschland x953. 
einem Regulierungsgesetz mit ihrer umfassenden Befugnis der Regierung zur Festlegung der Preise und Geschäftsbedingungen, die bezeichnenderweise weithin mit unbestimmten Begriffen arbeiten und nur die Löhne und Arbeitsbedingungen ausnehmen, über die zulässige Grenze von Beschränkungen der persönlichen Freiheit hinaus. Ein interventionistisches Wirtschaftssystem setzt - will es in den Grenzen rechtsstaatlich-freiheitlicher Verfassungsgestaltung bleiben - wirksamen Schutz der Grundlagen der persönlichen Freiheit - freie Berufswahl, Gewerbefreiheit, Freizügigkeit, Eigentumsschutz -, Anerkennung der Selbstverantwortung des einzelnen wie der sozialen Gruppen (Selbstverwaltung) voraus, und es erfordert sowohl einen ausgestalteten Rechtsschutz wie einen gerechten Ausgleich gegenüber Fällen der Entwährung und des staatlichen ungleich belastenden Sondereingriffs. Freiheit ist freilich im Massenzeitalter, wo die soziale und wirtschaftliche Unselbständigkeit überwiegt, nicht mehr nur als Freiheit vom Staate zu verstehen. Freiheit besteht darin, und das ist das große Problem unserer Gegenwart, daB auch in einer Gesellschaft mit einer Uberzahl wirtschaftlich abhängiger Individuen und mit mächtigen Gruppen der Bereich der Entfaltung des einzelnen geschützt bleibt sowohl in wirtschaftlicher wie in kulturellgeistiger Hinsicht ${ }^{37}$ ). Das ist keine leichte Aufgabe. Die Verteidigung der negativ gegen den Staat gerichteten Rechte des Individuums ist leichter als die Erfassung seiner Rechte auf gerechte Beteiligung an den obsorgenden und verteilenden Leistungen des Staates oder auf Schutz im Rahmen der Gruppenmacht und der indirekten Abhängigkeiten. Eine entscheidende Rolle wird dabei dem Gleichheitsgedanken zufallen. Aber hier, in einer ergänzenden und neuen Definition der Freiheit und des Rechtsschutzes in diesen mit den bisherigen Begriffen nur teilweise noch erfaßbaren Situation, liegt der Kern unseres Problems.

Freiheit besteht hier auch darin, da $\beta$ der einzelne nicht in seinen Lebensgrundlagen von administrativen Ermessensentscheidungen abhängt und nicht von ihm nicht $z u$ beherrschenden Risiken ausgesetzt ist. Mit der Freiheit ist gewiß das Risiko notwendig verbunden ${ }^{38}$ ), aber doch nur in dem Maße, als es der einzelne

37) Die Sicherung der persőnlichen Freiheit im Gefüge des Verwaltungsstaates und der teilweise geleiteten Wirtschaft ist ein Grundanliegen von K. Mannheim a. a. O. S. 279ff. Er weist dabei auf die Notwendigkeit einer ergănzenden Konzeption der Menschenrechte in dieser verănderten Umgebung hin.

s8) Das bürgerliche Recht hat hier die Vorstellung der Risikosphären entwickelt, aus denen es eine Risikoverteilung zwischen den Partnern eines Vertragsverhältnisses entnimmt (Soergel-Siebert, Komm. zum BGB. Anm. VI I zu \$ 242). Entsprechend kann auch im offentlichen Recht dem einzelnen die Verantwortung für einen Wirkungsbercich auferlegt werden, den er beherrscht und dessen Ordnung seinen Mitteln angemessen ist. Unter 
selbst gestalten und übersehen kann. Zur Freiheit gehört auch die freie Wahl zwischen organisatorischen Bindungen oder auch der Fernhaltung von ihnen.

lch möchte daher die eingangs gestellte Frage nach der Vereinbarkeit eines Systems begrenzter Wirtschaftslenkung mit dem demokratischen und rechtsstaatlichen Prinzip grundsätzlich bejahen, sofern jene Sicherungen einer gemäBigten Ordnung vorliegen, die wir hier behandelt haben.

2. Wenn wir uns nun der Frage zuwenden, welche Grundlagen was Grundgesetz der Bundesrepublik für die Wirtschaftsform enthält, so mögen zunächst einige Bemerkungen über den Begriff der Wirtschaftsverfassung am Platze sein. In jedem Staate ist durch die Rechtsordnung, sei es unmittelbar durch die Verfassung, sei es durch grundlegende Institutionen des Privat- und Verwaltungsrechts, eine bestimmte wirtschaftliche Ordnung ausdrücklich festgelegt oder als immanent vorausgesetzt. Nicht immer werden die Grundlagen des wirtschaftlichen Lebens dabei zu einer eigentlichen Wirtschaftsverfassung, einem in sich geschlossenen System von Normierungen zusammengefügt sein. Oft treten die maBgebenden Prinzipien nicht besonders hervor, sondern sind in der Grundaniage der Rechtsordnung, dem, ,Sozialmodell " 30) einbeschlossen. Man muB ferner den Blick nicht nur auf die gesetzliche Regelung richten, sondern auch ihre Handhabung und die in der Praxis herausgebildeten Prinzipien beachten. Dafür bildet die Weimarer Reichsverfassung ein Beispiel. Sie barg in ihrer Entstehung verschiedenartige Elemente in sich, liberale Freiheitsrechte auf der einen, soziale und sozialistische Sätze und Verheißungen auf der anderen ${ }^{40}$ ). Da die letzteren weniger präzis gefaßt waren und der Anwendung und Durchführung mancherlei Schwierigkeiten boten, hat - auch unter EinfluB der allgemeinen politischen Entwicklung - im Laufe der Zeit die Betonung der liberalen Momente das Ubergewicht erlangt und am Ausgang der zoer Jahre erschien die Wirtschaftsordnung

diesem Gesichtspunkt erscheint die Milderung der Eigentümerhaftung bei Ruinengrundstücken vertretbar. Vgl. Bad VGH. OV. 1952 S. 734 ; OVG. Münster DVBl. 1952 S. 664. Wo dem einzelnen durch interventionistische Verfügung die freie Disposition entzogen wird, kann daher die Grundlage einer Staatshaftung aus besonderem Opfer vorliegen, wenn Nachteile eintreten. Vgl. zu der Frage auch Erler, Ztschr. ausl. offentl. Recht u. Volkerrecht 15, r953 S. 23; Forsthoff, Verwaltungsrecht 3. Aufl. S. 253 f.; Hans Marti, Die Handels- und Gewerbefreiheit nach den neuen Wirtschaftsartikeln, Bern 1950 S. $29 \mathrm{f}$.

29) Diesen Ausdruck prägt F. Wieacker, Das Sozialmodell der klassischen Privatrechtsgesetzbücher und die Entwicklung der modernen Gesellschaft 1953 S. 4 f.

40) Vgl. Gustav Giere, Das Problem des Wertsystems der Weimarer Grundrechte (Abhandl. der Rechts- und Statsw. Fakultät der Univ. Kornigsberg) 3 r932. 
des Weimarer Staates stärker liberal geprägt, als dies in der ursprünglichen Normierung angelegt war ${ }^{41}$ ).

Man bezeichnet die rechtliche Festlegung einer bestimmten wirtschaftlichen Ordnung heute als Wirtschaftsverfassung. Sie steht mit der Staatsform in einem nahon wechselseitigen $\mathrm{Zu}$ sammenhang. Nicht als ob jede Staatsform eine ganz bestimmte Wirtschaftsordnung bedingt oder umgekehrt. Aber in einem totalitären Regime kann keine freie Marktwirtschaft existieren und umgekehrt ist eine rechtsstaatliche Verfassung nicht mit einer Ausbildung einer vollständigen Planwirtschaft vereinbar. Doch besteht in dieser Hinsicht ein gewisser Spielraum. Eine freiheitliche Verfassung kann sehr wohl mit der Ordnung eines freien Wettbewerbs wie mit einer interventionistischen Methode vereinbar sein. Die Festsetzung einer Wirtschaftsverfassung gehört' indes nicht $\mathrm{zu}$ den notwendigen Bestandteilen einer Verfassung. Die Verfassungen des 19. Jahrhunderts enthielten keine wirtschaftlichen Bestimmungen, wenn man von einigen Anordnungen der Paulskirchenverfassung von 1848 absieht. Die Grundlagen der wirtschaftlichen Ordnung ergaben sich damals vielmehr aus dem Gesamtaufbau der rechtlichen Ordnung, die einen freien Wettbewerb mit Gewerbefreiheit, Eigentumsschutz, stabiler Währung und Vertragsfreiheit sicherte.

Ob das Grundgesetz der Bundesrepublik Deutschland eine konkrete Wirtschaftsordnung verbindlich festlegt, darüber gehen die Meinungen auseinander. Von manchen wird angenommen, da $B$ eine Entscheidung für eine marktwirtschaftliche Ordnung des freien Wettbewerbes getroffen sei ${ }^{42}$ ). Richtig ist aber die Ansicht, daß das Grundgesetz sich bewuBt der Normierung einer eingehenden sozialen und wirtschaftlichen Ordnung ferngehalten hat ${ }^{48}$ ), $\mathrm{da} B$ es daher auch keine Wirtschaftsverfassung im eigentlichen Sinne enthält $\left.{ }^{4}\right)$. Es hat sich damit begnügt, gewisse leitende Prinzipien für eine wirtschaftliche Ordnung aufzunehmen, die in sich aber weder ein geschlossenes System ergeben, noch ganz ein-

1) Uber tatsächliche Wandlungen einer Wirtschaftsordnung siehe E. R. Huber a. a. O. S. 23 .

๑) Man wird dem Wesen einer Wirtschaftsverfassung nicht gerecht, wenn man sie im dezisionistischen Sinne als „Entscheidnng" versteht, da die Verfassung sie nicht neu formt, sondern im allgemeinen vorhergegangene soziale Gegebenheiten oder Verănderungen bestätigt oder ausbaut. Vgl. E. R. Huber a. a. O. Bd. I S. 24 f.

ज) So die besonderes Gewicht verdienende Feststellung v. Mangoldts, Das Bonner Grundgesetz S. 35, 94.

M) So schon zutreffend and grundlegend Herbert Krtiger, Staatsverf. and Wirtschaftsverf. in DVBl. I95 1 S. 363; ders., Grundgesetz und Kartellgesetzgebung 1950 S. 9 f. Seither: Eichler, Wirtschaftsrecht $195^{\circ}$ S. 35; E. R. Huber a. a. O. Bd. I S. 3of.; Hamann, Rechtsstaat und Wirtschaftslenkung 1953 S. 32; Stod ter, Rechtsfragen des Zündholzmonopols 1953 S. 55 f. 
heitlich sind. Von den Hauptpunkten einer modernen Wirtschaftsordnung, Regelung der Vertragsfreiheit und des Eigentums, der Zulassung zu beruflicher und gewerblicher Betätigung, der Stellung der Arbeit, dem Recht der wirtschaftlichen Organisationen und Verbände (Vereinigungsfreiheit), der Betriebsverfassung und der Eingrenzung der Staatswirtschaft haben nur Teile in der Verfassung eine Regelung gefunden ${ }^{45}$ ). Das Grundgesetz enthält auf der einen Seite in den Artikeln 2 Abs. I, 3 Abs. I, 9, I2 und I4 Abs. I freiheitliche Rechtsverbürgungen im alten Stil individueller Rechte und der Garantie grundlegender Rechtsinstitute. Es hat auf der anderen Seite in Art. I4 Abs. II, 20 und 28 Sätze der Betonung seines sozialen Gehaltes aufgenommen und in Art. I5 die Möglichkeit der Aufnahme gemeinwirtschaftlicher Elemente in die Rechtsordnungen eingeräumt. Das sind wichtige und grundsätzliche Entscheidungen zugunsten einer freiheitlichen Ordnung, aber versehen mit allgemeinen Vorbehalten sozialer Natur, die durch die Formeln der ",Rechte Dritter" und der ,,verfassungsmäBigen Ordnung" auch in Art. 2 Abs. I GG. verankert sind. Es wäre nicht zutreffend, hier von einem Gegensatz dieser Bestandteile, von einem Konflikt der bürgerlich-liberalen Rechtsstaatlichkeit und der sozialen Momente des Verwaltungsstaates auszugehen, wie es Friedrich Klein getan hat $\left.{ }^{46}\right)$. Die Auslegung einer Verfassung $\mathrm{muB}$ sich von dem Gedanken leiten lassen, daß sie ein geschlossenes Ganzes bildet, und es bedarf daher angesichts der Gegebenheit solcher verschiedenen Elemente einer kombinatorischen Interpretation. Sie führt nicht auf einen Widerspruch,

4) Zum Umkreis der verfassungsrechtlichen Bestandteile einer Wirtschaftsordnung siehe Strau $\$$, Wirtschaftsverfassung und Staatsverfassung 1952 S. r4 ff.; Nipperdey, Grundprinzipien des Wirtschaftsverfassungsrechts, DRZ. I950 S. 197 ff.; E. R. Huber a. a. O. Bd. I S. 27 ff.; Eichler, Wirtschaftsrecht $195^{\circ}$ S. $57 \mathrm{fi}$.

40) Fr. Klein, Z.ges.Staatswiss. I06, I950 S. $404 \mathrm{ff}$. Neuerdings hat von ähnlichen Gedanken aus Forsthoff (Ist die Regelung der Entschädigung im Bodenreformgesetz für Nordrhein-Westfalen vom 16. 5. I949 und seinen Durchführungsverordnungen mit dem Grundgesetz vereinbar?, Rechtsgutachten Januar 1953) S. r 2 ff. und Tagung der Dt. Staatsrechtslehrer, Bonn (1953) Leitsatz 8-i 5 die Verbindung des Sozialstaats, der nur im Verwaltungswege zu verwirklichen und als Prinzip zu unbestimmt sei, mit dem Rechtsstaat, der das grundlegende Prinzip des GG. bildet, für unmöglich, den sozialen Rechtsstaat als Rechtsbegriff für unvollziehbar erklärt. Zur Unbestimmtheit des Wortes sozial jetzt auch Carl Schmitt in "Gemeinschaft u. Politik" hrsg. vom Institut für Geosoziologie u. Politik, Jahrg. I (1953) S. 24. Ich kann mich hiervon nicht überzeugen. Wie andere politische Formeln (freiheitlich, weltanschaulich usw.) hat das Wort „sozial“" heute einen ganz bestimmten Sinn im Sinne ausgleichender, den Schwachen fördernder Intervention und der Beschränkung individueller Rechte im Blick auf das Ganze gewonnen. Es ist nicht einzusehen, weshalb daher dieser Begriff des sozialen Rechtsstaates nicht im Sinne des Textes als verfassungsrechtlicher Leitsatz die Auslegung des Grundgesetzes verpflichtend binden kann. 
sondern auf eine Lösung hin, in der die freiheitlichen Bestandteile des Grundgesetzes unter dem Vorzeichen einer verfassungsrechtlichen Bindung im Sinne des sozialen Rechtsstaates einer Abkehr von einer rein individuell-rechtlichen Deutung verstanden werden müssen. In dieser Ordnung liegt damit auch die Möglichkeit zu gewissen Beschränkungen der Freiheitsrechte, wie dies der Hinweis auf die verfassungsmäBige Ordnung in Art. 2 Abs. I und auf die Rücksicht auf die Rechte Dritter hervorhebt. Unter verfassungsmäBiger Ordnung ist dabei weder die Gesamtheit der Rechtsordnung ${ }^{47}$ ) zu verstehen, noch der Kernbestand der Verfassung im Sinne des Verfassungsschutzes der Art. I8, 2I, 9I GG. Gemeint sind hiermit die wesentlichen Verfassungsgrundsätze, vor allem auch die Leitsätze der rechtlichen sozialen und wirtschaftlichen Ordnung, die der erste Abschnitt des Grundgesetzes enthält, einschlieBlich des verbindlichen Leitsatzes vom sozialen Rechtsstaat ${ }^{48}$ ). In jedem Falle legt das Grundgesetz keine starre Ordnung der Wirtschaft fest, sondern läßt in dem von ihm vorgezeichneten Rahmen einen erheblichen Spielraum der freien Gestaltung des Gesetzgebers. Es sollte nicht ein Anliegen der Auslegung sein, diese Beweglichkeit $\mathrm{zu}$ sehr einzuengen.

Man mag, da das Grundgesetz auf eine eingehendere Festsetzung der sozialen und wirtschaftlichen Grundrechte im Stile der Weimarer Verfassung bewußt verzichtet hat, ein gewisses Ubergewicht der traditionellen individuellen Grundrechte, d. h. des Gedankens der Freiheit, feststellen ${ }^{49}$ ). Aber im Unterschied etwa zur Schweiz, wo der Ausgangspunkt klar im liberalen Sinne gegeben ist und die Ausnahmen und Einschränkungen durch das freilich weitgespannte System der neuen Wirtschaftsartikel hinzugefügt wurden $\left.{ }^{50}\right)$, sind im Grundgesetz die sozialen Momente in den Grundlagen selbst enthalten. Die ersten drei Artikel bilden eine Art höherer Richtsätze des ganzen Grundrechtsteils: Art. I wegen seiner Unabänderlichkeit, die im Hinblick auf Art. 20 (Demokratie) auch Art. 3 Abs. I und III auszeichnet, Art. 2 als Leitgedanke der Grundrechte. Hier treten die sozialen Momente sowohl in Art. 2 Abs. I als allen

17) So $2 u$ Unrecht v. Mangoldt, Grundgesetz S. 47.

18) Wie hier verstehen diesen Begriff in Art. 2 Abs. I Nipperdey, BB. I95I S. 584 f.; E. R. Huber a. a. O. Bd. I S. 662; zu eng Hamann, Rechtsstaat u. Wirtschaftslenkung S. 64 f., und Peters, Festschrift Laun 1953 S. 676 (nur polizeiliche Gesichtspunkte berechtigen zur Freiheitsbeschränkung); zu weit Dürig, AOR. 79 S. 57 ff., der alle polizeilichen Gesichtspunkte der Sicherheit und Ordnung zur verfassungsmäßigen Ordnung nehmen will.

49) Peters a. a. O. S. 671 f.

so) Hierzu Eric Homburger, Handels- und Gewerbefreiheit und Vertragsfreiheit (Zürcher Beiträge zur Rechtswiss., N. F. 145) 1948 S. $7 \mathrm{ff.}$. 94 ff.; Sch ürmann, Die rechtliche Tragweite der neuen Wirtschaftsartikel der Bundesverfassung 1948 S. 5f.; Huber, Ztschr. Schweiz. Recht, N. F. 7o S. I 75 ff.; ders., Wirtschaft und Recht r953 Heft 2. 
Grundrechten innewohnende Begrenzungen ${ }^{51}$ ) wie in der Untersagung klassenmäßiger Differenzierungen in Art. 3 Abs. III (,,Herkunft") deutlich in Erscheinung. In der ,verfassungsmäßigen Ordnung" des Art. 2 Abs. I GG. ist der Gedanke des sozialen Rechtsstaates in Bezug genommen. Das bedeutet, da $\beta$ man nirgends die Verbürgungen der Freiheitsrechte in einem vollen und unbeschränkten individualistischen Sinne verstehen darf, sondern daß die Gemeinschaftsbindung ihnen von Anfang an immanent ist. Darin liegt ein wichtiges Gegengewicht von verfassungsrechtlich bindender Kraft gegen die äußerlich überwiegende Hervorhebung der Freiheitsrechte im Grundgesetz, im Unterschied zu manchen Landesverfassungen (Bayern, Hessen, Bremen, Rheinland-Pfalz), die daneben auch die wirtschaftliche Ordnung ausführlicher geregelt haben.

3. Die oberste Leitung der Wirtschaftspolitik steht beim Bund. Adolf Schüle hat im Jahre 1948 schon mit Grund darauf hingewiesen, daB die umfangreichen Wirtschaftsteile einiger Landesverfassungen nicht nur manche voreilige Festlegung enthalten, sondern vor allem Fragen im Landesbereich zu entscheiden unternehmen, die nur einheitlich für die gesamte deutsche Wirtschaft ihre Lösung finden können ${ }^{62}$ ). Abgesehen von der bundesverfassungsrechtlichen Bindung, die die vorhin erwähnten Sätze des Grundrechtsteiles enthalten, weisen die Art. 73 und 74 nahezu alle maßgebenden wirtschaftspolitischen Entscheidungen der ausschließlichen oder konkurrierenden Zuständigkeit des Bundes $\mathrm{zu}^{53}$ ). Solange sie nicht ausgeübt werden, verbleibt den Ländern noch eine Bewegungsfreiheit auf den Gebieten des Arbeitsrechts, des Gewerbes, des Bergbaus und der Sozialisierung, um solche Materien zu nennen, in denen sie eine gewisse Aktivität gezeigt haben. Im ganzen aber ist der Tätigkeit der Länder eine sehr enge Grenze gezogen. Manche Bestimmung der Landesverfassungen mag als Ergänzung und Erweiterung des Grundgesetzes Kraft behalten, wie die Sicherung der Vertragsfreiheit und die Freiheit selbständiger Betätigung des einzelnen in Art. I5I Bayer. Verf. und Art. 52 Verf. von Rheinland-Pfalz ${ }^{54}$ ). Dagegen werden andere Normen, die im Sinne der Zwangswirtschaft vor 1948 dem Staate umfassende Lenkungsbefugnisse zuschreiben (Bayern Art. 155. Bremen Art. 39), nicht in vollem Umfang mehr mit dem Grundgesetz vereinbar sein. Das Gleiche gilt von den Anordnungen mehrerer Verfassungen (Bayern Art. 156, Bremen Art. 4I Abs. I, Hessen Art. 39 Abs. I), die Kartelle überhaupt oder unter un-

\footnotetext{
s1) So mit Recht Peters a. a. O. S. 677f.

of Schule, Verfassung und Wirtschaft, Mannheim 1948 S. $15 f f$.

*) Vgl auch Maunz, Dt. Staatsrecht, 2. Aufl. r952 S. 136.

M) Znm Verhaltnis der landesrechtlichen Grundrechte zum Grundgeset: siehe Kratzer, Festgabo Laforet I952 S. ro7ff.
} 
bestimmt weitgehaltenen Voraussetzungen untersagen, die also über die - insoweit auch materiell bedeutungsvolle ${ }^{55}$ ) - Vorschrift des Art. 74 Ziff. I6 hinausgehen. Nicht vereinbar mit dem Grundgesetz sind auch Bestimmungen über Sozialisierung ohne oder ohne genügende Entschädigung, wie sie Art. 4I und 39 Abs. IV Hess. Verf. vorsehen. Soweit hier eine Uberführung in Gemeineigentum bereits begonnen hat, wie es der Hess. StGH. angenommen hat ${ }^{56}$ ), darf sie jedenfalls nach diesen Bestimmungen nicht zu Ende geführt werden, sondern steht nun unter Art. 14 Abs. I und III GG. ${ }^{57}$ ). Ebenso wird man sich fragen müssen, ob die Bestimmungen über Bankenaufsicht (Hessen Art. 4I Ziff. 2, Rheinland-Pfalz Art. 62) zulässig geblieben sind. Man wird dies bejahen können, soweit eine lediglich kontrollierende und überwachende Tätigkeit des Staates gemeint ist, man wird es hingegen verneinen müssen, falls damit eine eigentliche Ubernahme der wirklichen Disposition und Leitungskontrolle beabsichtigt sein sollte. Dann läge die Uberführung in die Gemeínwirtschaft bei einem Wirtschaftszweige vor, den Art. I5 GG. nicht zu einer solchen Maßnahme freigibt ${ }^{58}$ ).

Als staatliche Intervention sehe ich auch die Maßnahmen des Staates gegeı wettbewerbsbeschränkende Abreden und gegen die Bildung marktbeherrschender Gruppen oder Unternehmungen an. Ein Teil der heutigen Rechtslehre - darunter namentlich die Anhänger einer liberalen Anschauung - steht hier auf einem anderen Standpunkt. Sie sieht in dem Vorgehen des Staates nur die Ausübung einer Ordnungsfunktion zum Schutze der Freiheit des Wettbewerbes und zur Wiederherstellung eines wirklichen Marktautomatismus. Auch der Berner Staatsrechtslehrer Hans Huber schlieBt sich dieser Auffassung an, die in dem Eingriff des Staates nicht eine Einschränkung, sondern gerade die Aufrechterhaltung des Wettbewerbes und der Gewerbefreiheit erblickt ${ }^{69}$ ). In Deutschland wird diese Meinung, die kartellartige

ss) Nach dem Grundsatze, daß sachlich normierenden Kompetenzbestimmungen auch materielirechtliche Bedeutung zukommen kann, da die Verfassung nicht selten die der Zustāndigkeitsnorm entsprechende Kompetenznorm oder umgekehrt weglaßßt, kommt Art. 74 Ziff. I6 wie auch z. B. Art. 74 Ziff. I9 (.Zulassung") eine gewisse matrriellrechtliche Bedeutung zu. A. A. Hamann a. a. O. S. 25.

6) Urteil vom 6. 6. 1952 VerwRspr. 5 S. I4ff.

s7) Wieacker, Die Sozialisierung im Rechtsstaat (Gutachten über Art. 4 I Hess. Verfassung) 1953 S. 55 ff.; Ipsen. Der finale Sozialisierungsbegriff (Rechtsgutachten) $1953 \mathrm{~S}$. $18 \mathrm{ff}$.

s8) Eine Uberschreitung des Kreises der in Art. 15 GG. zur Uberführung in Gemeinwirtschaft zugelassenen Wirtschaftsbereiche begründet Nichtigkeit der gesetzlichen Maßnahmen, vgl. Ipsen, VStRL. Io S. Io2f.

io) Das Staatsrecht der Intervention, Ztschr. f. schweiz. Recht, N. F. 7o (195I) S. I75f. Der gleiche Grundgedanke findet sich bei Z. Giacometți. in "Die Freiheit des Bürgers im schweiz. Recht" 1948 S. 185f. Vgl. jetzt 
Abreden als Entartung der Vertragsfreiheit betrachtet und die staatlichen Maßnahmen hiergegen als Verteidigung der Freiheit deutet, weithin vertreten. Wir begegnen ihr vor allem in der $\mathrm{Be}$ gründung zu dem Entwurf eines Gesetzes gegen Wettbewerbsbeschränkungen $\left.{ }^{60}\right)$. Dieser Entwurf behandelt die staatliche Bekämpfung der Kartelle als Beseitigung von Störungen des Marktablaufs. Dabei ist seine Begründung nicht frei von einer gewissen Widersprüchlichkeit. Sie gibt zu, daß auf weiten Gebieten des wirtschaftlichen Lebens der geforderte freie Marktverkehr nicht herzustellen sei ${ }^{61}$ ). So finden wir in dem Entwurfe die Bereiche der Landwirtschaft, des Seeverkehrs nach dem Ausland und der Binnenschiffahrt aus Gründen, deren Uberzeugungskraft sich mehr aus politischen Zweckmäßigkeitserwägungen als aus wissenschaftlichen Erkenntnissen abzuleiten scheint, von der Anwendung des geplanten Gesetzes ausgenommen, und die Begründung stellt fest, daß insbesondere in Zeiten eines Nachfragerückganges Störungen auftreten, die durch die marktkonformen Mittel nicht $\mathrm{zu}$ beheben sind ${ }^{62}$ ). Ich vermag mich diesen Anschauungen nicht anzuschließen. Ich glaube vielmehr, daB in der modernen Wirtschaft für gewisse Wirtschaftsbereiche eine natürliche Tendenz zur stärkeren Konzentration und zur Gruppenbildung besteht. Man mag diese Entwicklung bedauern, man kann versuchen, sie durch Förderung mittlerer und kleinerer Unternehmungen oder ähnliche Vorkehrungen zu kompensieren. Aber wenn man diesen Vorgang verneint, wenn man den Zusammenschlüssen und der Bildung größerer Unternehmens- und Betriebseinheiten das Ideal geringerer Betriebsgrößen und eines nicht durch $\mathrm{Ab}$ machungen gęregelten Wettbewerbes gegenüberstellt, so wird damit ein besonderes wirtschaftspolitisches Ziel aufgerichtet, das ebenso wie andere staatliche Einflußnahmen eine Veränderung des Geschehens nach vorgefa:Bten staatlichen Vorstellungen und Planungen bedeutet. Eingriffe zugunsten dieser Zielsetzung müssen darum als interventionistische $\mathrm{Maßnahmen}$ angesehen werden ${ }^{63}$ ). Das hat auch praktisch eine gewisse Bedeutung. Wenn man die Vorkehrungen des Staates gegen Kartellbindungen und marktbeherrschende Unternehmen ebenso wie andere Lenkungsmaßnahmen als interventionistische Einwirkungen betrachtet, so

zu der Erörterung auch Merz, Uber die Schranken der Kartellbindung (Abhandl. zum Schweizer Recht 302) 1953 S. Igf.

60) Bundestag I. Wahlperiode, Drucks. Nr. 3462 vom 13.6 . 1952 S. $20,24$.

i) a. a. O. S. 16f.: „Wirtschaftsbereiche mit unvollständigem Wettbewerb".

(2) a. a. O. S. I7.

*3) Wie hier auch Krüger, Grundrechte und Kartellgesetz 1950; ders., BB. I953 S. 565. Für die Schweiz. siehe für diese Ansicht Homburger, Handels- und Gewerbefreiheit und Vertragsfreiheit (Zürcher Beiträge zur Rechtswiss., N. F. 145) 1948 S. 82f., Iorf. 
unterliegen sie den gleichen rechtsstaatlichen Voraussetzungen und Schranken. Man kann dann nicht, wie es die hier abgelehnte Auffassung tut, diese Einwirkungen mit einem leichteren Maßstabe messen oder die Meinung vertreten, die Befugnis zu solchen Verboten und Sanktionen könne schon aus dem Grundgedanken der Gewerbefreiheit oder des von der Verfassung vorausgesetzten Wirtschaftssystems abgleitet werden. Der Berner Dozent Hans Marti hat hier auf einen tiefergreifenden Gesichtspunkt hingewiesen ${ }^{64}$ ). Die freie gewerbliche Betätigung, so führt er aus, kann entweder gerechtfertigt werden als ein Bestandteil eines von der Verfassung festgelegten ökonomischen Systems der vollen Wettbewerbsfreiheit, oder aber sie erfährt ihre Begründung aus einem ganz anderen Gesichtspunkt, von der - möglicherweise naturrechtlich verstandenen - Hervorhebung des Rechts der persönlichen Freiheit. Im ersteren Falle würde das Recht zum Einschreiten gegen Kartellabreden aus der Konsequenz eines verfassungsrechtlich angenommenen Wirtschaftssystems auch ohne spezielle gesetzliche Ermächtigung sich ergeben; im zweiten Falle schlieBt die wirtschaftliche Freiheit auch freiwillige Bindungen derselben mit ein und kann folglich nur auf Grund besonderer gesetzlicher Ermächtigungen eingeengt werden. Im Verfassungsrecht der Schweiz wird dem Bunde ausdrücklich die Befugnis erteilt (Art. 3I, bis Buchst. d), gegen ,,volkswirtschaftlich oder sozial schädliche Auswirkungen von Kartellen und ähnlichen Organisationen" Vorschriften zu erlassen. Wenn man das Grundgesetz betrachtet, so kann kein $Z$ weifel sein, daB es die wirtschaftliche Betätigungsfreiheit (Art. 2 GG.) und die Berufsfreiheit (Art. I2 GG.) nicht als Teile einer von ihm angenommenen bestimmten Wirtschaftsverfassung festlegt - wir haben früher festgestellt, daB sich das Grundgesetz nicht $\mathrm{zu}$ einer auf eine bestimmte Doktrin abgestellten Wirtschaftsordnung bekennt ${ }^{65}$ ) -, sondern sie als AusfluB der Anerkennung der freien Persönlichkeit gewährleistet. Daher finden wir auch im Grundgesetz die Ermächtigung zum Vorgehen gegen den ,Mißbrauch wirtschaftlicher Machtstellungen" in Art. 74 Ziff. 16 ausdrücklich ausgesprochen. Das bestätigt die Annahme, daB sich diese Zuständigkeit nicht einfach aus einer vorausgesetzten wirtschaftlichen Ordnung ergibt.

Es sollte auch nicht übersehen werden, daß die Maßnahmen gegen wettbewerbsbeschränkende Abreden nicht immer zu den gewünschten wirtschaftspolitischen Zielen führen. In einem vom amerikanischen Supreme Court entschiedenen Falle (v) wurden Verträge einer in Kalifornien ansässigen Olgesellschaft mit selb-

4) Die Handels- und Gewerbefreiheit 1950 S. 28/29.

e5) Vgl. hierzu neuerdings Krüger, BG. 1953 S. $565 \mathrm{ff}$.

c) Standard Oil of California v. Un. States 337 US 293 (1948). 
ständigen Tankstellenbesitzern, die letztere verpflichteten, nur Erzeugnisse und Ersatzteile der betreffenden Firma zu führen, als potentielle Beschränkung des Wettbewerbes angesehen, obwohl diese Firma nur $23 \%$ der in Kalifornien abgesetzten Brennstoffmengen lieferte, mit vier anderen Firmen im Wettbewerb stand, die ihrerseits gleiche Tankstellenverträge abzuschließen pflegten, diese Verträge also keine Umsatzsteigerung bewirken konnten. In ihren abweichenden Äußerungen hoben die dissentierenden Richter hervor, dies Urteil werde im Ergebnis nur dazu führen, daß die Gesellschaften an die Stelle selbständiger Tankstelleninhaber künftig Angestellte setzen würden, daB also im Ergebnis eine Reihe selbständiger wirtschaftlicher Existenzen vernichtet werden würde ${ }^{67}$ ).

\section{Abschnitt \\ Formen der wirtschaftlichen Intervention des Staates}

I. Unmittelbare Eingriffe des Staates

I. Bei der Behandlung der verschiedenen Erscheinungsformen der Intervention des Staates möchte ich mich mit einem kurzen Uberblick begnügen. Ein volles System des Wirtschaftsverwaltungsrechts kann hier nicht aufgestellt werden. Es muß genügen, eine grundsätzliche Einteilung vorzunehmen, deren Unvollständigkeit in Kauf genommen wird, die aber die Herausstellung einiger Haupttypen erlaubt. Als Grundschema möchte ich zwischen unmittelbaren und mittelbaren Einwirkungen des Staates unterscheiden ${ }^{88}$ ). Das ist eine auch in der Volkswirtschaft verwendete Einteilung, die zwar weder originell, noch in jedem Einzelfall streng durchzuführen ist, aber den Vorzug hat, leicht faßbar zu sein. Unter unmittelbaren Handlungen verstehe ich dabei solche Maßnahmen, bei denen der Staat sich mit bindenden rechtlichen Weisungen und Zwangsgeboten an den einzelnen wendet, um von ihm ein Handeln, Unterlassen oder Dulden zu

4) Vgl. die dissenting votes von J. Douglas S. 320/2I (,The small independent business man will be supplanted by clerks") und J. J acksun S. 323, der hervorhebt, daB die Ausschließlichkeitsklausel das Publikum nicht benachteilige, ihm im Gegenteil eine Qualitătsgewähr biete. Das LG. Stuttgart hat in einer zum amerikan. MRG. 56 Art. I und Art. V $9 c_{2}$ erghngenen Entscheidung es abgelehnt, die Ausschließlichkeitsklausel als Vorsto $B$ gegen den Wettbewerb anzusehen und sie als bona fide marketing arrangement beurteilt (N JW. r952 S. 827). Ubereinstimmend Tetzner: NJW. 1952 S. 252 ; vgl. auch BGH. 5 S. 7 I.

ob) Eine Einteilung der wirtschaftslenkenden MaBnahmen ist neuerdings versucht worden von Andreas Hamann, Rechtsstaat nnd Wirtschaftslenkung r953 S. 95 ff. Vgl. auch ders., BB. 1953 S. 34 rff. Ferner E. R. Huber, Wirtschaftsverwaltungsrecht Bd. I I953 S. 47-84, dessen Gliedorung die rechtlichen Formen und die Rechtswirkangen der Handlungen in den Vordergrund stellt. 
verlangen. Bei den indirekten (mittelbaren) Mitteln des Staatseinflusses - hierzu rechne ich die Steuerpolitik, die Kreditpolitik, die Manipulierung der Währung, Subventionen und Begünstigungen - dagegen erreicht der Staat sein Ziel nicht durch Herbeiführung des erwünschten Verhaltens durch Befehl und Zwang, sondern entweder durch einen wirtschaftlichen Anreiz, eine Verlockung oder umgekehrt eine Diskriminierung unerwünschter Handlungsweisen oder durch die Anwendung von Mitteln, die für einen anderen Zweck bestimmt sind (z. B. Steuern), die aber von ihm für wirtschaftslenkende Zwecke herangezogen werden ${ }^{80}$ ).

Man kann sehr verschiedene Maßstäbe für eine Einteilung der wirtschaftslenkenden Staatshandlungen verwenden. Am nächsten liegt eine Gliederung, die abstellt auf die wirtschaftlichen Bereiche, in denen die Lenkung sich abspielt (Hamann): Errichtung von Betrieben und Erzeugung, ferner Lenkung der Verteilung, der Ein- und Ausfuhr und der Preise, sowie Beeinflussung der Kapitalbildung, des Kredits, der Lohnpolitik. Bei dieser wirklichkeitsnahen Betrachtung werden freilich die typischen Formen weniger sichtbar werden. Eine andere Gliederung (E. R. Huber) will auf die rechtlichen Formen abstellen: Einwirkung durch Gesetz, Verwaltungsakt oder Vertrag, durch hoheitliches $Z$ wangsgebot oder durch privatrechtliche Gestaltungsmittel, durch Berechtigung oder Verpflichtung, durch Hervorrufen öffentlichrechtlicher oder privatrechtlicher Wirkungen. Man kann auch nach dem Träger des Einflusses differenzieren: Wirtschaftseinwirkungen durch Staatsbehörden, durch Staatseinrichtungen in privatrechtlicher Form, durch selbständige Körperschaften und Anstalten oder in Form einer Heranziehung der Beteiligten zur Mitwirkung (soziale oder berufliche Selbstverwaltung, autonome Rechtsetzung). Eine solche Einteilung wird im wesentlichen indessen nur den öffentlichrechtlichen Methoden staatlicher Lenkung gerecht werden und gerade die mittelbaren Einflußnahmen nicht erfassen, die oft öffentlichrechtliche und privatrechtliche Elemente verbinden (z. B. Gewährung öffentlicher Kredite, Gestaltung einer wirtschaftlichen Ordnung eines Gewerbes oder Berufes) oder ihre Wirkung gar

\footnotetext{
69) Die hier gemachte Unterscheidung deckt sich nicht mit der zwischen Lenkung durch Gesetz oder Verwaltungsakt einerseits und privatrechtliche Handlungen andererseits, wie sie der Ubersicht bei E. R. Huber zugrundeliegt. Es wird vielmehr abgestellt auf das offene Herbeiführen des angestrebten wirtschaftlichen Erfolges im Unterschied au der Verfolgung eines Zwecks mit verdeckten oder indirekten Mitteln. Ebensowenig kann angesichts der Verschmelzung offentlichrechtlicher und privatrechtlicher Formen und Wirkungen der Unterschied von Verwaltungsalkt und fiskalischer Handlung, von offentlichrechtlicher oder privater Gestaltung eines Rechtsverhältnisses - so wichtig er für die rechtliche Beurteilung der Verwaltungsvorgănge ist - für unseren Zweck entscheidend sein. Vgl. Siebert, Privatrecht im Bereich offentlicher Verwaltung in Festschrift $f$. Niedermeyer I953 S. 215ff., 221 f.
} 
nicht unmittelbar durch rechtsgestaltende Maßnahmen erreichen, sondern durch abgeleitete Folgen eines Vorgehens (Kapitallenkung durch Steuerbegünstigung, Einfuhrbeschränkung durch Festlegung unvorteilhafter Devisenkurse für Importe). Das hier gewählte anspruchslose Schema nimmt für sich keine strenge Folgerichtigkeit in Anspruch. Es möchte helfen, die orientierende Umschau an den charakteristischen Mitteln des Eingreifens auszurichten.

2. Ich fasse zunächst die Einwirkungen unmittelbarer Art ins Auge.

a) Hier begegnen zuerst Gebote und Verbote, Zulassungen zu Gewerbe und Beruf, Festsetzungen von Kontingenten, Bezugsberechtigungen, Verwendungsverbote. In diesem Bereiche finden wir die einfachen offenen Eingriffe altherkömmlicher Art, die die Errichtung oder Erweiterung eines Betriebes, den Zugang zu einem Gewerbe oder Beruf unter wirtschaftspolitischen (nicht polizeilichen) Gesichtspunkten regeln ${ }^{70}$ ) oder die Auflagen, Erlaubnisse aller Art und Konzessionen betreffen. So kann etwa im Rahmen des Getreidegesetzes für die Mühlen die Höhe ihres Verarbeitungsrechtes durch den Bundesminister für Ernährung festgelegt werden ${ }^{11}$ ). In der Rechtsprechung ist schon früher die Frage behandelt worden, ob der Pächter einer Mühle bei wesentlicher Verringerung eines solchen Kontingentes den Pachtzins mindern darf; das Reichsgericht hat das aus $\$ 581,537$ BGB. bejaht ${ }^{72}$ ). Die direkte Anordnung, verbunden mit Erlaubnissen, Geboten und Verboten, Anmelde-, Auskunfts- und Ablieferungspflichten beherrscht auch das staatliche Devisenrecht ${ }^{\text {78) }}$ sowie

70) Vgl. Hamann, Rechtsstaat und Wirtschaftslenkung r953 S. rorff. Im schweizer. Recht ist hier hinzuweisen auf den Schutz der Hotellerie (BB. vom 19. 6. 1953) und das Uhrenstatut (BB. vom 22. 6. 195I). Vgl. Giger, Die Mitwirkung privater Verbände bei der Durchführung offentlicher Aufgaben I95I S. II2ff.; Schürmann, Das Recht der gemischtwirtschaftlichen und offentlichen Unternehmungen mit privatrechtlicher Organisation, Ztschr. f. Schweiz. Recht, N. F. 72 (1953) S. 145 aff. Die Festsetzung eines Mindestumsatzes für Milchhandelsgeschafte (\$14 Abs. 5 Ziff. 6 MilchG.) gehort dagegen in das Gebiet gesundheitspolizeilicher Vorkehrungen (Sicherung ausreichender Einrichtungen). So OVG. Münster OV 1953 S. 218 und OVG. Lüneburg DVBl. 1953 S. 44I ff. (unter Hinweis auf Leitsatz $22 \mathrm{c}$ dieses Referates).

71) §4 Getreideges. vom 4. II. I950. Für ungültig halten diese Bestimmung Hamann a. a. O. S. II5 und Modest, Kommentar zum Getreidegesetz 1953 S. 44. In der Schweiz ist hier die als private Gesellschaft gebildete, seit 1948 als AG. fungierende Kaseunion mit festgelegten Mitgliedsrechten zu nennen. Vgl. Schürmann S. r52aff. Siehe auch $\$ 5$ Abs. 3 Zuckerges. i. Fassung vom 3. ro. 195x.

79) RGZ. 147, 157. Unter dem Gesichtspunkt eines Fehlers der Pachtsache wird Herabsetzung des Zinses begründet.

7) Neben den direkten Anordnungen spielt hier aber auch die Erfolgssicherung für die staatlichen Maßnahmen durch privatrechtl. Ungültigerklärung verbotener Transaktionen eine Rolle. Vgl. zu den Rechtsformen. 
die Materie der Ein- und Ausfuhrgenehmigungen 74).

b) Eine zweite Gruppe umschließt die inhaltliche Gestaltung von Rechtsgeschäften und Rechtsverhältnıssen durch den Staat, in der Regel durch Gesetz, rechtsgestaltenden Verwaltungsakt oder Ermächtigung an Verbände zur autonomen Rechtsgestaltung. Hierher gehört die gesetzliche Festlegung von Vertragsbedingungen oder Normalverträgen, kollektiver Mindestbedingungen (Mindestlöhne), Anschlußzwang oder die Ermächtigung, durch Verordnungen Vertragsbedingungen $2 \mathrm{u}$ bestimmen ${ }^{75}$ ) oder Qualitätsnormen, Güteklassen, Verpackungsnormen und dergleichen festzulegen ${ }^{78}$ ). Vor allem begegnen wir in dieser Kategorie der Eingriffe staatlichen Preisfestsetzungen und Preisbindungen "7). Durch ein umfangreiches Gesetz setzt der Staat jedes Jahr den Getreidepreis für das ganze Bundesgebiet nach regionalen und qualitativen Staffelungen fest ${ }^{78}$ ). Ein solches Gesetz stellt freilich

NuBbaum, Money in the Law 2. Aufl. r95o S. $446 \mathrm{ff}$; F. A. Mann, The Legal Theory of Money 2. Aufl. I953 S. $340 \mathrm{ff}$.

74) Hamann S. I2If. und insbesondere zum Außenhandelsrecht in Verbindung mit dem Devisenrecht Georg Erler, Ztschr. auslöfR. u. VR. I5 (1953) S. I ff.

76) Die Einwirkung auf das Privatrecht bezeichnet E. R. Huber S. 77 gerade als eine typische Erscheinungsform der staatlichen Intervention. Vgl. 2. B. Energieges. vom 13. 12. 1935 \$2.

70) Qualitätsnormen, Handelsklassen, Gütezeichen usw. kennen die meisten landwirtschaftlichen Ordnungsgesetze: Milch,- u. Fettges. i. d. Fassung vom 17. 12. 1952 § 10, I1, 18, 19; Getreideges. § 3; Weingesetz $\$ \S 2-I I$. Die oft minutiösen Anordnungen gehen bis zur genauen Normung der Verpackung. In der ButterVO. vom 2.6. 1951 und der KäseVO. vom 2.6. 195I werden eingehend Größe und Art der Umhüllung. Größe und Gewicht der in den Handel gebrachten Stücke einzelner genau beschriebener Käsesorten geregelt. Vgl. Godbersen, Butterverordnung und Verordnung über Käse, Schmelzkäse und Käsezubereitungen, Kempten o. J. (r951).

77) Eine durchgängige, die wirtschaftliche Freiheit nach Art. 2 GG. in Mitleidenschaft ziehende Preisregelung für alle Gebiete würde in normalen Zeiten für unstatthaft zu halten sein. Anders Preisregelungen, die für beschränkte Bereiche aus Gründen herkömmlicher Einheitlichkeit (Energietarife), sozialen Rücksichten (Mietpreisregelung, Herstellung eines billigen Konsumbrotes vgl. OLG. Hamm NJW. I95I S. 731) oder aus strukturellen Gründen dieses Gebietes ergehen. Ob das ganz allgemein für landwirtschaftliche Erzeugnisse zu bejahen ist (vgl. die weitgehenden Ermächtigungen in § 6 Abs. I Zuckerges. § 20 Milch-und Fettges.i.d. Fassung vom 10. 1 2. 1952), 1st nicht ohne Zweifel. Vgl. Ha ma n n S. 54 f. Zum Problem der Grenze preisrechtlicher Regulierung und vor allem zur Ermächtigung zu VOen auf diesem Gebiet siehe Haugleiter, OV I952 S. 750 ff.; zur Rechtsgrundlage und zivilrechtlichen Auswirkung von Preisvorschriften Rinck, ACP. I 52 (1953) S. $4^{81} \mathrm{ff}$.

78) Vgl. § ro Abs. I Getreideges. und dazu Ges. über Preise für Getreide inländ. Erzeugung für das Getreidewirtschaftsjahr I953/54 vom 6. 8. 1953 BGB1. I953 I S. 889. Solche Preisbindungen können nicht als Verletzung der Art. 2. 12 GG. angesehen werden, da sie einen begrenzten Wirtschaftsbereich mit besonderen Marktverhältnissen (infolge des notwendigen Imports) betreffen. Der Preisstand wird gesichert durch eine Abnahmepflicht der Einfuhr- und Vorratsstelle für Getreide u. Futtermittel zum Mindestpreis (\$ I Abs. II Gesetz 1953). Vgl. Modest S. I rof. 
keine echte Rechtsnorm dar. Sie ist kein dauerhaftes, als Teil der sittlich verbindenden Rechtsordnung aufgenommenes Gebot, sondern stellt in Wirklichkeit nur eine administrative Maßregel im Gewande des Gesetzes dar, dessen Form gewählt wird, um den Erfordernissen des heutigen formalisierten Gesetzesbegriffes - die jede generelle Anordnung bei Eingriffen in die individuelle Rechtssphäre als Rechtssatz bezeichnet - genugzutu ${ }^{79}$ ).

In erheblichem Umfang zeigen also diese Maßnahmen, so weit sie nicht unmittelbar durch Gesetz getroffen werden, die Form des privatrechtsgestaltenden Verwaltungsaktes. Der öffentlichrechtliche Eingriff zieht praktische Wirkungen nach sich, die dem Privatrecht angehören, etwa Begründung von Vertragsverhältnissen oder privaten Rechten. Es gehört zum Wesen dieser rechtlichen Figur, daß die öffentlichrechtliche Einwirkung nur punktuell ist, nicht das ganze Rechtsverhältnis umgestaltet und daher die privatrechtliche Natur der beteiligten Rechte und Rechtsverhältnisse bestehen läßt. Daraus erklärt sich, daß bei Fehlgreifen und Unwirksamkeit der öffentlichrechtlichen Einwirkungen das zugrundeliegende Privatrecht unberührt bleibt und beispielsweise Eigentum einfach gegenüber unwirksamen Beschlagnahmen durch die Eigentumsklage geltend gemacht werden $\left.k^{k} n^{80}\right)$. Anders liegt es freilich, wenn wir den Bereich unserer rechtsstaatlichen, nur begrenzte staatliche Eingriffe gestattenden und Rechtsschutz gewährenden Ordnung verlassen. Wenn in der Sowjetzone ein Betrieb zum volkseigenen Unternehmen erklärt wird, erfaßt die neue öffentlichrechtliche Form kraft des zugrundeliegenden Verwaltungsaktes alle Gegenstände des Betriebes ohne Rücksicht auf das daran etwa bestehende Eigentum Dritter, denen auch ein Rechtsschutz versagt bleibt ${ }^{81}$ ). Staatshandlungen, die Rechte gestalten, stellen auch jene Akte dar, die im Rahmen wirtschaftslenkender Vorgänge die Bildung und das Recht öffentlichrechtlicher oder privatrechtlicher Verbände und Organisationen gestalten. Ich kann auf dieses ausgedehnte Gebiet hier nicht näher eingehen. Errichtung von Verbänden und Verleihung der Rechtspersönlichkeit, Erlaß der Satzung unter Umgrenzung der

79) Insofern ein deutliches Beispiel für die Auflösung, die der Gesetzesbegriff durch seine Anwendung auf staatliche Lenkungsmaßnahmen erfährt. Vgl. Hans Huber, Festgabe für Giacometti r953 S. 75.

80) Vgl. OGHBrZ. VerwRspr. 3 S. I 52 sowie auch Württ.-Bad. VGH. VerwRspr. S. 320.

81) OG. in Neue Justiz 4 (1950) S. 45I: Ein einem Dritten gehörendes Pferd wird bei der Enteignung eines landwirtschaftlichen Betriebes zum Inventar geschlagen; es besteht daher kein Herausgabeanspruch. Die Festsetzung des Inventars erfolgt durch die Verwaltung and ist gerichtlicher Prüfung entzogen. Die offentlichrechtliche Qualität der volkseigenen Gegenstände erfa日t sie sogar schon in der Entstehung: Schulmöbel für eine Schule sind schon im Herstellungsbetrieb der zivilrechtlichen Pfändung nach § 81 I ZPO. entzogen. So AG. Neubrandenburg N J. 195I S. 523. 
Aufgaben, Anordnungen für das innere Leben dieser Vereinigungen werden zahlreichen Organisationen vom Staate mitgegeben, die er im Bereiche des öffentlichen Rechts entstehen läßt, aber auch privatrechtlichen Verbänden, denen er öffentliche Aufgaben zuweist oder deren er sich zur Erfüllung bestimmter Zwecke in privatrechtlicher Form bedient ${ }^{82}$ ). Besonders bedeutsam werden die organisatorischen Verfügungen des Staates, wenn die so geschaffenen oder anerkannten Verbände die Befugnis erhalten, ihrerseits Rechtsverhältnisse ihrer Mitglieder oder sogar dritter Personen zu regeln. Am weitesten geht die Mitwirkung von Verbänden auf dem Gebiete des Arbeitsrechtes, wo der Staat den beteiligten Organisationen der Unternehmer und der Arbeitnehmer im Tarifvertragsrecht eine normative Kompetenz, d. h. eine rechtsetzende Vollmacht zur verbindlichen Gestaltung privater Verhältnisse delegier ${ }^{83}$ ). Tendenzen zur Ausweitung des Bereiches solcher verbindlichen Vereinbarungen der Sozialpartner

82) Ein Beispiel öffentlichrechtlicher Verbände mit wirtschaftslenkender Funktion bilden die Schifferbetriebsverbände (offentliche Körperschaften) des Ges. über den gewerblichen Binnenschiffahrtsverkehr vom r. 10. I953 (RGBl. I S. I453) $\S$ I I, 12. Allgemein lehnt die Ubertragung hobeitlicher Aufgaben auf privatrechtliche Verbände ab ReuB, DVBl. I953 S. 685 f. Mir scheint die Auffassung von E. R. Huber (S. 543 f.) richtiger, der hier eine enge qualitative und quantitative Begrenzung annimmt, die Zuweisung aber nicht schlechthin ausschließt. Den landwirtschaftlichen Einrichtungen, die Ein- und Ausfuhr regeln, hat der Gesetzgeber heute die Form rechtsfähiger Anstalten des offentlichen Rechts gewährt (Einfuhr- und Vorratsstelle für Getreide und Futtermittel vgl. I. DuVO. z. Getreideges. vom 3. 2. I95I § 8, Mühlenstelle vgl. IV. DuVO. z. Getreideges. vom I7. I2. I95I, Einfuhrstelle für Zucker, Zuckerges. \$ 8). Diese Einfuhrstellen besitzen Einfuhrmonopole, vgl. E. R. Huber S. 5 I 7 f. Nicht selten wird ausdrücklich bestimmt, daß privatrechtlichen Organisationen hoheitliche Aufgaben nicht übertragen werden dürfen (z. B. Milch- und Fettges. $\S$ I4 Abs. 3, Vieh- und Fleischges. vom 25. 4. I95I $\$ 20$ Abs. II). Andererseits werden privatrechtlichen Verbānden öffentliche Vollmachten in der Form gegeben, daB sie rechtlich oder faktisch Monopolstellung erhalten. Das gilt etwa für die Exportrisiko-Versicherung, die praktisch für privatrechtliche Transaktionen in Deutschland bei der „Hermes Kredit Versicherung A. G." zentralisiert ist. Vgl. Lichey, Die Systeme der Exportrisikogarantie (Schriften des Hamburger Weltwirtschaftsarchivs Nr. 4) r953 und E. R. Huber S. I2rf. Ein anderes Beispiel bildet die Einsetzung von Notierungskommissionen für die Feststellung von Preisen für Butter und Käse (Milch- und Fettges. in Fassung vom ro. 12. $1952 \oint 20$ Abs. III). Diese Kommissionen setzen keine verbindlichen Preise fest, sondern sie ermitteln nur den jeweiligen Preisstand und geben ihn als ,Amtliche Preisnotierung der Notierungskommission" bekannt. Diese Kommissionen, zusammengesetzt aus Vertretern der Molkereien, Erzeuger und Abnehmer, üben also nicht durch verbindliche Preisbestimmung hoheitliche Funktionen, erfüllen aber durch die Bekanntgabe der gewissermaßen nur informativen Preisnotierung eine ähnliche Aufgabe.

*) Zur Rechtsnatur der Tarifverträge nach herrschendem Recht siehe Nikisch, Arbeitsrecht 1951 S. 355. 
sind heute erkennbar ${ }^{84}$ ), vor allem auch im schweizerischen Recht ${ }^{\mathrm{B5}}$ ). Andererseits engt der Staat aber dort, wo er bestimmte bisher in Tarifverträgen geregelte Fragen - z. B. Mindestarbeitsbedingungen - gesetzlj ordnet, den Bereich der freien sozialen Gestaltung der Gruppen wiederum ein $\left.{ }^{86}\right)$. Es wäre hier ferner auf die öffentlichrechtlichen Formen der Gestaltung der Verhältnisse bestimmter Berufe durch die Kammern für Anwälte, Ärzte usw. hinzuweisen ${ }^{87}$ ). Auf den meisten Gebieten der Wirtschaft hat der Staat eine solche Ermächtigung nicht ausgeteilt. Dort bleibt es Aufgabe der privaten Verträge, in der Gestalt von Allgemeinen Geschäftsbedingungen und Normenverträgen eine Typisierung und Regulierung der Veriıagsbeziehungen zu erreichen. Der Grundsatz der Freiwilligkeit muB in diesem Falle aber streng gewahrt bleiben ${ }^{88}$ ).

c) Als dritten Kreis interventionistischer Handlungen möchte ich Leistungsgebote, Pflichten zur Nutzung von Sachen, Auflage bestimmter Verpflichtungen zur Herstellung und Lieferung ${ }^{89}$ ), Zuweisung von Absatzgebieten, Verteilung, Heranziehung zu

84) In Deutschland gehen die Anregungen, die Sitzler, Sozialer Fortschritt I (1952) S. 75 ff. und Soziale Selbstverwaltung im demokratischen Staat (Verhandlungen der 2. Hauptvers. der Gesellschaft für Soz. Fortschritt 1952) S. 15 ff., gemacht hat, dahin, den Sozialpartnern zur Selbstverwaltung auch Fragen der Berufserziehung, der Lohnzahlung bei Betriebsstörungen, der Haftung des Arbeitnehmers usw. zuzuweisen. Vgl. dazu kritisch Herrschel, Soz. Selbstverwaltung S. 27ff.; Groß, Soz. Fortschritt I (1952) S. 2I I ff.

85) In der Schweiz ist heute die Allgemeinverbindlicherklärung auch schon außerhalb des Arbeitsrechts von Bedeutung (z. B. in der Milchwirtschaft) - vgl. Giger a. a. O. S. 147f. Darüber hinaus wird der Gedanke der qualifizierten Rechtsverordnung aufgegriffen und findet in die kantonale Gesetzgebung Eingang: Inhaltliche Bestimmung derNormen durch die beteiligten Verbände, die dann durch Verordnung des Staates in Kraft gesetzt werden. Vgl. hierzu Nägeli, Festgabe f. Nawiasky 1950 S. 205 ff.; Tschudi, Wirtschaft und Recht 4 (1952) S. $66 \mathrm{ff}$.

86) Die Subsidiarität staatlicher Festsetzungen von Mindestarbeitsbedingungen hinter den Tarifvereinbarungen legt $\S$ I des Ges. über die Festsetzung von Mindestarbeitsbedingungen vom ri. I. I952 (BGBl. I S. I7) fest. Vgl. ebenso Heimarbeitsges. vom 14. 3. I95 I \$ I9 (Festsetzung von Entgelten und Bedingungen durch Ausschüsse bei Fehlen geeigneter Verbände). Zum Verhältnis von Gesetz und Vertrag siehe Zanetti, Wirtschaft u. Recht 3 S. 5of.; Tschudi dort ${ }_{4}$ S. 68 ff. Zu weite Ausdehnung gesetzlicher Normativbestimmungen könnte im Arbeitsrecht zur Starrheit und zur Entleerung der Tarifvereinbarungen führen.

87) Vgl. Georg Erler, Freiheit und Grenze berufsständischer Selbstverwaltung $1952 \mathrm{~S}$. I $7 \mathrm{ff}$.

88) Zur Voraussetzung der Freiwilligkeit siehe BGHZ I, 183; 3, 200; 9, 1 und dazu Patschke, BB. I954 S. 5 .

89) Solche Maßnahmen der Verarbeitungsverbote, Kontingentierungen und Lieferpflichten stellen keinen unstatthaften Eingriff in die personliche Betätigungsfreiheit des Art. 2 GG. dar. So richtig OVG. Hamburg VerwRspr. 3 S. 731/32. Zur Milchabliefungspflicht siehe auch OLG. Stuttgart OV. 1953 S. 216. 
Sach- und Dienstleistungen, Verfügungsbeschränkungen nennen, sofern sich diese Eingriffe nicht wie bei der ersten hier genannten Kategorie auf einzelne punktweise Eingriffe beziehen, sondern Bestandteile eines umfassenderen, für begrenzte Zeit oder auch für die Dauer geschaffenen Systems von Einwirkungen darstellen, durch die die wirtschaftliche Disposition über ein bestimmtes Wirtschaftsgut oder einen ganzen Wirtschaftszweig erreicht wird. Die in der ersten Gruppe behandelten Maßregeln haben Einzelfälle der Intervention (Devisengenehmigungen, Betriebszulassungen) allgemeiner Art zum Gegenstand. Hier aber handelt es sich um Maßnahmen, die zwar der Art nach jenen anderen Fällen ähnlich sind, die aber durch ihre Einfügung in ein größeres Netz von Einwirkungen zusammengehalten werden. Sie reichen von der ,Marktlenkung" für bestimmte Erzeugnisse, etwa landwirtschaftlicher Art, über die Bewirtschaftung von Gütern und Rohstoffen in Zeiten der Mangellage oder des Krieges bis zum systematischen Aufbau von schützenden und fördernden Ordnungen für ganze Gewerbezweige, wie wir sie etwa im schweizerischen Recht in der Regulierung der Uhrenindustrie vor uns sehen. Einen Schritt weiter in der staatlichen Gestaltung eines Gewerbes ist dann schon die Stufe der durch öffentliche Verleihung oder den Vorbehalt der öffentlichen Hand begründeten rechtlichen Monopole oder der Verleihung von Monopolstellungen an private Unternehmungen erreicht, wie wir sie bei den fiskalischen Monopolen (Erzeugungs- oder Handelsmonopolen), den traditionellen Regalen der Post und Eisenbahn und den daneben vom Staat in eigener Regie oder in privater Ausübung begründeten Monopolen finden $\left.{ }^{90}\right)$.

Als Beispiele der Marktlenkung können wir die Maßregeln auf dem Gebiet der landwirtschaftlichen Erzeugung von Milch, Ge-

0) Ich vermag der Ansicht von Uber, Die Freiheit des Berufes 1952 S. I5rff., I6r, I7I, und Stodter, Rechtsfragen des Zündholzmonopols I 953 S. 50 ff., nicht zu folgen, daß zwar fiskalische Staatsmonopole durch Art. 105, 106, 108 GG. zugelassen und staatliche Verwaltungsmonopole (z. B. Arbeitsvermittlung, Fernsprechwesen) statthaft seien, aber eigentliche Wirtschaftsmonopole oder Monopolstellungen in Berufen nicht begründet werden dürften. Das Argument von Stöd ter, Art. 105, 106, 108 GG. dürften nur als Kompetenznormen, nicht als sachliche Anordnungen gewertet werden, halte ich für unzutreffend; im Grundgesetz gilt weithin der Satz von der Vertauschbarkeit formeller Kompetenzbestimmungen und inhaltlicher Anordnungen; er ist auch hier anwendbar. Das Grundgesetz läBt, wie der Württ.-Bad. VGH. richtig meint (VerwRspr. 3 S. 371), Monopole des Staates zu. Daher konnte das Schornsteinfegerwesen offentlichrechtlich gestaltet werden (BVerfGE. I S. 278/79, unrichtig Uber S. I80ff.) und ebenso das Hebammenwesen staatlicher Regelung unterliegen (vgl. Ges. vom 4. 1. 1954). Die Grenzen der Monopole liegen dort, wo sie herkommliche oder handwerkliche Berufe freier Gestaltung erfassen oder sonst mit Leitgedanken des Grundgesetzes über die freie Wirtschaftstätigkeit-in Widerspruch treten. Vgl. wie hier E. R. Huber Bd. I S. 48 If. 
treide, Zucker anführen. Hier finden wir nicht nur einzelne Gebote und Beschränkungen, sondern ein in sich zusammenhängendes Netz von Regelungen. Die Milcherzeuger beispielsweise sind zur Ablieferung der Milch an bestimmte Molkereien, diese zur Abnahme verpflichtet (Milch- und Fettges. $\S$ I), der Milchhändler ${ }^{91}$ ) darf in einem bestimmten Absatzgebiet die Milch nur von einer zugewiesenen Molkerei - es können auch mehrere sein - beziehen (\$2); bei Einfuhr von Butter, Schmalz und sonstigen Fetten aus dem Ausland müssen diese Einfuhren der Einfuhrund Vorratsstelle für Fette angeboten werden, die keine Ubernahmepflicht hat ( $(6)$, aber Preise und Mengen der Einfuhr reguliert. Diese landwirtschaftlichen Marktordnungen dienen einem doppelten $Z$ weck. Sie sind in der Hauptsache bestimmt, eine gewisse Stabilität der landwirtschaftlichen Märkte zu erhalten, die wegen ihrer besonderen Struktur nicht dem vollen freien Wettbewerb ausgesetzt werden. Daneben aber wird aus Gründen der Sicherung der Versorgung in Notfällen eine gewisse Vorratshaltung in diesen Erzeugnissen bewirkt. Ergänzend gelten in diesem Bereich dann zahlreiche Qualitätsnormen, deren Bedeutung ich in einer Fachschrift auf dem Gebiete der Käsebereitung dahin gekennzeichnet finde, daß eine sonst eintretende Qualitätsminderung "das Ansehen des deutschen Käses“ verderben würde ${ }^{22}$ ). Als Muster von bewirtschaftenden Eingriffen in einer Mangellage kann man aus neuerer Zeit die Regelung für Eisen und NE-Metalle anführen, die in der Zeit der auBerordentlichen Nachfrage nach der Koreakrise eingeführt wurde, jetzt aber wieder außer Geltung getreten ist. Diese Maßnahmen wurden gestützt auf das Gesetz für Sicherungsmaßnahmen auf einzelnen Gebieten der gewerblichen Wirtschaft vom 5.5. $195^{I^{95}}$ ). Sie enthielten zunächst umfangreiche Melde- und Anzeigepflichten über alle vorliegenden Bestellungen und durchzuführenden Lieferungen. Den Erzeugern konnten Herstellungsgebote für bestimmte Mengen und Sorten auferlegt werden, und sie durften ihre Abnehmer nur gekürzt bis zu einem bestimmten jeweils fixierten Prozentsatz - dann aber gleichmäßig - beliefern, wobei das Jahr 1950 als Vergleichszeitraum diente. Gewisse Lieferungen - für mandato-

11) Bei Straßenabsatz von Milch findet sich eine Vorschrift, die den Wettbewerbsgedanken betont. Es sollen in einem Bezirk mehrere Straßenhandler Milch und Milcherzeugnisse absetzen dürfen (Milch- und Fettges. §6 Satz 2).

92) Vgl. Godbersen, Butterverordnung (vgl. Anm. 76) S. 72.

9) Die sind enthalten in der VO. über die Kennzeichnung von Lieferaufträgen von Stahlerzeugnissen (VO. Eisen I/5I vom 28. 3. I95I BAnz. Nr. 59), der VO. über Herstellung, Lieferung und Bezug von Eisen- und Stahlerzeugnissen (VO Eisen II/5I vom 15. 10. 195I BAnz. Nr. 200), der VO. zur Sicherung der Durchführung dringlicher Ausfuhrgeschäfte (VO. Ausfuhr I/5I vom 15. I0. 1951 BAnz. Nr. 200) und der VO. über Lieferung und Bezug von Betonstahl (VO. Bau $1 / 51$ vom 21. 12. 195I BAnz. Nr. 249). 
rische Besatzungsaufträge und für den Export - genossen dabei einen näher festgelegten Vorrang; für sie konnten besondere Lieferpflichten begründet werden. Neue Kunden durften erst nach erfolgter amtlicher Zuweisung beliefert werden. Hand in Hand damit ging eine umfassende Preisregulierung, die erst nach Inkrafttreten der Montanunion im Sommer I952 abgelöst wurde ${ }^{94}$ ).

Umfassende wirtschaftspolitische Regelungen eines ganzen Wirtschaftszweiges unter wirtschaftspolitischen Zielsetzungen, wie sie das schweizerische Recht für die Uhrenindustrie mit Errichtungs- und Erweiterungsbeschränkungen, Organisation der vorhandenen Betriebe, genauester Uberwachung der Ausfuhr und Preisregelungen geschaffen hat, kennt das heutige deutsche Recht nicht, weil es im gewerblichen Bereich auf die Herstellung tunlichster Freiheit ausgeht. Man könnte hier nur auf die Regelung der Energieversorgung hinweisen, wo Anschluß- und Versorgungspflichten und Zuweisung von Gebieten eine Rolle spielen ${ }^{95}$ ).

Ein für alle diese Bereiche kennzeichnendes Merkmal ist der weite Umfang, in dem der Gesetzgeber Auskunfts-, Melde-, Registrier- und Buchhaltungspflichten mit großer Leichtigkeit verfügt. Tiefer freilich als diese lästigen Auflagen reichen - etwa im Energiegesetz - Dauereinwirkungen auf die Betriebsführung. Unter ihnen erscheint als ein besonders schwerer Eingriff die Verpflichtung des Landwirts zu ordnungsgemäßer Bebauung des Bodens. Sie ist aus dem deutschen Recht, wo sie in der nationalsozialistischen Zeit eingeführt worden war, heute wieder verschwunden, findet sich seither aber im englischen Recht, wo ein Landwirt wegen bad estate management oder bad husbandry unter Aufsicht gestellt oder von seinem Besitz entfernt werden kann $\left.^{96}\right)$. Dieses Beispiel zeigt zugleich, wie auf dem Gebiete des Wirtschaftrechts bestimmte Zielsetzungen selbst unter politisch sehr verschiedenen Regimen in ganz ähnlicher Weise in Erschei-

M) Jetzt kơnnen bei Mangellage von der Hohen Behorde der Montannnion gemå̉ Art. 59 des Vertrages über die Europ. Gemeinschaft für Kohle and Stahl Herstellungs- und Lieferpflichten festgelegt werden. Zu der Schwierigkeit solcher Anordnungen im internationalen Rahmen si.he Reuter, La Communauté Européenne du Charbon et de l'Acier r953 S. :.44. Für die Preise hat die Montanunion durch das Verlangen der Listenpreise nicht die erhoffte Auflockerung gebracht.

*) Das Energiewirtschaftsges. stammt vom 13. 12. 1935, ist aber durch das Notgesetz vom ro. 6 . 1949 (seither oft verlangert) beibehalten worden. In anderen Ländern - Frankreich und England - ist das Gebiet der Energie- und Gasversorgung nationalisiert and dadurch zentraler Leitung geoffnet, wobei das franzós. Recht sogar die eigene Kraftversorgung einzelner Betriebe mitumfät. Vgl. zum Rechtschutz gegen die Einbeziehung solcher Anlagen Conseil d'Etat Dalloz 1952 S. 642 (Electricité de France).

*) Agriculture Act 1947 Io \& II Geo VI c. 48 S. 16, 7 und daru Fried mann, Law and Social Change S. 26. Aus dem deutschen Recht ist noch auf die Ausschaltung leistungsunfähiger Energieversorgungsunternehmen hinzuweisen (EnergieWGes. \$\$ 7, 8). 
nung treten. Endlich mögen hier noch die Sach- und Dienstleistungen genannt werden. Von ihnen sind die ersteren mit dem Zurücktreten des Reichsleistungsgesetzes - und vor der Neubelebung durch die geplanten EVG-Verträge - - vorerst von geringerer Bedeutung. Die Dienstleistungspflichten hingegen, die uns Herr Ipsen so anschaulich vor Augen geführt hat ${ }^{97}$ ), gewinnen namentlich im Gebiete des Steuerrechts, aber auch etwa der Hilfstätigkeit der Banken in der Währungsumstellung und in der Devisenüberwachung immer mehr an Ausdehnung, ohne noch eine entsprechende rechtsstaatliche Durchgestaltung erfahren zu haben.

d) Als charakteristische Erscheinung des interventionistischen Wirtschaftsrechts tritt an vielen Stellen die Heranziehung von Privatpersonen und Verbänden des privaten Rechts wie der Schaffung öffentlicher Organisationen für die Durchführung der auftretenden mannigfachen Aufgaben der Lenkung und Leitung hervor. Auch hier zeigt sich große Mannigfaltigkeit. Die Erscheinungen reichen von öffentlichen Aufträgen - etwa der eben erwähnten Mitwirkung der Banken als Außenhandelsbanken bei der Devisenüberwachung - mit entsprechender Inpflichtnahme und Ausstattung mit bestimmten Befugnissen ${ }^{98}$ ) über das beliehene Unternehmen oder beliehene Verbände ${ }^{99}$ ) zu den zahlreichen öffentlichrechtlichen Verbänden. Gerade auf dem letzteren $r$ sbiete besteht heute ebensowenig wie in der Zeit, als Arnold Köttgen und Werner Weber ihre klärenden Ubersichten schrieben ${ }^{100}$ ), eine klare Abgrenzung zwischen den einzelnen Rechtsformen. Der Unterschied zwischen Körperschaften und Anstalten droht ebenso verunklärt zu werden ${ }^{101}$ ) wie der Begriff des gemischtwirtschaftlichen Verbandes ${ }^{102}$ ). Man hat zwar unter

97) Festgabe für Erich Kaufmann r950 S. I41 ff.; vgl. auch ders., AÖR. 78 S. 2901 .

9) Ipsen, Festgabe Kaufmann S. 153ff.; E. R. Huber, Bd. I S. $54^{2}$.

99) Mit Recht stellt E. R. Huber fest (S. 543 f.), daB verfassungsrechtliche Bedenken gegen solche Auftrăge nicht bestehen. A. A. Reu B, DVBl. 1953 S. 685.

100) A. Kottgen, Die rechtsfähige Verwaltungseinheit r939; Werner Weber, Die Korperschaften, Anstalten und Stiftungen des offentlichen Rechts 2. Aufl. 1943.

101) Zur Klärung vgl. Forst hoff, Verwaltungsrecht, 3. Aufl. 1953 Bd. I S. 377 ff., der mit Recht für die Korperschaft die mitgliedschaftliche Struktur, für die Anstalt den Sachzweck und das Fehlen eigentlicher Mitglieder betont. Aber die vom Staat als Werkzeuge mittelbarer Staatsverwaltung benutzten Korperschaften in ihrer Funktion als Leitungsverbände mit Zwangsmitgliedschaft auf der einen, die Anstalten mit Teilnahme der Interessenten an ihrer Verwaltung oder Beirăte stellen doch Ubergänge dar, die den Unterschied verwischen. Vgl, auch Forsthoff S. 379 Anm. 3 und S. 386 Anm. 6.

109) Entgegen dem Verzicht auf genossenschaftliche Mitwirkung und in der Abstellung allein auf die Funktion mittelbarer Staatsverwaltung durch 
dem Einfluß des Besatzungsrechtes, das solche Verwendung untersagt, den Brauch weitgehend aufgegeben, private Verbände mit öffentlichen Leitungsaufgaben $z u$ betrauen und an ihrer Stelle öffentlichrechtliche Einrichtungen geschaffen, bei denen die Interessenten nur in der Form von Fachbeiratten und Fachausschüssen in Erscheinung treten. Aber ganz verschwunden ist diese Beauftragung nicht.

Auch der Begriff der Selbstverwaltung wird dabei von dem Strudel der terminologischen Auflösung erfaßt. Er wird im wirtschaftlichen Bereiche auch dort verwandt, wo die Merkmale der eigentlichen Selbstverwaltung, die körperschaftliche, d. h. genossenschaftliche Gestalt und die selbständige Entscheidungsfreiheit ${ }^{102}$ ) abgehen. In diesem weiteren Sinne rechnet man zur Selbstverwaltung auf wirtschaftlichem und sozialem Gebiete dann auch jede Wahrnehmung öffentlicher Aufgaben durch selbstăndige Körperschaften, aber auch schon die Mitwirkung der beteiligten Kreise an der Organisation und Leitung solcher Körperschaften oder auch öffentlicher Anstalten ${ }^{108}$ ). Der Gedanke wirtschaftlicher und sozialer Selbstverwaltung ist in der Gegenwart zu einem allgemeinen Postulat verschiedener Tendenz geworden. Die Forderung richtet sich auf ein Zurücktreten des Staates zugunsten der autonomen Erledigung wirtschaftlicher Fragen durch den Kreis der daran Beteiligten, die Ausgestaltung einer Selbstverwaltung mit erweiterten offentlichen Befugnissen und die Ausdehnung der Rechte der Sozialpartner zur Regelung sozialer Fragen. Bei diesen Forderungen wird freilich nicht selten übersehen, daB hier doch sehr komplexe Erscheinungen und Probleme vorliegen. Auf der einen Seite benutzt der Staat die Verbände und Kräfte für seine

eigene juristische Personen, die Forsthoff unter voller Formalisierung des Begriffs der Selbstverwaltung vornimmt (VerwR. 3. Aufl. 1953 Bd. I S. 370), móchte ich doch an dem Element der maßgebenden Mitwirkung der Mitglieder für den Selbstverwaltungsbegriff festhalten. Vgl. meine Darlegungen ŐV. 1952 S. 609ff. zur wirtschaftlichen und sozialen Selbstverwaltung. Der Ansicht von Forsth off nähert sich die wertvolle Arbeit von Peter Saxer, Die AHV-Ausgleichskassen als neue Organisationsform der schweiz. Sozialversicherung (Abhandl. zum schweiz. Recht, N. F. 30r) I953 S. 4 off., 60.

108) In diesem weiteren Sinn wird von Selbstverwaltung auch bei $\delta$ ffentlichen Anstalten gesprochen, an deren Leitung die Beteiligten Anteil haben. So bei den Rundfunkanstalten in verschiedenen Landesgesetzen (vgl. Ubersicht OV. 1952 S. 612), wo der Ausdruck Selbstverwaltung irrig zur Bezeichnung der Neutralisierung vom StaatseinfluB durch Heranziehung verschiedener sozialer Gruppen zur Direktion verwendet wird. Ferner wird die Beteiligung der Unternehmer und Arbeitnehmer an den Organen der Sozialversicherung als Selbstverwaltung bezeichnet, obwohl es sich hier um Anstalten handelt: Ges. über die Selbstverwaltung auf dem Gebiete der Sozialversicherung i. d. Fassung vom 13. 8. 1952 BGBl. I S. 421 I 2 und Ges. über die Errichtung der Bundesversicherungsanstalt für Angestellte vom 7. 8. $1953 \mathrm{BGBl}$. I S. $857 \S 3$, ferner Ges. über die Bundesanstalt f. Arbeitsvermittlung und Arbeitslosenversicherung. 
Zwecke, wobei die derart herangezogenen Organisationen in ihrer Struktur und ihren Zielsetzungen weitgehend verwandelt werden und in Abhängigkeit geraten. Auf der anderen Seite haben wir es hier mit einer Vorstellung von einer bloB subsidiären Rolle des Staates zu tun, die erhebliche soziale Räume ganz der freien Gestaltung der mächtigen Gruppen überlassen will. Dabei fragt sich aber doch, ob in solchen Fällen nicht die Interessen dritter nichtbeteiligter Kreise, die Rechte des Individuums innerhalb solcher privilegierter Gruppen und endlich das Gleichgewicht der Allgemeinheit nicht gefährdet werden können. Die übergeordnete und leitende Stellung des Staates über den Kräften der Gruppen, die zu leicht der Versuchung pluralistischer Spaltung und partieller Allianzen unterliegen, darf bei allen diesen Entwicklungen nicht in Mitleidenschaft gezogen werden. Die wirtschaftliche und soziale Selbstverwaltung hat heute ihren notwendigen und wichtigen Platz, aber auch ihre Grenzen ${ }^{104}$ ).

Weiter als die Erscheinung dieser Selbstverwaltung im erweiterten Sinne reicht noch die Form der Beratung und Mitwirkung der Gruppen und Verbände bei öffentlichen Aufgaben, die in zahllosen Gesetzen und Verordnungen verankert ist $\left.{ }^{106}\right)$. Es gehört zur Struktur der modernen gesellschaftlichen Lage, daB der Staat auf wirtschaftlichem und sozialem Gebiet, vor allem im Arbeitsrecht, einen gewissen Bereich der sozialen Selbstgestaltung frei läBt, in dem er - Dietrich Schindler hat hier von werdendem Recht ${ }^{108}$ ) gesprochen - den gesellschaftlichen Kräften eine begrenzte Autonomie gewährt und ihnen sugar den Gebrauch von Machtmitteln wie dem Streik, freilich nur für sachlich begrenzte Zwecke des wirtschaftlichen Kampfes und unter AusschluB ihrer Verwendung zu politischen Zielen oder für sittenwidrige und gewaltsame Bestrebungen, gestattet ${ }^{107}$ ).

e) Den letzten Typ interventionistischer Mittel stellt der g estaltende Ausgleich dar, bei dem der Staat unter wirtschaftspolitischen oder sozialen Zwecksetzungen unter den Beteiligten eines Wirtschaftszweiges oder eines Wirtschaftsraumes gewisse gegenseitige Zahlungen anordnet, um strukturelle Unterschiede der Erzeugung und regionalen Situation oder der gewerblichen Gliederung auszugleichen. Wir finden in begrenzter Form solche Regelungen dort, wo ein einheitlicher Verbraucherpreis gebildet wird, durch den regionale Bedingungen der Produktion und der Standortlage relativiert werden, so etwa bei der Festlegung ein-

\footnotetext{
104) Vgl. zur Idee der wirtschaftlichen Selbstverwaltung in kritischer Abgrenzung und in Berücksichtigung des Grundverhältnisses von Staat und Gruppen Giger a. a. O. S. 207 ff., Saxer S. $59 f$., $223 f$.

106) Vgl. OV. r952 S. 6r $3 f$.

$100)$ Recht-Staat-Volkergemeinschaft 1948 S. $289 \mathrm{ff}$.

107) Vgl. oben Anm. 20.
} 
heitlicher Getreidepreise für das Gebiet der Bundesrepublik oder bei der Einführung von Frachtausgleich für landwirtschaftliche Erzeugnisse. Im letzteren Falle werden von den Beteiligteı öffentlichrechtliche Ausgleichsabgaben erhoben, die vom Bundesminister für Ernährung über eine Frachtausgleichskasse zum Frachtausgleich ungünstig gelegener Gebiete verwendet werden ${ }^{108}$ ). In einem etwas weiteren Zusammenhang finden wir die Landesbehörden ermächtigt, für eine gleichmäBige Versorgung mit Milch Abgaben $z u$ erheben und unter Beteiligung der betroffenen Kreise $\mathrm{zu}$ verwenden $\left.{ }^{109}\right)$. Einen außerordentlich weitgezogenen Rahmen zeigt dagegen der Ausgleich, den - nach dem früheren Beispiel der im Kriege eingeleiteten Gemeinschaftshilfe der Wirtschaft (für stillgelegte Werke) ${ }^{110}$ ) - die Investitionshilfe durch die $\mathrm{Zu}$ führung von I Milliarde DM. an die Grundstoffindustrien unter Aufbringung durch die Verbrauchsgüterindustrie vorsieht. Es handelt sich hier um eine Zwangsabgabe ${ }^{111}$ ), durch die ein Teil der Wirtschaft - ursprünglich auf freiwilliger Grundlage - dem anderen zu Hilfe kommt. Gegen dieses Gesetz sind unter dem Gedanken der persönlichen Betätigungsfreiheit (Art. 2 GG.) und des Eigentumsschutzes verfassungsrechtliche Bedenken erhoben worden ${ }^{112}$ ), die ich indessen nicht für durchgreifend halte. Es wird hier - in einem allerdings sehr weitreichenden AusmaB ein gestaltender Ausgleich durch abgabeähnliche aber begrenzte einmalige Auflagen ${ }^{118}$ ) unternommen, bei dem den Aufbringungspflichtigen keine Werte entzogen werden, da sie Obligationen der

10b) Getreideges: $\S$ II; Zuckerges. $\S 5$ Abs. III. Vgl. vom verfassungsrechtlichen Standpunkt kritisch hierzu Modest a. a. O. S. II4ff.

109) Milch- und Fettges. i. d. Fassung vom 10. 12.1952 \& 12.

110) Dazu Ipsen, AOR. 78 S. 300.

111) Die von Forsthoft, BB. I953 S. $421 \mathrm{ff}$. erhobenen Bedenken überzeugen nicht. F. meint, der einzelne habe wohl individuelle soziale Beschränkungen, aber keine wirtschaftliche Lenkung hinzunehmen, weil diese Art. 2 GG. verletze. Eine so enge Deutung des wirtschaftlichen Spielraums, den das Grundgesetz dem Staat läßt, ist unhaltbar und auch mit Art. 74 Ziff. 15-17 in Widerspruch. Ebenso unrichtig ist der Gedanke, Sozialbindnngen könnten nur für Bedürfnisse der Allgemeinheit, nicht einzelner erfolgen. Die Enteignung zugunsten privater Bauvorhaben (Banlandbeschaffungsges. vom 3. 8. r953 §6) zeigt das Gegenteil.

119) Ipsen, AÖR 78 S. 317 ff., möchte die bei der Ausgabe von Wertpapieren für die Aufbringungspflichtigen möglichen Zinsverluste and späteren Nachteile als Enteignung auffassen, übersieht aber, daB der Staat die Abgabe ohne Gegenleistung wie andere Ausgleichsbetrăge hătte einheben können. Auf preisrechtliche Vouschriften lassen sich freilich solche Ausgleichsabgaben nicht gründen, da diese nur vertragsgestaltende Wirkung entfalten dürfen, nicht aber Abgabepflichten auferlegen konnen. So hinsichtlich eines Ausgleichsbetrages für Mehlbestände der Württ.-Bad. VGH. vom 15. 2. 1952 VerwRspr. 5 S. $726 \mathrm{ff}$.

213) Im internationalen Bereich finden wir solche Ausgleichszahlungen in großem Umfang vorgesehen in der Montanunion. Siehe Art. 56, 62 MU. und $\$ \S 25,26,28$ tibergangsabkommen und ferner Anm. II 7 . 
Begünstigten hierfür in Empfang nehmen können. Die Verwaltung und Austeilung der aufkommenden Beträge erfolgt durch eine rechtlich merkwürdige Einrichtung: Ein Sondervermögen, dessen Vorstand eine juristische Person, die Industriekreditbank in Düsseldorf, ist und in dem die maBgebende Steuerung durch das aus den Beteiligten gebildete Kuratorium erfolgt, nimmt die eigentlichen Zuteilungen vor und bestimmt die Investitionsquoten und diejenigen Unternehmen, denen die Mittel gegen die Verpflichtung zur Ausstellung von Wertpapieren zufließen. Als Beispiel solchen Ausgleichs darf man wohl auch die vor kurzem durch die eidgenössische Volksabstimmung vom 5. 10. 1952 nunmehr gesetzlich bestätigte Tabakkontingentierung rechnen, durch die der schweizerischen Stumpenindustrie steuervergünstigte Tabakzuteilungen gesichert werden; sie dient der Stützung von Mittelbetrieben. Ähnliche Tendenzen dürften auch dem deutschen Tabaksteuergesetz nicht ganz fremd sein.

\section{Mittelbare Einwirkungen des Staates}

I. Wenn wir uns nunmehr der staatlichen Wirtschaftspolitik mit indirekten Mitteln zuwenden, so darf als ein gemeinsamer $\mathrm{Zug}$ die Schwierigkeit bezeichnet werden, sie in das überlieferte Schema unseres Verwaltungsrechtes einzuordnen und damit in eine rechtsstaatliche Form einzufangen. Diese Mittel sind auch deshalb bedenklicher, weil ihre Auswirkungen kaum übersehbar sind und oft unbeteiligte Dritte berühren. Vor allem aber gibt es gegen ihre mittelbaren Konsequenzen im Rahmen eines auf den unmittelbaren Eingriff (Verwaltungsakt) und das subjektive öffentliche Recht eingestellten Verwaltungsrechtsschutzes nur geringe $\mathrm{Ab}$ hilfe.

Ein erstes in diesem Zusammenhang zu erwähnendes Mittel der Lenkung ist die Subvention. Sie gehört nicht in den Kreis der als Daseinsvorsorge bezeichneten Vorgänge, in denen der Staat selbst die Besorgung bestimmter allgemeiner Bedürfnisse durch die Gewährung sozialer Ansprüche, durch Errichtung öffentlicher Anstalten und sonstiger Einrichtungen oder auch durch private Versorgungsbetriebe übernimmt. Bei der Subvention fördert der Staat vielmehr - der ZuschuB an Verwaltungsträger (z. B. für Schulzwecke) gehört nicht hierher ${ }^{114}$ ) - private Unternehmer oder Wirtschaftszweige durch Gewährung von Zuschüssen oder sonstigen Vorteilen. Die Rechtsform ist dabei sehr verschieden. Nur selten werden die Mittel geradezu als verlorene Zuschüsse gegeben; meist sind es Kreditgewährungen, Bürgschaften oder Risikogarantien, mit denen der Staat sein Wohlwollen erzeigt. Soweit die etatrechtlichen Vorschriften beachtet sind, und der in

114) Uber diese Zuschüsse jetzt Hettlage, DVBI. 1953 S. 717. 
diesem Bereich der Verwaltung wie überall im öffentlichen Felde zu beachtende Grundsatz der Gleichheit eingehalten wird ${ }^{115}$ ), werden verfassungsrechtliche Schranken der Handhabung dieses wichtigen und so wirksamen Mittels der modernen Verwaltung nicht entgegenstehen, das sich teilweise auch privatrechtlicher Formen bedient. Auf die Bedenken, die gegen eine zunehmende Verwendung der Subventionen vom Standpunkt des Bundesstaats und teilweise auch des Haushaltsrechts zu erheben sind, ist hier nicht einzugehen ${ }^{116}$ ). Bemerkenswert bleibt, daB die Subventionen in der Regel an Gruppen gegeben werden und da $B$ daher für weniger Begünstigte kaum eine rechtliche Möglichkeit besteht, dagegen Ansprüche geltend zu machen. Abhilfe werden andere weniger glückliche Kreise in der Regel nur auf jenem Wege finden, den wir hier in Bonn besonders gut beobachten können. Sie werden sich der hier stationierten Büros und Interessenverbände bedienen, um auch Anteil an der Austeilung zu erhalten. Auf der anderen Seite ist auch die Abhängigkeit schwer erfaßbar, aber höchst real, in die ein Verband oder ein Wirtschaftszweig durch die Subventionierung gerät. Der auf diese Weise eröffnete staatliche Einfluß ist häufig stärker als jeder Zwang ${ }^{117}$ ).

2. Das weitreichendste Instrument indirekter staatlicher Wirtschaftspolitik, ja, eigentlich mehr und mehr das Hauptwerkzeug des Interventionismus, ist die Steuerpolitik geworden. Ich muß es mir versagen, die Probleme in ihrer ganzen Weite und Tiefe aufzudecken. Wenn etwa seit dem Beginn dieses Jahrhunderts die Steuerpolitik als übliches und legitimes Mittel staatlicher Wirtschaftslenkung, ja, darüber hinaus als Vehikel legalisierender sozialer Umformung gilt, so bleibt sie doch ein im Grunde höchst gefährliches Mittel. Begonnen hat diese Verwendung der Steuer als Lenkungsinstrument, wie Schmölders hervorgehoben hat ${ }^{118}$ ), mit dem Ubergang von der proportionalen zur progressiven Be-

115) Zur Geltung des Gleichheitssatzes für die Subventionen, die in ihrem offentlichrechtlichen Charakter begründet liegt, Kottgen, DVBI. I953 S. 487; Siebert, Festgabe Niedermeyer S. 235, 239f. und ferner Di etrich Schindler, Die Bundessubventionen als Rechtsproblem (Zürcher Beiträge zur Rechtswiss., N. F. 78) 1952 S. 233 f.

118) Kottgen a. a. O. S. $485 \mathrm{ff}$.

117) Mit Recht weist Köttgen auf die erhebliche Bedeutung hin, die die Subventionen im Recht der Montanunion spielen. Die Hohe Behörde kann Beihilfen in Form von Ausgleichsumlagen als Mittel eines internationalen Dirigismus (Investitionen, Entschädigung für stillgelegte Betriebe, Umschulungsbeihilfen für Arbeiter) nach Art. 54, 56, 62, $68 \mathrm{MU}$. und $\$ \S 23-28$ Ubergangsabkommen auswerfen. Dagegen sind Subventionen des einzelnen Staates im gleichen Bereich untersagt (Art. 4 mit Ausnahme Art. 62). Vgl. Rolin, La Communauté Européenne du Charbon et de l'Acier $1953 \mathrm{~S}$. $165 \mathrm{ff}$., $212 f$.

119) Finanzarchiv 13 (1952) S. I ff. 
steuerung, die ungefähr $1890-1900$ einsetzt ${ }^{119}$ ), und mit dem Einbruch des Steuersystems in England in die überlieferte Besitzordnung unter den liberalen Kabinetten Campbell-Bannerman und Asquith (1905-I9I6). Heute ist dieser Einsatz der Steuer auch zur gesellschaftlichen Einebnung eine Selbstverständlichkeit geworden. Dabei sind die Folgerungen dieser Entwicklung in der Gegenwart wahrhaft extrem geworden. Die Begriffe unseres Privatrechts, aber auch die primäre Einkommensverteilung in Gehältern und Löhnen werden durch die Steuer zu weithin der materiellen Bedeutung entkleideten Scheinstrukturen. Uber sie lagert sich eine zweite Schicht ,realistischer" steuerlicher Verhältnisse, die jene erste Grundlage in erheblichem Umfang beiseiterückt $\left.{ }^{120}\right)$. In dieser zweiten Sphäre wird nicht nur das Eigentum zu einem Steuerbegriffe - hängt nicht der Eigentümer von Althausbesitz in seiner Nutzung von der Gesetzgebung über die Altbaumieten ab und wird nicht die Eigentumsbildung in bedeutendem AusmaB durch die steuerliche Begünstigung der Anlage im eigenen Betrieb ermöglicht - , auch das wahre Einkommen kann erst auf Grund der Steuer ermittelt werden, ja, es ist nicht von der Progression allein, sondern von den Ubberwälzungsmöglichkeiten - die heute teilweise auch für direkte Steuern bestehen und von Art und Umfang der erlaubten Absetzungen und Aufwendungen abhängig. Es wäre eine dringende Aufgabe der Wissenschaft, diese Auswirkungen des modernen Steuersystems, vor allem auch die von ihm bezweckte und bewirkte soziale Umschichtung, genau zu untersuchen.

3. Was ferner die Kreditpolitik als interventionistisches Mittel anlangt, so entzieht sie sich rechtlicher Erfassung in besonderem $\mathrm{MaBe}$, weil sie sich in privatrechtlichen Verträgen niederschlägt. Ablehnung eines Kredits, Kreditrestriktionen, Kündigung eines Darlehens, Zinshöhe, alles das sind Lenkungsmaßnahmen, die öffentlichen Charakter tragen, soweit wirtschaftspolitische Ziele verfolgt werden ( $z$. B. Flüchtlingshilfe), die aber infolge der äußeren privaten Form einer öffentlichrechtlichen Bindung entrückt erscheinen. Hier kann zunächst Hilfe bringen, $\mathrm{da} \beta$ man Rechtsgedanken des Privatrechts (Sittenwidrigkeit) heranzieht, dann aber für diesen öffentliche $Z$ wecke verfolgenden Bereich auch im Privatrecht die Maßstäbe der im öffentlichen Recht geltenden Gleichheit des Art. 3 GG. berücksichtigt ${ }^{121}$ ). Man wird

119) Noch der bedeutende franzősische Staatsrechtslehrer Dugnit hat gegen die Progression Stellung genommen.

180) Zu dieser Ausschaltung privatrechtlicher Begriffe im Steuerrecht, vor allem bei Handelsgesellschaften, sieht Flu me, Festgabe Smend 1952 S. $59 \mathrm{ff}$.

12i) Zur Anwendung der Grundsätze des Art. 3 GG. im Privatrecht siehe Dörinkel, Wirtsch. u. Wettbewerb 1953 S. 18; Hamann, BB. 1953 S. 866; Kottgen, DVBl. I953 S. 488: Siebert, Festgabe Niedermeyer 1953 S. $239 \mathrm{f}$. 
hier den Schritt tun müssen, und auch für solche Akte, die im Gewande eines privatrechtlichen Vertrages distributive Ermessensentscheidungen des Staates fällen, inhaltlich - unter Scheidung der öffentlichrechtlichen und der privatrechtlichen Seite des Verhältnisses - die Maßstäbe der Gleichheit und der Abwesenheit von Willkür zur Geltung zu bringen. Eine Anfechtung solcher Rechtsgeschäfte im verwaltungsgerichtlichen Verfahren wird dagegen nur im Ausnahmefall gelingen, und es kann auch einer generellen Verwischung der Formunterschiede privaten und öffentlichen Rechts nicht das Wort geredet werden ${ }^{122}$ ).

4. Was die Währungspolitik anlangt, so stellt sie unter den Lenkungsmitteln ein Instrument von verhängnisvoller Fernwirkung dar, weil sie unvermeidlich weite Schichten des Volkes in ihren Rechten berühren muß. Im I9. Jahrhundert als Lenkungsmittel tatsächlich durch die internationale Zusammenordnung der Währungen ausgeschaltet, ist sie auch heute in der Theorie keineswegs ein legitimes oder zulässiges Mittel der staatlichen Intervention. In Wirklichkeit aber werden Manipulationen der Währung - sei es zur Steigerung des Exports, zur Bekämpfung wirtschaftlicher Schwierigkeiten oder zur Sicherung einer Vollbeschäftigung - in der Gegenwart immer wieder wirtschaftspolitischen Zielen dienstbar gemacht. Die strukturelle Lage vieler Volkswirtschaften ohne ausgeglichene äußere Zahlungsbilanz wie auch - hier dürfte etwa auf die Haltung der skandinavischen Länder hinzuweisen sein - eine konsequente Politik der vollen Beschäftigung führen viele Länder dazu, Verschlechterungen des Wechselkurses hinzunehmen. Der Schweizer Bankier Felix Somary hat in eindrucksvoller Weise in einer im vergangenen Jahr erschienenen Schrift die Folgen der Monopolisierung der Geldschöpfung durch den Staat, die eine Konsequenz des Überganges zu nur durch den Zwangskurs gehaltenen Währungen ist, aufgezeigt: Während ein Vermögen in der Spanne von 1800 bis I900, als Geldsumme angelegt, eine erhebliche Vermehrung erfuhr, ging es in der Zeit von

122) Zum Grundproblem der inhaltlichen Bindung solcher Staatsakte in privatrechtlicher Form siehe Kottgen S. 487f.; Bach of, OV. r953 S. 423; Siebert a. a. O. S. $236 \mathrm{ff}$. Siebert betont richtig, daB heute schon im Zivilrecht Gesichtspunkte zur Verfügung stehen, man aber auch ergänzend den Gleichheitssatz heranziehen kann, daß aber verfahrensrechtlich der Unterschied in der Wahl privater und offentlichrechtlicher Formen bestehen bleibt. Zu weit geht Hamann, BB. I953 S. 865 ff., der das ganze Kreditgeschäft bei offentl. Krediten ins offentliche Recht ziehen will. Die Rechtsprechung beruft sich hier teils auf innerdienstliche Weisungen (OVG. Münster DVBl. I953 S. 25: Festsetzung von Bedingungen für eine Subvention), teils stellt sie das Fehlen von Verwaltungsalten fest. Vgl. auch BVerfGE. 3 S. 4. Zum Problem privatrechtlicher Verwaltungsführung im allgemeinen siehe $\mathrm{Heu} B \mathrm{er}$, Die Flucht des Gemeinwesens in die privatrechtliche Unternehmung als Rechtsproblem, Zürich 1949 S. 33 ff. Zur Haftung des Staates hierbei siehe Ka u fma nn, Ztschr. f. Schweiz. Recht, N. F. 72 S. 288 a ff. 
Ig0o bis I950, wenn es in Gèld ausgedrückt war, in den meisten Ländern fast vollständig verloren ${ }^{123}$ ). Rechtlich ist für den einzelnen, so lange der Staat am Prinzip des Nominalismus, d. h. der Erhaltung des Wertes des Geldes als gesetzliches Zahlungsmittel festhält ${ }^{124}$ ), keine Hilfe gegeben. Als das Reichsgericht nach dem ersten Weltkriege die Aufhebung der Goldmünzklausel (durch BundesratsVO. vom 28. 9. 1914) bestätigte ${ }^{126}$ ), blieb dem Staat der Weg eines die Geldentwertung negierenden Zwangskurses geöffnet. Erst später hat die deutsche Rechtsprechung die Aufwertungsgesetzgebung entwickelt, und die Gesetzgebung ist ihr nachgefolgt. Damals hat dann das Reichsgericht mit Recht eine Klage abgewiesen, die für erlittene Verluste an Wertpapieren und Hypotheken Ersatz im Wege der Amtshaftung vom Reichskanzler und den Ministern begehrte. Das Gericht hat zwar nicht in klarer Weise die Bedeutung der Währungspolitik als Teil der staatsleitenden Tätigkeit herausgestellt, die zugunsten eines einzelnen nicht geprüft werden kann, aber doch den formaleren Gesichtspunkt betont, daß eine Amtspflicht in Fragen der Währung nur der Allgemeinheit, nicht dem einzelnen gegenüber bestehe $\left.{ }^{126}\right)$.

5. An letzter Stelle nur ein Wort über die Planung. In unserem rechtsstaatlichen System kann sie nicht wie im sowjetischen Bereich zu einer obersten verbindlichen Normierung aller wirtschaftlichen Vorgänge werden, sondern erscheint nur als Vorschätzung unverbindlicher Art, als Richtlinie und Weisung ohne strikte Bindung ${ }^{127}$ ).

6. Uber den Bereich der Wirtschaftslenkung hinaus reichen eigentlich schon Maßnahmen, die nicht auf eine interventionistische Lenkung, sopdern eine weitreichendere Umgestaltung der Wirtschaftsform oder der sozialen Verhältnisse abzielen. Solche Akte der soziałen Umschichtung und der Einführung neuer Wirtschaftsformen gehören nur am Rande noch in den Bereich unserer Untersuchung. Unter ihnen ragt namentlich die Sozialisierung, die U'ber-

123), Felix Somary, Krise und Zukunft der Demokratie 1952 S. 6rff. Eindrucksvoll auch die Aufstellung (aus amtlichen britischen Quellen) bei F. A. Mann für das relativ von den Entwertungen verschonte Großbritannien. Die innere Kaufkraft des Pfundes sank von $1914=100 \mathrm{im} \mathrm{Jahr} 193^{\circ}$ auf 58, I945 auf 38, $195^{\circ}$ auf 31 Prozent. Zwischen 1938 und 1950 trat eine Entwertung um 50 Prozent ein. Vgl. F. A. Mann, The Legal Aspect of Money, 2. Aufl. I953 S. 84. Kein Wunder, daß Mann (S. 79) von unserer Zeit als einem "age of inflation" spricht.

12i) Uber die Lehre vom $Z$ wangskurs und ihre allgemeine Verbreitung siehe Mann a. a. O. S. $33 \mathrm{ff}$.

195) RGZ 108, 176.

128) Urteil vom 4. II. 1927 RGZ I 18,325 . Vgl. auch RGZ $125,373$.

187) Ein Beispiel solcher Planung die Bestimmung in $\S \mathrm{I}$ des $\mathrm{I}$. Wohnungsbauges. i. d. Fassung vom 25. 8. 1953, daB in den Jahren 1951/56 zwei Millionen Wohnungen gebaut werden sollen. Zur Planung im sowjetischen Bereich siehe Eckart Krömer, Die Sozialisierung in der sowjetischen Besatzungszone Deutschlands als Rechtsproblem I952 S. 6 Iff. 
führung von Unternehmungen eines bestimmten Wirtschaftszweiges in gemeinwirtschaftliche Formen, hervor. Auch in diesem Bereiche haben die Fragen des rechtsstaatlichen Verfahrens ihr Gewicht. Das Grundgesetz hat durch die Festlegung der Pflicht zur Entschädigung in Art. 55 Abs. III sich in betonter Form zu dem Gedanken der Erhaltung einer privatwirtschaftlichen Ordnung als Grundordnung bekannt, für die freilich in Art. 5 GG. die Möglichkeit einer Koexistenz und damit auch einer Zusammenfügung mit den gemeinwirtschaftlichen Gestaltungen auf Teilbereichen anerkannt wird. In dieser Norm sind also einerseits gewisse Befugnisse zu sozialer Umgestaltung enthalten, andererseits ist aber doch für diese Eingriffe eine Grenze gezogen, die zugleich allen wirtschaftspolitischen Zielsetzungen einen festen Rahmen gibt: außerhalb des Art. I5 GG. können sie sozialisierende Ziele nicht verfolgen. In strengem Gegensatz dazu sind die Maßnahmen der Entwährung in der sowjetischen Besatzungszone mit keinerlei Entschädigung verknüpft. Sogar von der Erklärung eines Unternehmens zum volkseigenen Betrieb betroffene Gläubiger verlieren den Anspruch gegen die überführte Unternehmung; erst in neuerer Zeit scheint sich die Erkenntnis der Bedeutung der Vertragstreue auch bei nationalisierten Betrieben dort durchzusetzen ${ }^{128}$ ).

\section{Abschnitt}

Die Auswirkungen der statlichen Intervention im Rechtsleben

I. Eine Erscheinung von solcher Vielfalt und Breite, wie sie der staatliche Interventionismus im Bereiche der Wirtschaft darstellt, bleibt nicht ohne bedeutsame Rückwirkungen auf das ganze Rechtssystem. Der Staat betritt hier mit seiner Aktivität ein Gebiet, das außerhalb der Rechtsgestaltungen liegt, wie sie sich im Verwaltungsrecht des I9. Jahrhunderts ausgeformt haben. Gehörten damals Wirtschaft und Kultur zu den Bereichen, in denen sich der Staat bis auf eine überwachende, gewissermaßen nur polizeiliche Funktion, zurückhielt, und war die Struktur des Verwaltungsrechts aufgebaut auf dem Gedanken eines Gegenüber von individueller Freiheit und staatlichem Eingriff, auf einer Zurückdrängung älterer wohlfahrtsstaatlicher Tendenzen, so hat die Entwicklung dieses Jahrhunderts jene Grenzen weit über-

128) Bei Enteignung einer Offenen Handelsgesellschaft bleibt die Haftung der früheren Gesellsohafter, nicht aber der OHG. bestehen, OLG. Erfurt, Neue Justiz I95I S. 38. Denn die Gesellschaft erlischt, vgl. Artzt, NJ. I95I S. 213. Dasselbe Gericht billigt am 7. 9. I95I (N J. 1952 S. 234), daß der Käufer einer Ware statt an den Konkursverwalter an dessen Vorlieferanten, einen volkseigenen Betrieb, gezahlt hatte. Dagegen aber die Kritik von Artzt, der auf die Bedeutung der Vertrăge für die Planerfüllung hinweist. 
schritten. Diese Ausbreitung staatlicher Wirksamkeit im Gebiete der Verwaltung läBt sich auf der einen Seite erfassen an dem Begriff der staatlichen Obsorge für gewisse technische und soziale Gegebenheiten, ohne die das moderne Zusammenleben schwerlich mehr denkbar wäre, also an einer fürsorglichen und gewährenden Aufgabe, denen die Kategorien des im späteren r9. Jahrhundert ausgeformten Verwaltungsrechts schon nicht mehr voll entsprechen. Auf der anderen Seite aber gewinnt sie Gestalt in der interventionistischen Wirtschaftspolitik, deren einzelne Maßnahmen nur teilweise noch in das überlieferte Schema einer Eingriffsverwaltung passen und die sich gerade in ihren Rechtsformen eine außerordentliche Beweglichkeit gesichert hat. Auch hier haben wir es weithin mit einer gewährenden und fördernden Tätigkeit des Staates zu tun, die mit den Kategorien von einem persönlichen Freiheitsbereich und staatlichem Zwange nur unvollkommen erfaßbar sind. Wir finden ferner eine Neigung des Staates, sich indirekter Mittel, ja, vielfach privatrechtlicher $\mathrm{Me}-$ thoden $\mathrm{zu}$ bedienen, um seine Ziele zu verwirklichen; eine Vermischung und Durchdringung öffentlichrechtlicher und privatrechtlicher Elemente kennzeichnet das inoderne Wirtschaftsrecht. Und keineswegs kann man bei seiner Betrachtung mehr mit dem Gegensatz Staat-Individuum auskommen. Hier wie nirgends sonst tritt die außerordentliche Bedeutung in Erscheinung, die in unserer gesellschaftlichen Wirklichkeit die sozialen Gruppen und Organisationen gewonnen haben. Teils als Gegenspieler des Staates, vielmehr aber mit ihm im Bunde und von ihm mit Aufgaben und Befugnissen ausgestattet, sind sie in erheblichem Maße zu mitgestaltenden Kräften im Wirtschaftsleben und zu Mitträgern auch öffentlicher Aufgaben geworden. In diesem Aufstiege der sozialen Gruppen liegt ein Element der tiefen Wandlung beschlossen, die die moderne Gesellschaft erfährt und die sie weit von jenem Bilde entfernt hat, auf das sich das Verwaltungsrecht aufgebaut hat, wie es im ausgehenden vorigen Jahrhundert festgelegt wurde. Die Isolierung des einzelnen ist aufgehoben, soweit seine soziale und wirtschaftliche Existenz in Frage steht, zwischen ihm und dem Staate stehen die großen Organisationen, deren Aktivität nicht mehr rein mit der Kategorie privater Vereinigungsfreiheit erfaBt werden kann. Die sozialen Bindungen sind gestiegen. Dennoch bleibt auch in einer veränderten Gesellschaft die Aufgabe des Aufbaus und der Erhaltung eines freiheitlichen Staatswesens und einer Begrenzung und Kontrolle der staatlichen Macht bestehen. Die technischen und ökonomischen Gegebenheiten haben zu einer früher unbekannten Möglichkeit der Konzentration, der zentralisierten Regierung und Kontrolle geführt. Gerade deshalb ist die staatliche Lenkung. auch in ihrer Funktion als Aufsicht über die großen Kräfte der 
sozialen Gruppen, notwendig geworden ${ }^{129}$ ). Was heute nötig geworden ist, ist die Erkenntnis dieser Wandlung und das Bestreben, die Konzeption des freiheitlichen und rechtsstaatlichen Gemeinwesens ihr anzupassen. War das Bild des Staatsbürgers, wie das Verwaltungsrecht der liberalen Zeit es gestaltete, das des selbständigen, tunlichst auf eigenem Boden sitzenden Bürgers; so müssen heute die Probleme der persönlichen Sélbständigkeit, des Rechtsschutzes und des geordneten Verfahrens auch für die industrielle Gesellschaft, für die großstädtischen Zusammenballungen, für den in technisch-sozialer Hinsicht abhängig gewordenen Menschen entwickelt werden. Dabei kann die Rechtsstellung des einzelnen nicht mehr allein vom Bilde der Freiheit bestimmt werden. Angesichts einer für wichtige Lebensbedürfnisse gewährenden und obsorgenden Tätigkeit des Staates tritt vielmehr die Bedeutung des gerechten Anteils an der Vermeidung von Willkür und des Rechts auf Zulassung zu den für die Existenz notwendigen Verbänden und Einrichtungen in den Vordergrund. Es wäre gewiß verfehlt, anzunehmen, da $B$ der Freiheitsgedanke nicht mehr seine grundlegende Funktion bewahrt. $\mathrm{Er}$ wird gerade auf dem Gebiete des persönlichen und kulturellen Lebens mit besonderem Nachdruck zu verteidigen sein. Aber im sozialen und wirtschaftlichen Bereich ist er als Ordnungsprinzip allein nicht mehr imstande, die Struktur der modernen Gesellschaft zu bewältigen. Die Bedeutung dieser Veränderungen reicht über die Grenzen des Verwaltungsrechts hinaus. Sie ist im Privatrecht, wenn auch schwächer, fühlbar, sie erfaBt vor allem, wie Hans Huber in eindrucksvollen Darlegungen gezeigt hat ${ }^{130}$ ), auch den Bereich des Verfassungsrechts. Diesen Erscheinungen wollen wir nun den Blick zuwenden.

2. Wenn wir zunächst die der Ausweitung staatlichen Einflusses parallel gehenden Vorgänge im Privatrecht ins Auge fassen, so möchte ich mich mit der Betrachtung zweier Institutionen begnügen. Das Eigentum und die Vertragsfreiheit, zwei elementare Grundlagen der Privatrechtsordnung, werden durch die staatlichen Einwirkungen wie auch durch das Auftreten der Gruppen umgeformt. Beim Eigentum können wir diesen ProzeB in doppelter Hinsicht beobachten. Einmal erfährt durch die staatlichen Ein-

199) Karl Mannheim hat diese Veränderung geschildert: , The immediate consequence of this concentration in social technique is that where formerly occasional and private infiuence prevailed now, gradually, public guidance has increasingly become the rule. Whereas formerly adjustment to immediate and narrow surroundings determined the character of man, now gradually the forces of the total structure of society condition the moulding of his essential features." Essays on Sociology and Social Psychology 1952 S. 256.

130) Das Staatsrecht des Interventionismus, $Z$ tschr. f. schweiz. Recht, N. F. 70, 1951, S. 173 ff. 
griffe der Inhalt des Eigentums eine beschränkende Umschreibung • Wenn der Staat in wachsendem Maße Einfluß auf die Betriebsführung von Unternehmen, die Verfügung über Erzeugnisse, überhaupt über die Disposition des Eigentümers trifft, so wird davon auch der Gehalt der Institution berührt. Das Eigentum unterliegt, auch schon im Hinblick auf den verfassungsrechtlichen Leitgrundsatz des sozialen Rechtsstaats (Art. 20, 28 GG.) erhöhter Beschränkung. Wichtiger aber noch erscheint die zweite Folge. Man kann sie als eine Aufgliederung der Eigentumsbefugnisse in die Bestandteile der Eigentumsrechte bezeichnen. Längst haben sich, vor allem im Gesellschaftsrecht, in der modernen Zeit die formelle Eigentümerstellung und die tatsächliche Verfügung und Kontrolle über das Eigentum geschieden. Die staatliche Wirtschaftspolitik verstärkt diese Aufspaltung der Eigentumsbefugnisse. Sie drängt steuerlich wie einflußmäßig den Aktionär noch weiter zurück (Mitbestimmungsrecht), sie schränkt die Rechte des Hausbesitzers ein, sie zieht der Dispositionsbefugnis des Unternehmers in wachsendem Maße Schranken. Die steuerliche Behandlung der Gewinne fördert die schon seinerzeit von Rathenau beobachtete Tendenz, dem Unternehmen in sich eine Eigenentwicklung zu geben, bei der die Bedeutung der Nutzung eigentums- oder anteilsmäBig Beteiligter mehr zurücktritt. Deutlich wird diese Spaltung auch bei Kontingentszuteilungen für Erzeugungsstätten. Hier gewinnen diese Kontingente nicht selten einen eigenen, auch durch Verfügungen ausgewerteten Wert neben der Betriebsanlage ${ }^{131}$ ).

3. Auch im Bereiche der Vertragsfreiheit sind schon seit langem an die Stelle des individuellen Vertrages weithin der Standardvertrag, die normierten Geschäftsbedingungen und der Kollektivvertrag getreten. Der Staat treibt auch hier die Entwicklung weiter. In dem MaBe wie die staatliche Kontrolle sich ausdehnt und andererseits der Umfang der Mitarbeit privater Kreise und Verbände an den öffentlichen Aufgaben zunimmt ${ }^{132}$ ), begünstigt der Staat die Typisierung von Lieferungsverträgen oder anderen Verhältnissen, legt den Inhalt von Vertragsbeziehungen fest, nötigt den einzelnen, z. B. den Hausbesitzer, zur Eingehung von unfreiwilligen Vertragsbeziehungen. Wo es dem Staate nötig erscheint, greift er in bestehende Beziehungen zugunsten des sozial Schwächeren - z. B. im Miet- und Pachtschutz - ein. Dort, wo die Vertragsfreiheit

1s1) Eingehende Darlegungen zu dieser Aufgliederung der Eigentumsbefugnisse bei $W$. Friedmann, Law and Social Change in Contemporary Britain I95I S. I4ff. Im Kontingent vgl. RGZ 147, 157.

132) Aus diesem Phänomen der Mitwirkung privater Unternehmen und Gruppen an den allgemeinen Aufgaben und der steigenden wirtschaftlichen Eigenbetätigung des Staates resultiert jene Verbindung offentlichrechtlicher und privatrechtlicher Elemente, die heute auch im französischen Recht von modernen Beobachtern als charakteristisch empfunden wird. Vgl. André de Laubadère, Traité élémentaire de droit administratif I953 S. 46 f. 
in den Händen mächtiger Gruppen zu einer Basis wirtschaftlicher Machtstellungen zu werden droht, beabsichtigt er, mit weitreichenden Mitteln, Erklärung der Unwirksamkeit oder direktem Verbot, einzugreifen. Auf weiten Gebieten, so hat ein Autor im Angesicht des amerikanischen Rechtes geurteilt ${ }^{123}$ ), ist der Vertrag eine soziale Institution geworden, die nicht nur die Interessen beider Parteien betrifft, und Kontrolle durch die Gesellschaft ist heute ein ganz wesentlicher Teil des Vertragsrechts.

4. Im Gebiete des Wirtschaftsrechts vollzieht sich als eine augenfällige Erscheinung, wiederum teilweise vom Staate begünstigt, teilweise von ihm kontrolliert und reguliert, der Aufstieg der sozialen Gruppen und Organisationen. Er ist am frühesten im Arbeitsrecht hervorgetreten und hat hier auch jetzt noch einen starken Rückhalt im Kollektivvertrag und in der ausgedehnten Mitwirkung der Unternehmerverbände und der Gewerkschaften an den Einrichtungen der Sozialversicherung und anderen Formen staatlicher sozialer Obsorge. In der Gegenwart findet der Kollektivvertrag schon in anderen Gebieten Anwendung. Die Beziehungen der Krankenkassen zu den mit ihr in Beziehung stehenden Ärzten werden ebenfalls durch Gruppenabreden festgelegt. In diesem Bereich wird mitunter sogar die Honorierung der Ärzte in einem Globalanteil an den Einnahmen der Kassen ausgeworfen und auf die einzelnen Ärzte nur unterverteilt. Im Jahre I953 haben in einem langen Streite die Berliner Ärzte erreicht, daß ihnen eine Erhöhung dieses Gesamtanteils zugestanden wurde. Der einzelne vermag seine wirtschaftlichen Interessen nur mehr als Glied einer größeren Gruppe und der von ihr erzielten Rahmenabmachungen durchzusetzen.

Wenn das Recht früher gezögert hat, die Gruppen und Verbände im Bereich von Wirtschaft und Arbeit als Teilhaber am Verwaltungsgeschehen anzuerkennen, so finden wir heute die Verbände, Gewerkschaften wie Unternehmerorganisationen, Bauernbünde und Fachvereinigungen der Wirtschaft, Frauenverbände und Genossenschaften überall als Mitwirkende in der Verwaltung. Diese Mitwirkung nimmt entweder nur die Form einer beratenden Tätigkeit in Beiräten, Ausschüssen usw. an, oder aber es erscheinen Vertreter jener Verbände als Mitglieder in den leitenden Organen von Körperschaften und öffentlichen Anstalten, aber auch als Beteiligte an der Entscheidung von Verwaltungsstellen. So werden für den Verwaltungsrat der als öffentliche Anstalt geformten Einfuhr- und Vorratsstelle für Getreide und Futtermittel neben Vertretern der Behörden Vertreter der Landwirtschaft, des Imports, des Großhandels, der Genossenschaften usw., aber auch der Ver-

159) Friedrich KeBler, Freiheit und Zwang im nordamerikanischen Vertragsrecht, Festgabe für Martin Wolff, 1952 S. 78. Siehe auch Friedmann S. 34 ff. 
brauchergenossenschaften und der Verbraucher nach Vorschlägen der jeweiligen Spitzenorganisationen vom Bundesminister bestellt $\left.{ }^{134}\right)$. Vertreter der Gewerkschaften, der Bauernverbände, der Frauenorganisationen, der Erzieher, der Industrie- und Handelskammern, der Jugendorganisationen und anderer Gruppen finden wir in den Rundfunkräten der durch Landesgesetze ausgestalteten Rundfunkanstalten. Am Verwaltungsrat der Deutschen Bundesbahn sitzen Vertreter der Gewerkschaften und der Wirtschaft im Stärkeverhältnis von Io unter 20 Mitgliedern dieses wie ein Aufsichtsrat zur Kontrolle und Mitentscheidung berufenen Organs eines Bundessondervermögens (Bundesbahnges. vom r3. I2. I95I \$ ro). Diese Vertreter handeln nicht im Auftrage ihrer Organisationen ${ }^{125}$ ), aber sie werden doch von ihnen vorgeschlagen. Diese Form der Mitwirkung der Verbände oder ihrer Vertreter an Verwaltungsaufgaben kann unter zwei Gesichtspunkten gewürdigt werden. Einmal dient sie der Heranziehung von Sachkunde und einem innerhalb dieser Gremien sich vollziehenden Interessenausgleich der Gruppen, ist also für den Staat ein Verwaltungsmittel des Ausgleichs. Zum anderen gewährt sie den Verbänden EinfluB und kann insofern nur bedingt unter den Gedanken einer Mitverantwortung der Staatsbürger an der Verwaltung im Sinn einer Selbstverwaltung gestellt werden. Diese rechtliche Form der Verwaltungsführung wird also dort ihre Grenze haben, wo eigentlich leitende und im höheren Sinne aufsichtliche und bestimmende Funktionen des Staates über den partikularen Interessen zur Entscheidung stehen. In diesem Bereiche würde die Tätigkeit von Verbänden in das politische Feld hineinragen. Hier wären Formen eines beratenden parlamentarischen Mitwirkens, etwa in einem Bundeswirtsthaftsrat ${ }^{136}$ ), am Platze. Und hier ist umgekehrt das Feld, wo sich die Bedeutung der Gruppen und Verbände außerhalb der rechtlichen Wege im EinfluB auf Regierung und Parlament ihre tatsächlichen Wege sucht und bahnt.

5. Ein rechtliches Problem kann dort entstehen, wo bei dieser Heranziehung der Gruppen keine ausreichende oder gleichmäBige Berücksichtigung stattgefunden hat. Kann man rechtlich von einem geschützten Interesse oder gar einem Recht eines Verbandes auf Beteiligung an solchen Gremien sprechen? Wo nicht das Gesetz in einer allgemeinen, meist einen erheblichen Ermessens-

134) I. DuVO. zum Getreideges. vom 3. 2. I95I § 7 .

$\left.{ }^{125}\right) \mathrm{Vgl}$. die ausdrückliche Vorschrift in Bundesbahnges. $\S$ ro Abs. IV; I. DuVO. zum Getreideges, 88 Abs. IV u. a.

130) Vgl. zur Aufgabe und Zusammensetzung eines Bundeswirtschaftsrates H. Krüger, OV. I952 S. 545 ff.; Forsthoff in „Ratgeber von Parlament und Regierung", hrsg. vom Institut zur Forderung offentl. Angelegenheiten 195I S. I27 ff. Zur Geschichte des vorl. Reichswirtschaftsrats der Weimarer Zeit dort Strau 8 S. 45 ff. 
spielraum lassenden Formel ${ }^{137}$ ) die Voraussetzungen der Heranziehung umschreibt - meist zieht es der Gesetzgeber (Getreideges. \$7, Zuckerges. \$8) vor, selbst die Zuteilung alsbald genau zu regeln -, wird kaum ein Anspruch auch nach einer neueren, von der engen Fassung des Begriffs subjektives Recht oder von der entscheidenden Abgrenzung durch diesen Begriff überhaupt absehenden Auffassung begründet werden können. Es dürfte den Beteiligten wohl nur der Weg der Verfassungsbeschwerde nach \$90 BVerfGG. wegen Verletzung des Gleichheitssatzes bleiben, den man in dieser Hinsicht wohl auch den Verbänden gemäß Art. I9 Abs. II GG. zubilligen darf. Zwei bemerkenswerte Konflikte in dieser Hinsicht haben sich im Jahre 1952 abgespielt. Die Wahlordnung für die Organe der sozialen Selbstverwaltung auf dem Gebiete der Sozialversicherung vom I4. 8. I952 (BAnz. Nr, II8) sah Vorschlagslisten der Gewerkschaften, der selbständigen Vereinigungen der Arbeitnehmer mit sozialer und berufspolitischer Zielsetzung und der Vereinigungen der Arbeitgeber vor. $\mathrm{Da} B$ sie darüber hinaus überhaupt die Möglichkeit für individuelle Wahlberechtigte einräumte, mit einer Mindestzahl von Unterschriften (30-250 Wähler) unabhängige Wahlverschläge aufzustellen, fand lebhafte Kritik von gewerkschaftlicher Seite ${ }^{138}$ ). Bedeutsamer ist der zweite Fall. Das Gesetz über die Bundesanstalt für Arbeitsvermittlung und Arbeitslosenversicherung vom 10. 3. I952 sieht für die Verwaltungsausschüsse der Unterinstanzen und den Verwaltungsrat der Bundesanstalt eine Zusammensetzung aus Vertretern der Arbeitnehmer, Arbeitgeber und der öffentlichen Körperschaften vor, die von deren Vereinigungen bzw. für die öffentlichen Körperschaften von Bundesregierung, Bundesrat und kommunalen Spitzenvereinigungen anteilig vorgeschlagen werden, wobei der Bundesminister für Arbeit an die jeweilige Reihenfolge der Personen auf den Listen gebunden ist $(\$ \S 9-\mathrm{r} 3)$. Für den Verwaltungsrat der Bundesanstalt forderte der Bundesminister für Arbeit den Deutschen Gewerkschaftsbund und die Deutsche Angestellten-Gewerkschaft um Einreichung von Vorschlagslisten auf und berief aus der Vorschlagsliste des Gewerkschaftsbundes 2, aus der der Angestelltengewerkschaft I Vertreter. $\mathrm{Da}$ die Gewerkschaften der Ansicht waren, ihnen gebührten mit Rücksicht auf ihre überwiegende Mitgliederzahl alle drei Plätze, nahmen sie vorübergehend nicht an der Arbeit dieses Gremiums teil. AuBerdem erhoben sie gegen den Bundesminister einen Verwaltungs-

137) Zum Beispiel Heimarbeitsges. vom I4. 3. 195I § 4; Ges. über die Errichtung einer Bundesanstalt für AV. und Arbeitslosenversicherung $\$ \$ 9$ Abs. III, 13 Abs. III.

188) Preller in Soziale Sicherheit I (1952) S. $226 \mathrm{ff}$. Es ist für die Entwicklung bezeichnend, daB die Gruppen zu einer ausschlieBlichen Vertretung tendieren. 
streit mit dem Antrage, die erfolgte Ernennung des dritten Mitglieds aufzuheben und ihren Anspruch anzuerkennen. Der Minister hat auf die Notwendigkeit einer Berücksichtigung von Minderheiten hingewiesen. Ein noch nicht rechtskräftiges Urteil des Landesverwaltungsgerichts $\mathrm{Köln}^{139}$ ) hat die Aktivlegitimation des Gewerkschaftsbundes anerkannt, aber unter Hinweis auf $\$ \S 9$ Abs. III, I3 Abs. III des Gesetzes, wo von einer angemessenen Vertretung der Wirtschaftszweige, Berufsgruppen und der Frauen und billiger Berücksichtigung der Minderheiten die Rede ist, einen Ermessensmißbrauch verneint. Ähnliche Streitigkeiten begegnen in Frankreich, wo Verwaltungsräte der zentralen und regionalen Gesellschaften der nationalisierten Betriebe mit Vertretern verschiedener Gruppen besetzt sind, zu denen auch Vertreter der „organisations syndicales les plus représentatives" gehören. Hier hat der Conseil d'Etat wiederholt über Streitigkeiten zur Auslegung der Frage entschieden, welche jeweils die für den betreffenden Bezirk bedeutsamsten Gewerkschaften seien, und er hat ebenfalls betont, auch in der Minderheit befindliche Organisationen könnten repräsentativ sein ${ }^{140}$ ).

Ein anderes Problem, das der Berücksichtigung der Verbraucher, ist wohl in diesen Gremien noch nicht ganz befriedigend gelöst. Im deutschen Recht wird diese Repräsentation meist den Vertretern der Frauenverbände und denen der Gewerkschaften (so I. DuVO. z. Getreideges. \& 8) oder denen der Konsumgenossenschaften überlassen. Ernsthaft hat sich im Rahmen der Organe der nationalisierten Wirtschaftszweige das englische Recht den Aufbau von beratenden Consumer Councils angelegen sein lassen, die die Interessen der Abnehmer von Kohle, Gas, Elektrizität vertreten sollen. In der Ernennung läßt z. B. die Electricity Act I947, Io \& II Geo VI c. 47, dem Minister for Fuel and Power einen erheblichen Ermessensspielraum. Er muB 1/2 - $/ 5$ der Vertreter aus Kreisen der Local Authorities nehmen, den Rest bestellt er nach Konsultation mit Verbänden (bodies), die die Landwirtschaft, den Handel, die Arbeit und das allgemeine Verbraucherinteresse vertreten. Diese Räte haben nützliche Arbeit in der Aufspürung und Vertretung von Wünschen des Publikums geleistet,

189) Urteil vom 3. Io. $1952-4$ K 204-207/52 - des LVG. Köln, nach freundlicher Mitteilung noch nicht rechtskräftig (Januar 1954).

140) Im Urteil Fédération nationale des travailleurs du sous-sol weist der C. d. Etat am 4. 2. I950 die Klage der Vereinigung dagegen zurück, daB der Minister neben fünf ihrer Vertreter auch einen Repräsentanten der christlichen Gewerkschaft im Verwaltungsrat der Charbonnages de France berücksichtigt habe. Nicht nur Mitgliederzahl, auch Alter, Bedeutung und der Gedanke der Minderheitenberücksichtigung seien in Erwägung zu ziehen. Vgl. hierzu Steindorff, Die Nichtigkeitsklage im Recht der Europ. Gemeinschaft für Kohle und Stahl, $195^{2}$ S. $65 \mathrm{f}$. 
werden aber doch noch nicht als ausreichend rechtlich ausgestaltet und aktiv genug empfunden ${ }^{141}$ ).

Ich vermag auf weitere Probleme dieser rechtlichen und faktischen Stellung der Gruppen hier nicht einzugehen. Um sie wenigstens zu erwähnen: Es handelt sich einmal um ihren Rechtsschutz gegenüber dem Staat, soweit es diese Teilhabe an öffentlichen Aufgaben betrifft. Zum anderen aber geht es um den Schutz des einzelnen gegen ein Ubermächtigwerden der Gruppen, die ausschließliche Vertretungsrechte in Anspruch nehmen und den einzelnen in tatsächliche soziale Abhängigkeit versetzen können. Hier treten die Fragen der Pflicht zur Zulassung zu Organisationen auch privater Art, die Kontrolle der Ausschließung von Mitgliedern - die oft schwere soziale Folgen nach sich ziehen kann ${ }^{142}$ ) und des Kontrahierungszwanges dort, wo die Verbände für Leistungen ein faktisches oder rechtliches Monopol besitzen, auf ${ }^{i 4 s}$ ). Endlich aber handelt es sich um die eigenartige Verwandlung individueller Grundrechte der Freiheit vom Staat - Vertragsfreiheit, Koalitionsfreiheit, Unterrichtsfreiheit, Pressefreiheit -, wenn diese Freiheiten nicht von Individuen sondern von Organisationen beansprucht werden. Bei ihnen können Freiheitsrechte die Basis einer sozialen Machtbildung und eines Ausschlusses staatlicher Kontrolle bilden ${ }^{144}$ ).

6. Wenn ich mich nun kurz den Folgen der staatlichen Intervention im Bereiche des Verfassungsrechts zuwende, so kann ich an die Darstellung des Berner Staatsrechtslehrers Hans Huber anknüpfen. Hier ist zunächst auf die Gefahren für den Rechtsstaat hinzuweisen. Der Rechtsstaat, wie ihn unsere Rechtsordnung ausgeformt hat, ist aufgebaut auf dem Gegensatz des generellen Gesetzes und des Einzelvollzuges durch die Verwaltung und auf der Möglichkeit des Rechtsschutzes gegen diese gesetzlich gebundenen Verwaltungsakte. Dieses Schema wird zusehends durchlöchert. An seine Stelle tritt der Eingriff durch das Gesetz selbst, die immer steigende Verwendung unbestimmter Begriffe, die selbst dort, wo Gesetze ergehen, den Spielraum der Verwaltung nicht mehr wirksam abgrenzen, tritt die ,Flucht des Staates in die Formen des Privatrechts", die nach der heutigen Rechtslage immer noch weitgehend die rechtliche Erfaßbarkeit der in dieser Form auf dem Gebiete der Subvention, des Kredits oder der wirt-

141) Die Beurteilung dieser Councils ist eher kritisch. Vgl. Robson, Problems of Nationalized Industry 1952 S. 164ff.; Haynes, Nationalization in Practice 1953 S. 26r ff.

149) Vgl. den oben in Anm. I mitgeteilten Fall Kuzych v. White.

143) Zum Kontrahierungszwang, zur Versorgungspflicht siehe Siebert a. a. O. S. $230 \mathrm{ff}$; Laren z, Lehrbuch des Schuldrechts Bd. I r953 S. $35 \mathrm{f}$.

14) Die franzősische Wissenschaft hat diese Wandlung der Freiheitsrechte in der Hand von Gruppen scharf bemerkt. Vgl. G. Burdeau, Manuel de droit public 1948 S. $19 \mathrm{f}$., $175 \mathrm{ff}$. 
schaftlichen Eigentätigkeit des Staates vor sich gehenden Vorgänge stark vermindert, das Vordringen der indirekten Mittel der Lenkung, durch privatrechtliche Akte, durch innerdienstliche Weisungen ${ }^{145}$ ), durch Lenkungsmaßnahmen ganz allgemeiner und weite Kreise erfassender Art (Steuerpolitik, Währungspolitik), die vom einzelnen nur schwer zum Gegenstand rechtlicher Gegenwehr gemacht werden können. Ein Beispiel der Schwierigkeiten des rechtlichen Schutzes mag die Notlage der Exportgläubiger im Brasilienhandel bilden, die sich im Sommer I952 herausgebildet hat. Der deutsche Exporteur erhält die Zahlung seines brasilianischen Abnehmers nicht unmittelbar, sondern über ein zwischen den beiden Staaten vereinbartes Clearingsystem. Die Gläubiger erhalten im Rahmen des Zahlungsabkommens erst mit der Durchführung der Verrechnung jeweils den bei der Bank des fremden Landes eingezahlten Betrag des Schuldners bei der eigenen Zentralbank gutgeschrieben. Tatsächlich zahlte indes die Bank deutscher Länder vor Verrechnung alsbald nach Zahlungseingang bei der brasilianischen Staatsbank aus. Diese Auszahlung stellte sie wegen des inzwischen angewachsenen brasilianischen Debetsaldos im September r952 ein, woraus sich für die deutschen Exporteure lange Wartefristen, praktisch zugleich eine Entwertung ihrer ausstehenden Forderungen ergab. Die Entschließung der Bank deutscher Länder entzog sich - zumal sie währungspolitisch begründet war - jeder Anfechtung, bewirkte aber unmittelbare Schädigungen $\left.{ }^{146}\right)$. Gerade gegenüber Manipulationen auf dem Gebiete der Währung - und hier sind wir in Deutschland heute im Unterschied von den dreiBiger Jahren, wo die deutsche Währungspolitik mit verschiedenen Valutatypen und Kursen arbeitete, das Opfer entsprechender Vorgänge in anderen Staaten - ist ein Schutz besonders schwer zu gewinnen.

Ein Vorgang, der in dieser Richtung einwirkt, ist auch die Verunklärung des Gesetzesbegriffes. Wenig mehr ist oft in unserer heutigen legislativen Tätigkeit mehr übrig von dem Gesetz als einer dauerhaften, die Allgemeinheit auch sittlich bindenden Norm. Gerade die Gesetzgebung auf dem Gebiete der Wirtschaft und der staatlichen Interventionen ist Tageswerk, befindet sich in steter Abänderung und Anpassung und löst den Gesetzesbegriff durch die Verwendung der Form des Gesetzes für ausführende Einzelheiten und für Maßnahmen vorübergehender Art auf ${ }^{\mathbf{1 4 7}}$ ). Eine weitere hier nur anzudeutende Erscheinung ist die Uberbürdung weitgehender Entscheidungsbefugnisse im wirtschaftspolitischen Gebiet auf den Richter. Wenn der Rahmen der wirtschaftspoli-

145) OVG. Münster DVBL. I953 S. 25.

110) Eingehende rechtliche Erơrterung der hier auftretenden Rechtsfragen bei Erler, Z. ausl. off. R. und Volkerrecht 15, 1953 S. Iff.

ii7) Vgl. Hans Huber, Festgabe f. Giacometti I953 S. 74 f. 
tischen Gesetze des Staates durch eine starre Verfassung festgelegt ist, die aber keine präzisen, sondern nur sehr allgemeine und einen weiten Spielraum gebende Vorschriften gibt, so kann es nicht dem Richter auferlegt werden, aus diesen Bestimmungen genaue Richtlinien zu entwickeln. Wie lassen sich etwa aus Art. 2 oder I2 des Grundgesetzes für einzelne Materien ganz bestimmte Grenzen staatlicher Eingriffe aufstellen? Der Begriff der freien persönlichen Entfaltung ist ebenso unbestimmt wie der der Berufsausübung. Man wird daher recht tun, den in den Normen des Grundgesetzes gegebenen erheblichen Spielraum des Gesetzgebers nicht durchi eine seine Bewegungsfreiheit immer mehr einengende Interpretation zu beschränken und nicht bestimmte Theorien und Wirtschaftssysteme in das Grundgesetz hineinzudeuten ${ }^{148}$ ).

7. Zuletzt mag noch auf die Gefahr hingewiesen werden, daß im Ringen der Wirtschaftsgruppen um Einfluß und Anteil sich die übergeordnete ausgleichende und gerecht zuteilende Stellung des Staates kompromittiert und gefährdet sehen könnte. Die Besorgnis vor der Herausbildung pluralistischer Auflösung der Staatseinheit wird heute häufig geäußert, gewiß manchmal übertrieben, aber doch nicht ohne begründeten Kern. Irgendwie bedürfen auch die wirtschaftlichen Konflikte und Gegensätze, wo die Einigung der Beteiligung ausbleibt oder dritte Gruppen beeinträchtigen kann, der höheren Verfügung des Staates. Im Gang interventionistischer Entscheidungen und der damit eintretenden Bindungen an Gruppeninteressen ist die Erhaltung dieses Abstandes und dieser Uberlegenheit des allgemeinen Gesichtspunktes eine wichtige Aufgabe des Staates und seiner Organe. Sie wird vermutlich einem Parlament vorteilhafter noch anvertraut sein als einem ständischen Wirtschaftsrate.

\section{Abschnitt}

Rechtsschranken der staatlichen Einwirkungen und Rechtsschutz innerhalb der staatlichen Wirtschaftslenkung

r. Ein Grundanliegen jeder Untersuchung der staatlichen Intervention muB es sein, die rechtlichen Schranken aufzuzeigen, die ihr anhaften. Lassen sich diese Grenzen natürlich im einzelnen nur aus der jeweiligen positiven Rechtsordnung gewinnen, so können doch einige allgemeine Erkenntnisse gewonnen werden. Weisen wir zunächst hin darauf, daß das herkömmliche Bild

148) Hans Huber hat die hier vorliegende Neigung zu einer „Uberanstrengung des Rechts" treffend gekennzeichnet, a. a. O. S. 79 ff. Es droht hier die Gefahr einer stăndig sich wandelnden beweglichen Interpretation, die gerade die durch jene höchsten Normen gewünschte Stetigkeit aufheben würde. 
unseres Verwaltungsrechts, das den Schutz der Freiheit gegen den staatlichen Eingriff in den Mittelpunkt rückt, nur teilweise hier anwendbar ist. Es erweist sich als wirkungslos dort, wo das Gesetz selbst Maßnahmen trifft, und es versagt gegenüber der zuteilenden und fördernden Verwaltung. Schon früher hat jenes, in Deutschland zuerst von Ot to Mayer entwickelte Schema mit seiner Entstehung ganze Teile des Verwaltungsrechts, für die es nicht paßteetwa das Schulrecht oder das Recht der auswärtigen Verwaltung dem Blick des Verwaltungsrechts ganz entrückt. Es wäre heute der Zeitpunkt gekommen, dies System, das etwa zwischen I870 und 1890 geformt worden ist, einer Erneuerung $z u$ unterziehen. Es wäre dabei ein Verwaltungsrecht der vorsorgenden Leistungen des Staates, der Berechtigungen im Bereich der austeilenden Verwaltung zu entwickeln. Es wäre zu ergänzen durch das Recht der wirtschaftslenkenden Einwirkungen des Staates und eine Durchdringung auch der Staatshandlungen in privatrechtlicher Form im Blick auf ihre öffentlichrechtlichen Elemente. Ich kann auf diese Aufgaben hier nur hinweisen.

Bei einer solchen Arbeit würde sich erweisen, $\mathrm{da} B$ im Gebiet der austeilenden Verwaltung und der Lenkung des Staates noch weniger als auf anderen Gebieten mit einem engen Begriff des subjektiven öffentlichen Rechts auszukommen ist $\left.{ }^{149}\right)$. Es würde sich ferner ergeben, daß hier der status negativus keine unwichtige, aber nur eine partielle Rolle spielt. Neben den Gedanken der Abwehr von Eingriffen treten andere Prinzipien auf, die hier dem Rechtsuchenden als materielle Grundlage seines Vorgehens zur Seite stehen. Es sind vor allem drei : das rechtsstaatliche Verfahren, die Gleichheit und die VerhältnismäBigkeit des Eingriffs. Gerade im Wirtschaftsrecht wird mit besonderem Nachdruck die Einhaltung eines geordneten, die Beteiligten zur Anhörung bringenden und offenen Verfahrens festzuhalten sein. Das amerikanische Recht hat in seiner Klausel des ,due process of law" diesen Rechtsgedanken, gerade in seiner unlöslichen Verbindung mit dem materiellen Recht des Verbots einer Rechtsentziehung, eindrucksvoll ausgestaltet.

2. Der wichtigste Gesichtspunkt aber dürfte im Bereich der Wirtschaftslenkung die Gleichheit sein. Nur aus dem Gleichheitssatz lassen sich Hilfen gegen mangelnde Zuteilung, ungerechten Ausgleich oder ungleichmäBige Verteilung der Lasten gewinnen. Wo der Gleichheitssatz verletzt ist, hat auch das Ermessen seine rechtlichen Grenzen verletzt. Die deutsche Rechtsprechung hat den Gleichheitssatz herangezogen bei Beiträgen zu einer öffent-

149) Zu der Problematik des Begriffs des subjektiven offentlichen Rechts im deutschen VerwaltungsprozeB siehe jetzt Bachof, OV. I953 S. 42 If. 
lichen Versorgungseinrichtung ${ }^{150}$ ) oder bei dem Versuche eines deutschen Landes, durch eine wirtschaftslenkende Maßnahme die eigenen Bürger vor denen anderer deutscher Länder zu begünstigen ${ }^{151}$ ). Mehrere einprägsame Beispiele bietet die französische Judikatur. So hat der Staatsrat die vom französischen Rundfunk wegen einer bei einer Konzertgesellschaft erfolgten Entlassung ausgesprochene Sperre in der Beteiligung an den Rundfunkkonzerten (und damit an Einnahmon) wegen Verletzung des Prinzips der Gleichheit, die die Tätigkeit eines service public regiere, aufgehoben ${ }^{152}$ ). Ein zweiter Fall betrifft noch deutlicher eine wirtschaftslenkende Maßnahme. Die französischen Schwefelfabriken müssen bei der Verarbeitung französischen Schwefels einen Zusatz ausländischen Schwefels machen. Bei der Einfuhr dieses fremden Produkts gewährt ihnen der Staat einen ZuschuB in Höhe der Differenz zwischen Gestehungs- und Verkaufspreis. Dafür setzt dann der Staat einen Taxpreis fest. Verarbeitet eine Fabrik aber inländischen Schwefel ohne fremden Zusatz, so trägt der Staat ebenfalls die Differenz zwischen Erzeugungskosten und Erlös, aber der Betrieb kann den Verkaufspreis selbst festlegen. Die letztere Bedingung erfüllt eine einzige Fabrik, die dadurch den Vorteil hat - da sie die Differenz vom Staate ersetzt erhält -, die anderen unterbieten zu können. Der Staatsrat betont das Gebot der Gleichheit und sieht ein System des Ausgleichs der Preise in einem Wirtschaftszweige (d. h. des Ausgleichs der Gestehungskosten zwecks Erzielung eines einheitlichen Preises) bei besonderen Verhältnissen als zulässig an. Sie entspreche dem mehr und mehr vordringenden Gedanken einer „égalité de la répartition des charges publiques". In der Annahme einer Verletzung des Gedankens der gleichen Lastenverteilung aber ist er vorsichtig. Notwendig müssen solche Maßnahmen einzelne begünstigen, anderen weniger vorteilhaft erscheinen. Eine nur tatsächliche Ungleichheit genügt nicht, sofern sie nicht einem gesetzlichen Gebot widerspricht, und solange die Differenzierung durch ein öffentliches Interesse begründet erscheint ${ }^{153}$ ). Wenn also auch das französische Recht die Idee der Gleichheit nicht als ein leitendes Prinzip des Verfassungsrechts in seiner allgemeinen Form kennt, so dringt dieser Gedanke doch als Lastengleichheit, Steuergleichheit oder Gleichheit vor dem Gesetz auch in diesem Rechtssystem vor.

150) VGH. Württ.-Hohenzollern OV. 1952 S. I84. Vgl. auch Hess. VGH. DVBl. 1952 S. 671 and Württ.-Bad. VGH. DVBl. 1951 S. 770.

131) DOG. Bd. 3 S. 120.

152) Soc. des concerts du Conservatoire, Urteil vom 9. 3. 5I, Sirey 195 , 3. $8 \mathbf{r}$.

169) Syndicat de la raffinerie de sonfre française, Urteil vom 29. 6. I95I, Sirey 1952, 3, 33. Dazn Steindorff a. a. O. S. 30f., I $20 \mathrm{f}$. 
3. Was den dritten Grundsatz, die Verhältnismäßigkeit, anlangt, so ist damit auf die Grenzen hingewiesen, die der staatlichen Intervention aus dem Grundgedanken der auf die Freiheit des Individuums und auf seine Selbständigkeit gegründeten Ordnung eines rechtsstaatlichen Systems erwachsen. Auch wo wir keine Verfassungsschranken haben, müssen die Interventionen begrenzt sein, wollen sie nicht jene freiheitlichen Grundlagen des Staates beeinträchtigen. Die staatliche Maßnahme bedarf einer Begründung, sie muß im öffentlichen Interesse nötig und geeignet sein. Die amerikanische Praxis zieht in diesem Zusammenhang den Gedanken der ,,reasonableness" heran ${ }^{154}$ ). Aus diesem Ansatz her würde es möglich sein, gewisse Grenzen etwa für staatliche Preisfestsetzungen oder Verwendungsverbote $z u$ finden.

4. In den Formen, wie materiell die Begrenzung der staatlichen Aktivität gezogen wird, weichen die einzelnen Staaten weit voneinander $a b$. In den Vereinigten Staaten von Amerika ist es die übergeordnete Stellung der Verfassung und die weite Ausdehnung, die die beiden Gedanken des ,,due process" und des "eminent domain" gefunden haben, die hier nachprüfbare, von den Bundesgerichten auch gegenüber den Staaten gehandhabte Schranken gezogen haben. England dagegen kennt keine Verfassung, keine Schranke der gesetzgeberischen Freiheit. Hier müssen die Abhilfen entwickelt werden aus dem System der Prerogative Writs, die in einem gewissen Umfang erlauben, Verwaltungsentscheidungen zur richterlichen Nachprüfung zu bringen. Neben der Betonung eines geordneten Verfahrens (Prinzip der "natural justice") ${ }^{155}$ ), begegnen wir im weiteren britischen Bereich auch dem MaBstab der "reasonableness". So erklärt das Privy Council bei der Beurteilung einer vom australischen Bunde eingeführten monopolistischen Befugnis der Staatsbank, daß ein Bankmonopol dem in Art. 92 der Verfassung niedergelegten Grundsatz der "freedom of trade" widerstreite, gewisse Beschränkungen dieser Freiheit aber statthaft seien. Alles hänge von Zeit und Umständen $\mathbf{a b}^{158}$ ). Auch in Frankreich wird der Kreis grundrechtlicher Freiheiten und Prinzipien, den die Präambel zur Verfassung enthält, nicht als übergeordnetes und den Gesetzgeber begrenzen-

16) Siehe Steindorff S. grf.

165) Zu diesem Gedanken siehe Sir Carleton Kemp Allen, Law and Orders 4. Druck I950 S. I43ff; A. L. Good hart, English Law and the Moral Law, 1953 S. 64 .

iw) Commonwealth of Australia v. Bank of New South Wales $195^{\circ}$ A. C. 235. Dort wird etwa betont (S. 3II): „Every case must be judged on its own facts and in its own setting of terms and circumstances, and it may be that in regard to some economic activities and at some stage of social development, it might be maintained that prohibition with a view to state monopoly was the only practical and reasonable manner of regulation ....". 
des Recht angesehen ${ }^{157}$ ). Trotzdem beginnt auch hier die Rechtsprechung, nicht aus einzelnen Absätzen des Vorspruchs, aber aus seinem ganzen ideellen Gehalt gewisse allgemeine, in der Rechtsanwendung zur Geltung gebrachte Gedanken zu entwickeln. So hat das Tribunal civil de la Seine die Klausel des Testaments eines Franzosen, der seine Tochter enterbte, wenn sie einen Israeliten heiratete, für unwirksam erklärt, weil sie den Grundlagen der französischen Verfassung und ihrer Verkündigung der Gleichheit aller Menschen widerspreche ${ }^{158}$ ).

In Deutschland wird heute ein wesentlicher Teil der materiellen Bindung des wirtschaftslenkenden Staates nicht nur durch die Grundsätze des Rechtsstaates und die Gesetzesbindung dargestellt. Der Schutz der Garantien der Freiheit verlagert sich angesichts der zunehmenden Intervention durch den Gesetzgeber in die Prinzipien des Rechtsstaats und in die Grundrechte, institutionellen Garantien und Leitgrundsätze der Verfassung. Es ist die Überordnung der Verfassung, die aus ihr fließende Grenzziehung gegenüber dem Interventionismus, die dem deutschen Recht - in gewissem Sinne damit dem amerikanischen und auch dem schweizerischen verwandt - seine besondere Note verleiht.

5. Am Anfang meiner Ausführungen habe ich darauf hingewiesen, daB das Grundgesetz sich nicht zu einem bestimmten Modell oder System einer wirtschaftlichen Ordnung bekennt und auch keine Wirtschaftsverfassung im Sinne eines umfassenderen Kreises von wirtschaftlichen Normen enthält. Es zieht aber durch einige wesentliche grundrechtliche Vorschriften der wirtschaftlichen Entwicklung einen festen Rahmen. Es sind vor allem die Bestimmungen der Art. 2, 9, I2, I4 und I5 des Grundgesetzes, daneben auch der Gleichheitssatz (Art. 3 GG) und die Leitgrundsätze der sozialen Rechtsstaatlichkeit und des freiheitlichenStaates (Art. 20, 28 GG), die diese Basis ausmachen. Sie stellen in ihrer Gesamtheit kein geschlossenes, viel weniger ein ganz unwidersprüchliches System dar, aber sie geben doch ganz bestimmte Richtweisungen: Erhaltung einer privatrechtlichen Rechtsordnung mit Eigentum und individuellen Freiheiten, Gewähr einer wirtschaftlichen Bewegungsfreiheit im Rahmen des Gedankens der freien persönlichen Entfaltung (Art. 2 Abs. I GG), einen gesicherten Bereich beruflicher Freiheit in selbständiger wie unselbständiger Arbeit und Tätigkeit. Dazu tritt aber begrenzend der Gedanke, daB im sozialen Rechtsstaat individuelle Rechtssituationen eine stärkere Bindung gegenüber der Allgemeinheit aufweisen, tritt die Anerkennung des möglichen Miteinanderbestehens eines $\mathrm{Be}$ reiches privater Wirtschaftsdisposition mit gemeinwirtschaftlichen

157) Vgl. Maxime Mignon Dalloz r95I S. I27ff.

158) Dalloz 1947 S. 126. 
Formen, tritt endlich in Art. 2 Abs. I GG die Hervorhebung allgemeiner innerer Grenzen grundrechtlicher Positionen. Die nähere Ausführung dieser wenigen aber gehaltvollen Sätze ist Aufgabe einer entfaltenden Auslegung. Sie wird klar legen, daß neben den Freiheitsrechten der einzelnen (wie der Gruppen, die außer in Art. 2I GG auch in Art. I9 Abs. II GG eine gewisse Anerkennung erfahren) und vielfach in ihnen zugleich institutionelle Garantien und Gewährleistungen grundlegender Elemente der Rechtsordnung liegen, da $B$ darüber hinaus das Grundgesetz richtunggebende Leitgrundsätze aufstellt ${ }^{159}$ ). Jede Auslegung dieser wirtschaftlichen Sätze des Grundrechtsteils muß eine zusammenfügende, d.h. die Widersprüche ausgleichende sein. Sie muß ferner eine konnexe, d. h. verknüpfende, sein, die niemals eine einzelne Vorschrift allein, sondern diese im allgemeinen systematischen Zusammenhang, vor allem aber in Verbindung mit den anderen verwandten Sätzen auslegt (z. B. Art. 12 nicht ohne Blick auf Art. 2 Abs. I GG, Art. 4 in Verbindung mit Art. 3 Abs. I GG). Sie wird heute, wie wir gesehen haben, bei einzelnen Grundrechtssätzen auch die Frage aufwerfen müssen, inwieweit sie über den Bereich des öffentlichen Rechts hinaus auch private Rechtsgeschäfte binden. Vor allem wird sich auch die Auslegung hüten müssen, den in den Vorschriften des Grundgesetzes in wirtschaftlicher Hinsicht dem Gesetzgeber eingeräumten Spielraum zu verkennen oder durch eine zu weit getriebene Interpretation einzuengen.

Im ganzen bedeuten die deutschen Bestimmungen mehr negative Schranken gesetzgeberischer und verwaltender Freiheit als eine präzise oder eingehendere wirtschaftliche Richtweisung. Wir haben solche Begrenzung des Gesetzgebers auch im französischen und sogar im britischen Recht ${ }^{160}$ ). Das Gewicht der Normen des Grundgesetzes geht aber erheblich über solche weiten Rahmenprinzipien hinaus, weil hinter ihnen einmal die in Deutschland üblich gewordene sehr verfeinerte Grundrechtsinterpretation steht und sodann auch die Möglichkeit der Anrufung gerichtlicher Entscheidung, letztlich bis zu dem Bundesverfassungsgericht. Man wird nur darauf zu achten haben, daB nicht allzusehr Fragen der Politik und wirtschaftlicher Zielsetzung durch jene Bindungen zu Problemen verfassungsrechtlicher Auseinandersetzung werden.

6. Die weittragendste unter den wirtschaftsrechtlichen Vorschriften des Grundgesetzes ist Art. 2 Abs. I GG. Dieser Satz der

16v) Ich darf für diese Fragen verweisen anf meine Ausführungen in Recht-Staat-Wirtschaft Bd. 4, 1953 S. $88 \mathrm{ff}$.

160) Auch in England wendet sich eine neuere Richtung gegen eine wortliche Deutung der "Supremacy of Parliament" im Sinne rechtlicher Bindungslosigkeit. Wenn auch nicht durch die Gerichte angewendet (enforced), bestehen auch im englischen Verfassungsrecht, so sagt A. L. Goodhart (English Law and the Moral Law 1953 S. 55f.): „certain established principles which limit the scope of Parliament". 
freien persönlichen Entfaltung, basierend auf einer bestimmten ideellen Sicht des Menschen als freien Geschöptes ${ }^{161}$ ), umschließt auch die wirtschaftliche Betätigungsfreiheit ${ }^{162}$ ). Nicht im Sinne der Festlegung eines Wirtschaftssystems der Wettbewerbsfreiheit, aber in dem einer grundsätzlichen Bekräftigung der Wettbewerbsfreiheit und der selbständigen wirtschaftlichen Disposition des einzelnen Individuums und des einzelnen Unternehmens. Mit den Gedanken des Art. 2 wird sich auch die Vertragsfreiheit verbinden. Allerdings unterliegt diese Betätigungsfreiheit wie alle grund-. rechtlichen Freiheiten einer grundsätzlichen Gemeinschaftsbezogenheit und gewissen aus der geschichtlich-institutionellen Natur jedes spezifischen Grundrechts folgenden Schranken. Art. 2 Abs. I GG hat zwar nicht etwa die Bedeutung eines allgemeinen Obersatzes aller Grundrechte. Eine solche scheinlogische Deutung widerspricht durchaus der selbständigen historischen Entfaltung der einzelnen Grundrechte und ihrer teilweise weit und speziell über Art. 2 GG hinausgreifenden Richtung. Aber in Art. 2 Abs. I GG sind mit einer der Vorrangstellung dieses grundlegenden Artikels entsprechenden Kraft für alle Grundrechte gewisse Begrenzungen aufgewiesen, die sich jedenfalls bei den Freiheitsrechten überall als begrenzender Rahmen des Grundrechts zeigen. Art. 2 bindet die Grundrechte an das Sittengesetz, d. $h$. an die in der Volksgesamtheit lebendigen Grundlagen moralischer Anschauung ${ }^{163}$ ), an die .,Rechte anderer", worunter nicht bloB individuelle Positionen anderer gemeint sind, sondern auch solche Rechtsgüter, die im Interesse aller wie Volksgesundheit und öffentliche Sicherheit ${ }^{164}$ ) gegenseitig $\mathrm{zu}$ respektieren sind ${ }^{165}$ ). Ferner aber werden die Grundrechte durch die Beachtung der ,verfassungsmäBigen Ordnung “ beschränkt. Darunter sind nicht bloB die eigentlichen Normen des Verfassungstextes oder die anderen Grundrechte, sondern die im Verfassungstext niedergelegten und vorausgesetzten allgemeinen Grundlagen der staatlichen und

101) Zur Grundlage des Art. 2 siehe Dürig, JR. I952 S. 259 ff.

162) So Nipperdey, DRZ. I950 S. r93 ff.; Hamann, BB. I952 S. 342; ders., Rechtsstaat und Wirtschaftslenkung I953 S. 62 ff.; E. R. Huber, Wirtschaftsverwaltungsrecht Bd. I I953 S. 660 f.; Krüger, BB. 1953 S. 566; Patschke, BB. 1954 S. 2; Würdinger, Wirtsch. u. Wettbewerb 1953 S. 72 If. A. A. Peters, Festgabe Laun r953 S. 674 f. Hamburg OVG. DVBl. I953 S. 6I7ff.

103) Peters a. a. O. S. 677. Vielleicht wird man hieraus den Gedanken des Verbots eines MiBbrauchs der Grundrechte im VerstoB gegen diese Prinzipien ableiten kơnnen. A. A. Krü ger, DVBl. r953 S. 97 ff.

14) Nicht ohne weiteres fallen hierunter polizeiliche Gesichtspunkte im technischen Sinne. So auch Dürig, AOR. 79, 1953 S. 63 f., der die ,, Rechte anderer" nur als Individualrechte verstehen will. Ebenso Krüger, BB. 1953 S. 566f.; Hamann, Wirtschaftslenkung S. 64; BGH, Gutachten in Wirtschaft u. Wettbewerb 3, I953 S. 64. Wie oben VGH Württ.-Bad. VerwRspr. 4 S. 490 und OVG. Lüneburg Entsch. Bd. 5 S. 412. 
sozialen Ordnung und die Leitgrundsătze der Verfassung (Rechtsstaat, Gewaltenteilung) zu verstehen, also für unser Gebiet jene Grundlagen, die wir vorhin als den festen Rahmen gekennzeichnet haben, den das Grundgesetz dem wirtschaftlichen Leben zieht ${ }^{160}$ ). Keineswegs aber umfaßt diese Formel der „,verfassungsmäßigen Ordnung" die gesamte Gesetzesordnung. Dieser Verweis ist also nicht auf die Kernsätze der Verfassung begrenzt, sondern umfaßt die Grundlagen der politisch-sozialen Ordnung; er ist eine normative Verweisung auf die Wert- und Rangordnungen der Verfassung.

Art. 9 Abs. III sichert mit umfassender Wirkung das soziale Vereinigungsrecht, ohne indes ausdrücklich das Streikrecht und die negative Vereinigungsfreiheit zu regeln. Dennoch gehört der Streik heute zum Bilde der Privilegierung eines gewissen sozialen Bereiches und der in ihm wirkenden Vereinigungen, und die negative Vereinigungsfreiheit wird man als mitgeschützt erachten dürfen. Jedenfalls sichert Art. 9 Abs. I und III die freie Bildung wirtschaftlicher Vereinigungen und schließt in diesem Bereich privaten Rechts Zwangsbildunger. aus ${ }^{167}$ ). Das Verbot der Zuweisung hoheitlicher Aufgaben und Funktionen an private Verbände läßt sich dagegen nicht aus Art. 9 GG herleiten ${ }^{168}$ ).

Art. I2 GG, der nicht bloB das Gewerbe, sondern auch die unselbständige Arbeit betrifft, setzt die Grundlage einer freiheitlichen Berufsordnung fest. Er bildet eine zusammenhängende Regelung grundlegender Fragen des Berufsrechts, nicht eine spezifische Verkündung der Gewerbefreiheit. Art. I2 GG wird durchaus miBverstanden, wenn man ihn in das für das Gewerberecht, also ein anderes und engeres Gebiet, herkömmliche Schema Berufszulassung-Beruísausübung zwängt ${ }^{109}$ ). Ebenso wie sozialpolitische Regelungen bei dem Zugang zum Arbeitsplatz begegnen (Schwerbeschädigteneinstellung), gestattet Art. 12 Abs. I auch gewisse Beschränkungen der Zulassung für Berufe an Hand des in der Tradition und der gesellschaftlichen Wirklichkeit entwickelten Berufsbildes ${ }^{170}$ ). Die Freiheit der Berufswahl findet ihre Grenze an diesen Berufsbildern, die Art. I2 Abs. I zuläBt, und an den Grenzen des Art. 2 Abs. I GG, die freilich eine freiheitliche Ordnung der Berufe belassen müssen. Aus Gründen der Sicherheit

116) Siehe auch Bad. VGH. DVBl. r951 S. 636.

100) Mit Einschluß also wirtschaftsgestaltender Möglichkeiten siehe Huber a. a. O. S. 662; Dürig, JZ. I953 S. I96. Zu weit aber geht Dürig, AOR. 79, 1953 S. 57 ff., der die allgemeine polizeiliche Generalermächtigung zur verfassungsmä日igen Ordnung rechnen will.

167) So Huber a. a. O. 252; ReuB, DVBl. I953 S. 685.

168) A. A. ReuB, DVBl. I 953 S. 685 .

169) Vgl. OVG. Lüneburg Entsch. Bd. 4 S. ${ }_{58}$. Vgl. auch Naumann. JZ. $195 \mathrm{I}$ S. 426.

170) OVG. Hamburg DVBI. I95I S. 387; OVG. Lüneburg Entsch. Bd. 5 S. 281. Zu eng OVG. Münster VerwRspr. 5 S. 227. 
und Gesundheit, aber auch aus einem überwiegenden öffentlichen Interesse an einem Berufe können nicht nur Beschränkungen der Ausübung, sondern auch des Berufseintritts und der gesamten Berufsgestaltung - immer im Gesamtrahmen freiheitlicher Regelung - gerechtfertigt werden. Eine Zulassung der Beschränkung des Berufszugangs und der Berufsgestaltung nur unter polizeilichen Gesichtspunkten ist daher $\mathrm{zu}$ eng, auch aus Art.I2 GG nicht zu entnehmen.

Die Bedeutung der Eigentumsgarantie des Art. I4 GG liegt in der Betonung einer privatrechtlichen Eigentumsordnung als gewăhrleisteter Lebensordnung und der über das bisherige Recht hinaus erfolgten Sicherung der Eigentumssubstanz durch die in jedem Falle bei Enteignung erforderte Entschädigung. Die Grenzen werden hier wieder durch die Betonung der Sozialpflichtigkeit und der Zulassung der gemeinwirtschaftlichen Ordnung begrenzter Gebiete hervorgehoben. Man wird aus den für Art. I4 und I5 GG entwickelten Grundsätzen auch Maßstäbe entnehmen können, um Fragen wie die Auferlegung von Leistungspflichten ohne Vergütung oder die nähere Ausformung des Prinzips der ausgleichenden Gestaltung im Wirtschaftsrecht zu entnehmen.

7. Wenn wir zum SchluB noch einen Blick auf die Probleme des Rechtsschutzes werfen, so kann zunächst festgestellt werden, da $B$ unser so weit ausgebautes System verwaltungsgerichtlichen Schutzes nur einen Teil der im Bereich der Intervention des Staates anfallenden Fragen erfassen kann. Es vermag diejenigen Einwirkungen zu decken, die als unmittelbare Begrenzungen von Freiheitsrechten, als „Eingriffe" oder Verwaltungsakte im allgemeinen Sinn ergehen. Dagegen werden Maßnahmen in Gesetzesform und Verordnungen nicht gedeckt, soweit hier nicht wie in den süddeutschen Gesetzen abstrakte Normenkontrolle wenigstens gegen Verordnungen zugelassen ist. Vor allem werden aber nicht von dieser Gestaltung des Rechtsschutzes genügend ergriffen die indirekten Mittel staatlicher Lenkung, soweit sie privatrechtliche Formen benutzen, mittelbare Wirkungen anstreben, Begünstigungen und Zuteilungen enthalten, auf die man keinen festen Rechtsanspruch herstellen kann. Unser Verwaltungsrecht arbeitet hinsichtlich der materiellen Grundlage einer Verwaltungsklage mit dem Begriff des subjektiven Rechts. Es wird sich mit der Zeit - zumal heute bereits dieser Begriff immer mehr erweitert wird - als notwendig erweisen, statt seiner einen beweglicheren Rahmen in dem Gedanken des schutzwürdigen Interesses zum Ausgang zu nehmen. Auch dann wird es immer ohne weiteres möglich sein, wischen rechtlich geschützten Positionen und bloBen faktischen Aussichten und wirtschaftlichen Vorteilen und Erwartungen zu unterscheiden. So hat auch das Reichsgericht früher solche wirtschaftlichen Chancen nicht als Rechtsstellungen 
anerkannt ${ }^{171}$ ). Es mag zugegeben werden, da $B$ in Einzelfällen Zweifel auftreten können. So hat der Internationale Gerichtshof im Haag den Anspruch eines englischen Staatsangehörigen Oscar Chinn gegen den belgischen Staat auf Entschädigung abgewiesen, der sich auf folgenden Tatbestand gründete: Chinn betrieb zugleich mit einer staatlichen Gesellschaft den Dampfertransport auf dem Kongo. In der Wirtschaftskrise um r93o subventionierte der Staat seine Gesellschaft, die zu Verlustpreisen arbeitete und Chinn erhebliche Verluste zufügte. Das Gericht hat trotzdem hier keine Verletzung der in der Kongo-Akte festgelegten ,,völligen wirtschaftlichen Gleichbehandlung " in der Zulassung zur Schifffahrt gesehen, weil Chinn seine Tätigkeit unter Opfern fortsetzen konnte. Man wird hier wohl der heute in der internationalen Rechtslehre an dieser etwas formalen Deutung geübten Kritik zustimmen können; hier lag eine Verletzung der Gleichheit vor ${ }^{172}$ ).

Gegen Eingriffe durch Gesetze und Verordnungen gewährt das deutsche Recht die Verfassungsbeschwerde. Bei individuellen MaBnahmen wird es darauf ankommen, sich von dem engen Begriff des Rechts freizumachen, das heute leicht zur Schranke des Rechtsschutzes wird. Vielfach wird die Folgerung, da $B$ man den Begriff des subjektiven Rechts weit fassen müsse, auch aus Art. I9 Abs. IV GG abgeleitet. Es mag doch wohl sein, daB bei den hier aufgeführten französischen Fällen oft ein formelles Recht des Klägers nicht anerkannt werden könnte. Schwerlich würde man der im Rundfunk beteiligten Konzertgesellschaft ein Recht auf regelmäBige Beteiligung an den bezahlten Darbietungen für den Rundfunk einräumen. Das französische Recht geht auch in zwei anderen Hinsichten noch weiter als das deutsche. Es läBt im allgemeinen auch weitherzig Klagen solcher Personen ${ }^{173}$ ) $\mathrm{zu}$, die durch die Begünstigung einer anderen Nachteile erleiden, während das deutsche Recht hier im allgemeinen weder beim Nachbarn gegenüber dem errichteten Bau, noch beim Gewerbetreibenden gegen die Zulassung eines Mitbewerbers die Befugnis zur Klage anerkennt $\left.{ }^{174}\right)$. Ferner läßt das französische Recht die Wahr-

171) Vgl. RGZ. I39, I77 (Kühlhausbau in Hoffnung auf weitere Fleischimporte); RGZ. I 29, 146 (Heilkundiger verliert Behandlung der Geschlechtskranken durch Geschlechtskrankengesetz).

172) Fall Oscar Chinn, Cour Perm. de Justice Internationale, Recueil A/B 63 (1934). Dazu kritisch im obigen Sinne Schwarzenberger, International Law Bd. I 2. Aufl. 1949 S. I17; S. Friedmann, Expropriation in International Law 1953 S. $54 \mathrm{f}$.

173) Es genügt ein „,interêt direct et personnel“", etwa des Beamten bei Bevorzugung eines anderen in der Beförderung, vgl. Traité $S .368 \mathrm{f}$.

174) Vgl. Hess. VGH. DVBI. I95I S. 184 (Nachbar und Baudispens); OVG. Lüneburg DVBl. 1952 S. 369 (Notar gegen weitere Zulassung eines anderen Notars); OVG. Münster VerwRsp. 4 D. 846 (Milchhandelserlaubnis). Anders für eine Apothekenkonzession infolge Verbindung privaten und offentlichen Interesses gegen Fernhaltung existenzbedrohender Eingriffe 
nehmung der wirtschaftlichen Interessen des einzelnen durch Gruppen und Verbände als Kläger $\mathbf{z u}^{175}$ ), während die deutsche Praxis grundsätzlich nur dem Individuum, nicht aber einem es vertretenden Verbande eine Klagebefugnis gewährt ${ }^{178}$ ).

Als materielle Maßstäbe werden die Prinzipien der Gleichheit und der Verhältnismäßigkeit der staatlichen Maßnahmen dienen können. Die Rechtsprechung wird dabei freilich berücksichtigen müssen, daß sie nicht zu eigenen wirtschaftspolitischen Entscheidungen berufen ist, sondern nur die Utberschreitung des äußeren Rahmens staatlicher Bewegungsfreiheit und behördlichen und gesetzgeberischen Ermessens zu prüfen hat. Gewisse Bevorzugungen und Benachteiligungen sind ein normales Element staatlicher Wirtschaftslenkung. Ein gewisses $\mathrm{MaB}$ an Risiko und an Bereitschaft zur Anpassung an die besonderen Bedingungen einer Lage darf von dem wirtschaftenden Unternehmen erwartet werden. Nur dort, wo rechtlich festgelegte staatliche Maßstäbe unter Verletzung des in sie in rechtlich begründeter Weise gesetzten Vertrauens geändert werden, wird man eine Rechtsververletzung feststellen können ${ }^{177}$ ).

Ein letztes und wichtiges Mittel des Rechtsschutzes mag auch in der Amtshaftung des Staates gelegen sein, die gerade dort, wo wirtschaftliche Dispositionen des Staates Schäden hervorrufen Verderben einer Menge Kohls, der im Sommer auf staatliche Anordnung an einen Ort ohne hinreichenden Absatz versandt werden muß ${ }^{178}$ ) - einen Ausgleich gewähren kann. Die zunehmende Objektivierung, der dieses Rechtsmstitut der öffentlichen Haftung unter rechtlicher oder doch infolge Typisierung (und damit Normativierung) des Schuldmoments unterliegt, mag diese Entwicklung erleichtern ${ }^{179}$ ).

und für Erhaltung der wirtschaftlichen Leistungsfăhigkeit LVG. Rheinland-Pfalz OV. I953 S. 734. Siehe OVG. Berlin DVBl. I952 S. 766 (bei Apotheken nur medizinalpolizeiliche Gesichtspunkte maßgeblich, jedoch darf hier wegen der Gesundheit der Bevőlkerung die Lebensfähigkeit berücksichtigt werden).

175) Syndicat des photographes-filmeurs du Sud-Ouest Conseil d'Etat Sirey r952, 3, 2 I (Klage eines Verbandes gegen ein lokales Verbot, Passanten ohne Bestellung zu photographieren). Die Gruppen dürfen nur beim recours wegen exces de pouvoir für den einzelnen eintreten. Vgl. Laubadère a. a. $O$. S. $366 \mathrm{f}$; ; Duez-Debeyre, Traité S. $360 \mathrm{ff}$.

170) LVG. Minden DVBI. I95I S. 64 I (Kreisverband der Kaufleute für Milch und Milcherzeugnisse kann nicht die einem Dritten erteilte Milchhandelserlaubnis anfechten); OVG. Hamburg DVBl. 1952 S. 667 (Verband des Personenverkehrsgewerbes und Anfechtung einer erteilten Erlaubnis); anders kraft positiven Rechts im Gaststättenrecht OVG. Münster VerwRspr. 3 S. 604.

177) Vgl. Erler, Z. ausl. offentl. Recht u. Volkerrecht I5, r953 S. $26 f$.

178) Ruel, Conseil d'Etat Sirey 1948, 3, 5.

179) Das deutsche Recht hălt bei der Amtshaftung am Verschulden (höchst typisierter Art) fest, erweicht aber durch die Zulassung der Anwendung 
Kein Rechtsschutz, aber ein Mittel der Sicherung von wirtschaftlichen Interessen liegt in der früher behandelten Mitwirkung wirtschaftlicher Gruppen an der Verwaltung. Sie gewinnen hier die Möglichkeit, für eine Berücksichtigung der verschiedenen beteiligten Interessen und den Ausgleich widerstreitender Gesichtspunkte zu sorgen. Sowohl die wirtschaftliche Selbstverwaltung im eigentlichen Sinne, wie das System der Anhörung, Mitarbeit in Verwaltungsräten und Ausschüssen, wie endlich auch die Betrauung von Einrichtungen der Wirtschaft mit öfentlichen Aufgaben vermögen diese Funktion zu erfüllen. Die Frage reicht dabei bis in den Kreis der Verfassung hinein. Hier erscheint die Frage einer Gesamtvertretung wirtschaftlicher Interessen, daneben aber das Problem der Relation zwischen Interessenverbänden und politischen Parteien, sowie der Grenzen des rechtlich geordneten wie des ungeregelten Einflusses der wirtschaftlichen Organisationen.

des $\$ 75$ ALR. für schuldlos-rechtswidrige Eingriffe diese Haltung. Das französische Recht bewahrt noch die faute, aber tendiert $2 u$ einer objektiven Lossung. Vgl. Waline, Traité elémentaire de droit administratif 6. Aufl. x95I S. 580f.; Street, Government liability 1953 S. 6I. Uber ähnliche Tendenzen im schweizer. Recht de lege ferenda siehe Otto $K$. Kaufmann, Ztschr. f. schweiz. Recht, N. F. 72, 1953 S. 32 I aff.; Graff dort S. 429 aff. 


\section{1a. Leitsătze des Berichterstatters über}

\section{die staatliche Intervention im Bereich der Wirtschaft}

Rechtsformen und Rechtsschutz

\section{Staatliche Wirtschaftslenkung}

I. Als staatliche Intervention im Bereich der Wirtschaft ist eine Gestaltung der staatlichen Wirtschaftspolitik zu bezeichnen, die sich nicht mit einer polizeilich-überwachencien Funktion begniigt, sondern unter bestimmten politisch-sozialen Zielen der Förderung oder auch der Umgestaltung in Erzeugung und Verteilung wie auch in die rechtlichen und sozialen Grundlagen der Wirtschaft eingreift, ohne eine Aufhebung der freien wirtschaftlichen Bewegung zugunsten eines geschlossenen Systems zentraler Planung und Anordnung im wirtschaftlichen Leben zu erreichen oder auch nur anzustreben.

2. In den meisten Staaten der westlichen Welt stellt ein System begrenzter staatlicher Wirtschaftslenkung (Interventionismus, Dirigismus) die herrschende Form der gegenreärtigen Wirtschaftspolitik dar. Staatsintervention ist heute in vielen Fällen nicht mehr Ubbergangsstufe oder vorïbergehende Aushilfe, sondern eine eigene Form des staatlichen Verhaltens zu den wirtschaftlichen Vorgängen. Die Ansicht ist abzulehnen, da $\beta$ die Intervention im Sinne der neoliberalen Theorie eine notwendige Vorstufe zu einer umfassenden Zentrallenkung bilde. Die Intervention steht in zeitroeiliger oder grundsätzlicher Abkehr von der liberalen Beschränkung des Staates auf Ordnungsfunktionen zwischen dem liberalen System individueller Freiheit und einer kollektivistischen Zwangswirtschaft.

3. Der Interventionismus kann je nach seinen ideologischen und verfassungstechtlichen Grundlagen mehr die Form eines punktuellen staatlichen Einzwirkens im Rahmen eines Systems grundsätzlicher wirtschaftlicher Freiheit oder die einer zusammenhängenden Planung und Formung eines grundlegenden Teiles der wirtschaftlichen Vorgänge, also einer Verbindung von $B e-$ standteilen gelenkter und freier Wirtschaft annehmen. Diese beiden Formen verden häufig zusammenfallen mit dem Unterschiede eines mehr liberal-sozialen Interventionismus in Korrektur eines freien Systems von dem eines halbsozialistischen Systems der Vollbeschäftigung und der Kontrolle der Grundindustrien. 
4. Ein System begrenzter Wirtschaftslenkung ist mit den Grundlagen eines demokratischen und rechtsstaatlichen Verfassungsrechts vereinbar. Angesichts der tiefgehenden Auswirkungen staatlicher Interventionen im Wirtschaftsleben ist dafür allerdings die wirksame Begrenzung und ein nachhaltiger Schutz der Grundlagen persönlicher und wirtschaftlicher Freiheit sowie der rechtsstaatlichen Prinzipien Voraussetzung.

5. Jede wirtschaftliche Ordnung wird getragen und maßgebend geformt durch die rechtliche Ordnung der Verfassung, der grundlegenden Institutionen des Privatrechts (Eigentum, Vertragsfreiheit, Erbrecht) und der Vervaltung sowie ihre Handhabung. Die Grundlagen, die man als Wirtschaftsverfassung bezeichnen kann, stehen mit der Staatsform und der politischen Verfassung in wechselseitigem Zusammenhang. Eine rechtsstaatliche Ordnung kann nicht mit einem System vollständiger kollektiver Zwangswirtschaft zusammengehen.

6. Die Festlegung eines bestimmten Systems der Wirtschaftsordnung gehört nicht zu den notwendigen Bestandteilen der Verfassung. Eine solche Festlegung kann sich, wie in der Rechtsordnung des späteren I9. Jahrhunderts, aus dem Gesamtaufbau der Rechtsurdnung und der Verwaltungsgrundsätze ergeben. Das Grundgesetz begnïgt sich in Art. 2, 9, 12, 14. 15 und 20 mit der Normierung bestimmter Freiheitsrechte, Institutionen und Leitgrundsätze, ohne ein bestimmtes Wirtschaftssystem festzulegen. Liberale Freiheitsrechte und Institutionen des Privatrechts stehen in ihm sozialen Grundsätzen gegenüber. Von grundlegender Bedeutung für das Verständnis der wirtschaftspolitischen Regelung des Grundgesetzes ist das Prinzip des sozialen Rechtsstaates (Art.20,28 GG); es steht einer Auslegung der Art. 2 und 12 GG im Sinne voller individueller Freiheit ebenso entgegen wie die Worte "verfassungsmäßige Ordnung" in Art. 2 GG.

7. Die Festlegung der obersten Grundsätze der Wirtschaftspolitik ist durch Art. 20, 28 und 73 Ziff. 4, 5, 9 sowie 74 Ziff. $1,3,7,9$, IO, II, I2, I4, I5, I7, I8, 21 und 22 dem Bunde aufgetragen. Eine selbständige Wirtschaftspolitik der Länder auf allen $G e-$ bieten staatlicher Intervention ist durch den Vorrang des Grundgesetzes und des Bundesrechts, aber auch durch die Grundsätze des sozialen Rechtsstaates, der grundsätzlichen Aufrechterhaltung bestimmter freiheitlicher Positionen des Individuums wie umgekehrt der Zulassung von Maßnahmen der sozialen Umgestaltung in Art. 15 GG in enge Schranken gebunden.

8. Auch die Eingriffe des Staates zur Herstellung eines freien Wettbewerbes und zur Bekämpfung marktbeherrschender Unter- 
nehmen stellen interventionistische Maßnahmen dar. Da sie auf die Herstellung eines Wirtschaftsbildes abzielen, das der modernen Tendenz zur Konzentration und zur Gruppenbildung im Wixtschaftsleben entgegentritt. handelt es sich nicht um die Beseitigung von Störungen eines natürlichen "marktkonformen" Verhaltens, sondern um staatliche Gestaltung der wirtschaftlichen Ordnung. Daraus ergibt sich die Forderung, diese Eingriffe nach den gleichen Grundsätzen wie andere interventionistische Einzoirkungen zu beurteilen und sie an strenge rechtsstaatliche Maßstäbe zu binden.

\section{Formen der Intervention}

9. Innerhalb der Maßnahmen des Staates kann man die unmittelbaren durchVerbot und Gebot in die Rechtsstellung der einzelnen oder der Verbände eingreifenden Maßnahmen von den Mitteln indirekter Beeinflussung des Wirtschaftslebens unterscheiden. Die indirekten Methoden reichen von den Wirkungen der Stewer-, Währungs- und Kreditpolitik bis zu propagandistischer EinfluBnahme (Verbrauchslenkung). Ihre rechtliche Form als Gesetze, Anweisungen und Ermessensakte entzieht gerade diese Maßnahmen vielfach rechtlicher Erfassung und fïhrt zur Versagung von Rechtsschutz.

I0. Unmittelbare Interventionen des Staates sind:

a) Verbote, Erlaubnisvorbehalt (Berufszulassung);

b) inhaltliche Gestaltung von Rechtsverhältnissen des offentlichen und privaten Rechts (Satzungen, kollektive Vertragsbestimmungen, privatrechtsgestaltende Akte, Preisbindungen):

c) Leistungsgebote, Aufgabe von Herstellung, Lieferung, Verteilung, Qualitätsnormen, Heranziehung zur Sach- und Dienstleistungen, Verfügungsbeschränkungen;

d) Betrauung von Privatpersonen oder Verbänden mit öffentlichen Funktronen durch Verleihung, Monopole, öfentlichrechtliche Vorrungstellungen, Befugnis zur Erhebung von Zrvangsbeiträgen und die daraus fließenden Folgepflichten des Privat- und offentlichen Rechts;

c) gestaltender wirtschaftlicher Ausgleich.

II. Indirekte Mittel der staatlichen Lenkung sind besonders die Steuer, die Gestaltung des Währungsrechts und die Kreditpolitik, die wesentlich als Aufgabe der Gesetzgebung und der Ausiibung nicht kontrollierbaren Ermessens leitender Stellen erscheinen. Daneben kommen Subventionen, Vergünstigungen, Förderung des AuBenhandels und Investitionsplanung in Betracht. 
12. Einen Bereich besonderer rechtlicher Erscheinungen bildet das Gebiet, das der Staat vor allem im sozialen Felde der Selbstgestaltung der wirtschaftlichen und sozialen Kräfte (Sozialpartner) überläßt. In diesem Bereich treten regulierende und begrenzende Rechtsgrundsätze indes nicht völlig zurück. Der Raum, den der Staat den Sozialpartnern einräumt und in dem er ihnen in gewissem Umfang öffentliche Funktionen freigibt, ist sachlich begrenzt und unterliegt den leitenden Grundsätzen der Gemeinschaftsordnung. Die in ihm gewährten Mittel der Selbsthilfe (Streik) bleiben daher sachlich und hinsichtlich der Ausïbung (Gervalt, Sittenwidrigkeit) gebunden. Neben den Kollektivverträgen erscheint in diesem Bereich als newe Form die Beteiligung der Sozialpartner an den Rechtsetzungsverfahren (qualifizierte Rechtsverordnung).

13. Ein anderer Bereich besonderer Gestaltung ist das Feld der wirtschaftlichen und sozialen Selbstverwaltung. Es stellt einen unentbehrlichen Bereich der Beteiligung freier Kräfte an der Wirtschaftsgestaltung dar. Die Selbstverwaltung ist ein wichtiges Mittel, neben den Individuen auch den Verbänden und sozialen Gruppen eine rechtlich geordnete Stellung und Mitwirkung zu eröffnen.

I4. Die Gegenreart entwickelt neue Formen der Wirtschaftslenkung im internationalen Bereiche. Sorveit sie in den gewohnten Formen des internationalen Rechts gehalten sind, wirken sie sich nur über staatliche Maßnahmen der Gesetzgebung und Außenhandelslenkung aus. Soweit sie indes, wie bei der Montanunion, internationalen Organen unmittelbare Zugriffe in den innerstaatlichen Bereich eröffnen, entsteht neben dem Problem des Rechtsschutzes die Frage der indirekten Auswirkung auf andere Bereiche des Wirtschaftslebens, für die keine rechtliche Abhilfe besteht. Auch hier können die individuellen Freiheitsrechte und Interessen nur durch Gruppen oder durch den Staat wirksam verteidigt werden.

15. Von den anderen Formen staatlicher Intervention unterscheidet sich die soziale Umgestaltung durch ihre Absicht, nicht nur lenkend und korrigierend, sondern umformend und verändernd auf das wirtschattliche und soziale Geschehen einzuwirken. Ihre $M i t t e l$ reichen von indirekten Einwirkungen (progressive $\mathrm{Be}$ steuerung, Kapitallenkung, Währungspolitik) zu unmittelbaren Veränderungen durch Entzug wirtschaftlicher Kontrollrechte (Mitbestimmung, Bekämpfung wirtschaftlicher Machtstellungen) und durch Sozialisierung (Gemeinwirtschaft). Auch dieses $\mathrm{Ge}$ biet unterliegt bestimmten materiellen Grundsätzen und kann rechtsstaatlich gebunden werden. Das gilt vor allem für das Verfahren von Entziehungen und die Prinzipien der Entschädigung. 
III. Auswirkungen und Probleme der Intervention im Verfassungs- und Verwaltungsrecht

16. Der staatliche Interventionismus hat im Verein mit anderen Erscheinungen zu tiefen Wandlungen grundlegender Institutionen des Privatrechts gefïhrt. Das Eigentum ist durch Sozialgebundenheit begrenzt, durch Herauslösen wichtiger Bestandteile (Mitbestimmung) und durch Aushöhlung durch die Stewergesetzgebung funktionalisiert. Die Vertragsfreiheit findet an Geschäftsbedingungen, Kollektivvereinbarungen und zunehmender Regelung des Vertragsinhalts wachsende. Schranken.

17. Eine grundlegende Wandlung vollzieht sich darin, daß im wirtschaftlich-sozialen Bereich weithin nicht mehr allein der Gegensatz Staat-Individuum maßgeblich ist, sondern die Gruppen und Verbände eine entscheidende Rolle spielen. Damit erhebt sich sowohl einerseits das Problem der Freiheit der Gruppen und ihrer Sicherung vor Staatseingriffen, wie andererseits die Notwendigkeit, da $\beta$ der Staat eingreift, um den Individuen vor der sozialen und wirtschaftlichen Macht der Gruppen Schutz zu gewähren. Die individyellen Freiheiten in der Hand von Gruppen (Vertragsfreiheit, Koalitionsfreiheit, Unterrichtsfreiheit) können gerade zu Mitteln der Machtausiibung und Anla $\beta$ zu staatlichem Eingreifen werden.

I8. Der Interventionismus erschüttert die rechtsstaatliche Ordnung von Gesetz und Gesetzesausführung. Seine Maßnahmen werden weitgehend unmittelbar durch Gesetz getroffen und lösen durch diese Verwendung der Rechtsetzung fïr voriibergehende Planungsund Lenkungsmaßnahmen den Gesetzesbegriff auf. Andererseits begünstigt die Wirtschaftslenkung Formen der exekutiven Rechtsetzung oder auch der Gestaltung durch Verwaltungsanweisungen.

r9. Die ausgedehnten Ermächtigungen an Verwaltungsbehörden, die Verwendung unbestimmter Begriffe mit weitem Spielraum, der unmittelbare Eingriff durch Individualgesetz sind weitere Abweichungen von den Gestaltungsformen des Rechtsstaates.

20. Im Bereich des Verfassungsrechts wirkt sich die Bildung sozial und politisch einflußreicher Gruppen und Verbände, soterie die laufende Befassung der Parlamente mit wirtschaftlichen Entscheidungen als Eindringen sozialer Kräfte in den Raum neutraler und ibbergeordneter staatlicher Leitung und Ausbalanzierung aus.

21. Mit den Gestaltungsmöglichkeiten des bisherigen deutschen Verwaltungsrechts, das am individuellen Freiheitsrecht und am 
staatlichen Einzeleingriff orientiert ist, lassen sich die Erscheinungen der Intervention nur teilweise erfassen. Es bedarf der ergänzenden Entwicklung eines Verwaltungsrechts der vorsorgenden Leistungen des Staates unter dem Gedanken der gerechten Beteiligung und des in der Personwürde begründeten Lebensrechtes und der gestaltenden (lenkenden, ausgleichenden und umformenden) Staatshandlungen unter dem Gedanken der Gleichheit und des gerechten Ausgleichs der Lasten.

22. Angesichts der durch die Gesetzgebung erfolgenden interventionistischen Gestaltung verlagern sich die Garantien der Freiheit, des Rechtsstaates und der Gleichheit in den Bestand der Verfassung. Grundrechte, institutionelle Garantien und Leitgrundsätze der Verfassung bilden die Schranken. Im deutschen Grundgesetz kommen namentlich in Betracht die Art. 2, 9, I2 und I4 GG.

a) Art. 2 schiitzt in der Persönlichkeit auch die freie wirtschaftliche Entfaltung, mithin die Wettbewerbsfreiheit. Allerdings unterliegt diese Freiheit wie alle grundrechtlichen Freiheiten einer grundsätzlichen Gemeinschaftsbezogenheit und gewissen aus der Entwicklung einzelner Grundrechte immanent folgenden Schranken. Der Begriff der ,verfassungsmäßigen Ordnung" ist nicht beschränkt auf die Kernsätze der Verfassungsordnung im Sinne des Verfassungsschutzes, sondern umgreift die in der Verfassung niedergelegten Grundsätze der wirtschaftlichen und sozialen Gestaltung. Andererseits bedeutet er nicht Aufrechterhaltung des bestehenden Rechts auf Einzelgebieten, sondern normative Verweisung auf die Wert- und Rangordnungen der Verfassung, in demen auch die ",Rechte anderer" höheren Schutz genießen können als die volle individuelle Entfaltung.

b) Art. 9 Abs. III GG sichert mit umfassender Wirkung das soziale Vereinigungsrecht, ohne indes die negative Vereinigungsfreiheit und das Streikrecht zu regeln. Es privilegiert auch nach der Richtung der Beeinflussung sozialer und wirtschaftlicher Machtbildung die in ihm genannten Vereinigungen.

c) Die Freiheit der Berufswahl findet ihre Grenzen an der aus Art. 2 Abs. I und der immanenten Ordnung der Berufsordnung abzuleitenden Gestaltung. fester und eingeführter Berufsbilder. Aus Gründen der öffentlichen Sicherheit und Gesundheit, aber auch aus einem ïberwiegenden offentlichen Interesse an einem Berufe können nicht nur Beschränkungen der Ausübung, sondern auch des Berufseintritts und der gesamten Berufsgestaltung gerechtfertigt werden. 
d) Die Bedeutung der Eigentumsgarantie liegt trotz der starken Betonung der Sozialpflichtigkeit in der institutionellen Sicherung und in der Bindung der sozialen Umgestaltung an den Grundsatz rechtsstaatlichen Verfahrens und der Entschädigung. Diese Grundsätze dürften auch für andere $\mathrm{Ge}$ biete (Auferlegung von Leistungspflichten ohne Vergütung) wie für die Ausformung des Grundsatzes des Ausgleichs offentlicher Lasten von Bedeutung sein.

\section{Rechtsschutz}

23. Der bestehende Rechtsschutz durch die verwaltungsrechtliche Generalklausel sichert ausreichend gegen unmittelbare Eingriffe in individuelle Rechtspositionen, wobei freilich der Begriff des subjektiven Rechts einer Fortbildung unter dem Gedanken des schutzwiirdigen Interesses bedarf.

24. Gegen die Gesetzgebung und die generellen Anordnungen gewährt die abstrakte Normenkontrolle und die Verfassungsbeschwerde einen begrenzten Schutz, insbesondere in Verbindung mit grundrechtlichen Bestimmungen.

25. Für das Gebiet der wirtschaftlichen Intervention wird im besonderen der Grundsatz der Gleichheit wichtig. Er wird hier namentlich in der Richtung auf die Gleichheit auch gruppenweiser Lösungen, auf den neuerdings auch im französischen Recht entwickelten Gedanken der Lastengleichheit und auf die Unzulässigkeit individueller wie gruppenweiser Privilegierungen und Belastungen zu entreickeln sein.

26. So erwägenswert die exweiterte Zulassung von Verbänden und Gruppen zum Rechtsschutz ist, so darf nicht außer Acht gelassen werden, daß die Gerichte nicht zu wirtschaftspolitischen Entscheidungen im Wege der Auslegung unbestimmter Formeln berufen sein können und daß zu einem System voller oder teilweiser Wirtschaftsfreiheit ein Raum des Risikos und der Anpassung gehört.

27. Für den Schutz gegen staatliche Einwirkungen wird neben der zunehmend in ihren Maßstäben objektivierten Amtshaftung vor allem der Gedanke des finanziellen Ausgleichs (öffentlichrechtliche Entschädigung) von Bedeutung sein.

28. In weiterem Sinne liegt ein Schutz der Wirtschaft in einer Erweiterung ihrer Mitwirkung an den staatlichen Entscheidungen. Hier kommen neben den in ihrer Anwendung begrenzten Formen eigentlicher körperschattlicher Selbstverwaltung die Möglichkeiten der Beteiligung und Mitreirkung durch Anhörung, Teil- 
nahme an beratenden und entscheidenden Gremien, Betrauung von Verbänden und Kammern mit öffentlichen Aufgaben in Betracht. Bei den grundlegenden Fragen der Teilnahme der wirtschaftlichen und sozialen Verbände an der Gestaltung der Wirtschafts- und Sozialpolitik reicht die Frage in den Kreis der Verfassung hinein. Hier wird das Verhältnis der politischen Parteien zu den Interessengruppen und auBerparlamentarischen Kräften ebenso berührt wie das Problem sachlicher und rechtlicher Grenzen politischen Einflusses der Verbände. 


\title{
Die staatliche Intervention im Bereich der Wirtschaft
}

\author{
Rechtsformen und Rechtsschutz
}

2. Mitbericht von Professor Dr. Adolf Schüle, Heidelberg

A. Internationale Wirtschaftslenkung und nationale Lenkung der Außenwirtschaft ${ }^{1}$ )

\section{I}

Es wäre unvollkommen, wollte man die hoheitliche Lenkung der Wirtschaft nur als innerstaatliche Erscheinung, mur im Rahmen des Staates, beschränkt auf sein Gebiet und abgestellt auf das Verhältnis seiner Staatsgewalt zu seiner Wirtschaft, sehen. Wirtschaft ist, vor allem in ihrem heute wieder erreichten Zustand, nirgends nur Volkswirtschaft, sondern immer zugleich auch irgendwie und irgendwo Weltwirtschaft. Die wechselseitige Verflochtenheit zwischen den Nationalwirtschaften und den weltwirtschaftlichen Abläufen ist in den letzten hundert Jahren ungeheuer fortgeschritten. Andererseits stehen sich auf der völkerrechtlichen Ebene die einzelnen Staaten nicht in Isolierung gegenüber. Dies gilt besonders auch bezüglich ihrer wirtschaftlichen Beziehungen und deren rechtlicher Ordnung. Die Staaten unserer Welt haben sich im Laufe der Zeit zu einer unübersehbaren Zahl von $z$ weiseitigen Abkommen, auBerdem, vor allem seit dem letzten Krieg, zu mannigfachen weltumspannenden Vereinbarungen und darüber hinaus zu einer ganzen Reihe von internationalen bzw. überstaatlichen Organisationen zusammengefunden. Durch sie werden zunächst die äußeren $\mathrm{Be}-$ ziehungen zwischen den einzelnen staatlich organisierten Wirtschaften berührt. Es werden durch sie aber auch rechtliche und wirtschaftliche Wirkungen ausgelöst, welche die staatlichen Grenzen sozusagen von außen her durchdringen und in der Folge auch innerhalb des Staates Einflüsse auf die Wirtschaft ausüben tief hinein bis zum letzten Betrieb. Es gibt daher heute schon einen beträchtlichen internationalen Dirigismus. Zum Teil handelt es sich dabei allerdings um innerstaatliche Maßnahmen, die nur durch einen außerstaatlichen Lenkungsmechanismus veranlaßt sind.

Die damit angeschnittenen Probleme sind, jedenfalls was die Nachkriegsentwicklung betrifft, juristisch noch wenig erforscht,

1) Dieser Abschnitt ist in nahezu gleichlautender Fassung in DOV. 1952, S. 615 ff. (W. Kohlhammer Verlag) zum Vorabdruck gekommen. 
und $z$ war weder vom Völkerrecht ${ }^{2}$ ), noch vom internationalen Verwaltungsrecht oder vom Privatrecht. Die wirtschaftswissenschaftliche Betrachtung ist schon weiter gediehen. Für die publizistische Rechtswissenschaft liegt hier noch ein weites Feld offen, freilich auch ein sehr schwieriges. Wir müssen uns vorliegend darauf beschränken, das Thema des internationalen Dirigismus lediglich herauszustellen und einige wichtigere Erscheinungen auf diesem Gebiet anzuführen.

Sieht man von den Vereinten Nationen selbst $a b$, so ist vor allem auf die International Trade Organization (ITO) hinzuweisen. Sie ist zwar noch nicht errichtet, dürfte aber später in diesem Zusammenhang eine wesentliche Rolle spielen. Der sogenannten „Weltbank" sowie dem Internationalen Währungsfonds, beide gleichfalls Unterorganisationen der UN, ist die Bundesrepublik kürzlich beigetreten ${ }^{3}$ ); Geld und Kredit unseres Landes werden davon nicht unberührt bleiben. Die bedeutendste Erscheinung auf diesem Gebiet stellt gegenwärtig die Pariser Organisation über die wirtschaftliche Zusammenarbeit in Europa dar (OEEC) ${ }^{4}$ ), deren vollberechtigtes Mitglied die Bundesrepublik schon längel ist. (Bis vor kurzem) Mitwirkung bei der Festsetzung unserer Stahlquote in Uberschreitung des besatzungsrechtlichen Plafonds, Bereitstellung von Investitionsmitteln für einzelne größere Unternehmen, Ausmaß der Liberalisierung unseres Außenhandels das sind nur wenige Beispiele, welche die Einwirkung der OEEC auf das deutsche Wirtschaftsleben illustrieren. Kaum weniger wichtig ist die Europäische Zahlungsunion (EZU) ${ }^{5}$ ) mit ihrem Währungsausgleich zwischen den Mitgliedsstaaten. Marshallplan und ECA, heute zwar im wesentlichen der Vergangenheit angehörend und Westdeutschland gegenüber nicht ohne „Besatzungseinschlag", dürfen ebenfalls nicht vergessen werden. Das Internationale Weizenabkommen (IWA) mit seinem Weizenrat ${ }^{6}$ ) dient zunächst der Steuerung des internationalen Weizenmarktes, aber wer als deutscher Importeur im Rahmen des Abkommens einführt, bedarf einer besonderen behördlichen Einkaufsermächtigung mit einer IWA-Kontrollnummer ${ }^{7}$ ). Von der in Entstehung begriffenen Internationalen Zuckerkonvention wird ähnliches zu

2) Eine ausgezeichnete Einführung hierzu bietet Stodter, Völkerrecht und Weltwirtschaft. Ztschr. f. ausl. off. Recht u. Völkerrecht, Bd. XIII, S. 67 ff. - Die neuen Schriften des Frankfurter Instituts für Internationales Wirtschaftsrecht dürften hier eine Lücke ausfüllen.

3) Gesetz vom 28. 7. 1952, BGBl. II, S. 637 ff.

4) Vgl. Der Europäische Wirtschaftsrat in Paris und seine Bedeutung für die Bundesrepublik, herausgeg. vom Bundesmin. für den Marshallplan.

5) Gesetz vom I4. 3. I95I, BGBl. II, S. 31.

9) Gesetz vom 12.6. 1950, BGB1., S. 231.

7) BAnz. 1952, Nr. I34, S. I. 
gelten haben. $\mathrm{DaB}$ schließlich neuerdings die Montan-Union ${ }^{8}$ ) und künftig auch eine etwaige Europäische Agrar-Union die stärksten Einwirkungen - und zwar auch solche direkter, nicht erst durch die deutsche Staatsgewalt $z \mathfrak{u}$ transformierender Art auf die in Frage kommenden Wirtschaftszweige und darüber hinaus äußern werđen, liegt auf der Hand. Die „Verfassung der Weltwirtschaft" unserer Zeit scheint an den kritischen Punkten nicht ohne internationale Lenkungsmaßnahmen auszukommen.

Das gedankliche Gegenstück zu dem eben Behandelten bilden die $\mathrm{MaB}$ nahmen des Staates, durch die er, sei es aus eigenem Antrieb, sei es auf Grund völkerrechtlicher Verpflichtungen, seinen Außenhandel reguliert. Hierfür kommen, was gegenwärtig die Bundesrepublik anbetrifft, vor allem vier gro Be Instrumente in Frage: die Einfuhrzölle, die Handelsverträge, die Devisenbewirtschaftung und schließlich die Ein- und Ausfuhrregelung. Theoretisch kann jeder dieser Komplexe gesondert erfaßt werden; praktisch sind sie aber alle derart miteinander verzahnt, daß, jedenfalls wirtschaftspolitisch, eher von einem Ganzen gesprochen werden muß - vergleichbar einem Tisch mit vier Beinen, von denen keines fehlen darf, soll der Tisch nicht umfallen.

$\mathrm{DaB}$ die Festsetzung eines Einfuhrzolls für eine bestimmte Ware eine staatliche LenkungsmaBnahme darstellt, sollte keinem Zweifel unterliegen. Ob Prohibitivzoll oder Einfuhrverbot - die Wirkung ist beidemal annähernd gleich. Das weite Thema der Zölle kann hier aber vernachlässigt werden, weil Zölle seit jeher ein geläufiges Steuerungsmittel der staatlichen Handelspolitik gewesen, also für die moderne Staatsintervention gegenüber der Wirtschaft nicht typisch sind. Außerdem bietet das neue deutsche Zollrecht in rechtlicher Hinsicht nichts grundsätzlich Neues. And ers liegt es bei den Handelsverträgen. Die Bundesrepublik hat gegenwärtig wieder mit etwa 50 auswärtigen Staaten vertraglich geordnete Handelsbeziehungen. Ihr Inhalt zerfällt im großen gesehen in zwei Teile. Einmal in die sozusagen klassischen Bestandteile; dazu gehören Meistbegünstigung, Niederlassungsrecht, Rechtsverfolgung, Gleichbehandlung gewerblicher Schutzrechte u. a. Jüngeren Datums und die gegenwärtige Situation beleuchtend sind dagegen diejenigen Klauseln, in denen die Einhaltung der beiderseitigen Einfuhr-, Ausfuhr- und Devisenbestimmungen zugesagt wird, und sodann vor allem die Festsetzung von Handels-

-) Insbesondere deren Hohe Behorde, vgl. etwa Mosler, Vertrag über die Europåische Gemeinschaft für Kohle und Stahl, Ztschr. f. ausl. off. Recht u. Volkerrecht, Bd. XIV, S. Iff. (40), sowie H. Kra us, Betrachtungen über die rechtl. Struktur der Europäischen Gemeinschaft für Kohle und Stahl, in: Rechtsprobleme in Staat und Kirche, I952, S. 189ff. 
kontingenten, abgestellt auf bestimmte Warengruppen sowie auf Werte. Durch die Kontingente werden die Ströme des Warenverkehrs zwischen der Wirtschaft des Bundesgebiets und derjenigen des betreffenden anderen Landes nach Volumen und Richtung in bestimmte Bahnen gelenkt. In der Gesamtheit dieser Handelsverträge offenbart sich die von deutscher Seite vorgenommene weltwirtschaftliche Steuerung unseres Außenhandels. Allerdings ist in den letzten Jahren durch die von der OEEC ausgehende Liberalisierung ein fühlbarer Abbau der zwischenstaatlichen Kontingentsbeschränkungen eingetreten, jedoch nur bezüglich bestimmter Warenkreise und mit räumlich begrenztem Geltungsbereich. Liberalisierung bedeutet außerdem nur Wegfall der mengenmäßigen Beschränkungen im Verhältnis von Staat zu Staat, nicht auch Befreiung von den Fesseln der Ein- und Ausfuhrregelungen oder Devisenbestimmungen für den einzelnen Handeltreibenden.

Das für Westdeutschland geltende Devisengesetz ist noch immer besatzungsrechtlicher Natur ${ }^{9}$ ), wenn auch seine Ausführung deutschen Stellen übertragen ist. Es trägt die bezeichnende Uberschrift ,Devisenbewirtschaftung und Kontrolle des Güterverkehrs". Da es einen von dem Güteraustausch losgelösten Geldund Kapitalverkehr über die Grenzen der Bundesrepublik hinaus in nennenswertem Umfang noch nicht wieder gibt, läßt sich schon aus der Gesetzesbezeichnung ablesen, daß das Schwergewicht unserer gegenwärtigen Devisenbewirtschaftung bei dem Ein- und Ausfuhrhandel liegt. Sie hat von diesem her ihre Impulse und ihren Zuschnitt erhalten. Der Kern der Devisenbewirtschaftung liegt in der Erfassung der anfallenden Ausfuhrerlöse und der Bereitstellung der für die Bezahlung unserer Einfuhren erforderlichen Gegenwerte, jeweils in fremden Währungen.

Auch das Besatzungs-Devisengesetz ist, wie früher unser deutsches, ein großes Verbotsgesetz mit dem Vorbehalt genereller oder spezieller Ausnahmen. Die Ein- und Ausfuhrregelungen stellen daher nichts anderes dar als Ausnahmen, die man gemacht hat, um dem deutschen Importeur oder Exporteur Geschäftsabschlüsse mit seinen Partnern im Ausland rechtmäßig zu ermöglichen. Die beiden grundlegenden Runderlasse über die Außenwirtschaft ${ }^{10}$ ) stützen sich daher auch ausdrücklich auf das Devisenrecht.

Was die Ausfuhr betrifft, so ist zwischen genehmigungspflichtigen und nicht-genehmigungspflichtigen Waren zu unterscheiden. Der Kreis der ersteren ist bestimmt durch ein Gemisch von be-

9) MRG. Nr. 53 (Neufassung vom 19. 9. 1949, BAnz. vom 27. 9. 1949). Einen Uberblick gibt neuestens Fing el, JZ, 1952, S. 518ff., 549ff. mit weiteren Nachweisen.

10) Nr. 28/51 vom 20.9. 1951 (mit nachfolgenden Änderungen) und Nr. $56 / 51$ vom 15.12 .1951 . 
satzungsrechtlichen Geboten und innerdeutschen Notwendigkeiten. Wer solche Waren ausführen will, bedarf einer Lieferungsgenehmigung, die von der Bundesstelle für den Warenverkehr der gewerblichen Wirtschaft bzw. der Außenhandelsstelle für Erzeugnisse der Ernährung und Landwirtschaft zu erteilen ist. Gegen die Versagung einer solchen Genehmigung war schon bisher die Möglichkeit einer verwaltungsgerichtlïchen Klage gegeben ${ }^{11}$ ), außerdem Gegenvorstellung und Verwaltungsbeschwerde. Da die Erteilung einer Lieferungsgenehmigung aber vollauf in das Ermessen der genannten Behörden gestellt ist und nicht einmal die unbedingten Verbote der Besatzungsmacht bekanntgemacht sind, hätte die Einlegung eines der genannten Rechtsbehelfe in der Praxis kaum Aussicht auf Erfolg. - Von dem Vorigen abgesehen ist sodann bei allen Ausfuhrgeschäften den Zollstellen die Prüfung der Zulässigkeit der Ausfuhr und den Außenhandelsbanken die Uberwachung des Zahlungseinganges übertragen. Interessanterweise finden wir an dieser Stelle reine Privatinstitute, wenn auch auf Grund besonderer Betrauung, mit hoheitlichen Befugnissen für die $\mathrm{Zwecke}$ der Devisenbewirtschaftung befaßt ${ }^{12}$ ).

Bei den Einfuhren ist die behördliche Kontrolle noch stärker ausgebildet. Zwar besteht auch hier grundsätzlich Vertragsfreiheit, aber der Kaufvertrag mit dem ausländischen Lieferanten darf erst abgeschlossen werden, wenn eine Einkaufsermächtigung erteilt ist: Weiterhin bedarf es für das Verbringen der Ware in das Inland einer Einfuhrbewilligung und für ihre Bezahlung einẹ Zahlungsbewilligung. Alle drei Hauptvorgänge, die eine Einfuhr mit sich bringt, sind also je besonders genehmigungspflichtig. Hinzu kommt das System der behördlichen "Ausschreibungen". Abgesehen von dem liberalisierten Bereich, kann der Kaufmann hiernach nur dann und nur insoweit im Ausland einkaufen, als die Behörden im Einzelfall die vorhandenen Einkaufsmöglichkeiten bekanntgegeben haben. Nur in diesem Rahmen ist ihm der Zugang zu den ausländischen Märkten offen. Schließlich darf heute nicht jedermann Einfuhrgeschäfte tätigen, sondern nur die wirklichen Importeure. Die Einfuhrkontrolle bewirkt also eine betriebliche Auslese und läuft damit praktisch auf eine Zulassung zum Importhandel hinaus.

Bei der Vielzahl der für die Abwicklung eines Einfuhrgeschäftes erforderlichen Genehmigungen könnte man sich vorstellen, daß hier das Rechtsschutzbedürfnis für den Fall der Versagung einer

14) Vgl. Eyermann-Frohler, Verwaltungsgerichtsgesetz, Komm., r950, S. 74f. (Ich muB damit meine Ausführungen in DOV. 1952, S. 616/617, richtigstellen.) Nach dem neuen Gesetz über das Bundesverwaltungsgericht vom 23. 9. 1952 (BGBl. I, S. 625) ist die Klagemöglichkeit eindeutig klargestellt.

19) Dazu neuerdings E. R. Haber, DVBl. 1952, S. 458. 
der Genehmigungen besonders dringend ist. Das Gegenteil ist aber richtig, wenn auch aus ungewöhnlichen Gründen. Wird nämlich etwa eine Einkaufsermächtigung nicht erteilt, so ist ein Rechtsmittelverfahren für den Importeur ohne jedes Interesse, weil die konkreten Marktchancen längst verpaßt sind, bis das Verfahren, gleichviel mit welchem Ergebnis, zum Ende käme.

\section{B. Eingriffe der Besatzungsmächte}

Unsere Wirtschaft ist in den hinter uns liegenden Jahren nicht nur einer gewissen Lenkung durch deutsche Instanzen, sondern in sehr großem Umfang auch Eingriffen seitens der Besatzungsmächte ausgesetzt gewesen. Es erscheint nicht möglich, diese Seite einfach als anormal zu übergehen ${ }^{13}$ ). Wie auf zahlreichen anderen Gebieten, so findet sich auch auf dem des Verhältnisses zwischen Staat und Wirtschaft jenes unsichere $\mathrm{Ge}$ menge zwischen deutschen Maßnahmen und solchen der Besatzungsmächte, ausgeübt auf Grund der Besatzungshoheit, und diese Lage ist sowohl für die Gesamtsituation als auch für das Recht unseres innerstaatlichen Lebens seit dem Zusammenbruch typisch. Das macht auch eine rechtliche Analyse dieser Situation und ihrer Einzelfragen vielfach so schwierig.

Maßnahmen einer Besatzungsmacht gegenüber einer ihr fremden Wirtschaft unterscheiden sich wesentlich von den ,gewöhnlichen" Lenkungsmaßnahmen einer Staatsführung gegenüber der eigenen Wirtschaft. Diese haben überwiegend interne wirtschaftspolitische Zielsetzungen. Mit jenen dagegen wird beabsichtigt, bestimmte außenpolitische Zwecke, wie sie mit der Besatzung im ganzen verfolgt werden, zu erreichen. Sie sind also Ausfluß nicht einer innerstaatlichen Wirtschaftspolitik, sondern der Außenpolitik, und zwar in dem besonderen Gewande der Besatzungspolitik und auf dem wirtschaftlichen Feld des besetzten Landes. Bei strenger Abgrenzung gehört also dieses Kapitel nicht mehr zum Thema. Wenn es gleichwohl angeschnitten und mit einigen Hinweisen illustriert wird, so wegen der schon erwähnten rechtlichen Gemengelage. Echte besatzungsrechtliche Eingriffe wechseln ab oder treffen zusammen - letzteres, entsprechend dem Abbau der Besatzungsbefugnisse, mit wachsender Hä̈ufigkeit - mit nach Form und Inhalt deutsch-rechtlichen Regelungen, die durch Besatzungsanordnungen entweder geboten oder veranlaßt sind. Außerdem darf nicht verkannt werden, daß gerade diejenigen Wirkungen, die von Maßnahınen der Besatzungsmächte auf unsere Wirtschaft ausgegangen sind, ganz besonders vielfältig und tiefgreifend waren.

19) In gleichem Sinne Eichler, Wirtschaftsrecht, 1950, wie seine Ausführungen auf S. I2 und 69 zeigen. 
Mit Beschlagnahmen, Requisitionen und Demontagen hat es angefangen. Die gewerbliche Tätigkeit konnte nach dem Zusammenbruch nur auf Grund besatzungsrechtlicher „Permits" begonnen werden. Zahlreiche Produktionsverbote wurden erlassen, die allerdings mit der Zeit aufgelockert und durch die Möglichkeit von deutschen Ausnahmegenehmigungen durchbrochen wurden ${ }^{14}$ ). Mengenmäßige Beschränkungen, wie z. B. bei der Stahlerzeugung, sind erst kürzlich wieder aufgehoben worden. Besonders bedeutsam waren die Entflechtungsmaßnahmen bei Kohle, Eisen und Stahl, Großbanken, Film und IG-Farbenindustrie, ebenso die Kartellverbotsgesetze. Der Außenhandel unterlag längere Zeit ausschließlich besatzungsrechtlicher Regelung und wurde durch die sattsam bekannte JEIA mehr stranguliert als reguliert. $\mathrm{DaB}$ unser heutiges Devisenrecht noch immer besatzungsrechtlicher Natur ist, wurde schon bemerkt. Zwangsexporte in Kohle und Schrott vervollständigen das nicht gerade erfreuliche Gesamtbild. Schließlich sind zur Deckung des enormen Besatzungsbedarfs zahllose „mandatorische Aufträge" ergangen, die mit Hilfe von Vorrangverpflichtungsscheinen notfalls erzwungen werden konnten ${ }^{15}$ ). Dieses System und manches andere, was soeben erwähnt wurde, wird hoffentlich bald der Vergangenheit angehören.

Zusammenfassend kann gesagt werden, da $B$ die Eingriffe der Besatzungsmächte in unsere Wirtschaft diese nicht etwa nur an gewissen Stellen beeinflußt, sondern sie an entscheidenden Punkten wesentlich umgestaltet haben. Den hierbei gebrauchten Rechtsformen kann im einzelnen nicht nachgegangen werden. Sicher ist nur, da $\beta$ nirgends, auch nicht in der jüngeren Zeit, förmliche Rechtsschutzmöglichkeiten für die betroffenen Unternehmen gegeben waren. Wenn das auch im Hinblick auf das Wesen eines Besatzungsregimes bis zu einem gewissen Grade verständlich erscheint, so ist hier doch, insbesondere nach dem Erlaß des Besatzungsstatuts, ein echtes Bedürfnis nach rechtsstaatlicher Sicherung gröblich vernachlässigt worden.

\section{Hauptkapitel der staatlichen Intervention}

\section{I.}

Unter den Grundprinzipien, die für unsere gegenwärtıge Wirtschattsordnung kennzeichnend sind, stehen die Gewerbefreiheit und die Wettbewerbsfreiheit an erster Stelle. Es ist darzulegen, welche Gestalt das heutige Recht ihnen gegeben hat.

19) Als Beispiel aus neuerer Zeit vgl. die Anordnung Chemie Nr. 1/52 vom 19. 4. 1952, BAnz. Nr. 97.

15) Vgl. VO. zur Sicherung des Besatzungsbedarfs vom 21. 3. I951, BAnz. Nr. 59, und vom 5. ro. 1951, BAnz. Nr. I94. 
I. Was zunächst die Gewerbefreiheit betrifft, so besteht eine Art von quantitativer Relation zwischen ihr und dem staatlichen Interventionismus. Je weiter sie ausgebildet, desto geringer der Interventionismus - bzw. umgekehrt. Einschränkungen der $\mathrm{Ge}$ werbefreiheit sind nämlich in der Regel interventionistischen $\mathrm{Ur}$ sprungs. Das gilt vor allem von dem eigentlichen Widerpart der Gewerbefreiheit, den Beschränkungen in der Zulassung. Gewerbefreiheit und Zulassungsverbot sind jedoch nirgendwo in absoluter Weise verwirklicht. Vielmehr stellen sie die beiden äußersten Pole dar, zwischen denen der Staat den Zutritt zur Wirtschaft in mehr oder minder großem Umfang freigibt oder auch absciınürt. Daher die naheliegende Frage, wie es bei uns heute mit der Zulassungsfrage bestellt ist.

Ein historischer Rückblick zeigt eine sehr wechselvolle Rechtsentwicklung ${ }^{16}$ ). Bis 1933 - trotz zahlreicher Zulassungsbeschränkungen in Sondergesetzen ${ }^{17}$ ) - Aufrechterhaltung des in der Mitte des vergangenen Jahrhunderts erreichten, sich in der Folge tief einwurzelnden Freiheitsbestandes. Die zweite Periode bildet die nationalsozialistische Gesetzgebung mit ihren umfangreichen Gewerbesperren; ihre Zulassungsvorbehalte bedeuten wenig gegenüber der grundsätzlichen Sperrwirkung ${ }^{18}$ ). Nach dem Kriegsende löst sich das Zulassungsrecht in zahlreiche partikulare Rechtsvorschriften auf. Zunächst greift Besatzungsrecht ein, das, unter sich wieder verschieden, in den „Permit"-Verfahren der ersten Zeit seinen Nieđerschlag findet. Es folgen die Lizenzierungsgesetze der deutschen Länder $\longrightarrow z \mathrm{u}$ verschiedenen Zeitpunkten und in den Einzelheiten voneinander abweichend; doch werden die rechtspolitischen Linien aus der Zeit vor I945 im großen und ganzen fortgesetzt, vor allem hinsichtlich der Bedürfnisprüfung, allerdings mit dem Unterschied, daB von den Zulassungsmöglichkeiten jetzt ein sehr viel stärkerer Gebrauch gemacht wird. Die letzte Periode beginnt mit der Proklamierung einer nahezu vollständigen Gewerbefreiheit durch die US-Militärregierung an der Wende r948/49. Sie beseitigt in der amerikanischen Zone die Zulassungspflicht praktisch überall und wirkt auch auf die beiden anderen Westzonen hinüber, wo nunmehr die Bedürfnisprüfung ebenfalls beseitigt wird. Das geschieht freilich auch auf Grund des inzwischen in Kraft getretenen Art. I2 (I) $\left.\mathrm{BGG}^{19}\right)$. - Gegenwärtig muß die Lage als einigermaßen chaotisch

16) Hierzu Sieg, Das Recht der Gewerbezulassung, in: Gesetz und Recht, Hamburg 1949, S. $256 \mathrm{rff}$.

17) Landmann-Rohmer, Komm. z. GewO., Io. Aufl., I952, Bd. I. S. $84 \mathrm{f}$.

18) H. Kra use, Der deutsche Volkswirt, 1935, S. 2173, hat - für die damalige Zeit - den $\S$ I GewO. als eine "ehrwürdige Ruin " bezeichnet.

19) Landmann-Rohmer a.a.O., S. 7o. 
bezeichnet werden. Die verschiedenen „Rechtsschichten" lagern übereinander und erschweren die Rechtsfindung im Einzelfall ebenso wie die Feststellung des Grundsätzlichen; die Unsicherheit über den Gehalt der vorerwähnten Verfassungsbestimmung trägt dazu bei. Nur soviel erscheint sicher, daß die letzte Periode wieder einen Abbau der Zulassungsbeschränkungen gebracht hat und damit eine deutliche Tendenz zur Wiedergeburt der überkommenen Gewerbefreiheit. Der Bundesgesetzgeber wird nunmehr die Rechtsvereinheitlichung vornehmen und die richtige Mitte zwischen Freiheit und Beschränkung finden müssen. Der Generalvertrag gibt ihm die Kompetenz dazu wieder zurück, erlaubt jedoch keine Beeinträchtigung des nach I945 erlangten „Besitzstandes" der seit dieser Zeit zugelassenen Betriebe ${ }^{20}$ ).

Ungeachtet dieser Rechtsverwirrung sei wenigstens auf zwei Einzelheiten hingewiesen, die uns für die juristische Seite des Zulassungsproblems wichtig erscheinen. Wir sehen zunächst in der Einführung eines neuartigen Rechtsinstituts, der generellen Kontingentierung von Gewerbegenehmigungen, einen grundsätzlich bemerkenswerten Vorgang. Es bedarf nicht nur der einzelne Güterfernverkehrsunternehmer einer individuellen $\mathrm{Ge}$ nehmigung, um seinen Betrieb beginnen zu können, sondern solche Genehmigungen dürfen seit einiger Zeit auch von den zuständigen Behörden nur insoweit erteilt werden, als sie im Rahmen der vori dem Bundesverkehrsminister festgesetzten und auf die Länder aufgeteilten Höchstzahlen der Kraftfahrzeuge bleiben ${ }^{21}$ ). Hier wird also mit dem Mittel der Gewerbezulassung auf eine sehr massive Weise die Gesamtkapazität des betroffenen Wirtschaftszweiges gedrosselt.

Das Zweite betrifft die Bedürfnisfrage, die ja den Kern der ganzen Zulassungsproblematik bildet. Es ist bekanntlich sehr umstritten, in welchem Umfang es dem Gesetzgeber nach Art. I2 (I) BGG erlaubt ist ${ }^{22}$ ), als Voraussetzung für die Zulassung zu einem Gewerbe das Vorliegen eines wie immer gearteten Bedürfnisses zu machen. Dieses weitverzweigte Problem kann hier nicht im einzelnen erörtert, nur eine Frage soll aufgeworfen werden, nämlich die, ob es sich bei diesem „Bedürfnis" wirklich um einen unbestimmten Rechtsbegriff handelt, wie das häufig gelehrt wird. Die Bedürfnisfrage hat, wenn wir recht sehen, ihren modernen Ursprung im Gaststättenrecht. Es dürfte auch noch möglich sein,

30) Vgl. das Zusatzabkommen „Vertrag zur Regelung aus Krieg und Besatzung entstandener Fragen", Teil II, Art. Io.

21) $\S 7$ des Güterfernverkehrs-Anderangsgesetzes vom 2. 9. 1949, WiGBl. S. 306, i. d. Fassung vom 27. 2. 1952, BGBl. I, S. 122 (und vO. über die Hochstzahlen der Genehmigungen für den Güterfernverkehr vom 17. 7. 1952 , BAnz. Nr. 138) -, abgeløst durch $\$ 9$ des Güteikraftverkehrsgesetzes vom 17. 10. 1952, BGBl. I S. 697 ff.

is) Landmann-Rohmer a.a.O. S. 24 f. 
im Bereich einer Stadt oder eines Landbezirks einigermaßen objektiv zu beurteilen, ob, vom Publikum aus gesehen, genügend oder zu wenig Schankstätten vorhanden sind. Es ist aber ausgeschlossen, auch nur einigermaßen überzeugend darzutun - und das gehört doch $z u$ einem Rechtsbegriff - ob z. B. neben sieben süddeutschen Knopffabriken noch eine achte zur Versorgung des Bedarfs erforderlich ist. Mit anderen Worten: es scheint uns eine Fiktion zu sein, hier noch von einem, wenn auch unbestimmten Rechtsbegriff $\mathrm{zu}$ sprechen. Soweit die Bedürfnisfrage als eine Rechtsfrage qualifiziert wird, hat das seinen wahren Grund in dem Bestreben, den verwaltungsgerichtlichen Schutz sicherzustellen. Das mag verständlich sein, aber man sollte es dann auch offen anerkennen. $\mathrm{DaB}$ im übrigen der Verwaltungsrichter nicht in der Lage ist, wirtschaftlich derart intrikate Fragen, wie sie eine Gewerbezulassung unter der Voraussetzung eines Bedürfnisses mit sich bringt, zuverlässiger zu entscheiden als die Verwaltungsbehörde, liegt für uns auf der Hand ${ }^{23}$ ).

Grundsätzlich ist es richtig, auch die Gewerbezulassung unter die Mittel der staatlichen Wirtschaftslenkung zu rechnen. Aber man muß im Einzelfall sehr genau prüfen, weil auch andere Motive, insbesondere solche gewerbepolizeilicher Art, mit hineinspielen, die mit Wirtschaftssteuerung nichts zu tun haben. In der gegenwärtigen Diskussion treten die gewerbepolizeilichen Gesichtspunkte wieder stärker in den Vordergrund; daneben solche berufspolitischer Art, wie sie sich vor allem in den Erfordernissen der Sachkunde und der persönlichen Zuverlässigkeit des Antragstellers dokumentieren. $\mathrm{Ob}$ die Gewerbezulassung ein besonders wirksames Mittel der Wirtschaftssteuerung darstellt, muß bezweifelt werden. Sie ist $z \mathrm{u}$ roh, weil sie zu wenig auf die besonderen Branchenverhältnisse abstellt und nur eine sehr allgemeine quantitative Beschränkung zur Folge hat. In der Praxis hat sie sich als wenig tauglich erwiesen. Sicherlich ist jedem Zulassungsverfahren eine gewisse abweisende und ebenso auch eine „FilterWirkung" eigen. Sie dürfen aber nicht zu hoch eingeschätzt werden. Wirtschaftspolitisch ist jedenfalls die Zulassungsfrage im Zusammenhang des staatlichen Interventionismus nicht annähernd so bedeutsam, wie sie zumeist hingestellt wird.

2. Weiter gehört die Freiheit des Wet tbewerbs zwischen den Gewerbetreibenden zu den wesentlichen Prinzipien unserer gegenwärtigen Wirtschaftsverfassung. Wer in der Wirtschaft tätig ist, darf dabei seine Kräfte, sei es in Werbung, Preisstellung, Warenqualität oder in anderer Hinsicht, vom Staate ungehindert mit seinen Konkurrenten messen, sofern er sich nur lauter im Sinne des gesetzlichen Wettbewerbskodexes verhält und auch nicht gegen

13) In gleichem Sinne wie oben neuerdings Giese, JZ. 1952, S. 588. 
sonstige Gesetze verstößt. Die Freiheit des Wettbewerbs ist nicht verfassungsrechtlich gewährleistet, auch nicht durch Art. 2 Abs. I BGG, denn die freie Entfaltung der Persönlichkeit und die freie Entfaltung des Geschäftes sind etwas grundsätzlich Verschiedenes. Die Wettbewerbsfreiheit gilt vielmehr lediglich als wirtschaftspolitische Maxime und hat als solche in programmatischer Form ihren gesetzgeberischen Niederschlag gefunden ${ }^{24}$ ).

Die Rechtslage ist hier, anders als bei den Einschränkungen der Gewerbefreiheit, einigermaßen geordnet. Sie ist aber gleichwohl in der Schwebe. Im Augenblick gelten noch die Kartellgesetze der Besatzungsmächte ${ }^{25}$ ), die, bestimmt durch die nordamerikanische Rechtsauffassung, von dem absoluten Verbot jeglicher Kartelle beherrscht sind und deren Ursprünge bis in das Potsdamer Abkommen zurückverfolgt werden können ${ }^{26}$ ). Die Besatzungsbestimmungen sollen nach Inkrafttreten des Generalvertrages durch ein entsprechendes Bundesgesetz abgelöst werden. Der Entwurf eines solchen „Gesetzes gegen Wettbewerbsbeschränkungen" liegt vor. Mit seiner Verabschiedung, und zwar vermutlich in den Grundsätzen unverändert, darf gerechnet werden.

Man hat die Frage aufgeworfen ${ }^{27}$ ), ob ein Gesetz, das sich gegen die Eingehung von privatrechtlichen Wettbewerbsbeschränkungen richtet und für die Erhaltung des freien Wettbewerbs einsetzt, als eine Maßnahme staatsinterventionistischen Charakters gegenüber der Wirtschaft aufgefaßt werden kann. Das wird z. T. verneint: nur was "Ausnahme" von der Gewerbefreiheit, was „Einbruch" in diese bzw. in die mit ihr zusammenhängende Wettbewerbsfreiheit sei, könne als Intervention angesehen werden. Diese Meinung hat etwas Richtiges an sich, sie ist aber dann nicht zutreffend, wenn, wie wir es tun, weniger auf den Begriff der "Intervention" (d.h. des Eingriffes, Einbruches, Eindringens usw.) als auf den der Lenkung abgestellt wird. Wo immer nämlich der seinen Eigengesetzlichkeiten folgende Wirtschaftsablauf vom Staat korrigiert wird, liegt „Lenkung“ vor. In diesem Zusammenhang ist es gleichgültig, ob eine sich von eigenen Wettbewerbs-

24) Vgl. III der Anlage zu dem Gesetz über Leitsātze für die Bewirtschaftung und Preispolitik nach der Geldreform vom 24. 6. 1948, GVBl. WR. S. 59.

ab) Vgl. Gesetz Nr. 56: Verbot der übermäßigen Konzentration deutscher Wirtschaftskraft vom 12. 2. 1947, RegBl. der Mil.Reg. Württ.-Baden vom 20. 3. 1947, S. 17; Ordinance Nr. 78 über das Verbot der übermåßigen Konzentration deutscher Wirtschaftskraft, Mil.Reg.Amtsbl. der brit. Zone, 1947. S. $4^{12}$ ff.; VO. Nr. 96 vom 9. 6. 1947 zur Verhinderung übermäBiger Machtanhäufung in der deutsch. Wirtschaft, Journ. Officiel vom 13.6.1948, S. 784 .

20) Abschnitt III B Ziff. 12.

27) Hans Huber, Das Staatsrecht des Interventionismus, Ztschr. f. schweiz. Recht, N.F. Bd. 7o, S. 175f., aber abstellend auf die dortige spezielle Verfassungssituation. - Gleicher Meinung wie wir Scheuner, DOV. 1952, S. 609 Anm. 1. 
beschränkungen freihaltende Wirtschaft in diesem Bezuge vom Staat kontrolliert wird, oder ob umgekehrt der Staat die von der Wirtschaft selbst angestrebten Wettbewerbsbeschränkungen verbietet und damit die Wirtschaft der vom Staat gewünschten Wettbewerbsfreiheit zuführt.

Von hier aus lassen sich die beiden Hauptereignisse qualifizieren, die in Westdeutschland auf dem Gebiet des Wettbewerbsrechts seit 945 eingetreten sind bzw. eintreten werden. Die Aufhebung aller wettbewerbsbeschränkenden Abmachungen durch die alliierte Gesetzgebung bedeutete, von der Wirtschaft aus gesehen, eine hoheitliche Lenkungsmaßnahme großen Stils. Denn unsere Wirtschaft war bis zum Zusammenbruch weitgehend durchkartelliert; nunmehr ergaben sich wieder de iure völlig freie Wettbewerbsbedingungen. Eine ähnliche Bedeutung wird das kommende deutsche Gesetz gegen Wettbewerbsbeschränkungen haben. Es dürfte ebenfalls ein "Verbotsgesetz" werden, nur gemildert durch gewisse, freilich nicht unwichtige Ausnahmemöglichkeiten. Da indessen jede freie Wirtschaft die Tendenz in sich trägt, die gegenseitige Konkurrenz nicht ruinös werden zu lassen und damit zwangsläufig, vor allem in Krisenzeiten, zu autonomen Marktregelungen drängt ${ }^{23}$ ), beeinflußt das Verbot solcher Marktregelungen Struktur und Ablauf der Wirtschaft auf das empfindlichste. Daher muB auch das künftige deutsche Gesetz als eine wesentliche staatliche Lenkungsanordnung bezeichnet werden. Erfreulicherweise ist hier dem Rechtsschutzbedürfnis der Beteiligten große Sorgfalt gewidmet worden. Ein endgültiges Urteil in dieser Hinsicht kann aber im Augenblick noch nicht gefällt werden.

\section{II}

I. Wirtschaftslenkung darf man sich nicht nur in der Form hoheitlicher Maßnahmen vorstellen. Wenn mit der staatlichen Beeinflussung der Wirtschaftsvorgänge der Zweck verfolgt wird, bestimmte dem Staat wichtig erscheinende Ziele zu verwirklichen, so kann er sich dabei vielfältiger Mittel und Rechtsformen bedienen, praktisch aller, die ihm im konkreten Fall nützlich erscheinen und die legitim sind. Er tut das bekanntlich auch. Dabe: kommt es nicht darauf an, ob er seinen Lenkungswillen der Wirtschaft zwangsweise aufoktroyiert oder nur mäßiger bzw. nur mittelbar wirkende Mittel gebraucht; auch nicht darauf, ob er nur sozusagen "von außen her" auf die Wirtschaft einwirkt, oder ob er sich selbst unter die Gewerbetreibenden mischt - manchmal offen, manches $\mathrm{Mal}$ in seltsame juristische Formen gekleidet, so daß man Mühe hat, den "Wolf im Schafspelz" zu erkennen. Damit schneiden wir das bekannte Thema der wirtschaftlichen Betätigung der

so) So mit Recht Marbach, Zur Frage der wirtschaftlichen Staatsintervention, Bern 1950, S. 95 ff. 
öffentlichen Hand an. Es kann, grundsätzlich gesehen, keinem Zweifel unterliegen, daB der Staat durch die.von ihm oder von seinen Unterverbänden vorgenommene Betätigung in der Wirtschaft diese nicht nur mitträgt, sondern sie auch mitgestalte ${ }^{29}$ ). Damit ist jeweils auch eine entsprechende wirtschaftspolitische Einflußnahme verbunden ${ }^{30}$ ). Das gilt überall, in größeren wie in kleineren Rahmen. Es gilt für das Riesenbeispiel der vollsozialisierten Wirtschaft der Sowjetunion, dessen fragwürdige Nachbildung, wenn auch in geringeren Ausmaßen, wir gegenwärtig in der deutschen Ostzone miterleben, wie auch etwa für den Bereich der Public Utilities in den angelsächsischen Ländern oder bei uns, wie schließlich für eine so bescheidene Angelegenheit, wie sie etwa der Behördenhandel einer beliebigen Amtsstelle darstellt. Die Entwicklung in diesem Zusammenhang seit dem Ausbruch des ersten Weltkrieges ist, gerade auch in Deutschland, dadurch gekennzeichnet, $\mathrm{daB}$ die hoheitliche Form des Verwaltungshandelns ganz allgemein zurückgetreten und die wirtschaftliche Betätigung der öffentlichen Hand entsprechend im Vordringen begriffen ist ${ }^{31}$ ).

2. Besondere Aufmerksamkeit auf diesem Gebiet hat seit jeher die Sozialisierung hervorgerufen. Einmal deswegen, weil es zu ihrem Wesen gehört, daß nicht nur einzelne Unternehmungen, sondern ganze Gruppen von solchen oder ganze Wirtschaftszweige zu ihrem Gegenstand gemacht werden ${ }^{32}$, wodurch jedem Sozialisierungsvorgang an sich schon eine besondere Tragweite zukommt; zum anderen wegen des damit verbundenen Einbruches in die Eigentümerstellung. Der letztere Gesichtspunkt hat unsere Wissenschaft bisher am meisten interessiert. In vorliegendem Zusammenhang steht dagegen im Vordergrund, daß trotz des durch die Sozialisierung eintretenden Wechsels in der Trägerschaft der „wirtschaftliche Standort" des Unternehmens und alles, was damit zusammenhängt, nicht geändert werden. Dagegen werden möglicherweise die Leit ungsimpulse in den betreffenden Unternehmungen andere. Gleichgültig wer zum Träger des sozialisierten Unternehmens wird, der Staat selbst, eine „Sozialgemeinschaft"

20) Ballerstedt, Rechtsstaat und Wirtschaftslenkung, Arch.8ff.R., Bd. 74, S. 132, weist auf die Bedeutung der wirtschaftlichen Betätigung des Staates für die „sachliche Integration“ hin.

30) Die Bewreggründe für die Aufnahme der betreffenden wirtschaftlichen Funktion durch den Staat können aber andere gewesen sein. Beispiele bei Forsthoff. Lehrbuch des Verw. Rechts, Bd. I, 1950 S. 378; zu der ganzen Frage vgl. auch S. $52 \mathrm{ff}$., 60ff., $373 \mathrm{ff}$., hier mit weiterer Literatur.

31) Dies ist schon für die Zeit nach dem ersten Weltkrieg festgestellt worđen, etwa Köttgen, Die erwerbswirtschaftliche Betätigung der offentlichen Hand und das offentliche Recht, r928, passim. - Für die heutige Zeit vgl. Forsthoff a.a.O.

22) Ipsen, Enteignung und Sozialisierung, Veroffentlichungen der Vereinigung der Deutschen Staatsrechtslehrer, Heft 10, 1952, S. I18, betont mit Recht die Unzulässigkeit von individuellen Sozialisierungen. 
oder ein anderes Gebilde - in dem Verhalten des Unternehmens am Markte, d. h. den Lieferanten, Abnehmern und Konkurrenten gegenüber, werden die wirtschaftspolitischen Auffassungen derjenigen Kräfte zum Ausdruck kommen, die es nunmehr leiten. Damit verfügt der Staat unmittelbar oder mittelbar über wesentliche wirtschaftliche Einflußmöglichkeiten.

Im heutigen Westdeutschland ist, von einer Ausnahme abgesehen ${ }^{33}$ ), die Entwicklung auf dem Gebiet der Sozialisierung nicht besonders fortgeschritten. Zwar finden sich in nahezu allen neuen Länderverfassungen sowie im Bonner Grundgesetz Sozialisierungsbestimmungen. Nur Hessen hat bekanntlich davon Gebrauch gemacht. Im Ausland, jedenfalls in einigen europäischen Staaten (England, Frankreich, Ósterreich), sind dagegen seit dem letzten Kriege umfangreiche Sozialisierungen, übrigens auch im Bereich des Handels, vorgenommen worden, deren Auswirkungen auf Struktur und Ablauf der Gesamtwirtschaft bedeutend waren. Da bei uns der hessische Vorgang noch vereinzelt geblieben, er auch weder rechtlich noch wirtschaftlich ausgereift ist, braucht das Thema der Sozialisierung nicht weiter verfolgt zu werden.

3. Eine weitere Gruppe, bei welcher die öffentliche Hand als Träger wirtschaftlicher Funktionen hervortritt, bilden die Versorgungsbetriebe. Dieser Begriff sollte weitergefaßt werden, als es üblich ist. Man ist gewohnt, ihn im wesentlichen nur auf die Gemeinden zu beziehen. Offentliche Unternehmen, wie die Bundesbahn und die Bundespost, gehören aber, ungeachtet ihrer besonderen Rechtsgestalt, gleichfalls in diesen Zusammenhang. Denn auch bei ihnen handelt es sich um wirtschaftliche Unternehmungen, die deswegen von der öffentlichen Hand betrieben werden, weil der breiteren Bevölkerung lebenswichtige Leistungen zu Bedingungen dargeboten werden sollen, wie dieses von privater Seite in der Regel nicht geschehen könnte.

Hier tritt die Frage auf, ob zu den bisherigen herkömmlichen Versorgungebetrieben seit I945 neue hinzugetreten sind. Das ist auf überkommunaler Ebene, soweit wir sehen, nicht in nennenswertem Umfang der Fall, abgesehen von dem Bankensektor, auf den noch in der Folge zurückzukommen sein wird. Immerhin kann auf einzelne Erscheinungen hingewiesen werden. Die Staatliche Erfassungsgesellschaft für öffentliches Gut (STEG), eine wirtschaftlich dem Bund verantwortliche, zentrale Handelsgesellschaft in privatrechtlicher Form, zum Teil mit eigenem Filialsystem, hatte die Aufgabe, überschüssiges amerikanisches Heeresund Beutegut verbilligt der Verwertung und dem Konsum zuzuführen; sie dürfte eine vorübergehende Erscheinung sein. Dagegen

59) Wir meinen Hessen. Für das - nicht durchgeführte - Berliner Sozialisierungsgesetz vo $n 1948$ vgl. Peters, Lehrbuch der Verwaltung. 1949, S. 503 f. 
wird die künftige Luftfahrtgesellschaft aller Wahrscheinlichkeit nach ein Unternehmen werden, das mit der Zeit den alten öffentlichen Verkehrsunternehmen an Rang gleichkommen wird. Sollte das neuerdings aufgetauchte Projekt der Gründung einer „Bank für Bundesunternehmen", die als Haus- bzw. Geschäftsbank für alle bundesmittelbaren Unternehmen dienen soll, zur Ausführung kommen, so würde das auf der gleichen Linie liegen ${ }^{34}$ ). - Auf der kommunalen Ebene ist dagegen auf eine hochbedeutsame Erweiterung des Kreises der Public Utilities hinzuweisen, die freilich bisher nur selten als solche erkannt wird. Es handelt sich um den sozialen Wohnungsbau der Gemeinden. Er wird fast durchweg in der Form gemeinnütziger privatrechtlicher Gesellschaften betrieben und bietet damit ein besonders gutes Beispiel für den Ubergang der öffentlichen Hand zu wirtschaftlicher Betätigung im Gewande privatrechtlicher Unternehmungen. So wie bei Strom, Gas, Wasser und örtlichen Verkehrsbetrieben, so geht auch die Inangriffnahme des sozialen Wohnungsbaues durch die Gemeinden darauf zurück, daß diese Aufgabe von privater Seite nicht bewältigt werden konnte, wobei die Gründe, an denen der Staat mit seiner Mietpreisregelung nicht unschuldig ist, hier auf sich beruhen können. Von dem sozialen Wohnungsbau abgesehen, scheint auch bei den herkömmlichen kommunalen Versorgungsbetrieben eine allgemein expansive Entwicklung, besonders in der Elektrowirtschaft, vorzuliegen.

Außerdem hat sich hier eine weitere Sonderentwicklung ergeben, die zwar gesamtwirtschaftlich nicht zu wichtig genommen zu werden braucht die aber nicht uninteressant ist. Gemeindliche Versorgungsunternehmungen sind neuerdings in steigendem Maße dazu übergegangen, sich handwerkliche Hilfsbetriebe anzugliedern ${ }^{25}$ ) und neben ihren eigentlichen Versorgungsaufgaben Handel zu treiben, etwa mit Gas- und Elektrogeräten. Dieser Entwicklung gegenüber ist ein Eingreifen des Gesetzgebers verlangt worden ${ }^{36}$ ). In rechtlicher Hinsicht ist hier die wichtige Frage aufgetreten, ob auch der öffentlichen Hand das Grundrecht

s4) Die Einfuhr- und Vorratsstellen der Ernährungswirtschaft - siehe unten S. IOI - wird man hier nur mit Einschränkungen nennen können, zumal sie als Nachfolger der Organisationen des Reichsnährstandes nicht vollig neu sind. Ihrer Rechtsform nach sind sie sämtlich Anstalten des offentlichen Rechts. Sie stellen keine Wirtschaftsbetriebe und daher auch keine Versorgungsbetriebe dar. Aber sie nehmen als Zwischenkãufer, Kreditgeber und Auftraggeber für gewaltige Lagergeschäfte unzweifelhaft am wirtschaftlichen Verkehr teil, und sie besitzen ebenso unzweifelhaft auch Lenkungsfunktionen. Insofern mag ihre Anführung in diesem Zusammenhang nicht fehl sein.

s5) Vgl. die Angaben von $\mathrm{Nipperdey,} \mathrm{Der} \mathrm{Betriebsberater,} \mathrm{6.} \mathrm{Jg.,} \mathrm{S.} 593$.

๗) Vgl. Nipperdey wie zuvor und Drucksache Nr. 3133 des Deutschen Bundestags, I. Wahlperiode 1949. 
der Gewerbefreiheit zusteht; das ist mit Recht abgelehnt worden ${ }^{87}$ ). Wir erwähnen diesen Vorgang nur am Rande, gleichwohl aber deswegen, weil das Lenkungsproblem einen Ausschnitt aus dem allgemeineren Problem des Verhältnisses zwischen Staat und Wirtschaft darstellt und es daher nicht gleichgültig ist, wo die rechtlichen Grenzen der wirtschaftlichen Betätigung der öffentlichen Hand gezogen werden.

4. Abschließend zu diesem Punkte sei bemerkt, daB das vorliegende Thema eigentlich noch fortgesetzt werden müßte, und zwar auf das Gebiet der gemischtwirtschaftlichen Unternehmungen und auf die stark im Zunehmen begriffenen kapitalistischen Beteiligungen der öfentlichen Hand ${ }^{39}$ ). In beiden Formen sind weitere Einflußmöglichkeiten enthalten. Das ist jedoch ein weites Feld, auf dessen auch nur grundsätzliche Behandlung hier verzichtet werden muß.

\section{III}

Bei der Einsetzung einer Staatsaufsicht über bestimmte Wirtschaftszweige läßt der Staat die betreffenden wirtschaftlichen Unternehmen in der privaten Hand, unterwirft sie aber einer besonderen Verwaltungskontrolle. Das Unternehmen steht also ,in der Mitte" zwischen Privat- und Staatswirtschaft. Es wird nicht vom Staat oder einem anderen öffentlichen Rechtsträger betrieben, doch ist es in seiner geschäftlichen Gebarung nicht ebenso frei wie die reinen Privatbetriebe. Es gehört nach Rechtsform und Tätigkeit nach wie vor der privatrechtlichen Sphäre an, nur unterliegt es gewissen öffentlich-rechtlichen Verpflichtungen, denen entsprechende Einwirkungsmöglichkeiten des Staates gegenüberstehen. Vor I933 war diese Rechtsfigur seltener ${ }^{30}$ ). Seither hat sie sich weiter verbreitet, was sich noch fortsetzen dürfte. Das Institut des staatsbeaufsichtigten Wirtschaftsunternehmens verdient daher grundsätzliche Aufmerksamkeit. Solche Unternehmen bieten übrigens eine besonders günstige Gelegenheit zur Inanspruchnahme für öffentliche Verwalt ungsaufgaben ${ }^{40}$ ).

37) Von Nipperdey a.a.O.

s8) Das Deutsche. Industrieinstitut hat neuerdings Untersuchungen úber den Umfang der wirtschaftlichen Betätigung der 8 ffentlichen Hand eingeleitet, aus denen sich nach dem Stand von 1943 ergibt, daB damals etwa ein Drittel des Vermogens der gewrerblichen Wirtschaft - soweit sie in den Formen der Kapitalgesellschaften organisiert war - direkt oder indirekt als Vermogen der offentlichen Hand im weitesten Sinne bezeichnet werden kann. Für die heutige Zeit dürtten die Verhaltnisse kaum anders liegen.

39) E. R. Huber, Wirtschaftsverwaltungsrecht, 1932, S. Ir2f., verzeichnet nur ,wenige Fălle“.

40) Hierza Ipsen, Gesetzliche Indienstnahme Privater für Verwaltungsanfgaben, Festgabe für Erich Kanfmann, 1950, S. I4Iff. 
Neben der Energiewirtschaft ${ }^{41}$ ) sind es im wesentlichen zwei Hauptgebiete, in denen sich eine Staatsaufsicht über wirtschaftliche Unternehmungen findet, nämlich im Geld- und Kreditwesen (im weiteren Sinne) sowie bei dem Verkehr. Das private Bankgewerbe, früher schon die Hypotheken- und die Schiffspfandbriefbanken, die öffentlichen Sparkassen, die Versicherungsunternehmen und Bausparkassen sind hier zu nennen ${ }^{42}$ ). Bei dem Verkehr sind es die Privateisenbahnen, die Binnenschiffahrt, die Personenbeförderung zu Lande und der Güterverkehr mit Kraftfahrzeugen ${ }^{43}$ ). Unwichtiger Art ist die private gewerbsmäßige Arbeitsvermittlung ${ }^{44}$ ). In allen diesen Fällen stehen die betreffenden Unternehmen in jenem Sonderverhältnis zum Staat ${ }^{45}$ ). Unter ihnen finden sich freilich auch solche der öffentlichen Hand. Das ist aber nicht wesentlich. Denn ergriffen von der Staatsaufsicht wird der ganze Wirtschaftszweig, gleichgültig von wem die $\mathrm{ihm}$ angehörenden Unternehmen betrieben werden. Die Unterwerfung der Privatunternehmen ist in unserem Zusammenhang das entscheidende Merkmal.

Die Staatsaufsicht wird ausgeübt entweder auf direktem oder indirektem Wege, letzterenfalls unter Zwischenschaltung besonderer Organisationen. Organisatorisch ist die Aufsicht verschieden geordnet. Teils sind es ordentliche Verwaltungsbehörden der Länder oder des Bundes, denen die Ausübung der in Frage stehenden Befugnisse obliegt, teils sind damit, insbesondere im Bank- und Versicherungswesen, Sonderbehörden betraut. Bei der indirekten Staatsaufsicht sind die Gewerbebetriebe (was heute

4) Gesetz zur Förderung der Energiewirtschaft vom I3. 12. I935, RGBl. I, S. I45I, mit weiteren Ergänzungen.

4) RGesetz über das Kreditwesen vom 5. I2. 1934, RGB1. I, S. 1203. Hypothekenbankgesetz vom 13. 7. 1899, RGB1. S. 375, Gesetz über Schiffspfandbriefbanken vom 14.8. 1933, RGBl. I, S. 583; für die Sparkassen: Vo. des RPräs. vom 6. Io. 193I, RGBI. I, S. 537, Teil 5 Kap. I; Gesetz über die Beaufsichtigung der privaten Versicherungsunternehmen und Bausparkassen vom 6. 6. I93I, RGBl. I, S. 315 - jeweils mit weiteren gesetzlichen Ergänzungen.

In Hessen und Rheinland-Pfalz (Art. 41 Ziff. 2 bzw. Art. 62 der jeweiligen Verfassung) ist die staatliche Aufsicht über Banken und Versicherungen schon verfassungsrechtlich vorgesehen.

49) 55 des Allgemeinen Eisenbahngesetzes vom 29.3. I951, BGBl. I, S. 225; Gesetz zur Bekämpfung der Notlage der Binnenschiffahrt vom 16. 6. 1933, RGBl. II, S. 317; Gesetz ũber die Beförderung von Personen zu Lande voin 4. 12. 1934, RGB1. I, S. I217; Güterkraftverkehrsgesetz vom 17. 10. 1952, BGBl. I, S. 697 - zumeist mit zahlreichen gesetzgeberischen Ergănzungen.

4) Gesetz über Arbeitsvermittlung, Berufsberatung und Lehrstellenvermittlung vom 5. r1. 1935, RGBl. I, S. I281, I (3) bis (5).

4) Typisch in diesem Zusammenhang $\$ 4$ des Ersten Wohnungsbaugesetzes vom 24. 4. 1950, BGB1. I, S. 83. Hier wird die Bundesregierung ermächtigt, den Kapitalsammelstellen bestimmte Vorschriften über die Anlage langfristiger Gelder zur Finanzierung des Wohnungsbaues zu machen. 
aber selten ist) zu Zwangsverbänden zusammengefaßt, wie bei den Schiffer-Betriebsverbänden der Binnenschiffahrt ${ }^{46}$ ) und früher bei dem Reichs-Kraftwagen-Betriebsverband, dem neuerdings sogar eine ganze Bundesanstalt öffentlich-rechtlichen Charakters gefolgt ist ${ }^{47}$ ). Hier sind die Zwischenorganisationen mit öffentlichrechtlichen Befugnissen gegenüber dem einzelnen Unternehmer ausgestattet und ihrerseits als ganzes wieder vom Staat beaufsichtigt.

Als Zweck der Aufsicht ist zumeist die Einhaltung der jeweiligen Gesetzesbestimmungen sowie der Konzessionsbedingungen vorgesehen - der letzteren deswegen, weil die einer Staatsaufsicht unterworfenen Unternehmen sämtlich zulassungsbedürftig sind. In der Sache wird man den Aufsichtszweck etwas anders umschreiben müssen: Fernhaltung oder Beseitigung unzuverlässiger Gewerbetreibender, Verkehrssicherheit in allgemeiner und in technischer Hinsicht, Sicherung der Geldanlagen des Publikums, Schutz der Sparer oder Versicherungsnehmer, Angemessenheit der zu zahlenden Entgelte - dies und ähnliches sind die Ziele, zu deren Verwirklichung die staatliche Aufsicht eingesetzt ist.

Die Aufsichtsmittel sind vielfältiger Art. Das praktisch wichtigste dürfte die Zurücknahme der Zulassung sein. Daneben finden sich Uberprüfungen in geschäftlicher und in technischer Hinsicht, Besichtigungen, Büchereinsicht, Bilanzenvorlage, Teilnahme an Sitzungen und dergl. mehr; Ordnungsstrafen und polizeiliche Verfügungen, Ersatzvornahme usw. - das ganze Arsenal der aus dem Verwaltungsrecht geläufigen Aufsichtsmittel und ihrer Durchsetzungsmöglichkeiten müßte dargelegt werden, wollten wir vollständig sein.

Die entscheidende Frage liegt für uns darin, inwieweit hier vermittels der Staatsaufsicht eine wirtschaftspolitische Steuerung möglich ist und tatsächlich betrieben wird. Nach unserer Meinung ist sie möglich, aber es wird nur zurückhaltend davon Gebrauch gemacht. Die Dinge liegen auf den einzelnen Gebieten verschieden, und es kommt auf die jeweilige Gesamteinstellung des Staates zur Wirtschaft an. In der nationalsozialistischen Zeit ist mit dieser Staatsaufsicht zweifellos a uch Wirtschaftsführung getrieben worden. Heute scheinen uns im ganzen die technischen Gesichtspunkte im Vordergrund zu stehen; das wirtschaftspolitische Moment spielt zwar hinein, ist aber nicht ausschlaggebend. Immerhin, wenn z. B. die Bankenaufsicht auch heute noch die Aufgabe hat, für die Beachtung allgemeinwirt-

\footnotetext{
4) Vgl. etwa VO. vom 15. 9. r934, RuPr.Staatsanz. vom 19. 9. 1934.

17) Vgl. $\$ 53$ ff. des Güterkraftverkehrsgesetzes vom I7. Io. 1952, BGBl. I. S. $697 \mathrm{ff}$.
} 
schaftlicher Gesichtspunkte in der allgemeinen Kredit- und Bankpolitik zu sorgen, wenn man sich bei dem Verkehr vor Augen hält, da B die Staatsaufsicht gerade deswegen eingerichtet ist, um eine gesamtwirtschaftliche Ordnung auf dem betreffenden Sektor zu gewährleisten, und wenn man schließlich die enge Verflechtung mit allen Tarif- und Entgeltsfragen berücksichtigt, dann werden unsere Fragestellung und unser Urteil verständlich sein. Es liegt auf der Hand, da $B$ alle Einzelmaßnahmen einer solchen Aufsicht letztlich getragen sind von denjenigen wirtschaftspolitischen Auffassungen, deren Verwirklichung den aufsichtführenden Instanzen aufgegeben ist.

\section{IV}

I. Für die Wirtschaft im ganzen und für das einzelne Unternehmen ist die Form, in der von seiten des Staates der wirtschaftliche Ablauf in bestimmte Bahnen gelenkt wird, im Grunde unwesentlich, die Wirkung alles. Gewiß - eine geschlossene Planwirtschaft totalitären Charakters bedeutet für die Wirtschaft eine besonders tiefgreifende Reglementierung. Auch die Bewirtschaftung nur einzelner Grundstoffe oder Warengruppen bringt für den betroffenen Betrieb eine empfindliche Beeinträchtigung seiner Freiheitssphäre. Daneben gibt es aber noch eine Unzahl sonstiger Maßnahmen, die vom Standpunkt der staatlichen Lenkungsabsichten aus nicht weniger wirksam sind und die von der Wirtschaft auch entsprechend empfunden werden. Dazu gehört heute in allererster Linie das Steuergesetz. Daß die staatliche Lenkung auch durch den bloßen Erlaß von Gesetzen oder sonstigen Rechtsbestimmungen vor sich gehen kann, steht außer Zweifel ${ }^{48}$ ). Das Gesetz dürfte heutzutage sogar mit die wichtigste Form darstellen.

Wirtschaftslenkung durch steuerliche Gesetze ist selbstverständlich nichts Neues. Sie gehört, seit es überhaupt öffentliche $A b-$ gaben gibt, in das bewährte Arsenal auch der Wirtschaftspolitik. Denn kaum jemals in der Geschichte dürfte das berechtigte Bedürfnis der öffentlichen Hand, ihre Kassen mit den Steuergroschen des Volkes zu füllen, nicht auch zu außerfiskalischen Zwecken benutzt worden sein. Das Besondere an der heutigen Situation ist nur, $\mathrm{da} B$ niemals, weder in unserer Zeit noch wohl auch früher, derartig hohe Steuern erhoben worden sind, wie das gegenwärtig nicht nur in Deutschland, sondern auch in anderen Ländern der Fall ist. Das steuerliche Aufkommen stammt zwar nicht allein aus der Wirtschaft, es ist aber bei nahezu allen wichtigeren Steuern von deren Entwicklung wesentlich

18) Ballerstedt a.a.O. S. $13^{8}$ zählt mit Recht auch Gesetze zu den LenkungsmaBnahmen. 
abhängig. Je vielseitiger das Steuersystem und vor allem je höher die Steuersätze, desto wuchtiger und schärfer ist das Schwert des Staates mit der Devise ,Wirtschaftslenkung durch Steuergesetz ${ }^{\prime 49}$ ).

Dafür bedarf es nur weniger Hinweise. Wer die Entwicklung etwa unseres Ertragssteuerrechtes in den letzten Jahren verfolgt hat, dem ist bekannt, wie nach der Währungsreform das Ruder der Steuerpolitik auf die "Selbstfinanzierung der Wirtschaft" umgestellt worden ist. Sonderabschreibungen, Bewertungsfreiheiten, die Begünstigung nichtentnommener Gewinne u. a. m.sie alle dienten dazu, den Betrieben die für den Wiederaufbau nötigen Mittel zu belassen. Diese Linie ist zwar I95I wieder verlassen worden, aber die Wirkung war gleichwohl erheblich. Es darf auch erinnert werden an die steuerliche Förderung der Ausfuhr, an die Umsatzsteuer mit ihren besonderen Sätzen bei den sozialwichtigen Nahrungsmitteln, der geringeren Belastung des Großhandels und neuerdings etwa der Zusatzsteuer für mehrstufige Unternehmen; Förderung der Genossenschaften, Wiederherstellung des Kapitalmarktes, Tabaksteuerreform, Herabsetzung der Sektsteuer (als Hilfe für die Erzeuger) sind weitere Stichworte, aus denen sich ergibt, daß insoweit nicht Finanz-, sondern ganz eindeutig Wirtschaftspolitik mit steuerlichen Mitteln getrieben wird. Lastenausgleich und Investitionshilfe gehören ebenfalls in diesen Zusammenhang. Der erstere entspringt zwar allgemeinpolitischen Motiven, aber beide sind auf der Aufbringungsseite abgabenrechtlich gestaltet und bedeuten für die Wirtschaft eine große Kapitalentziehung bzw. - bei der Investitionshilfe - eine Kapitalumschichtung.

Wenn der vorliegende Punkt nicht in den Einzelheiten ausgesponnen wird, so nicht, weil wir ihn mit diesen wenigen Worten erschöpft hätten. Die Kürze unserer Ausführungen darf nicht dazu verleiten, sie gering zu werten. Das Anziehen bzw. das Lockerlassen der Steuerschraube ist vielmehr das en tsch eidende Mittel unserer gegenwärtigen Wirtschaftslenkung. Es hat die unerfreuliche Folge, daB der Unternehmer heute beinahe weniger in den seiner Aufgabe entsprechenden Kategorien des Wagnisses und der Rendite denkt, als daran, wie und wo er seine steuerliche Belastung mindern kann. Keine betriebliche Maßnahme, ohne da $B$ zuvor nicht die steuerlichen Folgen bedacht werden!

2. Die finanzielle Unterstützung der Wirtschaft mit öfentlichen Mitteln gehört zu den charakteristischen Merkmalen unserer Entwicklung seit dem Kriegsende und in verstärktem Maße seit der Währungsreform. Bei einer Wirtschaftsordnung mit - dem Grundsatze nach - liberalen Zielen und Betonung der Unternehmerverantwortung könnte das erstaunen.

49) In gleichem Sinne Marbach a.a.O. S. $22 \mathrm{f}$. 
Aber der geschwächte Wirtschaftskörper war nach I945 zunächst natürlich nicht in der Lage, aus eigener Kraft den ungeheuren Aufgaben gerecht zu werden. Nach der Währungsreform kam ein weiterer, überaus simpler volkswirtschaftlicher Vorgang hinzu: die finanzielle Decke der Wirtschaft war hoffnungslos zu kurz geworden; die konfiskatorisch wirkende Besteuerung machte die Anlegung betrieblicher Reserven, trotz der zeitweiligen Steuererleichterungen, weithin unmöglich und verhinderte vor allem die Entstehung eines Kapitalmarktes. Statt dessen sammelten sich sehr erhebliche Gelder in den öffentlichen Kassen, nicht zwar als Dauervermögen, aber doch geeignet, um für die Finanzierung der Wirtschaft ausgegeben oder ausgeliehen zu werden. Die Akkumulierung von Finanzmacht bei den öffentlichen Kassen ${ }^{50}$ ), im Verein mit der zum großen Teil vom Staat mitverursachten Finanznot der Wirtschaft, ist der reale Untergrund, auf dem sich gegenwärtig der weitverzweigte Prozeß der finanziellen Hilfegewährung des Staates an die Wirtschaft abspielt. Die fraglichen Gelder entstammen zablreichen Quellen; sie werden gegeben in den verschiedensten Formen und eingesetzt zu allen nur denkbaren Zwecken. Als Gebender ist der Bund ebenso daran beteiligt wie die Länder, wenn auch das Schwergewicht bei dem Bund liegen dürfte - mit der natürlichen Folge einer zentralisierenden Wirkung. Daraus haben sich schwierige Probleme rechtlicher, insbesondere auch bundesstaatsrechtlicher Art, ergeben ${ }^{61}$ ), vor allem dort, wo die Finanzhilfe nicht nach bestimmten Gesetzesvorschriften ${ }^{52}$ ) oder nicht aus normalen Haushaltsmitteln gewährt wird, also (auf der Ausgabenseite) im Bereich der ,gesetzesfreien Verwaltung". Was diese ganze Erscheinung so bedeutungsvoll macht, das ist die nicht zu bestreitende Tatsache, daß, wo immer öffentliche Gelder verteilt werden, auch staatlich gelenkt wird. Und es handelt sich dabei um außerordentlich große Summen ${ }^{53}$ ). Darlehen, Zuschüsse, Bürgschaften und Garantien sind die wichtigsten Formen bei der Verteilung der Gelder. Auch die Subventionen ${ }^{54}$ ) in der Gestalt von Preisverbilligungen sind in diesem Zusammenhang zu nennen. Wir halten diese finanziellen Unterstützungen für das dem Gewicht nach zweitwichtigste Instrument der staatlichen Wirtschaftslenkung unserer Tage.

so) Formulierung von Köttgen, Verfassungsrechtliche Grenzen der Ausgabenwirtschaft des Bundes, Stădtetag, 1952, S. 3 ff.

s1) Hierzu Kottgen wie zuvor; für die Schweiz vgl. Dietrich Schindler, Die Bundessubventionen als Rechtsproblem, Züricher Beiträge zur Rechtswissenschaft, 1952, passim.

b2) Vgl. etwa $\$ \oint 3,13$ bis 22 des Ersten Wohnungsbaugesetzes vom 24. 4. 1950, BGBI. I, S. 83 .

(3) Gast, Deutsche Steuer-Rundschau, 2. Mai-Heft r952, schätzt sie von der Währungsreform bis zum Frühjahr 1952 auf 14 bis 15 Mrd. DM. 
Was die Quellen betrifft, aus denen alle diese öffentlichen Mittel fließen, so bedürfte es einer finanzwissenschaftlichen Untersuchung, um zu klären, welcher Art und Bedeutung sie im einzelnen sind. Für unsere $Z$ wecke ist wesentlich, da $B$ es sich keineswegs nur um normale Haushaltsmittel (Steueraufkommen) des Bundes oder der Länder handelt, wenn diese auch einen erheblichen Teil davon ausmachen dürften. Beim Bund kommt vor allem weiter in Frage der ganze Komplex, der mit den amerikanischen Hilfeleistungen zusammenhängt, also die bekannten Gegenwertfonds aus ERP- und GARIOA-Einfuhren ${ }^{55}$ ), die innerdeutsch bezahlt, aber von Staat zu Staat zunächst noch nicht ausgeglichen werden, ferner die ECA-Mittel. In letzter Zeit bringen die aus den Gegenwertfonds gewährten Darlehen ihrerseits wieder Zinseinkünfte und Tilgungsbeträge, die revolvierend ausgeliehen werden. Die aus dem amerikanischen Hilfeleistungskomplex bei dem Bund angereicherte Finanzmacht ist beachtlich. Auch die Mittel, die bei dem Bund aus den Verkaufserlösen der STEG aufkommen, spielen eine Rolle. Die Bundesanstalt für Arbeitslosenvermittlung usw. ist ein weiterer, zunehmend wichtiger werdender Geldgeber. SchlieBlich ist auf die Soforthilfe- bzw. künftig die Lastenausgleichsmittel hinzuweisen, aus denen gleichfalls viele Hunderte von Millionen unmittelbar oder mittelbar der Wirtschaft zufließen. Auch das Sondervermögen auf Grund des Investitionshilfegesetzes darf in diesem Zusammenhang nicht vergessen werden, wenn auch die hieraus vergebenen Mittel mit gesellschaftsrechtlichen Beteiligungen abgedeckt werden sollen. Man hat neuerdings nicht weniger als 12 große ,zentralgesteuerte Kreditprogramme“ auf Bundesebene gezählt, unter sich natürlich von verschiedenem Gewicht, aber im ganzen sowohl staats- wie volkswirtschaftlich von beträchtlichem Ausmaß. Daneben sind noch die entsprechenden Aktionen der Länder zu berücksichtigen, die niemand zu übersehen vermag. Nach alldem kann man sich unschwer vorstellen, welche Machtfülle und welche Möglichkeiten der Wirtschaftslenkung dem Staat bei der Verteilung dieser außerordentlichen Summen in die Hand gefallen sind und welche politische An-

s) Beispiele: Gesetz über die Festsetzung und Verrechnung von Ausgleichs- und Unterschiedsbeträgen für Einfuhrgüter der Land- und Ernăhrungswirtschaft vom 22. 8. I949, WiGBl. S. 29I, verlängert durch Gesetz vom 27. 2. 1950, BGBl. I, S. 33; VO. über Verbilligung von Dieselkraftstoff für die Große Hochsee- usw. Fischerei vom 6. 6. I95I, BGBl. I, S. 376, i.d.F. vom 13.6. 1952, ferner die entspreckende VO. für die Landwirtschaft vom 28. 7. I95I, BGBl. I, S. 482. - Schindler a.a.O., passim, zieht den Begriff der „Subvention" weiter, sachlich nicht ganz zu unrecht, aber es entspricht das nicht dem gegenwärtigen deutschen Wortgebrauch.

ob) Art. IV f. des Abkommens über die wirtschaftliche Zusammenarbeit $z$ wischen der Bundesrepublik Deutşchland und den Vereinigten Staaten von Amerika vom 5. 12. 1949, BGBl. S. 10. 
ziehungskraft die geldverteilenden Stellen ausüben. Nur die weitgehende organisatorische und verfahrungsmäßige Aufsplitterung, die auf diesem Gebiet vorhanden ist, bannt einigermaBen die Gefahren, die durch einen Mißbrauch solcher wirtschaftlichen Machtstellung etwa eintreten könnten.

Von besonderem Interesse ist die Art und Weise, in welcher die öffentliche Hand die verschiedenen Gelder der Wirtschaft zuführt. Hier ergeben sich organ isatorisch und in bezug auf die Rechtsformen wichtige Feststellungen. Zunächst einmal die, daB die Kredite, Zuschüsse, Bürgschaften usw. nur zum geringeren Teil von Verwaltungsbehörden vergeben werden. Es ist das z. B. der Fall bei den Soforthilfe- bzw. Lastenausgleichsmitteln, bezüglich deren eine eigene Verwaltungsorganisation eingerichtet worden ist. Auch die Länder scheinen ihre Förderungsmittel überwiegend durch Behörden ihrer Wirtschaftsverwaltung vergeben $\mathrm{zu}$ lassen, bei größeren Summen unter Mitwirkung der Finanzausschüsse der Landtage. Hiervon abgesehen, ist es mehr und mehr zur Regel geworden, daß ein deutlicher Trennungsstrich gezogen wird zwischen der Bereitstellung der Mittel und ihrer Vergebung im einzelnen. Das erstere liegt im öffentlichen Bereich, das zweite ist weitgehend privatisiert und damit kommerzialisiert. Man hat inzwischen eingesehen, daß etwa bei einem Staatsdarlehen und bei einem Bankkredit jedenfalls ein es völlig gleich liegt, nämlich das Interresse an einer ordnungsmäßigen Rückzahlung. Staatsdarlehen oder Staatsbürgschaften sind eben Kreditgeschäfte, wie sie in gleicher Weise auch im privatwirtschaftlichen Bereich vorkommen. Das ist der Grund, warum in breitem Umfange zwischen den Staat und den privaten Empfänger Kreditinstitute eingeschoben worden sind. Ihre Erfahrungen bieten sehr viel größere Sicherheit, als wenn die Verwaltung selbst mit ihrer bürokratischen Einstellung und bankmäßigen Unerfahrenheit die Gelder vergeben würde.

Als hervorragendste Neuschöpfung auf diesem Gebiete ist die Kreditanstalt für Wiederaufbau zu nennen, eine Körperschaft des öffentlichen Rechts ${ }^{56}$ ). Ihr sozusagen ,nachgeordnet" findet sich die Industriekreditbank, eine Aktiengesellschaft, aber unter gewissem EinfluB von seiten des Bundes. Die Landwirtschaftliche Rentenbank darf mit ihr verglichen werden. Weitere Banken auf dem Agrarsektor mit ähnlichen Aufgaben stellen die Deutsche Rentenbank-Kreditanstalt, die Deutsche Siedlungsbank und andere dar. Die Vertriebenenbank A. G. wickelt einen Teil der Soforthilfekredite ab. Dazu kommen die Banken des Genossenschaftsbereiches, voran die Deutsche Genossenschaftskasse. Bei

\footnotetext{
si) Gesetz über die Kreditanstalt für Wiederaufbau i.d.F. vom 22. I. I952, BGB1. I, S. 65. Interessant: die Ausstattung einer offentlich-rechtlichen Korperschaft mit Kapital!
} 
den Saatenkrediten des Bundes fungiert ein Münchener Privatbankhaus als „führendes Geldinstitut" 57 ). Diese Reihe ließe sich noch fortsetzen, vor allem auch auf Landesebene, wo es z. B. Landeskreditanstalten für Wohnungsbau und ähnliches gibt. Ein Teil dieser Bankinstitute besitzt öffentlich-rechtlichen Charakter ${ }^{58}$ ). Andere, wie das eben genannte Münchener Bankhaus, haben keinen öffentlich-rechtlichen Status, sind aber bezüglich bestimmter Funktionen mit öffentlichen Aufgaben betraut. Zumeist unterstehen sie einer Aufsicht durch den Staat ${ }^{59}$ ). Die staatlichen Stellen sichern sich ihren Einfluß auch durch das Recht, die Vergebungspläne entweder selbst aufzustellen oder doch zu bestätigen, oder es werden die Richtlinien hierzu vom Staat erlassen. Auch staatliche Treuhänder oder Kommissare finden sich bei diesen Banken. Schließlich ist die öffentliche Hand weitgehend in den Verwaltungsräten dieser Institute vertreten.

Was schlieBlich die Hing a be des Darlehens, die Ubernahme der Bürgschaft usw. im Einzelfall betrifft, so ist dieser Vorgang, wie gesagt, vollständig privatisiert. Das ist ja der Zweck der Einschaltung der Kreditinstitute; weitaus der größte Teil der öffentlichen Gelder wird auf diesem Weg vergeben. Nur bei den verlorenen Zuschüssen ist es anders. Aber auch dort, wo die Einzelvergebung nicht durch Kreditinstitute, sondern durch Verwaltungsbehörden geschieht, schließt sich an den gewährenden Verwaltungsakt ein bürgerlich-rechtliches Geschäft an, und zwar in Gestalt eines gewöhnlichen Darlehens- oder Bürgschaftsvertrages, abgeschlossen zumeist mit der zuständigen Schuldenverwaltung. Er unterscheidet sich rechtlich kaum von einem entsprechenden Vertrag aus AnlaB eines privaten Bankgeschäftes, nur $\mathrm{da} B$ vielleicht die Bedingungen, vor allem die Sicherungen, die verlangt werden, noch schärfer sind, weil hier das persönliche Vertrauensverhältnis, das eigentliche Element eines jeden Kredits, natürlicherweise fehlen muß.

3. Mit dem nächsten Punkt, der Bewirtschaftung, gelangen wir zu dem Kerngebiet unseres Themas. Das gilt jedenfalls für eine rechtliche Betrachtung. Denn die Bewirtschaftung ist unzweifelhaft das Musterbeispiel einer staatlichen Intervention. Hier tritt der staatliche Eingriff in die lebendigen wirtschaftlichen

57) III der Richtlinien zur Durchführung des Gesetzes über eine Bundesbürgschaft zur Abwicklung von Saatenkrediten für die Ernten bis zum Jahre I949 vom 25. 9. I951, BAnz, Nr. 194.

58) Soweit sich das nicht schon aus ihren Organisationsbestimmungen ergibt, läßt es sich auch aus der Befreiung von der Körperschafts- und Vermögenssteuer ablesen, vgl. etwa \$ 3 (I) Ziff. I des Vermögenssteuergesetzes von 1934 i.d. F. vom I6. I. 1952 .

B9) Vgl. z. B. $\$ 12$ des in Note 56 zit. Gesetzes; auch $\$ 11$ des Gesetzes über die Deutsche Genossenschaftskasse i.d.F. vom 3. 2. I95I, BGBl. I. S. 13 I. 
Vorgänge am augenfälligsten in Erscheinung. Freilich, gemessen an der Bedeutung für die Gesamtwirtschaft oder verglichen mit anderen Lenkungsmitteln oder unter dem Gesichtspunkt der Auswirkungen in der Praxis, steht das Instrument der Bewirtschaftung heute bei uns keineswegs mehr an vorderster Stelle. Zwei Tendenzen kreuzen sich bekanntlich in unserer Wirtschaftsordnung und laufen zum Teil in einer merkwürdigen Mischung durcheinander: das Prinzip der freien Wirtschaft einerseits und der staatliche Interventionismus andererseits. Im Bereich der gewerblichen Wirtschaft ist die Bewirtschaftung auf bestimmte, mehr oder minder wichtige Ausschnitte beschränkt - mit der Tendenz zu weiterer Lockerung. Bei der Ernährungswirtschaft liegt es anders. Hier ist die gesamte Grundordnung weitgehend staatlich gelenkt, und zwar in besonders gearteten Bewirtschaftungsformen; Wirtschaftsfreiheit und Marktfunktion kommen demgegenüber nur sekundär zur Geltung.

Für die Bewirtschaftung, diese nunmehr als Ganzes genommen, ist es wesentlich, daß sie ein Mittel der direkten verwaltungsmäßigen Lenkung darstellt. Direkt deswegen, weil das einzelbetriebliche Geschehen davon unmittelbar berührt wird. Die geschäftlichen Dispositionen des Unternehmers, sei es in Bezug auf Erzeugung oder Absatz, auf Warenart und -qualität, sei es in bezug auf die Auswahl seiner Lieferanten oder Abnehmer, sind nicht mehr frei. Verwaltungsmäßig deswegen, weil zur Durchführung der Bewirtschaftung nicht nur mit - meist allzu vielen - generellen Anordnungen gearbeitet wird, sondern darüber hinaus auch mit Einzelverfügungen genehmigenden, verbietenden oder sonstwie bestimmenden Inhalts, die von den Bewirtschaftungsbehörden zur konkreten Gestaltung einzelner Betriebsvorgänge erlassen werden. Typisch für die Bewirtschaftung ist weiter das hoheitliche Moment. Allerdings finden sich unter den Bewirtschaftungs organen auch seltsame Erscheinungen in Form privatrechtlicher Gesellschaften, die an sich, wie man denken sollte, auch nur privatrechtlich tätig werden. Aber sie sind zumeist noch irgendwie mit öffentlich-rechtlichen Funktionen ausgestattet, weil das zur Durchführung ihrer Aufgaben erforderlich ist. Ferner wirkt jede Bewirtschaftungsmaßnahme ihrer Natur nach nicht fördernd oder anregend, sondern im Gegenteil negativ, d. h. verhindernd; entweder vollständig oder jedenfalls doch im Sinne einer Lenkung in andere Bahnen, als sie sich aus den natürlichen Tendenzen des Wirtschaftsablaufs ergeben würden. Unsere heutige Bewirtschaftung erstreckt sich schlieBlich nur auf Erzeugung und Absatz; bei diesem trifft sie den Einzelhandel kaum mehr ${ }^{60}$ ) und

o) Ausnahmen z. B. in Bekanntmachung über den Kleinhandel mit Garmen vom 10. 4. I9I8, RGBl. Nr. 5I, und § I8 der Butter-Vo. vom 2. 6. 195I, BAnz. Nr. IJo. 
den Letztverbraucher, $d . h$. die weite Konsumentenschicht, überhaupt nicht ${ }^{61}$ ). Damit dürften die wichtigeren allgemeinen Merkmale aufgezeigt sein.

Von der Verschiedenartigkeit der Situation bei der gewerblichen Wirtschaft und bei der Ernährungswirtschaft wurde schon gesprochen. Bei der ersteren sind es Teilausschnitte (Eisen, Schrott, Kohle, Nichteisen- und Edelmetalle, außerdem Besatzungsbedarf und dringliche Ausfuhren) ${ }^{62}$ ); auf dem Agrarsektor sind es dagegen die großen Hauptgebiete (Getreide und Futtermittel, Vieh und Fleisch, Fette und teilweise auch noch Zucker) ${ }^{\text {(3) }}$, die der Bewirtschaftung unterliegen. Die Verschiedenheit hat ihren Grund in den Besonderheiten der jeweiligen Aufgabe, die mit der Bewirtschaftung erfüllt werden soll. Bei der gewerblichen Wirtschaft handelt es sich um eine der bekannten Mangel-Bewirtschaftungen, wie wir sie vor der Währungsreform in breitestem Umfang gehabt haben. Dort, wo Lücken in der Versorgung gegeben sind, setzt die staatliche Hand an, sucht den Bedarf zu beschränken und die knappen Güter gesamtwirtschaftlich zu verteilen; daher (heute) der Ausnahmecharakter und die Beschränkung auf ganz bestimmte Teilgebiete $\left.{ }^{64}\right)$. Die Bewirtschaftung auf der Ernährungsseite ist anders geartet. Hier könnte man vielleicht von einer marktordnenden Bewirtschaftung sprechen. Sie dient sowohl der Bedarisdeckung im Interesse des ganzen Volkes, wobei die Einfuhr eine besondere Rolle spielt, als auch dem Erzeugerschutz im Interesse der Landwirtschaft. Nationale Versorgungspläne und Vorratshaltung durch den Bund auf der einen Seite, Mindestpreise, Qualitätsverbesserung der Erzeugnisse, Absatzsicherung durch Ordnung des Marktes auf der anderen Seite, bezeichnen die wichtigsten Mittel dieser zweiten Art von Bewirtschaftung. Die grundsätzlichen Unterschiede wirken sich sowohl organisatorisch als auch rechtlich in vielfältiger Hinsicht aus.

Was die Organisation anbetrifft, innerhalb derer sich die gegenwärtige Bewirtschaftung vollzieht, so bietet sich ein sehr

1) § I des Gesetzes für Sicherungsmaßnahmen auf einzelnen Gebieten der gewerbl. Wirtschaft vom 5. 5. I95I, BGB1. I, S. 299, mit nachfolgenden Änderangen.

62) Rechtsgrundlage ist das in der vorigen Note zit. Gesetz. Ein Verzeichnis der hierzu erlassenen zahlreichen Verordnungen findet sich in Das Deutsche Bundesrecht, Loseblatt-Gesetzessammlung, Teil III G 20, S. I 7 ff.

o) Rechtsgrundlagen: Getreidegesetz vom 4. Ir. 1950, BGBl. S. 72 r ; Vieh- und Fleischgesetz vom 25. 4. 195I, BGBl. I, S. 272; Milch- und Fettgesetz vom 28. 2. 1951, BGBl. I, S. I35 - jeweils mit Abänderungsgesetzen und zahlreichen Durchführungsbestimmungen. Die Zuckerbewirtschaftung (Zuckergesetz vom 5.1.195I - BGBl.I, S.47, 852) ist weitgehend abgebaut.

44) § I des "Sicherungsgesetzes" (oben Anm. 6I) hat enumerativen Charakter, worauf mit Recht Hamann, Wirtschaftslenkung und Grundgesetz, Betriebsberater, 195I, S. 341, hinweist. 
buntscheckiges Bild. In oberster Instanz ist jeweils eines der großen Bundesministerien zuständig, für Wirtschaft bzw. für Emährung und Landwirtschaft. ZweckmäBigerweise hat man unterhalb von ihnen gewisse Bundesoberbehörden errichtet, in denen die Lenkungsfunktionen verwaltungsmäßig konzentriert sind, wenn auch nur als Durchführungsaufgabe. Es sind dieses vor allem die Bundesstelle für den Warenverkehr der gewerblichen Wirtschaft ${ }^{65}$ ), sodann - mehr mit dem Schwergewicht nach der AuBenwirtschaft - die AuBenhandelsstelle für Erzeugnisse der Emährung und Landwirtschaft ${ }^{66}$ ), auBerdem die Bundesstelle für Besatzungsbedarf ${ }^{67}$ ). Aber das war auf dieser Ebene noch nicht ausreichend, um so mehr als die Landesbehörden jeweils nur mit nachgeordneten Funktionen betraut sind ${ }^{68}$ ), die nicht allzu sehr ins Gewicht fallen. Eine Bewirtschaftung drängt immer zur Zentralisation. Als Lenkungsorgane sind ferner eingeschaltet und in ihrem Bereich besonders wichtig die vier großen Einfuhrund Vorratsstellen der Emährungswirtschaft (für Getreide und Futtermittel, für Vieh und Fleisch, für Fette und für Zucker), wozu noch die $M$ ühlenstelle kommt ${ }^{69}$ ). Sie sind sämtlich rechtsfähige Anstalten des öffentlichen Rechts, also Bestanđteil der öffentlichen Verwaltung, wenn auch mit einem Eigenleben. In ihren Organen finden sich Ministerialvertreter mit solchen der beteiligten Wirtschaftskreise zusammen. Selbstverwaltung im echten Sinne liegt bei ihnen nicht vor $\left.{ }^{70}\right)$. - Weniger bekannt sind andere Erscheinungen, wie etwa die vor kurzem errichtete Schrottvermittlungs-GmbH. ${ }^{\text {71)}}$. Sie ist, ungeachtet ihrer privatrechtlichen Verfassung, an entscheidender Stelle der Schrottbewirtschaftung eingesetzt und dürfte als eine Art von Vermittlungssyndikat monopolartigen Charakters angesprochen werden; $\mathrm{daB}$ sie insoweit öffentlich-rechtliche Funktionen ausübt, steht außer Zweifel. Was die Kohle anbetrifft, so sind hier die Dinge noch im Fluß. Die bisherige „Deutsche Kohlenbergbauleitung" ist ebenso wie der "Deutsche Kohlenverkauf" in privatrechtlicher Form errichtet worden, aber auf Grund Besatzungsrechts ${ }^{\mathbf{2}}$ ). Als Außenstellen des DKV wirkten bisher die Tochtergesellschaften

4) Gesetz vom 29. 3. I95I, BGBl. I, S. 216.

e) Gesetz vom 17. 12. 195I, BGBI. I, S. 967.

67) Vgl. VO. Besatzungsbedarf II/5I vom 5. 10. 195I, BAnz. Nr. 194.

18) Bei Kohle etwa $\S 5(2)$ der VO. Kohle $1 / 51$ vom 22. 3. 195I, BAnz. Nr. 59.

09) $\S 7 \mathrm{ff}$. des Getreidegesetzes, § I6ff. des Vieh- und Fleischgesetzes, $\S \mathrm{I} 4 \mathrm{ff}$. des Milch- und Fettgesetzes, $\S 8 \mathrm{ff}$. des Zuckergesetzes (siehe die Nachweise oben Anm. 63).

70) Gleicher Meinung wohl auch Scheuner, DOV, 1952, S. 612.

71) VO. Schrott I/52 vom 30. 7. 1952, BAnz. Nr. 147.

22) Vgl. E. R. Huber, DVBI. I952, S. 458, mit weiteren Nachweisen; auch Isay, Deutsches Kohlenwirtschaftsrecht im Rahmen des Schumanplans, 1952, S. $33 \mathrm{ff}$. 
der früheren Zwangssyndikate, reine Handelsgesellschaften mit öffentlichen Verteilungsaufgaben. Für die kommende Zeit ist die Ruhrkohle GmbH. in Essen ,zur Wahrnehmung kohlenwirtschaftlicher Aufgaben " errichtet worden, der eine Anzahl von dezentralisierten Verkaufsbüros beigegeben werden soll. Die Vermengung öffentlich-rechtlicher Aufgaben mit privaten Handelsfunktionen bringt Gefahren wegen der Interessenkollision mit sich. Derartige Organisationen sollten daher künftig juristisch besser durchgearbeitet, und es sollte dabei auf eine saubere Scheidung der Funktionen geachtet werden.

Uber Rechtsnatur nnd Inhalt der Verwaltungsakte zur Durchführung der Bewirtschaftung können ebenfalls nur Andeutungen gemacht werden. Als erster und wichtigster Akt kommt die Aufstellung der jährlichen Versorgungspläne in Frage, wie sie vor allem auf dem Ernährungsgebiet ${ }^{73}$ ), aber auch im gewerblichen Sektor vorgesehen sind ${ }^{74}$ ). Hierbei handelt es sich um Interna der obersten Lenkungsorgane, die noch keine Wirkungen nach außen haben, jedoch für alles Weitere von folgenschwerer Bedeutung sind. Denn anhand dieser Programme wird die Bewirtschaftung im einzelnen abgewickelt. Die Durchführungsmaßnahmen selbst ergehen vielfach in Form von „Lenkungsverfügungen“. Man hat sie in vier Gruppen eingeteilt: Herstellungsgebote, Verarbeitungsverbote und -gebote, Liefergebote und Kontingentierungen, d. h. mengenmäBige Beschränkungen ${ }^{75}$ ). So wertvoll dieser Einteilungsversuch ist - er wird der „Fülle der Gesichte“ nicht gerecht. Hinzu kommen noch die Anordnungen über die Vorratshaltung, die Festlegung von Bezugs- und Absatzwegen, Andienungs- und Anbietungspflichten, Schlußscheinzwang u. a.m. Sie werden ergänzt durch eine Reihe von Nebenverpflichtungen: zu einzelnen Meldungen, zu umfassenden statistischen Angaben, zur Erteilung von Auskünften, zur Führung von Geschäftsbüchern oder besonderen Lagerbüchern. Dieses dürften die wichtigsten Mittel zur Durchführung der Bewirtschaftung sein. Ihre weitverstreuten Rechtsgrundlagen ergeben sich aus den jeweiligen gesetzlichen Bestimmungen. Sie bedürfen aber noch häufig der konkretisierenden Verwaltungsverfügung.

Bei alledem liegt es nahe, nach den Rechtsschutzmöglichkeiten zu fragen. Wir haben dabei nicht die straf- oder ordnungsstrafrechtliche Seite im Auge; hier ist alles in Ordnung. Vielmehr in-

72) Vgl. $\$ 2$ des (oben zit.) Getreidegesetzes, des Vieh- und Fleischgesetzes und des Zuckergesetzes.

74) Etwa das Herstellungsprogramm des Bundeswirtschaftsministers auf dem Eisengebiet, hierzu Hamann, Zweifelsfragen der EisenlenkungsVO. (Westz.), Betriebsberater, 1952, S. $245 \mathrm{ff}$.

75) Rink. Formen und verfassungsmaßige Grenzen der Bewirtschaftung. MDR. 1952, S. 524, ein verdienstvoller, leider vereinzelter Beitrag. 
teressiert der Schutz durch Verwaltungsgerichte. Soweit die Bewirtschaftungsverfügungen von Landesbehörden ausgehen, boten und bieten die Landes-Verwaltungsgerichtsgesetze mit ihren Greneralklauseln genügend Möglichkeiten, um dem Betroffenen zu seinem Recht zu verhelfen. Merkwürdig, es gehört aber nach unserer Kenntnis zu den Seltenheiten, daB der Versuch gemacht wird, in Bewirtschaftungsangelegenheiten eine verwaltungsgerichtliche Klage anzubringen. Das dürfte im wesentlichen auf zwei sehr verschiedenartigen Gründen beruhen. Einmal fehlte es, soweit die Lenkungsverfügungen vơn einer Bundesbehörde oder einer bundesunmittelbaren Körperschaft ausgehen, bisher an einer in die Augen fallenden verwaltungsgerichtlichen $\mathrm{Zu}$ ständigkeit $\left.{ }^{76}\right)$. Mit der Errichtung des Bundesverwaltungsgerichtes wird das erfreulicherweise anders werden ${ }^{77}$ ), obwohl sich der Sitz in Berlin als für die Praxis nachteilig erweisen wird. Zum anderen aber bietet die Anrufung eines Verwaltungsgerichtes vielfach nicht diejenigen Möglichkeiten, die den Bedürfnissen der Wirtschaft entsprechen. Wird z. B. bei der Zuteilung eines Kohlenkontingentes vorschriftswidrig eine zu geringe Menge festgesetzt, so fehlt es dem Betrieb entsprechend an Kohle; er muß sich entweder so behelfen oder nach einem anderen Ausweg suchen. Vorsprache bei der ererlassenden Behörde, Ansetzung der Verbandsmacht, Mobilisierung eines befreundeten Abgeordneten - alles dies hilft weiter (und vor allem schneller) als das Klagerecht. Bei den belastenden Verfügungen, etwa einem Herstellungsgebot, ist die Lage etwas anders, weil hier die Strafdrohung befürchtet wird und im Streitfalle die Sache im strafgerichtlichen Verfahren ausgefochten werden kann. Im ganzen kann es also nicht wundernehmen, wenn bisher nur verhältnismäBig wenige Bewirtschaftungssachen verwaltungsgerichtlich anhängig geworden sind. Nur Gebührenstreitigkeiten und ähnliches sind häufiger. Hiervon abgesehen verfehlt aber der materielle verwaltungsgerichtliche Schutz überall dort seinen Zweck, wo infolge des raschen Wechsels der betrieblichen Verhältnisse aucl: ein obsiegendes Urteil uninteressant ist. Mit anderen Worten: die überkommene Form des verwaltungsgerichtlichen Schutzes erweist sich als unzureichend gegenüber den Eigenarten der modernen Wirtschaftsverwaltung. Gegenvorstellung,

70) Es ist richtig, daB auch schon vor ErlaB des Gesetzes über das Bundesverwaltungsgericht (s. folgende Anm.) Verwaltungsakte von Bundesbehorden vor den Landesverwaltungsgerichten angefochten werden konnten, vgl. Eyermann-Fröhler a.a.O., S. 74/75 mit weiteren Nachweisen. Aber sozusagen ,prozeßpolitisch" macht es einen Unterschied, vor allem vom Standpunkt des Rechtsuchenden aus, ob eine in die Augen fallende oder nur eine mittelbar deduzierte Gerichtszuständigkeit gegeben ist.

${ }^{77}$ ) Vgl. \$9 (I)a des Gesetzes über das Bundesverwaltungsgericht vom 23. 9. I952, BGBl.I, S. 625 ff.; hierzu Ule, Das Bundesverwaltungsgericht, DVBl. 1952, S. 519 Anm. 33. 
Einspruch und Beschwerde, obwohl schwächere Rechtsbehelfe, scheinen für die Wirtschaft wichtiger $z u$ sein als die Klage. Ihre bekannte Abneigung gegen das Prozessieren vor staatlichen Instanzen dürfte dabei eine Rolle spielen.

4. Mit dem Preisrecht wird ein weiteres bedeutsames Gebiet staatlicher Einwirkungsmöglichkeiten auf die Wirtschaft betreten. Zwar gilt im ganzen wieder das Prinzip freier Preisbildung, d. h. einer Preisbildung, die sich allein innerhalb der Wirtsch a ft vollzieht und vom Staat nicht beeinflußt wird. Dieses Prinzip ist aber an zahlreichen Stellen durchbrochen. Dabei handelt es sich nicht um vereinzelte Einsprengsel oder unwesentliche Reste aus der Zeit der totalen Preiskuratel. Es sind vielmehr wichtige Güter und gewerbliche Leistungen, zum Teil ganze Wirtschaftszweige, bei denen die Preise noch staatlich reguliert sind. Gleichwohl verläuft die Entwicklung, ausgehend von der bekannten Preisstoppverordnung von 1936 über den großen Wendepunkt der Freigabe-Anordnung vom Juni $194^{78}$ ) und viele spätere Preisvorschriften bis auf unsere Tage, weiter in Richtung auf völlige Freigabe der Preise. Besonders in den letzten Jahren sind die Preise bedeutsamer Grundstoffe - wie Holz, Nichteisenmetalle, Rohöle, Schrott und neuerdings Eisen - sowie einer Reihe sonstiger Waren freigegeben worden.

Was aber noch immer preislich gebunden ist, ist wichtig genug. Aus dem Bereich der Landwirtschaft : entscheidende Grundnahrungsmittel wie Milch, Getreide und Brot, ferner Branntweir. und Handelsdünger; aus dem Bereich der gewerblichen Wirtschaft: Kohle, Strom, Wasser, Gas, Edelrnetalle, um nur die wichtigsten anzuführen; aus dem Verkehr: Güternah- und -fernkraftverkehr, Seehafenspedition, Binnenschiffahrtsfrachten und anderes. In diesen Zusammenhang gehören auch die Tarife der Bundesbahn und Bundespost, die, wenngleich mittelbar staatseigen betrieben, einen wesentlichen Teil der allgemeinen Verkehrswirtschaft ausmachen. Bei der starken Bautätigkeit der öffentlichen Hand ist auch auf die VO über die Baupreisbildung für öffentlich finanzierte Aufträge ${ }^{79}$ ) hinzuweisen, von der natürlich das Baugewerbe am stärksten unmittelbar berührt ist.

Das Preisrecht als Ganzes gliedert sich in zwei große Teile, die staatliche Bildung und die staatliche Uberwachung von Preisen. Die letztere kann hier beiseite bleiben; sie ist reiner $\mathrm{Ge}-$ setzesvollzug und besitzt keinen Lenkungscharakter. Anders natürlich bei der Preisbildung, diese im weiteren genommen. Hier setzt der Staat - überwiegend der Bund - durch Gesetz

78) AO. über Preisbildung und Preisüberwachung nach der Wăhrungsreform vom 25.6. 1948, WiGBl., S. 6r.

79) Baupreis-VO. vom II. 5. 195: - VO. Pr. Nr. 32/51, BAnz. Nr. 92 
oder Rechtsverordnung Preise generell fest. Es geschieht dieses, um bestimmte wirtschaftliche oder sozialpolitische Ziele $\mathrm{zu}$ erreichen; das tritt besonders hervor bei den "Anreizpreisen“, etwa für vorzeitige Ablieferungen (Frühdruschprämie) oder für Mehrförderungen (Kohle), auch bei den Preisvergünstigungen aus sozialen Gründen. Oder der Staat will gewissen, aus den allgemeinen Preistendenzen entstehenden Ubeln steuern. Alle diess Preisfestsetzungen erfolgen - theoretisch - autonom, d. h. ohne Mitwirkung der Wirtschaft. Freilich kann er dabei die Lage des jeweiligen Marktes nicht unberücksichtigt lassen, wie er auch nicht umhin kann, sich des Rates der betreffenden Wirtschaftskreise zu bedienen - mit der Folge meist erheblicher Auseinandersetzungen zwischen diesen und den Fachressorts bis hinauf zu dem Minister. Solche Kämpfe zeigt die Praxis jeden Tag, nicht nur bei neuen Preisfestsetzungen, sondern auch bei umstrittenen Preisfreigaben. - Die eben behandelte Form könnte man rechtssatzmäßige Preisfestsetzungen nennen. Sie findet sich nahezu als Regel. Daneben gibt es andere Formen, wie etwa die st aatlich anerkannten Preise. Nach einer Anordnung aus dem Jahre $194^{80}$ ) können industrielle Hersteller und Einführer eigene Verbraucherpreise bilden, die dann der Preisbehörde gemeldet, von ihr genehmigt und damit staalich anerkannt werden $\left.{ }^{81}\right)$. Praktisch ist diese Möglichkeit nicht von Belang, dogmatisch aber von Interesse. Denn hier übernimmt der Staat einen marktwirtschaftlich gebildeten Preis, während es bei den üblichen rechtsatzmäBigen Preisfestsetzungen sein Wille ist, der den Preis bestimmt, zumeist gegen die Markttendenzen. Als weitere Form darf auf die in dividuelle Preisbeanstand ung hingewiesen werden, die sich, soweit wir sehen, nur noch bei den Grundstückspreisen findet. Der einzelne Kaufvertrag muß der Behörde vorgelegt werden. Eine Beanstandung des Preises hat die Nichtigkeit des Vertrages zur Folge, es sei denn, daß er zu dem zulässigen Preis aufrechterhalten wird. Die Unbedenklichkeitsbescheinigung dagegen wirkt entweder als Bestätigung der Zulässigkeit des Preises oder als Bewilligung einer Ausnahme von dem Preisstopp.

In den juristischen Einzelheiten stützt sich das gegenwärtige Preisrecht auf den herkömmlichen Bestand. Höchstpreise, die nicht über-, aber unterschritten werden dürfen; Festpreise, von denen keine Abweichung gestattet ist; Mindestpreise, die nicht unterboten, wohl aber überboten werden dürfen; Rahmenpreise (,,von ... bis“), die dem einzelnen Geschäftsabschluß einen

so) PR. $130 / 4^{8}$ vom 27. $12.194^{8}$ über Verbraucherpreise, VfWMBl. II, S. 196.

81) Ahnlich die Festsetzung von Binnenschiffahrtsfrachten durch die Frachtenausschüsse, vgl, VO. vom 25. 9. 1935, RVerkehrsBl, 1935, S. $203 \mathrm{ff}$. - mit nachfolgenden Ânderungen. 
gewissen Spielraum lassen - dies alles ist uns geläufig. Nur ist der wirtschaftspolitische $Z$ weck dieser einzelnen Arten von Preisfe:isetzungen verschieden. Dem Festpreis liegt der Sinn zu Grunde, daß sowohl der Käufer nicht zu sehr belastet werden, als auch der Verkäufer zu einem ausreichenden Erlös kommen soll. Höchstpreise dagegen dienen nur dem Käufer, letztlich dem Verbraucher, wohingegen die Mindestpreise, vor allem in der Landwirtschaft, eindeutig zum Schutze der Erzeuger bestimmt sind. So zeigen sich schon in den rechtlichen Formen der Preisfestsetzungen ganz bestimmte Ziele, auf die das wirtschaftliche Geschehen hingelenkt werden soll.

Das ganze AusmaB der preisrechtlichen Lenkung tritt aber erst hervor, wenn man sich anhand der konkreten Wirtschaftsvorgänge und der hieran beteiligten Wirtschaftsstufen vergegenwärtigt, wo die Preisregelung überall einsetzt und was dabei alles einbezogen wird. Es sind nicht etwa nur "die" Erzeugerpreise oder nur ,die" Verbraucherpreise, die durch staatlichen Hoheitsakt festgelegt werden. Handels- und Bearbeitungsspannen, Rabatte, Skonti, Verpackungszuschläge, Qualitätsmaßstäbe, Zahlungs- und Lieferungsbedingungen, Frachtbasen, Ortsklassen u. a. m. finden sich - teils allein, teils miteinander verbunden, teils in völliger Lückenlosigkeit - als Inhalt staatlicher Preisregelungen. Bei der ungeheuren Verflochtenheit der Produktions- und Absatzvorgänge hätte es auch keinen Sinn, einfach nur den nackten Preis ein er Wirtschaftsstufe zu erfassen. Mit anderen Worten: das Bild, das eine konkrete Preisnormierung bietet, spiegelt die ganze Fülle der kaufmännischen Usancen und $\mathrm{Ab}$ sprachen wieder, die ohne eine staatliche Preisregulierung Gegenstand der freien vertraglichen Abmachungen sein würden.

Was den Rechtsschutz auf dem Gebiet des Preisrechtes anbetrifft, so haben sich die Dinge völlig verschoben. Die bekannte Ausnahmegenehmigung, d. h. die behördliche Erlaubnis, von einer Preiśnorm abzuweichen, war während der nationalsozialistischen Zeit ebenso häufig wie wichtig. Zwischen Zusammenbruch und Währungsreform ist sie wegen der damaligen chaotischen Umstände kaum gebraucht worden. Sie ist heute, nachdem die Freigabe der Preise zunehmend fortschreitet, zu einer Seltenheit geworden. Daher kann die Frage, wie der Ablehnung eines Antrages auf Ausnahmegenehmigung verfahrensrechtlich begegnet werden kann, auf sich beruhen. Für die Wirtschaft als dem Objekt der staatlichen Intervention konzentriert sich vielmehr das ganze Interesse auf den ErlaB bzw. die Aufhebung der Vorschriften des Preisrechts, mit anderen Worten auf das bekannte Ringen zwischen den Organisationen der Wirtschaft und den Fachressorts bzw. den politischen Instanzen im vorparlamentarischen sowie im parlamentarischen Raum. Hierbei handelt es sich aber um 
wirtschaftspolitische Auseinandersetzungen. Die Frage des Schutzes der Wirtschaft gegenüber dem Staat tritt hier nicht in der spezifischen Form des Rechtsschutz bedürfnisses auf.

Bei der Preisüberwachung ist dagegen auf einen neuralgischen Punkt aufmerksam zu machen, nämlich die Auskunftspflicht. Sie spielt bei der behördlichen Aufklärung etwaiger Preisverstöße, sei es auf dem Gebiet der gebundenen, sei es auf dem der freien Preise, eine beachtliche Rolle. Die Offenlegung interner Betriebsvorgänge, unter Umständen verbunden mit Büchereinsicht und Durchsuchung von Betriebsräumen, ist in jedem Fall - nicht nur im Steuer- und Devisenrecht, wo sie am stärksten ausgebildet ist - eine sehr einschneidende Angelegenheit. Leider wird weithin verkannt, da $B$ es sich dabei, gleichviel ob die private Sphäre eines Menschen oder die nicht minder schutzwürdige eines Betriebes betroffen wird, um einen der schwersten staatlichen Eingriffe handelt. $\mathrm{Da} B$ als Rechtsgrundlage hierfür nur die schlecht redigierte, in den Wirren der ersten Inflationszeit erlassene VO. über Auskunftspflicht ${ }^{\mathbf{B 2}}$ ) zur Verfügung steht, ist ein Mißstand, zumal die auf diese VO. gestützten Befugnisse nicht nur in Fällen konkreten Verdachts, sondern manchmal auch ohne einen solchen, d. h. zu allgemeinen Uberprüfungszwecken angewendet werden. Die Anfechtung von Auskunftsersuchen ist zwar nach den landesrechtlichen Gesetzen, letztlich auch vor dem Verwaltungsrichter, zulässig. Nichts aber ist kennzeichnender für die ganze Situation, als daB es in der Praxis kaum jemals zu derartigen Rechtsmittelverfahren kommt, weil die Behörde, der Unsicherheit ihrer Rechtslage bewußt, zumeist von der Durchsetzung eines Auskunftsersuchens abläßt, falls der Betrieb sich weigert, einem solchen zu entsprechen.

Im übrigen liegen die entscheidenden Rechtsschutzprobleme bei der Ahndung von Preisverstößen, also nicht auf der verwaltungsrechtlichen Seite. In Frage kommt hier sowohl die Verletzung einer einzelnen Preisnorm als auch die uns seit langem geläufige „Preistreiberei“, nämlich dort, wo es keine besonderen Preisvorschriften gibt, sondern nur das allgemeine Gebot gilt, auch bei freier Preisbildung keine unangemessenen Entgelte $z u$ fordern oder zu gewähren. Seit dem Erlaß des Wirtschaftsstrafgesetzes $^{83}$ ) und des Gesetzes über Ordnungswidrigkeiten ${ }^{84}$ ) kann in diesem Zusammenhang nicht mehr über mangelnden Rechtsschutz geklagt werden. Allerdings ist der Tatbestand der Preisreiberei nach wie vor derart kautschukartig gefaßt und seine Anwendung, auch soweit Richtpreise bekanntgegeben sind, für

82) RGBl. I, S. 723.

s9) Vom 26. 7. 1949 i.d.F. vom 25. 3. I952, BGBl. I, S. I90.

r) Vom 25. 3. 1952, BGBl. I, S. I77. 
alle Beteiligten im Einzelfall derart schwierig, daß er immer noch nicht als objektiv befriedigend angesehen werden kann. Das liegt aber im Wesen der Materie und kann hier nicht weiter verfolgt werden.

$$
\text { V. }
$$

Schließlich muß der arbeitsrechtliche Bereich noch behandelt werden. Denn für die praktische Wirtschaft sind Arbeitskräfte ebenso wichtig wie Rohmaterial, Hilfsstoffe oder Handelsware, und die Aufwendungen, die einerseits in Gestalt von Löhnen und Gehältern, andererseits in Gestalt von Anschaffungspreisen den Betrieb, einen Wirtschaftszweig oder die ganze Volkswirtschaft belasten, fallen mit gleicher Schwere ins Gewicht. Davon abgesehen, kennen wir aus der eigenen Vergangenheit zahlreiche Beispiele dafür, wie auf arbeitsrechtlichem Gebiet und mit den hier zur Verfügung stehenden Mitteln nicht nur Sozialpolitik, sondern gerade auch Wirtschaftslenkung ${ }^{85}$ ) betrieben worden ist.

Uberblickt man in dieser Hinsicht unsere gegenwärtige Situation ${ }^{86}$ ), so sind zwei grundsätzliche Feststellungen vorweg zu treffen. Einmal die, daß unser geltendes Arbeitsrecht überwiegend von dem Gedanken des Sozialschutzes beherrscht ist gemäB Art. 20 (I) BGG, nach welchem die Bundesrepublik auch ein sozialer Staat sein will. „Dirigistische" Möglichkeiten, zumal zu wirtschaftspolitischen Zwecken, finden sich nur in geringem Umfang, und wenn, dann nur in Verbindung mit sozialpolitischen Zielsetzungen. Die weitere Feststellung betrifft die Tatsache, $\mathrm{daB}$ in unserem heutigen Recht zwei überaus wichtige Einrichtungen nicht mehr vorhanden sind: eine Lenkung des Arbeitseinsatzes, wie sie vor allem in der VO. über die Beschränkung des Arbeitsplatzwechsels von I939 niedergelegt war, findet nicht mehr statt (entsprechend Art. I2 Abs. I Satz I BGG); ferner gibt es keine staatliche $Z$ wangsschlichtung kollektiver Lohnkonflikte mehr, wie das in der Weimarer Zeit der Fall war. Mit dem ersteren Mittel war der Staat Herr über die gesamten Arbeitskräfte, und mit der Zwangsschlichtung konnte er die Lohnentwicklung entscheidend beeinflussen.

Die heutigen Eingriffsmöglichkeiten des Staates in den sozialpolitischen Verlauf sind demgegenüber sehr viel beschränkter. Eine direkte Arbeitsmarktpolitik vermag er nicht zu betreiben. Er bedient sich einer bundesunmittelbaren Körperschaft, der kürzlich wiedererrichteten Bundesanstalt mit Parität und ausgebildeter Selbstverwaltung, und diese Anstalt ist beschränkt auf bloße Arbeitsvermittlung, die sie sich freilich allein vorbehalten

85) In gleichem Sinne Ballerstedt a.a.O., S. 137.

86) Vgl. auch A. Hueck, Freiheit und Zwang im deutschen Arbeitsrecht, in: Staat und Wirtschaft, Festgabe f. H. Nawiasky, 1950, S. $187 \mathrm{ff}$. 
hat. Der Chef der Bundesanstalt kann allerdings Anweisungen geben, daß bestimmte Personengruppen bevorzugt in Arbeit zu vermitteln sind, wenn ,staatliche Notwendigkeiten dazu vorliegen". Diese Weisungsbefugnis stellt eine, möglicherweise auch wirtschaftspolitisch verwendbare Lenkungsmöglichkeit dar; sie ist aber wenig wirksam und wird kaum gebrauch t. Das Wesentliche ist: der Arbeitnehmer ist dem Staat gegenüber frei, welches Beschäftigungsverhältnis er eingehen, der Arbeitgeber ebenso frei, wen er einstellen will. Vollzogene Einstellungen müssen vom Betrieb der Behörde angezeigt werden, sie sind aber nicht erlaubnispflichtig. Anders liegt es nur bei der Beschäftigung ausländischer Arbeitnehmer ${ }^{87}$ ), deren Einstellung von einer behördlichen Genehmigung bzw. einer Arbeitserlaubnis abhängig ist. Bei der Erteilung solcher Genehmigungen sind u. a. "die Bedürfnisse der inländischen Wirtschaft" und „die Lage des inländischen Arbeitsmarktes" zu berücksichtigen, also Gesichtspunkte der Arbeitsmarkt- und Wirtschaftspolitik, jedoch ohne Einschlag von Sozialschutz. Dagegen steht im Schwerbeschädigtenrecht der Sozialschutz im Vordergrund und hat hier zu den bekannten Pflichteinstellungsquoten der Betriebe geführt. Bezüglich Kurzarbeit und Entlassungen ist dem Unternehmer ebenfalls weitgehend Freiheit gewährt. Die Einführung von Kurzarbeit ist lediglich anzeigepflichtig, und nur zur Vermeidung von Massenentlassungen bedarf sie unter Einschaltung einer Sperrfrist behördlicher Genehmigung. Diese Regelung, wenngleich spürbar für den Unternehmer, geht jedoch lange nicht so weit, wie dieses nach der alten "Stillegungsverordnung" von I920/23 der Fall gewesen ist.

Was die Arbeitsentgelte betrifft, so erfolgt deren Festlegung grundsätzlich in freier Vereinbarung zwischen den Tarifparteien. Dieser grundlegende Satz, der schon aus der GewO. von I869 stammt ( $\$$ I05), der aber auch heute wieder für die Distanzierung des Staates gegenüber der Entwicklung der Löhne und Gehälter kennzeichnend ist, findet sich gegenwärtig merkwürdigerweise nicht im Tarifvertrags-Gesetz, sondern in dem über die Festsetzung von Mindestarbeitsbedingungen. Nur dort, wo es infolge unzureichendem Aufbau der Organisationen der Sozialpartner nicht zu tarifvertraglichen Abschlüssen kommen kann, greift der Staat durch die Festsetzung von Mindestarbeitsbedingungen ein. Der Schutz der betreffenden Arbeitnehmergruppen hat hier wiederum Pate gestanden. Wie sehr unser Arbeitsrecht dem frei ausgehandelten Tarifvertrag den Vorzug gibt, geht schon daraus hervor, daß bei einer etwaigen Kollision

ir) BAnz. Nr. 43 vom r. 3. 1952. 
zwischen Tarifvertrag und staatlichen Mindestarbeitsbedingungen der erstere den Vorrang hat.

Ist ein Tarifvertrag geschlossen, so bedarf es seiner Registrierung bei der Behörde. Dieser Akt hat aber regelmäßig nur deklaratorische Bedeutung, und ein nichtregistrierter Tarifvertrag ist, von wenigen landesrechtlichen Ausnahmen abgesehen, gleichwohl gültig. In der Folge besteht dann die Möglichkeit, da $\beta$ er von der Arbeitsbehörde für allgemeinverbindlich erklärt wird. Bezeichnend ist hier aber, daß der Inhalt des Tarifvertrages schon vorliegt - als Ergebnis der Verhandlungen zwischen den Sozialpartnern -, und der Staat kann sich nur überlegen, ob er auf Antrag einer der Partner den Anwendungsbereich des Tarifvertrages maximal ausweitet, ihn also allgemeinverbindlich macht. Neben anderen Voraussetzungen muB hierfür ein öffentliches Interesse vorliegen. Darin wird man aber kein durchgreifendes und kein eigenständiges Mittel für eine staatliche Lohnpolitik sehen können, vor allem wegen des nur akzessorischen Charakters einer solchen Erklärung. Die Voraussetzungen für eine Allgemeinverbindlichkeits-Erklärung sind übrigens recht schwer, so daß man sich wundern muß, daß in den letzten Jahren doch relativ häufig davon Gebrauch gemacht worden ist.

Als Schlußstück einer kollektiven Lohnauseinandersetzung bleibt die Frage, wie der Staat es bei fehlender Einigung der Sozialpartner irgendwie doch zu einem Abschluß und damit zur Beendigung des tariflosen Zustandes bringen kann. Dafür steht gegenwärtig nur ein relativ wenig ausgebautes Ausgleichs- und Schiedsverfahren zur Verfügung ${ }^{88}$ ). Staatliche Schiedsausschüsse (ohne Erscheinungszwang!) sollen zunächst vermitteln. Ein etwaiger Schiedsspruch ist aber nicht verbindlich, es sei denn, die Parteien haben sich ihm im vorhinein unterworfen oder sie nehmen ihn nachträglich an. Ist beides nicht der Fall, so hat der Staat heute keine rechtliche Möglichkeit, einen bestehenden Arbeitskampf zum Ende zu bringen. Nur ein Zwangstarif alten Stiles könnte insoweit helfen. $\mathrm{DaB}$ diese Einrichtung fehlt, wurde schon als bedeutungsvoll hervorgehoben. Wenn unser Staat aber den Grundsatz der Nichteinmischung in den einzelnen Lohnkampf aufrechterhalten will, wie sich das mindestens aus der gegenwärtigen Rechtslage ergibt, sollte es bei dieser verbleiben. Sonst werden die Arbeitskämpfe, mindestens die größeren, noch mehr politisiert, als sie es ohnehin schon sind.

(Abgeschlossen im November 1952)

8) Kontrollratsgesetz Nr. 35 vom 20.8. 1946, KRABl. I946, Nr. Io, S.174- 


\title{
2a. Leitsätze des Mitberichterstatters über:
}

\section{Die staatliche Intervention im Bereich der Wirtschaft}

\author{
Rechtsformen und Rechtsschutz
}

I. Wirtschaftslenkung ist nicht nur eine innerstaatliche Erscheinung. Es gibt heute auch schon einen beachtlichen inter- bzw. übernationalen Dirigismus.

2. Kennzeichnend für die deutsche Nachkriegssituation ist der doppelte Interventionismus, einmal von seiten der Besatzungsmächte, zum anderen von deutscher Seite. Die ersteren Maßnahmen, wenngleich anderen als wirtschaftspolitischen Zielen entsprungen, haben die westdeutsche Wirtschaft tiefgreifend umgestaltet.

3. Das Ausmaß der Gewerbefreiheit ist ein Prüfstein für das Vorliegen von staatlichem Interventionismus. Trotz deutlicher Tendenz zum Abbau der Zulassungsbeschränkungen ist die Rechtslage im grundsätzlichen nicht geklärt. Die Gererbezulassung kann $z u$ den Mitteln der staatlichen Wirtschaftslenkung gerechnet werden. Ihre Bedeutung als Lenkungsinstrument wird überschätzt.

4. Kartellgesetze mit Verbotsgehalt besitzen einer freien Wirtschaft gegenüber Lenkungscharakter, weil eine solche Wirtschaft zur Kartellierung drängt. Die alliierte Kartellgesetzgebung nach 1945 sowie das kommende deutsche Kartellgesetz stellen, wenn der Entwurf des letzteren Wirklichkeit wird, Lenkungsmaßnahmen großen Stils dar.

5. Die wirtschaftliche Betätigung der öffentlichen Hand bedeutet Mitgestaltung der Wirtschaft durch den Staat. Bei der Sozialisierung tritt das am stärksten hervor, daneben auch bei den Versorgungsunternehmen. Als neuer großer Zweig ist bei diesen der gemeinnützige Wohnungsbau der Gemeinden hinzugekommen.

6. Das Institut der Staatsaufsicht über ganze Wirtschaftszweige hat sich weiter ausgebreitet. Es ist möglich, daß mit seiner Hilfe Wirtschaftssteuerung getrieben wird; in der gegenwärtigen Zeit scheint die Uberwachung in technischer Hinsicht im Vordergrund zu stehen.

7. Das entscheidende Lenkungsinstrument des Staates stellt heute das Steuergesetz dar. 
8. Die Förderung der Wirtschaft mit öffentlichen Mitteln gehört zu den charakteristischen Merkmalen unserer jüngsten Entrevicklung. Die zentralgesteuerten Kreditprogramme sind insgesamt von sehr erheblichem Ausmaß, entsprechend groß die damit verbundenen Lenkungsmöglichkeiten. Die Einschaltung zahlreicher öffentlicher oder halböffentlicher Kreditinstitute bei der Einzelvergebung der Gelder stellt ein Novum dar.

9. Die Bewirtschaftung ist die augenfälligste Erscheinung des staatlichen Interventionismus. Sie besitzt in Westdeutschland wesentliche Bedeutung nurmehr auf dem Ernährungsgebiet als marktordnende Beweirtschaftung. Die Mangel-Bewirtschaftung auf dem gewerblichen Sektor ist in zunehmendem Abbau begriffen. Bei der Organisation finden sich neben öffentlichen Behörden oder Körperschaften auch der Form nach privatrechtliche Träger der Bewirtschaftung. Die verwaltungsgerichtliche Klngemöglichkeit erweist sich gegenüber den Bedürfnissen der Wirtschaft vielfach als unzureichend.

Io. Trotz grundsätzlich freier Preisbildung finden sich noch zahlreiche staatliche Preisfestsetzungen. Ihre Rechtsformen lassen wirtschaftspolitische Zielsetzungen erkennen. Ausnahmegenehmigungen sind selten geworden. Bei dem Rechtsschutz steht die straf- bzw. ordnungsstrafgerichtliche Seite im Fall von Preisverstößen im Vordergrund.

II. Der arbeitsrechtliche Bereich ist heute ïberwiegend vom Sozialschutz bestimmt. Obroohl an vereinzelten Punkten möglich, wird hier kaum mehr staatlich gelenkt. Dieses gilt insbesondere bezüglich des Arbeitseinsatzes und der Höhe der Arbeitsentgelte. 


\section{Die staatliche Intervention im Bereich der Wirtschaft}

Rechtsformen und Rechtsschutz

3. Aussprache

Spanner-Graz: Die beiden Hauptreferate des Vormittags haben in so ausgezeichneter Weise nicht nur die allgemeinen Fragen der staatlichen Intervention im Bereich der Wirtschaft beleuchtet, sondern darüber hinaus zu zahlreichen Einzelfragen in außerordentlich instruktiver Weise Stellung genommen, so da $B$ es schwer fällt, hierzu noch einige ergänzende Bemerkungen zu machen.

Was ich hierzu zu sagen habe, kann von vornherein nur eine kurze Randbemerkung, eine kleine Ergänzung aus dem österreichischen Rechtskreise sein, eine Ergänzung, die dazu bestimmt sein mag, einige Probleme zu beleuchten, die sich bei uns speziell in der Praxis ergeben haben.

Ich möchte eingangs darauf hinweisen, $\mathrm{da} B$ schon in den beiden Referaten des Vormittags darauf aufmerksam gemacht wurde, $\mathrm{da} B$ wir Maßnahmen, die wir unter dem Titel Intervention des Staates in der Wirtschaft erfassen, nicht nur in der jüngsten Zeit antreffen, sondern daß wir auch schon in der älteren Gesetzgebung Beispiele hierfür finden. Auch aus dem österreichischen Rechtskreis mag hier auf das Gewerberecht hingewiesen werden, dann aber scheint es mir wichtig, den Bereich des Baurechtes zu erwähnen, in dem ja verhältnismäBig früh schon über bloB polizeiliche Gesichtspunkte hinaus eine planende Tätigkeit des Staates in Erscheinung tritt. Das gleiche gilt etwa für den Bereich des Forstrechtes, für den Bereich des Wasserrechtes, wobei das Wasserrecht im Zusammenhang mit dem Energierecht wesentlich an Bedeutung gewonnen hat. Ferner sei erwähnt der weitere Bereich der Bodenreform, die in Österreich seit der Bauernbefreiung in Jahre 1848 stets eine Rolle gespielt hat und spielt. Die älteren Maßnahmen im Bereich der Staatsintervention sind allerdings im wesentlichen noch lenkende Maßnahmen ohne wesentlichen $\mathrm{Z}$ wang, die neuere Zeit zwischen den beiden Weltkriegen und während der Kriege brachte den dichten Bereich von ZWangsmaßnahmen, wie wir sie heute auf diesem Gebiet in weitem Umfang sehen. Es sind natürlich die Maßnahmen der Intervention des Staates nicht nur bedingt durch die kriegerischen Entwicklungen, sondern sie sind wesentlich wohl auch bedingt durch andere ökonomische Vorgänge, etwa vor allem durch die Ausweitung der Industrialisierung, die Zusammenballung großer 
Menschenmassen in den Städten, also durch Umstände, die wohl durch die Kriege eine Verschärfung erfahren haben, die aber vielleicht auch ohne die Kriegswirtschaft zu einer stärkeren Staatsintervention geführt hätten.

Wie schon die Hauptreferenten gezwungen waren, weite Bereiche von der Erörterung auszuschließen, so gilt das natürlich umso mehr für einen Diskussionsbeitrag, der sich in noch stärkerem Ausma $B$ darauf beschränken muB, nur einige und wichtige Dinge hervorzuheben. Ich möchte daher von vornherein von der Erörterung ausschließen die finanzpolitischen Maßnahmen und die Maßnahmen der Arbeitslenkung. Ich möchte im folgenden schlagwortartig einen Überblick geben über die wichtigsten Lenkungsmaßnahmen im engeren Sinn und daran eine Darstellung einiger Rechtsprobleme anknüpfen, die vielleicht am Vormittag noch nicht näher berührt worden sind, insbesondere Rechtsprobleme vom organisatorischen Standpunkt aus und soweit sie auch zusammenhängen mit der bundesstaatlichen Organisationsform.

Was zunächst die Sachgebiete anlangt, auf denen wir in Österreich von einer staatlichen Intervention im Bereich der Wirtschaft sprechen können, so sind es selbstverständlich mehr oder weniger die gleichen oder fast die gleichen Sachgebiete, wie sie sich überall in größerem oder kleinerem AusmaB vorfinden. Ich möchte hier nach dem historischen Werdegang an erster Stelle erwähnen die Maßnahmen der Bodenreform, die ja in ihrer gesetzlichen Festlegung ein eindrucksvolles Spiegelbild der jeweiligen wirtschaftspolitischen Auffassungen $\mathrm{zu}$ geben vermögen. Unter den Maßnahmen der Bodenreform sind jene Maßnahmen auf dem Gebiet der Landeskultur zu verstehen, welche die gegebenen Besitz-, Benützungs- oder Bewirtschaftungsverhältnisse den geänderten sozialen oder wirtschaftlichen Anschauungen oder Bedürfnissen entsprechend, einer planmäßigen Neuordnung oder Regulierung unterziehen wollen. Dies ist der Begriff der Bodenreform, wie er der österreichischen Verfassungslage und Gesetzgebung entspricht und wie er in der Rechtsprechung des Verfassungsgerichtshofes (Sammlung der Erkenntnisse des Verfassungsgerichtshofes, Nr. 1390) herausgearbeitet wurde. Zu diesem Bereich der Bodenreform sei - ohne daB natürlich in irgendeiner Weise auf Einzelmaßnahmen eingegangen werden kann - erwähnt, daß hier Sonderverwaltungsbehörden (Agrarbehörden) eingerichtet sind, wobei den kollegialen Landesagrarsenaten und dem obersten Agrarsenat eine besondere Bedeutung zukommt. Ergänzend zu diesen Maßnahmen treten dann einschränkende Maßnahmen über den Verkehr mit Grundstücken in dem Grundverkehrsgesetz (BGBl. Nr. 25I/37, 123/46), wonach zu bestimmten Rechtsgeschäften über land- und forstwirtschaftliche Grundstücke die Zustimmung besonderer Kommissi- 
onen (Grundverkehrskommissionen) erforderlich ist. Dazu kommen dann weiter - das Reichserbhofgesetz ist aufgehoben - die Vorschriften des sogenannten Anerben- und Höferechtes in einigen Ländern, Vorschriften, welche den Zweck verfolgen, im Rechtsverkehr unter Lebenden und zum Teil beim Eigentumsübergang von Todes wegen für die Erhaltung des mittleren und kleineren landwirtschaftlichen Besitzes zu sorgen.

Im Anschluß an diese Maßnahmen der Bodenreform seien erwähnt die eine erhebliche Rolle spielenden Maßnahmen im Bereich der Wohnraumwirtschaft, Maßnahmen, die im besonderen Ausma $\beta$ durch die Kriegsereignisse notwendig geworden sind. Hier sind zwei große Gruppen von Bestimmungen zu unterscheiden, nämlich einmal die Vorschriften, welche sich eine Förderung des Baues von Wohnhäusern zum Ziele gesetzt haben, eine Förderung des Baues von Wohnhäusern durch die private Hand und in Form des sozialen Wohnhausbaues, also vor allem des kommunalen Wohnhausbaues, und zweitens die Bestimmungen zur Verteilung des allenfalls zur Verfügung stehenden Wohnraums. Für den Aufbau des durch den Krieg zerstörten Wohnraumes gelten in erster Linie die Bestimmungen des Wohnhauswiederaufbaugesetzes (BGBl. 130/48 mit Novellen), die eine finanzielle Förderung dieses Wiederaufbaues und ebenfalls eine finanzielle Hilfe zur Wiederbeschaffung zerstörten Hausrates geben. Eine sehr unbefriedigende Rechtslage ergibt sich - das liegt in der Natur der Sache - im Bereich der Wohnungsanforderung, also des Wohnungsanforderungsgesetzes (BGBl. Nr. 204/49, IOI/52), eines Gesetzes, das die Aufgabe hat, solchen Wohnraum, der im Sinne des Gesetzes nicht entsprechend ausgenützt ist, anzufordern und an Bedürftige zuzuweisen, eine unbefriedigende Rechtslage vor allem deshalb, weil die damit befaßten Behörden es sind das in erster Linie die Gemeinden - die Aufgabe haben, etwas verteilen $\mathrm{zu}$ sollen, was praktisch nicht vorhanden ist, nämlich verfügbaren Wohnraum.

Im Zusammenhang mit dem Wasserrecht wäre darauf hinzuweisen, daß wir in Osterreich nach wie vor zum großen Teil das deutsche Energiewirtschaftsgesetz von 1935 in Geltung haben, so daß ich diesbezüglich an das erinnern darf, was bereits heute vormittag zu diesem Gesetz gesagt worden ist.

Im Zusammenhang mit der Elektrizitätswirtschaft ist ein besonderes österreichisches Gesetz zu erwähnen, nämlich das zweite Verstaatlichungsgesetz (BGBl. Nr. 8I/I947). Dieses zweite Verstaatlichungsgesetz befaßt sich mit der Verstaatlichung der Energiewirtschaft, und zwar mit der Verstaatlichung der Energiewirtschaft nicht nur im Sinne einer Uberführung der Energiewirtschaft auf die öffentliche Hand im weiteren Sinn es wurden auch im Gemeindeeigentum stehende Elektrizitäts- 
werke verstaatlicht $\rightarrow$, so daß ,verstaatlicht" bedeutet, in das Eigentum des Bundes oder in das Eigentum der Länder übergeführt. Die Verstaatlichung erfolgte hier in der Weise, daB das Eigentum der Elektrizitätswerke übergeführt wurde einmal auf sogenannte Landesgesellschaften, Aktiengesellschaften, deren Anteile im Eigentum der Länder stehen, und zweitens für gewisse große Energieanlagen - denken Sie etwa an die Illwerke, deren Leistung bekanntlich ja auch für die deutsche Industrie eine große Rolle spielt - in Sondergesellschaften, an denen der Bund mit mindestens $50 \%$ beteiligt sein muß. Gerade die Verstaatlichung, soweit es sich um die Utberführung von schon in Gemeindeeigentum, also schon in der öffentlichen Hand stehenden Werke handelt, gab zu ziemlichem Widerstand AnlaB: die Gemeinden erhoben zum Teile heftige Gegenvorstellungen, über die das letzte Wort wohl noch nicht gesprochen ist. Ein besonders unerfreulicher Umstand aber gerade im Zusammenhang mit der Verstaatlichung der Elektrizitätswerke liegt hier noch in folgendem Punkt: sowohl dieses zweite Verstaatlichungsgeset $z$ als auch das erste Verstaatlichungsgeset $z$, von dem noch später kurz zu sprechen sein wird, sehen nämlich vor, daß die Enteignung und Überführung auf den Staat bzw. auf solche im Eigentum des Staates stehende juristische Personen gegen Entschädigung erfolgen soll. Hinsichtlich dieser Entschädigung beschränken sich aber die beiden Verstaatlichungsgesetze darauf zu verfügen: „Das Nähere regelt ein Bundesgesetz". Diese Bundesgesetze sind bis heute noch nicht ergangen. Der Verfassungsgerichtshof hatte schon wiederholt AnlaB, sich mit dieser Frage zu beschäftigen, und er hat ausgesprochen, daß die beiden Gesetze grundsätzlich eine Entschädigung vorsehen; es bestehe kein Anlaß anzunehmen, daß der Bundesgesetzgeber sich dieser Verpflichtung entziehen wolle (z. B. Erk.Slg. 1854). Es will allerdings scheinen, daß mit jedem vergehenden Tag doch eigentlich der AnlaB hierzu im Zunehmen begriffen ist, denn es wäre doch an der Zeit, auch diese Entschädigungsfrage anzugehen. Im Zusammenhang mit der Elektrizitätswirtschaft darf noch darauf hingewiesen werden, $\mathrm{da} B$ auch hinsichtlich der Stromverteilung besondere Vorschriften bestehen, die den nicht klaren Namen Lastverteilungsgesetz (BGBl. Nr. 255/49, II7/52) führen, also etwas ganz anderes unter dieser Bedeutung erfassen, als man etwa hier unter dem Lastenausgleich zu verstehen hat.

Von besonderer praktischer Bedeutung im Zusammenhang mit den Kriegsereignissen sind natürlich alle jene Vorschriften, die der Sicherung des Bedarfs an Lebensmitteln und anderen Bedarfsgegenständen dienen. Das gilt vor allem von den Maßnahmen zur Sicherung der Erzeugung und Lenkung des Absatzes der landwirtschaftlichen Erzeugnisse, wobei hier vor allem drei Ge- 
setze aus dem Jahre I950 besondere Aufmerksamkeit verlangen, nämlich das Milchwirtschaftsgesetz, das Getreidewirtschiaftsgesetz und das Viehverkehrsgesetz (BGBl. Nr. I67-169 aus I950). Diese đrei Gesetze sind nämlich deshalb von besonderer Bedeutung, weil sich aus der dort getroffenen Regelung verschiedene Probleme und Fragen ergeben, die heute bereits erwähnt worden sind. In allen diesen drei Gesetzen sind nämlich zur Durchführung der dort vorgesehenen Maßnahmen in weitestem Ausmaß besondere juristische Personen, nämlich besondere Fonds, der Viehverkehrsfonds, der Milchwirtschaftsfonds und der Getreidewirtschaftsfonds vorgesehen. Alle diese Fonds sind als selbständige juristische Personen eingerichtet, die von besonderen Verwaltungskommissionen verwaltet werden. Diese Verwaltungskommissionen sind paritätisch zusammengesetzt aus Vertretern der Landwirtschaftskammern, aus Vertretern des das ganze Bundesgebiet umfassenden Arbeiterkammertages und endlich aus Vertretern der Bundeskammer der gewerblichen Wirtschaft. Auch bei der Zusammensetzung dieser paritätischen Verwaltungskommission ist der Grundsatz des organisierten Mißtrauens wieder sorgsam durchgeführt. Diese Fonds haben auch die Aufgabe, Verwaltungsakte zu setzen, die, je nachdem ob sie sich an einen Einzelnen oder an eine Mehrheit von Personen wenden, als Verordnungen oder als Bescheide anzusehen sind. Die Fonds stehen unter der Aufsicht der sachlich zuständigen Bundesministerien, wobei auch bei diesen Bundesministerien, also Bundesministerium für Handel und Wiederaufbau, Landwirtschaftsministerium, Innen- und Finanzministerium, wiederum dafür gesorgt ist, daß diese Stellen im Einvernehmen miteinander vorgehen.

Dann wäre der Vollständigkeit halber zu erwähnen đas Lebensmittelbewirtschaftungsgesetz (BGBl. Nr. 183/52), weiter das AuBenhandelsverkehrsgesetz (BGBl. Nr. 105/5I, II3/52), das Preisregelungsgesetz (BGBl. Nr. I94/50, II6/52) und Devisengesetz (BGBl. Nr. I62/46). Was die ersten drei erwähnten Gesetze anlangt, nämlich Lebensmittelbewirtschaftungsgesetz, Außenhandelsverkehrgesetz, das übrigens noch ergänzt wird durch das Rohstofflenkungsgesetz (BGBl. Nr. ro6/5I, II4/52) und das Preisregelungsgesetz, so enthalten diese drei Gesetze im wesentlichen Verordnungsermächtigungen für die sachlich in Betracht kommenden Zentralstellen, deren Aufgabe es dann ist, auf Grund dieser Verordnungsermächtigungen die in der Praxis erforderlichen Maßnahmen zu treffen. Was das Devisengesetz anlangt, so ist die Aufgabe des Devisengesetzes die allgemein den Devisengesetzgebungen zukommende Aufgabe. Bemerkenswert scheint hier, daB zur Durchführung des Devisengesetzes im weitesten Ausmaße die österreichische $\mathrm{Nat}$ tion albank, also ein vom Staat getrennter selbständiger Rechtsträger, der beim 
Handelsgericht Wien protokolliert ist, herangezogen ist, so daß also hier die Rechtsform des beliehenen Unternehmens in Erscheinung tritt. Die österreichische Nationalbank hat hier funktionell behördliche Aufgaben zu erfüllen, insoweit als sie Einzelgenehmigungen (Bescheide) oder generelle Festlegungen (Verordnungen) zu erlassen hat. Soviel als kurzer Uberblick über die wichtigsten in Frage kommenden Gesetze und nun im AnschluB daran noch ein paar Worte über einige Rechtsprobleme, die bei der Durchführung eine Rolle spielen.

Zunächst einmal wurde heute schon sehr zutreffend darauf hingewiesen, da $B$ natürlich jedwede Lenkungs- und Planungsmaßnahme im Bereich der Wirtschaft eine gewisse Zentralisierung voraussetzt und notwendig macht. Eine solche Zentralisierung ist nun organisatorisch gerade in einem Bundesstaat besonders schwierig infolge der Verteilung der in Betracht kommenden Kompetenzen zwischen Bund und Ländern. Eine wesentliche Erleichterung in dieser Hinsicht bietet in Osterreich die Kompetenzbestimmung des Art. Io Ziff. I5 der Bundesverfassung. Danach ist der Bund zuständig in Gesetzgebung und in Vollziehung, soweit es sich um Maßnahmen handelt, welche aus AnlaB eines Krieges oder im Gefolge eines solchen zur Sicherung der einheitlichen Führung der Wirtschaft notwendig erscheinen, insbesondere auch, soweit es sich um Maßnahmen zur Sicherung der Versorgung der Bevölkerung mit Bedarfsgegenständen handelt. Durch diese Bestimmung ist der Bundesgesetzgebung die Möglichkeit gegeben, hier die notwendigen einheitlichen $\mathrm{Maßnahmen}$ zu treffen und zwar auch auf solchen Gebieten, die ansonsten nach den allgemeinen Kompetenzbestimmungen in den Aufgabenkreis der Länder fallen. Das gilt z. B., soweit der Bund Vorschriften getroffen hat über die früher erwähnte Lastverteilung auf dem Gebiet der Elektrizitätswirtschaft, also zur. Verteilung des zur Verfügung stehenden Stromes. In dieser Hinsicht hat sich die Frage ergeben, in welchem Verhältnis dann solche Bundesvorschriften gegenüber landesgesetzlichen Bestimmungen stehen, die vielleicht schon früher sich mit solchen Fragen befaßt haben. Hierzu hat der Verfassungsgerichtshof (Erk.Slg. Nr. 1882/49) dahingehend Stellung genommen, da $\mathrm{B}$ die landesrechtlichen Vorschriften in einem solchen Fall nicht auf die Dauer außer Kraft treten, sondern lediglich für die Zeit der Geltung der bundesrechtlichen Vorschriften verdrängt werden; sie treten dann automatisch wieder in Kraft, wenn die bundesrechtlichen Vorschriften ihre Geltung verloren haben.

Ein besonders vielfältiges Bild bietet auch in Österreich die Abstufungdes staatlichen Eingreifens im Bereich der Wirtschaft, eine Abstufung, die sich ja zum Teil schon erkennen ließ aus der vorhergehenden Ubersicht über die wichtigsten 
in Frage kommenden Gesetze. Am weitesten geht der Staat natürlich im Falle der Verstaatlichung, wobei zwei Arten unterschieden werden können, nämlich die unmittelbare Verstaatlichung in dem Sinne, daß hier irgendwelche Unternehmungen oder Sachgüter auf den Staat selbst als Rechtsträger übergehen oder aber eine mittelbare Verstaatlichung in der Form, daB zunächst die Uberführung auf vom Staate formell getrennte juristische Personen erfolgt, die ihrerseits wieder im Eigentum des Staates stehen, wie das bei den beiden Verstaatlichungsgesetzen der Fall ist, - ich darf daran erinnern, daß wir im Bereich der Elektrizitätswirtschaft von Landesgesellschaften und Sondergesellschaften gesprochen haben -, auf welche das Eigentum an den Werken übergeht, und die dann erst ihrerseits wiederum mit ihren Anteilen in Staatseigentum stehen. Die volle Verstaatlichung oder unmittelbare Verstaatlichung in dem Sinn, daB der Staat selbst Eigentümer wird, ist ja eigentlich auch nichts neues, sondern schon von früher her bekannt - ich denke etwa an die verschiedenen Systeme des Eisenbahnwesens, wo wir auch einen Wechsel zwischen Staatsbahn- und Privatbahnsystem haben und wo der Staat unmittelbar als Unternehmenseigentümer in Erscheinung trat. Die beiden Verstaatlichungsgesetze, das erste und zweite Verstaatlichungsgesetz, wählten die Form der mittelbaren Verstaatlichung in dem angegebenen Sinn. Das erste Verstaatlichungsgesetz von 1946 (BGBl. Nr. I68) verstaatlichte in weitem Ausma $B$ Bankinstitute und auch Industrien, und zwar insbesondere die Grundindustrien. Hier wurden zum Teil durch eine besondere Verordnung (BGBl. Nr. I99/46) sogenannte Auffanggesellschaften gegründet, auf die die betreffenden Unternehmungen übergegangen sind. Die Gesellschaften ihrerseits stehen dann im Eigentum des Staates. Neben dieser weitestgehenden Form staatlicher Intervention gibt es dann eine Fülle von Abstufungen, wie sie heute schon in weitem AusmaB erwähnt worden sind, Abstufungen besonders in der Form, daB für bestimmte Geschäfte eine Genehmigung einer staatlichen Behörde notwendig wird, oder daB bestimmte Geschäfte nur gegen Anmeldung zulässig sind, daß Verbote ausgesprochen werden können und dergleichen mehr. In diesem Zusammenhang der Genehmigungspflicht für bestimmte Geschäfte möchte ich noch zwei Rechtsfragen erwähnen, die mitunter auch zu größeren Schwierigkeiten führen und geführt haben. Das sind vor allem jene Fälle, in denen die Nichterteilung einer Erlaubnis oder ein ausgesprochenes Verbot die zivilrechtliche Nichtigkeit des betreffenden Rechtsgeschäftes zur Folge hat. Eine solche Nichtigkeitsfolge für den Bereich des Zivilrechtes hängt dann wieder zusammen mit dem schwierigen Problem der Bindung der Zivilgerichte an rechtskräftige Verwaltungsakte, ein Problem, mit dem sich ja auch die Zivilrechtslehrer- 
tagung und die gemischte Kommission in Heidelberg im Frühjahr dieses Jahres befaßt haben. Weiterhin möchte ich in diesem $\mathrm{Zu}$ sammenhang darauf hinweisen, daB in den Bewirtschaftungsgesetzen wiederholt die Verwaltungsbehörden berechtigt sind, Verwaltungsstrafen, und zwar sehr erhebliche Verwaltungsstrafen zu verhängen. Es zeigt sich hier eine außerordentliche Ausweitung des Verwaltungsstrafrechts, die vom Standpunkt des Rechtsstaates, vom Standpunkt des Rechtsschutzes aus als sehr bedenklich bezeichnet werden muß. Wenn wir auch gerade in Österreich durch die Verwaltungsverfahrensgesetzgebung und im Verwaltungsstrafrecht Bestimmungen haben, die in weitestem Ausmaß rechtsstaatlichen Prinzipien entsprechen, so läßt sich jedoch nicht verkennen, daß ein Verwaltungsstrafverfahren bei weitem nicht die Rechtsschutzgarantien zu gewähren vermag, die ein gerichtliches Strafverfahren bietet. Es kommt also mitunter vor, daß für eine kleine Ubertretung der ganze Apparat der ordentlichen Gerichtsbarkeit in Bewegung gesetzt wird, der Betreffende bekommt dann womöglich drei Tage Arrest, während urrgekehrt dort, wo es sich um die Entziehung einer Berechtigung handelt, die die Grundlage für die wirtschaftliche Existenz des Betroffenen bildet, einfach das Verwaltungsstrafverfahren mit seinen weniger wirksamen Rechtsschutzgarantien wirksam wird. Es ist richtig, der Betroffene kann dann gegen den Verwaltungsbescheid den Weg an das Verwaltungsgericht Osterreich hat nur einen Verwaltungsgerichtshof - beschreiten. Aber der Weg an den Verwaltungsgerichtshof, der verwaltungsgerichtliche Weg überhaupt, ist, worauf gleichfalls heute schon sehr zutreffend hingewiesen worden ist, gerade in wirtschaftlichen Belangen oft nicht ausreichend, vor allem deshalb nicht, weil infolge der Uberlastung des Verwaltungsgerichtshofes es ein bis zwei Jahre dauern kann, bis dessen Erkenntnis vielleicht unter Aufhebung des verwaltungsbehördlichen Bescheides folgt.

Eine weitere wichtige Rechtsfrage, die wiederum zusammenhängt mit der schon erwähnten Zentralisierung der Wirtschaftslenkung, hat in Österreich eine erhebliche Rolle gespielt und spielt noch eine erhebliche Rolle. Sie haben schon früher vielleicht aus meinen Ausführungen entnommen, daß in vielen Fällen der Bewirtschaftung verschiedene Zentralbehörden, verschiedene Bundesministerien, tätig zu werden haben. Es liegt auf der Hand, daß es hier zweckmäßig erscheinen mochte, für eine Koordinierung dieser in Frage kommenden Zentralstellen zu sorgen. Mit dieser Aufgabe wurde durch ein Bundesgesetz (BGBl. Nr. x04/I95I) das Wirtschaftsdirektorium der Bundesregierung betraut, ein Kollegium, das sich zusammensetzt aus den Mitgliedern der Bundesregierung mit Ausnahme des Bundesministers für Justiz und für Unterricht als stimmberechtigten Mitgliedern. Diesem 
Gremium gehören dann mit beratender Stimme auch noch andere Vertreter außerstaatlicher Interessenvertretungen an. Dieses Wirtschaftsdirektorium der Bundesregierung, das sich also als Ausschu $\beta$ der Bundesregierung, soweit es sich um die stimmberechtigten Mitglieder handelt, darstellt, hat die Aufgabe, die Tätigkeit der mit Lenkungsvorschriften befaßten Bundesministerien zu koordinieren. In den einzelnen Bewirtschaftungsgesetzen, z. B. im Außenhandelsgesetz, ist dann vorgesehen, daß die im einzelnen Fall sachlich zuständigen Bundesministerien nach diesen Richtlinien vorzugehen haben. Im Sommer dieses Jahres, im Juni r952, kam diese Bestimmung des Außenhandelsverkehrsgesetzes vor den Verfassungsgerichtshof, nämlich die Bestimmung, wonach das Bundesministerium für Handel und Wiederaufbau nach den Richtlinien dieses Wirtschaftsdirektoriums vorzugehen hat. Der Verfassungsgerichtshof (Erk. v. 17.6. I952, Zl. G. 7/52) hat die bezüglichen Bestimmungen aufgehoben und darauf hingewiesen, da $B$ nach den Bestimmungen der Bundesverfassung die einzelnen Bundesminister als oberste Bundesbehörden nicht an die Weisungen eines solchen, wenn auch aus den meisten Bundesministern bestehenden Gremiums gebunden werden dürfer. Ebenso hat der Gerichtshof in diesem Erkenntnis ausgesprochen, daß Beiräte in Bewirtschaftungssachen ausschließlich eine beratende Aufgabe haben dürfen, nicht aber in irgendeiner Weise eine Bindung für die obersten Zentralstellen bedeuten dürfen.

Im Zusammenhang mit der bundesstaatlichen Organisationsform möchte ich noch besonders darauf hinweisen, da $B$ grundsätzlich nach den Bestimmungen der österreichischen Bundesverfassung auch bei solchen Bewirtschaftungsmaßnahmen in der Landesstufe der Landeshauptmann in Form der mittelbaren Bundesverwaltung eingeschaltet ist, in denen etwa besondere juristische Personen - etwa die früher erwähnten Fonds im Bereich des landwirtschaftlichen Bewirtschaftungsrechtes tätig werden. Hier geht der Rechtszug von diesen Fonds an den Landeshauptmann und dann erst gegebenenfalls an das zuständige Ministerium.

Schließlich noch eine weitere Rechtsfrage, die sich häufig ergibt im Zusammenhang mit Bewirtschaftungsbestimmungen: ich habe früher schon darauf hingewiesen, daß eine Reihe von Bewirtschaftungsgesetzen im wesentlichen Verordnungsermächtigungen enthalten, was selbstverständlich praktisch notwendig ist, weil ja der Zeitpunkt oder das AusmaB solcher Lenkungsvorschriften sich nicht schon auf weite Sicht immer im Vorhinein festlegen läßt. Hier ergibt sich nun häufig eine Schwierigkeit daraus, daß nach den Bestimmungen des österreichischen Verfassungsrechtes auf der Grundlage einfacher Bundesgesetze nur 
Durchführungsverordnungen zulässig sind (Art. I8/2 B.VG.). Es sind wiederholt von den Bundesministerien erlassene Bewirtschaftungsvorschriften in Form von Verordnungen aufgehoben worden, weil sich eben gezeigt hat, $\mathrm{da} B$ die gesetzliche Ermächtigung nicht ausreichte, daß es sich vielmehr um selbständige Verordnungen gehandelt hat.

Was schließlich die Frage des Rechtsschutzes anlangt, so bestehen besondere Rechtsvorschriften in dem behandelten Bereich nicht. Es gelten vielmehr die allgemein in Frage kommenden Rechtsschutzbestimmungen des Verwaltungsrechtes, die Schutzbestimmungen, die sich aus dem Verwaltungsverfahrensrecht ergeben, welche in weitem AusmaB auch dort anwendbar sind, wo etwa juristische Personen, wie die genannten Fonds, tätig werden. $\mathrm{Daß}$ der Verwaltungsgerichtsweg in Wirtschaftssachen häufig ein völlig unzulängliches, praktisch oft überhaupt nicht in Frage kommendes Rechtsmittel ist, habe ich schon gesagt, und das wurde auch heute vormittag schon nachdrücklich erwähnt. Das gleiche gilt wohl zum Teil auch für die amtshaftungsrechtlichen Bestimmungen - wir haben in Österreich ein neues Amtshaftungsrecht von I948/49 (BGBl. Nr. I9 u. 20/49) -, so daB der Rechtsschutz im Bereich der Wirtschaft noch wesentlich auszubauen wäre.

Damit hoffe ich, Ihnen wenigstens an ein paar Beispielen Probleme gezeigt zu haben, die sich in Österreich im Bereich des Wirtschaftslenkungsrechtes ergeben haben.

Huber-Bern: Der Haupteindruck, den ein Schweizer heute morgen von der bunten Musterkarte der Interventionsformen sowohl in ihrer mehr juristischen als in ihrer wirtschaftlich praktischen Einteilung gewinnen mußte, war sicher der, daß diese Formen auch in unserem Lande bis in alle kleinsten Einzelheiten, z. B. der Bewirtschaftung, wiederkehren, auch wiederkehren im Organisationsrechtlichen bei jenen halbamtlichen Körperschaften und bei jenen Institutionen, die aus der Ämterhierarchie ausgenommen sind und zum Auftrage haben, besondere Bewirtschaftungsgebiete zu behandeln.Wir nennen in der Schweiz diese nicht in der Ämterhierarchie stehenden Funktionäre Delegierte, Delegierte für Handelsverträge, Delegierte für Arbeitsbeschaffung, Delegierte für das Problem Schiene und Straße und so fort. Ich will mich deshalb bemühen, nicht zu wiederholen, und einige schweizerische Besonderheiten hervorkehren. Die rechtliche Möglichkeit, Interventionismus zu treiben, ist in der Schweiz im Jahre I947 konstitutionalisiert worden durch die sogenannten neuen Wirtschaftsartikel, und zwar in der Weise, daB daraus eine Ausnahme von der Handels- und Gewerbefreiheit gemacht wurde, gleichzeitig aber auch eine ausschlieBliche Rechtsetzungskompe- 
tenz des Bundes. Ich muB beifügen, $\mathrm{da} B$ die Handels- und Gewerbefreiheit im Jahre 1874 - heute morgen hat Herr Scheuner mit Recht gesagt, das sei die Zeit des wirtschaftlichen Hochliberalismus gewesen - in der Schweiz zu einem echten Grundrecht wurde. Sie begreift in sich das, was Sie nach der deutschen Gewerbeordnung als Gewerbefreiheit auffassen. Sie ist aber viel weiter, sie wird aufgefaßt als Wettbewerbsfreiheit. Die Frage, die bei Ihnen zum Teil mit widersprechenden Ansichten diskutiert wird, ob der Staat zugleich mit der Verfassung ein Bekenntnis für eine bestimmte Wirtschaftsform abgelegt habe, muB in der Schweiz entschieden bejaht werden, wegen dieses Grundrechtes der Wettbewerbsfreiheit, obwohl diese nicht das einzige Element dieser Wirtschaftsverfassung ist. Nach unseren Erfahrungen beruht es jeroch - ich will mich vorsichtig ausdrücken - auf einer falschen Ausgangskonzeption, wenn das Interventionsrecht als Ausnahme dieses Grundrechtes aufgefaßt wird, denn es scheint, da $B$ die Gewerbefreiheit nicht zufällig, sondern notwendig durch dieses Interventionsrecht in ihrem Wesensgehalt angetastet werde. Heute morgen ist ja auch die Rede davon gewesen, da B die Interterventionsvorschriften und Maßnahmen eine chaotische Natur hätten, eine Ausnahmebestimmung von einem Grundrecht sollte nicht zu chaotischen Bestimmungen und Maßnahmen führen. Der Art. 3Ib Abs. 3 unserer Bundesverfassung, der eigentliche Interventionsartikel, verwendet zur Umschreibung diese Ausnahme vom Grundrecht und zugleich zur Umschreibung dieser ausschließlichen Bundeszustänđigkeit Formeln, die weitgestreckte Zielsetzungen sind. Es heißt in diesem Verfassungsartikel nicht, der Bund darf Zwangskartelle einführen, einen Bewilligungszwang einen numerus clausus, Kontingentierungen usw. einführen, sondern es heißt, er soll in ihrer Existenz gefährdete Wirtschaftszweige schützen. Er soll wirtschaftlich bedrohte Landesteile schützen, er soll einen gesunden Bauernstand erhalten, eine leistungsfähige Landwirtschaft herbeiführen, für Kriegszeiten Vorsorge treffen, also lauter weitgestreckte Zielsetzungen. Zum Teil sind die Mittel dazu deshalb nicht angegeben worden, weil ja bei uns die Verfassungsrevision und die Gesetze dem Referendum unterliegen. Wenn die Mittel mit diesen etwas abschreckenden Termini gebraucht worden wären, so hätten solche Vorlagen riskiert, verworfen zu werden; wenn man dagegen so hehre Zielsetzungen verwendet, hat man eher Chance, damit die Mehrheit für sich zu gewinnen. Heute morgen hat namentlich Herr Schüle darauf hingewiesen, daB entscheidend ja eigentlich die Wirkung der Interventionsvorschriften und der Interventionsmaßnahmen sei. Ich würde sagen, in unserem Verfassungsartikel kommen die erhofften Wirkungen alleine zum Ausdruck. Allerdings scheint es, da $B$ daneben der Interventionismus überhaupt nicht anders durchkommt 
als mit solchen Zielsetzungen, mit möglichst weitgestreckten Zielsetzungen. Es dürfte nicht möglich sein, sich auf der Verfassungsstufe auf die konkreten Mittel festzulegen für den Interventionis: mus. Mit der Vorstellung von der Intervention verbindet sich in der Schweiz die andere Vorstellung, daB die Einmischung in die Wirtschaft etwas Außergewöhnliches sei und in der Regel zu unterbleiben habe. Die diskriminierende Note, von der heute morgen auch schon gesprochen wurde, zeigt sich etwa daran, da $\beta$ in der Schweiz die interventionistischen Gesetze in der Regel befristet werden, auf drei, auf fünf, auf acht Jahre, sogar dann, wenn eigentlich die Absicht besteht, sie dauernd beizubehalten, um sie dann später zu verlängern. Auf diese Weise wird die nun schon seit geraumer Zeit bestehende heterogene Zusammensetzung des modernen Verwaltungsrechtes, etwa die Gegensätzlichkeit von Polizeirecht, das mit der Gewerbefreiheit als vereinbar gilt, und Wirtschaftsverwaltungsrecht übersehen. $\mathrm{DaB}$ die gestaltende Verwaltung, wie Herr Forsth off in seinem Lehrbuch dargelegt hat, unter Bedingungen arbeitet, die sich der Technik der Freiheitsverwirkung und Rechtskontrolle - ich möchte einen Vorbehalt machen - weitgehend nicht vollständig entziehen, das erweist sich am Interventionsrecht als richtig. Ich sage weitgehend - ein Gegenbeispiel wäre etwa der Grundsatz der Verhältnismäßigkeit der Eingriffe, der sich sehr wohl vom Polizeirecht auf das Interventionsrecht übertragen läßt.

Hervorzuheben sind etwa die Verwandlung des Ermessensbegriffes, die Unentbehrlichkeit von reinen Ermächtigungsformeln und im Zusammenhang damit die Aufhebung des Unterschiedes zwischen Rechtsetzung und Rechtsanwendung, zwischen allgemeiner Regel und Finzelverfügung, dann die Verzahnung von öffentlichem Recht und Privatrecht, von Verfügung und Vertrag, soziologisch von Herrschaft und Paktieren, von Rechtsunterworfenheit und privater Machtausführung.

Jellinek-Heidelberg: Goethe mit seinem Hymnus auf die Persöhlichkeit hätte seine helle Freude an dem, was die Juristen aus Artikel 2 des Grundgesetzes gemacht haben. Auch verdanken wir diesem Artikel 2 die schöne Abhandlung über die Freiheit des.Berufs von Uber, einem Schüler des Kollegen Ipsen. Aber was zuviel ist, ist zuviel. So hat sich in einem gegenwärtig anhängigen Rechtsstreit der Rechtsbeistand der Firma Henkel für die Zulässigkeit der Anbringung eines Reklameschildes: „Zum Saubermachen Henkelsachen" auf das Recht der freien Entfaltung der Persönlichkeit berufen. Ich glaube, viele werden Herm Schüle Dank wissen, daß er vor solchen Ubertreibungen eindrucksvoll gewarnt hat.

Herr .Schüle hat dann auf den Verwaltungsrechtsstreit eines Münchener Verlegers gegen den staatlichen Bayerischen Schul- 
buch-Verlag angespielt. Dieser ProzeB wurde aber nur dadurch möglich, daB die Bayerische Landesverfassung im Art. I53 eine Bestimmung enthält, wonach der Mittelstand vor Aufsaugung zu schützen ist. Herr Schüle hat weiter die Einfuhr- und Vorratsstellen des Bundes erwähnt. Vielleicht äußert er sich im Schlußwort darüber, ob diese Stellen auch auf eigene Rechnung Importe tätigen dürfen oder ob irgendeine Bestimmung des Grundgesetzes dem im Wege steht.

Herr Scheuner hat die wichtige Frage angeschnitten, wieweit die Einführung von Monopolen gestattet ist, und dabei die Unterscheidung zwischen Finanz- und Wirtschaftsmonopolen gemacht. Worin liegt der Unterschied zwischen diesen beiden Monopolen? Das Branntweinmonopol ist sicher ein Finanzmonopol, aber kann man dies auch noch vom Zündwarenmonopol angesichts seiner kümmerlichen Erträgnisse behaupten? Wenn beide Arten von Monopolen rechtlich verschieden behandelt werden müssen, ist eine Klärung des zwischen ihnen bestehenden Unterschiedes unerläBlich.

Von Wichtigkeit bei dem ganzen Fragenkomplex ist natürlich die Frage des Rechtsschutzes. Herr Schüle meinte, der verwaltungsgerichtliche Rechtsschutz komme zu spät. Wir haben es aber in Karlsruhe erlebt, da $\beta$ ein auf den Montag angesetzter Damenringkampf am Sonnabend verboten wurde und daß dies Verbot am Montag Vormittag vom - unteren - Verwaltungsgericht und am gleichen Nachmittag vom Verwaltungsgerichtshof aufgehoben wurde, so daB die Vorstellung am Montag Abend möglich war.

Etwas, was uns sehr interessiert mit Rücksicht auf die gestrigen Beratungen der Gemischten Kómmission von Zivilprozessualisten und Verwaltungsrechtslehrern, ist die Frage, ob die künftigen Kartellgerichte den bürgerlichen Gerichten oder den Verwaltungsgerichten angegliedert werden sollen. Vielleicht äußert sich Herr Schüle in seinem Schlußwort auch zu dieser Frage.

Herr Scheuner führte aus, daß gegen unmittelbare Eingriffe durch ein Gesetz der gerichtliche Rechtsschutz ungenügend ausgestaltet sei. In der hoffentlich bald verabschiedeten Verwaltungsgerichtsordnung des Bundes ist aber die abstrakte Normenkontrolle vorgesehen, und Herr Scheuner wird sich von einer Streitsache her, in der er als Gutachter tätig war, daran erinnern, daß gegen ein Gesetz unter Umständen auch die Verfassungsbeschwerde möglich ist. Es gibt daher heute in Westdeutschland kaum einen staatlichen Eingriff, gegen den der Betroffene nicht ein Gericht anrufen könnte.

Klein-Münster: Wir haben heute morgen in zwei Referaten von "selten exlebter" Sachkunde und Eindringlichkeit - um 
mit Herrn Schüle zu sprechen - die Interventionsmöglichkeiten und Interventionswirklichkeiten des Staates im Bereich der Wirtschaft aufgezeigt erhalten. Beide Redner haben in höchst anschaulicher Weise ein ganzes Arsenal solcher Möglichkeiten und Wirklichkeiten vor uns ausgebreitet. Ich glaube nicht zu übertreiben, wenn ich der Vermutung Ausdruck gebe, daß unser hochgeschätzter Bundeswirtschaftsminister Erhard, hätte er hier sein können, angesichts einer solchen Instruktionsstunde auf die Juristen etwas böse geworden wäre, die ihm sein unter nationalökonomischen Gesichtspunkten so verhältnismäßig reines Bild der sogenannten freien oder sozialen Marktwirtschaft mit einer Unzahl größerer und kleinerer schwarzer Kleckse verziert oder - richtiger verunziert haben.

Mußte schon die Ankündigung des ersten Themas unserer diesjährigen Tagung: Intervention des Staates in einer angeblich doch freien, daher auch interventionsfreien Wirtschaft gewissermaßen als Fanal empfunden werden, so haben die beiden Referate meines Erachtens mit aller Schärfe die grundsätzliche Frage aufgedeckt und zur Beantwortung aufgenötigt: Haben wir ein Staatswesen mit einer wirklich freien Wirtschaft, einer echten sozialen Marktwirtschaft? Es ist gewiß verständlich, daß die beiden Herren Referenten nicht den Versuch einer Antwort auf diese Frage unternommen oder sie gar eindeutig und abschließend beantwortet haben, und es liegt mir gewiB nichts ferner, als die beiden Herren deswegen der Unterlassung zu zeihen. Gleichwohl ist es nach meinem Dafürhalten schade, daß von keinem der beiden eine $a b-$ schließende Stellungnahme gegeben worden ist. Vielleicht kann man aber $\mathrm{zu}$ ihr gar nicht gelangen, und zwar allein schon deswegen nicht, weil Juristen und Nationalökonomen vermutlich sehr verschiedener Meinung darüber sein werden und vom Standpunkt ihrer jeweiligen Betrachtungsweise aus wohl auch sein müssen.

Immerhin hat Herr Scheuner in seinen einleitenden Betrachtungen einige Bemerkungen gemacht, die - wenn ich sie richtig verstanden habe - einschlägig genannt werden dürfen. Er hat in dem Abschnitt, in dem er sich mit den Fragen ,Was ist unter Intervention des Staates in der Wirtschaft zu verstehen ?" und "Was ist Staatsinterventionismus beziehungsweise -dirigismus in diesem Sinne?" des näheren befaßt hat, in wörtlicher Formulierung bemerkt: "Interventionismus ist eine Form eigener Art"; „Interventionismus steht in der Mitte zwischen kollektiver oder umfassend gelenkter Zwangswirtschaft und der freien Marktwirtschaft" ; "Interventionismus ist im Unterschied zum autoritären Staatsbild undogmatisch". Ich weiß nicht, ob Herr Scheuner damit so verstanden werden wollte, als ob er neben die beiden eigenständigen Hauptformen der geschlossenen Planwirtschaft totalitären Charakters und der freien Wirtschaft eine dritte eigen- 
ständige Wirtschaftsform und Wirtschaftsverfassung des Interventionismus setzen will. Ich möchte das allerdings nicht annehmen, denn es ist ja eine auch ihm gewiB bekannte Binsenwahrheit, daß selbst eine freie Wirtschaft ganz ohne Lenkungs-, Planungs-, Steuerungs-, Eingriffs-, Direktions- und Interventionsmaßnahmen des Staates nicht auskommt und nicht auskommen kann.

Bezeichnend ist ja auch, daß Herr Scheuner unter den von ihm nach Art einer ,bunten Musterkarte“, wie Herr Huber formuliert hat, aufgeführten zahlreichen unmittelbaren und mittelbaren Formen der Intervention die Steuerpolitik gebührend hervorgehoben hat. Herr Schüle hat - darin stimme ich ihm grundsätzlich $\mathrm{zu}$ das Anziehen und Lockerlassen der Steuerschraube als das ,entscheidende Mittel unserer gegenwärtigen Wirtschaftslenkung" bezeichnet. Es ist ebenfalls eine Wahrheit, daß die Lenkung durch Steuern beziehungsweise durch "das Steuergesetz", wie Herr Schüle sich ständig ausgedrückt hat, in das bewährte Arsenal nicht nur der staatlichen Finanzpolitik, sondern auch und gerade der modernen Wirtschaftspolitik gehört. Und zwar machen davon in diesem Sinne und zu diesem Zwecke nicht nur die geschlossenen Planwirtschaften totalitären Charakters, insbesondere diejenigen der Union der Sozialistischen Sowjetrepubliken und ihrer Trabanten- und Satellitenstaaten, sondern auch und nicht zuletzt die Staaten mit freier Wirtschaft Gebrauch; die Unterschiedlichkeiten in diesem Punkte sind nicht grundsätzlicher, sondern nur gradmäBiger Art.

Wenn es aber so ist, $\mathrm{da} \beta$ das entscheidende, zumindest aber ein stark mitentscheidendes Mittel der gegenwärtigen Wirtschaftslenkung von Staats wegen, nämlich die Besteuerung, sowohl in der einen als auch in der anderen der beiden Grundformen der Wirtschaftssysteme und Wirtschaftsverfassungen ein $\epsilon$ malsgebende Rolle spielt, dann erweist sich, daß der darin in Erscheinung tretende Staatsinterventionismus nicht eine selbstänđige dritte Größe, sondern eine in beiden Wirtschaftssystemen und Wirtschaftsverfassungen anzutreffende, eine sie beide, wie ich sagen möchte, gewissermaßen überwölbende Erscheinung ist.

Vielleicht ist der Herr Erstreferent so liebenswürdig, in seinem Schlußwort eindeutig klarzustellen, ob beziehungsweise daB er so verstanden werden wollte, und darüber hinaus zu versuchen, das deutsche Wirtschaftssystem, die deutsche Wirtschaftsverfassuug der Gegenwart in der fraglichen Hinsicht noch etwa genauer zu charakterisieren.

Merk-Tübingen: Die beiden Vorträge von heute morgen haben deutlich gezeigt, daß nach dem BGG zwar der Ausgangspunkt die Anerkennung des Wertes der Einzelpersönlichkeit ist, wie dies 
in den Grundrechten und in den rechtsstaatlichen Sicherungen zutage tritt, aber da $B$ man dabei nicht stehengeblieben ist, wie dies äußerlich schon in der Bezeichnung ",Sozialer Rechtsstaat" sich kundgibt. Das Rad der Geschichte läßt sich eben nicht auf den Stand vor I933 zurückdrehen, infolge der Veränderungen, die seitdem eingetreten sind. Im übrigen hat man bei uns ja bekanntlich auf dem Gebiete des Wirtschaft- und Arbeitsrechts gegenüber einer bis dahin vorwiegend liberalen Gestaltung die Wende zu einer sozialen Gestaltung schon Ende der siebziger und Anfang der achtziger Jahre des vorigen Jahrhunderts vorgenommen. Jetzt sehen wir so, daß neben den Grundrechten, wie insbesondere der Art. 2, 4 und I4 BGG, die Bestimmung des Art. I5 die Möglichkeit der Vergesellschaftung von Grund und Boden, Naturschätzen und sachlichen Güterherstellungsmitteln vorsieht; im übrigen aber ist in Art. 74 das Recht der Wirtschaftsgesetzgebung einfach der mitwerbenden Gesetzgebung des Bundes zugewiesen. Ob und wie davon Gebrauch gemacht wird, ist in der Verfassung nicht bestimmt. Es besteht so die Möglichkeit, sich jeweils den vorhandenen Verhältnissen und Bedürfnissen der Volksgemeinschaft anzupassen. Es ist also eine Zweckmäßigkeitsfrage, nicht eine Weltanschauungsfrage, ob und inwieweit eine Vergesellschaftung durchgeführt wird. Dies steht im Gegensatze zu einer Gesamtplanung, wie wir sie in der östlichen Staatenwelt unter der Führung Rußlands sehen. Eine völlige Gesamtplanung in diesem Sinne würde aber auch nicht mehr den Grundlagen des BGG mit dessen Ausgangspunkt von der Würde des Menschen und seiner Freiheit, wie sie in den Grundrechten zum Ausdruck kommt, entsprechen. Im übrigen haben wir gehört, wie weit heute schon die Einmischung des Staates in das Wirtschaftsleben unmittelbar oder mittelbar reicht. Ich möchte in einer solchen Gestaltung ihrer ganzen Art nach - was sich also nicht auf Einzelheiten zu beziehen braucht - nicht einen U'bergangszustand erblicken, son dern einen goldenen Mittelweg zwischen den beiden äußersten, einander entgegengesetzten Polen, einer rein einzeltümlichen und einer rein gemeinschaftsmäßigen oder sozialistischen Gestaltung. Bemerkenswert ist noch, wie sehr auf dem Gebiete des heutigen Wirtschaftsrechts öffentliches und bürgerliches Recht sich auf das engste durchdringen, was wieder weitere Auswirkungen, z. B. hinsichtlich der Zuständigkeit der Verwaltungsbehörden oder der ordentlichen Gerichte, zur Folge hat, worauf hier nicht weiter eingegangen werden kann.

Nur auf einen Punkt möchte ich noch hinweisen: schon der Altmeister der deutschen Finanzwissenschaft, Adolf Wagner, ist s.Zt. dafür eingetreten, die Art der Besteuerung als Mittel zu einer Einkommensverteilung unter sozialen Gesichtspunkten zu verwenden. 
Ipsen-Hamburg: Der Interventionismus, dessen Bild die Herren Referenten uns so anschaulich gezeichnet haben, wirft täglich konkrete, immer wiederkehrende Rechtsfragen auf. Sie können in Ermangelung positiver Spezialregelungen aus dem geltenden, überdies meist ungeschriebenen allgemeinen Verwaltungsrecht nur mühselig beantwortet werden. Es kommt hinzu, da $\beta$ ihre Lösung eine besondere, vom Zivilrecht abweichende Methodik verlangt, die jedenfalls (aber keineswegs nur) der $Z$ ivilgerichtsbarkeit, die vor solche Fragen gestellt wird, schwer zugänglich ist und dort nicht selten $\mathrm{zu}$ unbefriedigenden Ergebnissen führt. Als Beispiele solcher konkreten, auf den verschiedensten Interventionsgebieten vorkommenden Rechtsfragen, die mir insbesondere in der Wirtschaftsberatung und der Tätigkeit am Oberverwaltungsgericht entgegengetreten sind, darf ich die folgenden aufführen:

I. Planende Wirtschaftsintervention führt zur Annahme einer Pflicht des Staates, der von der Planung betroffenen und zu bestimmten Risiken veranlaßten Wirtschaft gegenüber für eine Innehaltung, Durchführung und ordnungsgemäße Abwicklung des Planes einzustehen. Man mag diese Pflicht als eine Art „Plangewährleistung" bezeichnen. Aus ihr folgt, daß bei Widerruf, Änderung oder unvorhergesehener Beendigung der Planung „Planungsschäden" zu ersetzen sind - ein Tatbestand, der z. B. nach der Liberalisierung der Fettwirtschaft für die bis dahin gelenkte Margarine-Industrie eingetreten ist. Diese Plangewährleistung entspringt der Erkenntnis, daß jede Lenkung und Planung ein $z$ weiseitiges Rechtsverhältnis entstehen läßt, dem auf beiden Seiten Rechte und Pflichten entwachsen. Hierher gehört auch die gegenwärtig gerade bei uns in Hamburg intensiv erörterte Frage, ob nicht der Bank Deutscher Länder gegenüber den deutschen Exporteuren eine Transfer-Gewährleistungspflicht im Rahmen des Brasilienhandels obliegt, nachdem die Handelsvertragsregelung zwischen der Bundesrepublik und Brasilien den deutschen Exporteur verpflichtet hat, seine in Brasilien erworbenen Zahlungsansprüche aus Verkäufen über ein Verrechnungskonto abwickeln zu lassen, das zwischen der BdL und der brasilianischen Staatsbank geführt wird. Wenn der deutsche Exporteur keinen Einblick in den Stand der hin- und hergehenden Güterbewegungen hat, kann ihm schwerlich das Transferrisiko eines deutschen Guthabenüberhangs in Brasilien dadurch aufgebürdet werden, daß seine überseeischen Guthaben dort von hoher deutscher Hand eingefroren werden. Vielleicht können anerkannte Regelungen der Widerrufslehre, so der Satz vom „Inswerksetzen" oder vom Anspruch auf Vertrauensschaden bei unzulässigem Widerruf, hier Hilfe leisten. 
2. Wenn Interventionsmaßnahmen den Einzelnen zu Leistungen an Dritte zwingen, wird der Staat für die Gegenleistung des Dritten an den Pflichtigen einzustehen haben Das kann heute allenfalls aus dem Rechtsgedanken der $\$ \S 26,27$ des Reichsleistungsgesetzes abgeleitet werden. Für die umstrittene Investitionshilfe, die den einen nötigt, einem anderen $\mathrm{Kredit}$ zu geben, läßt sich ein entsprechendes Ergebnis, dem der Gesetzgeber ausgewichen ist, etwa mit Hilfe des Rechtsgedankens des $\S 778 \mathrm{BGB}$ (Kreditauftrag) oder auch aus dem Enteignungsrecht begründen. Näheres hierzu hoffe ich in Kürze an anderer Stelle darlegen zu können.

3. Wenn der Staat im Rahmen von Wirtschaftsinterventionen, was immer häufiger vorkommt, unmittelbar kraft Gesetzes Dienste des Einzelnen zur Erfüllung von Verwaltungsaufgaben in Anspruch nimmt - ich nenne als Beispiel die Durchführung von Aufgaben der Wertpapierbereinigung, früher die Einschaltung der Kreditinstitute bei der Durchführung der Währungsumstellung - , so muB der Staat dort, wo er nicht nur allgemeine öffentliche Lasten aufbürdet, als vergütungspflichtig angesehen werden. Ich habe das in meinem Beitrag zur Kaufmann-Festschrift zu begründen versucht.

4. In immer größerem Ausmaß interveniert der Staat mit seinen "Wohltaten", indem er einzelnen Wirtschaftszweigen Kredite, Subventionen, Bürgschaften oder dergl. zuwendet. Meist handelt der Staat hier nicht, wiewohl er es nochte, als Privatbankier, da er den Interventionsvorgang als öffentliche Aufgabe qualifiziert - wie z. B. in der Filmwirtschaft, wo der Bundestag entsprechende Maßnahmen im öffentlichen Interesse durch Bereitstellung von Haushaltsmitteln ermöglicht hat, ferner etwa im Gebiet des sozialen Wohnungsbaues, der Außenhandelsförderung, der Schiffbaufinanzierung usw. Hier sind die behördlichen Entscheidungen über das „ob" oder „ob nicht" der WohltatGewährung, d.h. die Antragsgenehmigungen oder -ablehnungen, als Akte der öffentlichen Hoheitsverwaliung, als Verwaltungsakte, anzusehen, und die Verwaltung muß insoweit ihr Verhalten nach dem Prinzip der Gesetzmäßigkeit, nach dem Gleichheitssatz, nach den Grenzen des Ermessens, der Widerruflichkeit, der Verhältnismäßigkeit des Mittels, also, allgemeiner gesprochen, nach den anerkannten Rechtsgrundsätzen des Verwaltungshandelns ausrichten, während nur das nachfolgende sogenannte „Erfüllungsgeschäft", also die Bürgschaftsübernahme, die Darlehenshingabe usw. zivilrechtlich qualifiziert werden darf. Das Gefühl dafür, daß zwischen diesen beiden Vorgängen rechtlich unterschieden werden muß, daß der wohltätig intervenierende Staat sich eben nicht in der Rolle des Privatbankiers befindet, den keine Ermessensgrenzen, kein Gleichheitssatz binden, dieses 
Verstänđnis für die Öffentlichkeit der hier wahrgenommenen Aufgabe und der daraus resultierenden Bindungen und Verpflic tungen wird manche, auch höchste Verwaltungsbehörde erst noch erwerben müssen.

$\mathrm{DaB}$ diese wenigen Beispiele konkreter Rechtsregeln, die die staatliche Intervention in rechtsstaatliche Ordnung bringen müssen, keinen Anfang eines "Allgemeinen Teils" des Interventionsrechts bilden können, sei abschließend bemerkt. Er vermöchte nur Steine statt Brot zù geben, und jeder Interventionsvorgang muB die ihm immanenten Rechtsgrundsätze aus seiner Eigenart heraus entwickeln.

Naumann-Hamburg: Ich darf mich auf einige Bemerkungen zum Problem des Rechtsschutzes im Bereich der Wirtschaftsintervention des Staates beschränken. Der Leitsatz Nr. 23 von Herrn Scheuner lautet: „Der bestehende Rechtsschutz durch die verwaltungsrechtliche Generalklausel sichert ausreichend gegen unmittelbare Eingriffe in individuelle Rechtspositionen, wobei freilich der Begriff des subjektiven Rechts einer Fortbildung unter dem Gedanken des schutzwürdigen Interesses bedarf." Das hat wohl in erster Linie die herkömmliche Klage vor dem Verwaltungsgericht, nämlich die Anfechtungsklage, im Auge, wo allerdings in der Regel ein subjektives Recht rechtswidrig verletzt sein muß, damit der Kläger mit seiner Klage Erfolg haben kann. Diese Grundvoraussetzung des verwaltungsgerichtlichen Schutzes - Verletztheit in subjektiven Rechten - gilt nach der bisherigen Auffassung aber auch für die sogenannte Verpflichtungs- oder Vornahmeklage. Solche Klagen können vielleicht gerade bei den zuletzt von Herrn Ipsen in der Diskussion genannten Beispielen eine größere Bedeutung haben als die Abwehrklagen (Anfechtungsklagen) gegenüber nachteilig interventionistisch eingreifenden Hoheitsmaßnahmen.

Beim staatlichen Dirigismus der Wirtschaft ist im Hinblick auf den verwaltungsgerichtlichen Rechtsschutz noch etwas zu bedenken: Man kann in erheblichem Umfang eine "Flucht aus der Hoheitsgewalt" beim wirtschaftsdirigierenden Staat beobachten. Ob diese Flucht immer gelingt, die Flucht aus dem Verwaltungsakt ins zivilrechtliche Rechtsgeschäft, ist allerdings fraglich; denn man wird z. B. den Ausführungen von Herrn Ipsen durchaus folgen müssen, daB die Ablehnung einer Bürgschaft durch den Staat ein Hoheitsakt sein kann. Ebenso wird z. B. die von einer Landsiedlungsstelle auf Grund eines Bodenreformgesetzes erklärte vorzeitige Kûndigung eines Pachtvertrages ein Hoheitsakt sein und nicht eine rechtsgeschäftliche Willenserklärung des Privatrechts, so daß weder Zivilgericht noch Pachtschutzgericht, sondern nur das allgemeine Verwaltungs- 
gericht mit Anfechtungsklage angerufen werden kann. $\mathrm{Ob}$ also die scheinbare Verwendung bürgerlich-rechtlicher Mittel unter Vermeidung öffentlich-rechtlicher Wege, wie man sie nicht selten beim Dirigismus auch in der Einschaltung von Kreditinstituten beobachten kann, wirklich dazu führen kann, da $B$ verwaltungsgerichtlicher Rechtsschutz ausgeschlossen oder vermindert wird, ist zu bezweifeln. Ich möchte im übrigen nicht der Auffassung Ausdruck geben, es handele sich bei der ,Flucht aus dem Hoheitsakt ins Privatrecht" um einen bewußt eingeschlagenen Weg, um den verwaltungsgerichtlichen Rechtsschutz zu vermeiden; alle Erfahrungen sprechen gegen solche Annahme, denn der in die Wirtschaft intervenierende Staat hat bisher sicherlich nicht unter der Generalklausel "gelitten“.

Soweit nun Verwaltungsakte erlassen, abgelehnt oder unterlassen werden, möchte ich an dem subjektiven Recht als Voraussetzung für eine verwaltungsgerichtliche Anfechtungs- und Verpflichtungsklage im Prinzip festhalten. Ich habe mich schon vor zwei Jahren in Frankfurt auf dem Juristentag dafür eingesetzt, man solle am subjektiven Recht festhalten, habe allerdings gleichzeitig empfohlen - das betont auch der Leitsatz Nr. 23 von Herrn Scheuner - den Begriff des subjektiven Rechts heute im sozialen Rechtsstaat genauer unter die Lupe zu nehmen. Wenn man die Fülle und Eigenart der Entwicklungen und Erscheinungen auf dem Gebiet des Wirtschaftsverwaltungsrechts sieht, wie sie uns heute hier vorgeführt worden sind, dann muB man gegenüber dem althergebrachten Begriff des subjektiven Rechts ganz besonders nachdenklich werden. Ich teile daher die Auffassung von Herm Scheuner, da $B$ man den Begriff des subjektiven Rechts weiterhin kritisch fortentwickeln muB, möchte aber wegen der möglichen Gefahr der Popularklage davor warnen, ohne weiteres zu dem Gedanken des schutzwürdigen Interesses überzugehen. Allerdings habe ich in scherzhafter Weise bei der Besprechung eines Urteils vor kurzem einmal geschrieben, der Hinweis auf die Gefahren der Popularklage werde mitunter offenbar als eine Art Kinderschreck für überlastete Verwaltungsgerichte verwendet. Aber es ist etwas Richtiges daran: Wenn man jedes schutzwürdige Interesse genügen läßt, das sich etwa auch in organisierten Interessen-Verbänden der Industrie oder des Handels darstellen kann, käme man vielleicht zu einer Ausweitung des verwaltungsgerichtlichen Rechtsschutzes, die nicht immer erfreulich wäre. Ich würde aber einen anderen Weg zur sinnvollen Gestaltung des Verwaltungsrechtsschutzes noch vorschlagen:

Der Gesetzgeber möge sich doch bei der Einführung bestimmter dirigistișcher Maßnahmen jeweils die Frage vorlegen, ob er ProzeBführungsbefugnisse oder Prozeßstandschaftsrechte auch bestimmten Verbänden zubilligen sollte. Ich empfinde es als einen Anachronis- 
mus, wenn heute beispielsweise auf Grund des $\S$ I9 des Gaststättengesetzes die Vereinigung der Gastwirte $z$ war dagegen klagen kann, daß eine neue Schankwirtschaft konzessioniert wird, $\mathrm{daB}$ aber in einer wirtschaftspolitisch höchst bedeutsamen Frage, z. B. im Kampf Schiene - Straße, einem Personenbeförderungsverband oder einem großen Verband von Liniengüterfernverkehrsunternehmen die sogenannte Aktivlegitimation vom Verwaltungsgericht versagt wird und eine Klage des Verbandes schon im Vorfeld der Prüfung zusammenbricht, weil der Verband nicht in eigenen subjektiven Rechten betroffen wird, das Gesetz es aber bisher versäumt hat, dem Verband ohne Rücksicht hierauf ein ProzeBführungsrecht zur Geltendmachung seiner Interessen klar zu verleihen. Es sind vielleicht nicht zuletzt unter dem Eindruck von Erscheinungen, wie wir sie auch im Wirtschaftsverwaltungsrecht antreffen können, neuerdings noch andere Stimmen laut geworden, die an die Grundkonzeption des verwaltungsgerichtlichen Rechtsschutzes aufbauende Kritik ansetzen. Man hat nämlich folgendes gesagt: Bisher hat der verwaltungsgerichtliche Rechtsschutz in Gestalt der Anfechtungs- und Verpflichtungsklage immer an eine hoheitliche Einzelmaßnahme angeknüpft. Es wird ein Verwaltungsakt verlangt, d. h. ein Einzeleingriff bzw. die rechtswidrige Unterlassung eines begünstigenden Einzelaktes; der Staatsbürger, der dadurch betroffen ist, kann den Akt erzwingen oder ihn aufheben lassen. Hiergegen sind Bedenken aufgetreten, wohl allerdings nicht zuerst im Bereich des Wirtschaftsverwaltungsrechts, wo die Neigung der betreffenden Kreise in der Wirtschaft bisher sowieso nicht sonderlich groß gewesen ist, die Verwaltungsgerichte anzurufen. Aber man hat z. B. auf dem Gebiet des Bauverwaltungsrechtes gefragt, warum der Staatsbürger, der etwa durch einen willkürlichen oder ungleich verfahrenden Fluchtlinienplan oder einen offensichtlich unsinnigen Neuaufbauplan betroffen wird, nicht von vornherein diesen Plan sollte anfechten können, statt abwarten zu müssen, bis auf Grund des Planes ein Einzelakt gegen ihn ergeht oder abgelehnt wird. $\mathrm{Ob}$ sich das heute schon in den bisherigen Begriff der Allgemeinverfügung einfangen läßt, ist jedenfalls $z$ weifelhaft. Jedenfalls hat man ernstlich angeregt, man möge doch in der künftigen Bundesverwaltungsgerichtsordnung den Begriff des Verwaltungsakts nicht mehr wie bisher als Einzelmaßnahme der öffentlichen Gewalt definieren, um zweckmäßige Möglichkeiten eines erweiterten, aber gleichzeitig auch vereinfachenden Rechtsschutzes zu eröffnen. Man könnte sich dann vorstellen, daß vielleicht ein verwaltungsgerichtlicher Schutz mit Anfechtungs- oder Vornahmeklage z. B. auch gegenüber sogenannten Verteilungsplänen auf dem Gebiet des Wirtschaftsverwaltungsrechts zulässig ist. 
Richtig ist, wenn ich zum Leitsatz Nr. 24 von Herrn Scheuner kommen darf, daß die abstrakte Normenkontrolle, die in Zukunft entsprechend dem bewährten süddeutschen Vorbild auch im bundeseinheitlichen Verwaltungsprozeßrecht vorgesehen ist, einen wesentlichen lückenausfüllenden Platz im Rechtsschutz bieten kann. Allerdings bleiben dann immer noch Lücken übrig; denn soweit es sich nicht um abgeleitete Rechtsnormen, sondern um generelle Maßnahmen oder Dirigierungsmaßnahmen nicht normenrechtlicher Art handelt, würde man als Betroffener auch mit der Normenkontrolle schwerlich zum Zuge kommen. Hier kann in einigem Umfang die Verfassungsbeschwerde helfen. Ich muß offen gestehen, da $\beta$ man in der Praxis der Verwaltungsgerichtsbarkeit die "Superrechtsbeschwerde" in Gestalt der Verfassungsbeschwerde nach $\S 90$ des Bundesverfassungsgerichtsgesetzes zuerst oft als eine Hypertrophie des Rechtsschutzes angesehen hat. Wenn man sich aber nach den heutigen so besonders eindrucksvollen Referaten das Gebiet des Wirtschaftsverwaltungsrechts modernster Prägung ansieht, dann muß man anerkennen, $\mathrm{daB}$ in der Verfassungsbeschwerde in der Tat ein außerordentlich wirksamer Rechtsschutz für die Staatsbürger liegen kann, vor allem in solchen Fällen, in denen ein verwaltungsgerichtlicher Proze $B$ nicht vorausgehen kann. Voraussetzung ist nur, da $B$ über die Verfassungsbeschwerden schnell entschieden werden kann.

Ich darf noch zum Leitsatz Nr. 8 von Herrn Schüle Stellung nehmen. Ich weiß nicht, ob ich ihn ganz recht verstanden habe. Er sagt dort im vorletzten Satz dieses Leitsatzes, der verwaltungsgerichtliche Schutz sei bisher zum Teil unvollständig gewesen. Ich möchte dem etwa aufkommenden Irrtum zu begegnen suchen, als habe das Gesetz über das Bundesverwaltungsgericht den verwaltungsgerichtlichen Rechtsschutz gegenüber Verwaltungsakten der Bundesministerien oder der Bundesoberbehörden überhaupt erst eröffnet. Den Rechtsschutz auch gegen höchste Bundesbehörden hat es bereits in vollem Umfang vor diesem Gesetz gegeben. Nach süddeutschem Recht waren in erster und letzter Instanz die Verwaltungsgerichtshöfe zuständig, nach norddeutschem Recht die Landesverwaltungsgerichte, auf Berufung die Oberverwaltungsgerichte. Neu ist durch das Bundesverwaltungsgerichtsgesetz nur, da $B$ jetzt - abgesehen von der Revision in gewissen Fällen eine erst- und letztinstanzliche Zuständigkeit des Bundesverwaltungsgerichts gegenüber Verwaltungsakten der obersten Bundesbehörden eingeführt und $\mathrm{daB}$ die örtliche $\mathrm{Zu}$ ständigkeit bei Klagen gegen Akte von Bundesbehörden neu geregelt ist. $\mathrm{DaB}$ sich die eininstanzliche Zuständigkeit des Bundesverwaltungsgerichts im Sinne der Beschleunigung des Rechtsschutzes günstig auswirken kann, zumal dort kein Vorverfahren vorausgeht, und daß diese schnellere Möglichkeit von den be- 
teiligten Wirtschaftskreisen vielleicht eher ergriffen wird als die bisher gegebene Möglichkeit, mag sein. Alles hängt aber, wie auch bei den Verwaltungsgerichten bisher, davon ab, daß diese Rechtsschutzeinrichtung in ausreichendem Maße personell besetzt wird, sonst hat, zumal noch unter den Erschwerungen des Sitzes des Bundesverwaltungsgerichts und den dadurch bedingten langen Ladungsfristen nach dem Gesetz, auch die qualitativ beste Gerichtsbarkeit wenig Sinn.

Ich kann aus der Praxis der Verwaltungsgerichtsbarkeit über eine Anzahl von Wirtschaftsverwaltungsprozessen berichten, die in Hamburg geschwebt haben; so darf ich an die zahlreichen Prozesse nach dem Importausgleichsabgabengesetz erinnern, wo es sich um manche grundsätzliche Fragen des Importausgleichs handelte. Neuerdings haben Klagen der Margarineherstellungsbetriebe geschwebt, die zu einem Frachtausgleich herangezogen oder durch ihn begünstigt werden sollten. Von beiden Seiten ist gegen den Staat vor den Verwaltungsgerichten vorgegangen worden, nämlich von der einen Gruppe, die sich gegen Heranziehung zum Frachtausgleich wehrt und geltend macht, die Voraussetzungen dieses Frachtausgleichs seien entfallen; die andere Gruppe aber verfolgt ihren Anspruch, den sie angeblich aus den Frach tausgleichsregelungen bekommen hat, und verklagt den Staat vor dem Verwaltungsgericht auf Durchführung des Frachtausgleichs. Wenn solche Prozesse gleichzeitig zum Teil in Karlsruhe, zum Teil in Düsseldorf und zum Teil in Hamburg anhängig gemacht wiirden, dann wäre das ProzeBbild naturgemäß unerfreulich. Man hat es wohl zum Teil dadurch mildern können, daB man z. B. in Hamburg in einem ProzeB der den Frachtausgleich verlangenden Betriebe sämtliche deuts-hen argarinefabriken, die in dem Frachtausgleichsverfahren auf der anderen Seite als möglicherweise Betroffene in Betracht kommen, beigeladen hat. So hat man einen Gesamtprozeß von etwa 65 deutschen Margarinefabriken, die um das Rechtsverhältnis des Frachtausgleichs streiten: die einen gegen Heranziehung zum Frachtausgleich, die anderen auf Durchführung des Frachtausgleichs. Ob Urteile in solchen Prozessen immer voll befriedigen können, ist gelegentlich bezweifelt worden. Es tauchen hier die Schwierigkeiten auf, die auch in den Referaten angedeutet worden sind: Ob man es den Verwaltungsgerichten zumuten kann, etwa auf dem Umweg über die Auslegung sogenannter unbestimmter Rechtsbegriffe oder bei der Rechtsanwendung überhaupt in Wahrheit wirtschaftspolitische Entscheidungen zu fällen.

Zum Abschluß möchte ich noch auf eine Möglichkeit hinweisen, die, wie ich immer wieder glaube, im verwaltungsgerichtlichen Rechtsschutzverfahren immer noch viel zu wenig ausgeschöpft wird: die Feststellungsklage. Ein angenommene Beispiel: 
Nehmen wir an, eine Bundesstelle oder der Bundeswirtschaftsminister benützte die Ausschreibung nach den devisengesetzlichen Bestimmungen dazu, um bei der Zuteilung der Devisen für ein ausgeschriebenes Gut bestimmte Importeure oder Industrien durch Ausschluß vom Devisenkontingent niederzuhalten, die Devisenbewirtschaftungsmöglichkeit also zu benutzen, um eine bestimmte Produktionssteuerung im Inland vorzunehmen. Angenommen das geschähe womöglich auch noch im sogenannten Bankenverfahren, wo also ein Hoheitsakt außer dem ferneliegenden dirigierenden Anweisungsakt des Ministeriums kaum greifbar ist, dann kommt man mit einer Anfechtungsklage wohl ebensowenig zurecht wie mit einer Verpflichtungsklage, aber auch nicht mit der Normenkontrolle. Es ist aber die Frage, ob nicht der Betroffene auch zwecks Klärung des künftigen gleichmäßigen oder verhältnismäßigen oder gesetzmäßigen Verhaltens der obersten Dirigentenstelle eine Klage vor dem Verwaltungsgericht anstrengen kann, mit dem Antrag festzustellen, da $\beta$ bei Ausschreibung so und so verfahren werden muB. DaB hier ein subjektives Recht überhaupt erforderlich ist, wird zu verneinen sein. Mit der Feststellungsklage könnte man die Gefahr vermindern, da $B$ der Kläger vor Klageerhebung oder jedenfalls vor der Entscheidung über die Klage das wirtschaftliche Interesse an dem inzwischen längst überholten, in der Vergangenheit liegenden Verfahren des Einzelfalls (etwa einer einzelnen Ausschreibung oder Zuteilung) verliert. Die Verwaltungsgerichte sollten sich mehr darauf besinnen, welche Möglichkeiten in der Feststellungsklage liegen. Man sollte nicht so engherzig, wie oft bisher - worauf Herr Jellinek schon I925 hingewiesen hat und nicht so ängstlich an dem Feststellungsinteresse oder an dem Begriff des Rechtsverhältnisses herumdeuteln und die Klagen nicht dađurch als unzulässig zu Fall bringen. Wenn es gelänge, aus der Feststellungsklage auch die gewissermaßen vorbeugende Feststellungsklage hinsichtlich bestimmter Fragen künftigen Verhaltens innerhalb eines Dirigentenplanes zu entwickeln, dann könnte man vielfach den verwaltungsgerichtlichen Rechtsschutz sowohl im Interesse der Wirtschaftskreise wie im Interesse des rechtsstaatlich dirigierenden Staates sinnvoll intensivieren.

Stanka-Wien: Ich möchte kurz darauf hinweisen, daß die Tatsache der großen Zahl der Staatsbediensteten dazu führt, da $B$ eine gewisse Konsumentenschicht entsteht, deren Kaufkraft durch das Gehaltsgesetz und das darin enthaltene Gehaltsschema reguliert erscheint. Wir wissen, daB die Gehaltsschemen unwillkürlich auf die Lohnverhältnisse der Privatwirtschaft immer abfärben. Ein jedes Gehaltsschema hat auch zugleich gewisse Wertungen der geleisteten Arbeit und eine jede Änderung in 
diesen Wertungsverhältnissen - das Verhältnis geistige Arbeit und manuelle Arbeit usw. - führt auch in der Privatwirtschaft zu gewissen Änderungen der Lohnverhältnisse, was jedenfalls auch als eine Art staatliche Einflußnahme auf die Lohnverhältnisse in der Privatwirtschaft anzusehen ist.

Krüger-Hamburg: Aus der Fülle dessen, was uns beide Referenten heute morgen geboten haben, möchte ich das Problem der Formen der staatlichen Wirtschaftsintervention herausgreifen. Herr Scheuner hat sich bemüht, die Formen zu gliedern in direkte und indirekte, und Herr Schüle hat einen Lösungsversuch gegeben in der Richtung, da $\beta$ man es auf die Art der Wirkung der betreffenden Maßnahme abstellen solle.

Nicht zuletzt aus meiner Kenntnis der Praxis scheint es mir vor allen Dingen notwendig, zu unterscheiden zwischen den herkömmlichen befehlenden Akten mit der Aussicht auf Zwang und Strafe einerseits und den Wohltaten des Staates andererseits, also hier der Benutzung von Wohltaten zur Wirtschaftslenkung. Ich glaube, diese letztere unjuristischere, unherrschaftlichere Form ist diejenige, die uns heute besonders interessieren muB. Dieses Interesse ist von ganz allgemeiner Bedeutung, weil die Wohltat bekanntlich eine wichtige Möglichkeit ist, Herrschaft zu begründen oder auszuweiten. Dies geschieht einmal in beträchtlichem $\mathrm{Maße}$ in der Außenpolitik. Man kennt dieses Mittel aber auch aus dem Staatsrecht, insbesondere aus der Fonds-Wirtschaft der Weimarer Zeit. Dieses Mittel findet aber in reichem Maße auch im Verwaltungsrecht Anwendung, und zwar nicht nur in Deutschland, sondern vor allem auch in den Vereinigten Staaten. Roscoe Pound hat diese Sachverhalte sehr eindrucksvoll beschrieben.

Diese Möglichkeit einer Begründung und Ausweitung von Herrschaft tritt einmal auf in der juristischen Form des begünstigenden Verwaltungsaktes, den man mit einer Auflage versieht, die wirtschaftslenkenden Charakter hat. Die juristische Begründung für die Zulässigkeit eines solchen Vorgehens ist scheinbar einleuchtend: Wenn die Behörde einen begünstigenden Verwaltungsakt grundsätzlich nicht zu erlassen braucht, dann kann sie ihn offenbar auch als Minus, d. h. mit einer Auflage erlassen. Ich war frappiert über die Mitteilung von Herm Huber, daß irgendeine Konnexität zwischen dem begünstigenden Verwaltungsakt und der Auflage, die dieser Verwaltungsakt mit durchzieht, in der Schweiz nicht zu entdecken ist. Ich kann nur bestätigen, da $B$ etwas derartiges auch bei uns vielfach vorkommt, und zwar gilt das nicht nur für begünstigende Verwaltungsakte, sondern für alle anderen, unherrschaftlicheren Formen der staatlichen Wirtschaftsintervention und Wirtschaftsförderung erst recht, insbesondere naturgemä $B$ für 
die Kreditgewährung. Die Kreditgewährung wird nicht allzu selten dazu benutzt, um eine vollständige Herrschaft über dasjenige Unternehmen auszuüben, das sich in die Notwendigkeit versetzt sah, diesen Kredit aufzunehmen. Es läßt sich also auf diesen Wegen Beträchtliches erreichen. Das aber, was uns an diesem Vorgang besonders interessiert und was vielleicht anstößig sein müßte, ist die Tatsache, daß hier der Staat seine Herrschaft begründet oder ausweitet ohne jede gesetzliche Grundlage. Angesichts dieser Entwicklung muß ernsthaft die Frage aufgeworfen werden, ob die Lehre noch haltbar ist, daß nur belastende, nicht aber begünstigende Verwaltungsakte einer Grundlage im Gesetz bedürfen. In dieses Problem hinein spielt auch die Frage der Kontrolle der Volksvertretung über die Verwaltung, die naturgemäß dann eine erhebliche Lücke aufweist, wenn die Verwaltung ohne gesetzliche Grundlage begünstigen und über die Begünstigung Herrschaft ausüben kann. Solange man jedoch hier noch nicht zu anderen Auffassungen gekommen ist, stellt sich umso dringlicher die Frage des Rechtsschutzes in diesem Bereich.

Die Referenten sind der Frage nachgegangen, warum in diesem Bereich von den Betroffenen nur in verhältnismäßig geringem Umfange versucht wird, Rechtsschutz zu erlangen. Mir scheint die Antwort hierauf darin zu liegen, daB man es der Wirtschaftsverwaltung gegenüber oft gar nicht riskieren kann, die Gerichte anzurufen. Es ist keinerlei Wagnis, eine polizeiliche Verfügung anzufechten, die sich gegen das nächtliche Bellen eines Hundes richtet. Wenn der Betroffene durch eine erfolgreiche Anfechtung die Polizei davon abhält, in Zukunft ähnliche Verfügungen zu erlassen, dann kann ihm das nur recht sein. Wenn man aber versucht, durch Inanspruchnahme der Gerichtsbarkeit eine Wohltat zu erzwingen, und wenn man sich dadurch auf jeden Fall die Wohltaten spendende Behörde vergrämt, dann kann man ziemlich sicher sein, daß man bei der zukünftigen Vergebung von Wohltaten nicht gerade bevorzugt behandelt wird. Es wird daher in den meisten Fällen untunlich sein, sich Wohltaten mit Hilfe des Gerichts zu erkämpfen. Aber selbst wenn man annimmt, daB eine Person hierauf keine Rücksicht zu nehmen braucht und sich daher an das Verwaltungsgericht wendet, dann wird sich hinderlich bemerkbar machen die Tatsache, auf die hier schon mehrfach hingewiesen wựde - die Tatsache nämlich, daß nicht nur offenbar unser System des Verwaltungsrechts, sondern insbesondere auch die Systematik des Rechtsschutzes im Grunde genommen immer noch abgestellt ist auf den befehlenden und zwingenden Staat, nicht aber auf den Wohltaten gewährenden Staat. Diese These möchte ich auf die Gefahr hin, mich ins Detail zu verlieren, an einigen Beispielen aus meinen Erfahrungen veranschaulichen. So kann z. B. die Wohltat, die dem einen gewährt wird, von höchstem 
Nachteil für einen anderen sein. Man stelle sich folgenden Fall vor: Jemand hat eine befristete Erlaubnis zum Betrieb eines Omnibusverkehrs erhalten. Während des Laufs dieser Frist erhalten gleichartige Unternehmen eine unbefristete Erlaubnis. Es entsteht die Gefahr, daß die Verlängerung der befristeten Erlaubnis deswegen versagt werden könnte, weil angesichts der neu eingetretenen Unternehmer ein Bedürfnis nicht mehr bestehe. Die Klage wegen der Erteilung der Erlaubnis an die neuen Unternehmer wird jedoch aus dem prozessualen Grunde abgewiesen, da $\beta$ niemand ein Recht darauf habe, daß einem anderen eine Erlaubnis nicht erteilt werde. Der Klage kann sich aber auch ein anderes prozessuales Hindernis in Gestalt eines zu eng verstandenen Begriffes des Verwaltungsaktes entgegenstellen, und dies vor allem dann, wenn man den Begriff der Amtshandlung bei der Untätigkeitsklage gleichhfalls als Verwaltungsakt versteht. Es erweist sich nach alledem als notwendig, den Begriff des subjektiven Rechtes, der Voraussetzung sowohl für den Erfolg einer Anfechtungs- wie einer Untätigkeitsklage ist, nicht allzu dogmatisch zu verstehen. Diese Notwendigkeit ergibt sich vor allem aus der Tatsache, daß die Gewährung von Wohltaten durchweg in das Ermessen der Behörde gestellt ist und infolgedessen ein Recht auf derartige Wohltaten grundsätzlich nicht besteht. Ich sehe also letztlich - allerdings befinde ich mich damit im Widerspruch zu Herrn Naumann - keine andere Möglichkeit, als da $B$ man das subjektive Recht sowohl aus der Anfechtungsklage wie der Untätigkeitsklage verschwinden und im Rechtsschutzbedürfnis aufgehen läßt. Die Prüfung des Rechtsschutzbedürfnisses reicht meiner Auffassung nach aus, um die Gefahr einer Popular-Klage abzuwehren. Weiter wäre es mit Rücksicht darauf, daß die Gewährung von Wohltaten durchweg in das Ermessen gestellt ist, notwendig, das System der Ermessensfehler feiner auszubauen, insbesondere die Frage der Sachwidrigkeit einer Auflage als Problem zu erkennen und zu lösen. Die von Herrn Naumann gekennzeichnete Gefahr, daß der Richter wirtschaftspolitische Entscheidungen trifft, wird sich ohne besondere Schwierigkeiten vermeiden lassen.

Und schließlich noch etwas, was sich, wie ich glaube, weitgehend deckt mit dem, was Herr Ipsen als Plangewährleistung bezeichnet hat. Wenn man die Formen der staatlichen Wirtschaftspolitik kennzeichnen will, dann muß man außer den bereits beschriebenen Merkmalen feststellen, da $B$ sie weitgehend nicht mehr subordinationsrechtlicher, sondern koordinationsrechtlicher Natur sind. Wirtschaftspolitische Ziele werden heute vielfach nicht mehr in der Weise verfolgt, daß der Staat den Weg festlegt und die Bürger zur Mitwirkung hoheitlich heranzieht. Immer mehr wird vielmehr in der Weise verfahren, daß sich Staat und Bürger gewissermaßen gemeinsam an einen Tisch setzen und sich über Ziel und vor allem 
Weg verständigen. Wenn dann der Bürger den ihm absprachegemäß zufallenden Teil der Aufgabe vielfach mit erheblichen finanziellen Risiken ins Werk setzt, dann muB er sich darauf verlassen können, daß auch der Staat den ihm zugefallenen Teil der Aufgabe durchführt und insbesondere etwa in Aussicht gestellte Hilfen gewährt. Dieser koordinationsrechtlichen Wandlung des Wirtschaftsverwaltungsrechts ist unsere Dogmatik noch nicht gefolgt. Hier gilt immer noch, daß der Staat mit dem Bürger nur in der Form des einseitigen Befehls spricht, aber nicht paktiert. Solange solche Auffassungen vertreten und praktiziert werden, ist eine moderne Wirtschaftsverwaltung ebensowenig möglich wie eine freie Mitwirkung der Bürger an ihr. Auch in diesem Falle bestätigt sich wieder die These, daB das System des Verwaltungsrechts und vor allem auch die Systematik des Verwaltungsrechtsschutzes diesen neuartigen Dingen, die wir in irgendeiner Form auch meiner Überzeugung nach immer behalten werden, noch nicht entspricht. Es gibt heute zwei rechtsleere Räume. Der eine stammt aus der Tradition und ist das sogenannte besondere $\mathrm{Ge}$ waltverhältnis. Es gibt daneben einen neuen rechtsleeren Raum. Das ist der Raum der Wirtschaftsverwaltung. Ich glaube, man kann von einem Rechtsstaat und erst recht von einem sozialen Rechtsstaat erst dann sprechen, wenn diese beiden rechtsleeren Räume von Recht und Rechtsschutz durchdrungen sind.

Abendroth-Marburg: Es ist zunächst zu erwähnen, daß Herr Scheuner in seinem Referat die Auffassung vertreten hat, die Interventionen, die wir heute hätten, seien undogmatisch. Ich möchte sagen, es sind ad hoc-Interventionen der Staatsgewalt. Umfassende Planung aber sei nach seiner Meinung mindestens, wenn sie zur Zentralverwaltungswirtschaft führt, mit dem Charakter eines demokratischen Rechtsstaates unvereinbar. Ich möchte hier nur andeutend sagen, daB mir diese These in dieser Form doch ergänzungsbedürftig scheint. Ganz sicher, eine zentrale Verwaltungswirtschaft im Extremfalle, die den Bürger seiner Rechtssubjektivität völlig entkleidet, wäre mit dem Gedanken des demokratischen Rechtsstaates nicht mehr vereinbar. Aber führt umfassende Planung, Koordinierung also der ad hoc-Interventionen zu einer systematischen Umplanung der Gesellschaft notwendig in dieses Gleis? Das ist doch zum mindesten fragwürdig, und ich würde Herrn Scheuner bitten, im Schlußwort vielleicht mit wenigen Worten hier seine Auffassung klarzustellen.

Nun zur Lage in unserem konkreten westdeutschen Verfassungssystem. Herr Scheuner hatte mit vollem Recht betont, daß das Grundgesetz sich in bezug auf die Wirtschaftsverfassung ganz einfach nicht entschieden hat; höchstens hat es das insoweit, daß das Grundgesetz seiner Struktur nach der Option für eine zentrale 
Verwaltungswirtschaft, die jede Rechtssubjektivität des Bürgers verneint, entgegensteht. Aber insoweit nicht, als das Grundgesetz, wie mir scheint, doch jede andere Möglichkeit offenhält und bewußt offengehalten hat. Denn auch der Gedanke umfassender Umplanung der Gesellschaft, vermittelt durch staatliche Willensbildung, ist ja keineswegs gesperrt. Art. 15 ist keineswegs das einzige Einfallstor in dieser Richtung, und ich bin überzeugt, daß ich mit Herrn Scheuner auch in dieser Beurteilung der Dinge übereinstimme, weil etwa die innere Umdeutung des Eigentumsbegriffs, die Art. I4 durchaus offen hält, noch weitere Möglichkeiten erschließt, die im einzelnen bewußt vom Verfassungsgeber nicht klargestellt worden sind, weil sie sich apriori auch gar nicht klarstellen sondern nur situationsmäßig konkretisieren lassen. Es hat mich gefreut, daß sowohl von Herrn Schüle als auch von Herrn Jellinek dabei dem Versuch entgegengetreten wurde, Art. 2 des GG. aus einer Garantie für die menschliche Persönlichkeit umzudeuten in eine Garantie des homo oeconomicus der liberalen Wirtschaftsordnung. In dieser Úberspitzung hätte ja auch zweifellos Herr Scheuner das Ergebnis nicht gewollt, aber immerhin ließen manche seiner Formulierungen hier Zweifel zu. Und von hier aus scheint es mir fragwürdig, ob der These Herrn Scheuners zugestimmt werden kann, daß die Neuerrichtung staatlicher Monopole in unserem heutigen System unmöglich sei. Ich glaube nicht, daß, wenn - man denke etwa an die Entfaltung der Atomenergie oder dergleichen Möglichkeiten mehr - plötzlich neue technische und vom Technischen ins Ökonomische hineinragende Möglichkeiten auftauchen, hier der Betätigung des Staates eine Schranke gesetzt ist, und ich glaube auch nicht, daß bei gegenwärtig bereits bestehenden Produktionszweigen jeder Möglichkeit hier Tür und Tor verbaut ist. Die eine Möglichkeit, die aus Art. 15 - allerdings mit der Auflage der Entschädigungspflicht - folgt, wird ja auch Herr Scheuner nicht in Frage stellen wollen.

Die Diskussion hat - wie mir scheint - ein Thema bereits in den Vordergrund gerückt, das in beiden Referaten zu kurz gekommen ist, das Thema nämlich des Einfallstors staatlicher Intervention aus dem Grenzbereich der innerstaatlichen Wirtschaft nach außen, aus jenem Grenzbereich, der sich in der Devisenbewirtschaftung wie in Außenhandelsregelungen irgendwelcher anderer Art sehr deutlich zeigt. Ich würde es wünschen, daB in den Schlußworten wenigstens andeutend von den beiden Referenten die Möglichkeiten, die sich hier auftun, auch nach der rechtlichen Seite hin etwas erörtert werden.

Und endlich noch eine letzte Bemerkung zur Diskussion. Von Herrn Ipsen wurde - klug begründet - der Plangewährleistungsgedanke und der Gedanke der Vergütung bei Inpflichtnahmen behandelt. Diese Gedanken sind natürlich sehr erwägenswert. Aber 
ist es nicht erforderlich, hier sehr deutlich zu scheiden zwischen dem, was unser Verfassungsrecht und unser Gesetzesrecht gebietet, und dem, was eventuell de lege ferenda erwägenswert erscheinen mag? Jch würde es für äußerst bedenklich halten, wenn - seien es die Verwaltungsgerichte, sei es das BVG. - hier qua Judikatur Entscheidungen vorwegzunehmen trachten würden, die nicht durch die Judikatur gefällt werden können.

Leibholz-Göttingen: Ich glaube, daß etwas heute noch nicht diskutiert worden ist, was auch diskutiert werden sollte, nämlich die Frage des verfassungssystematischen und verfassungstheoretischen Standortes des staatlichen Interventionsrechtes. An sich ist der Interventionsbegriff ein formaler Begriff, der mit einem beliebigen Inhalt gefüllt werden kann, und Herr Huber hat uns heute gesagt, da $\mathrm{B}$ in der Schweiz z. B. vom Staate das Interventionsrecht gebraucht wird, um bestimmte liberale Machtpositionen zu halten und zu festigen. Im Grunde genommen dient aber heute das staatliche Interventionsrecht anderen Zwecken. Es dient dazu, den sozial schwächeren Schichten zu helfen. Insoweit fügt es sich in den allgemeinen Entwicklungsproze $B$ ein, der in den letzten hundert Jahren, zu der vielleicht bedauerlichen, aber als Faktum nicht bestreitbaren Entliberalisierung und radikalen Egalisierung und Demokratisierung des gesamten Lebens geführt hat. Man denke nur etwa an die Entwicklung des Wahlrechts im Laufe des letzten Jahrhunderts, insbesondere auch die Einführung des Frauenwahlrechtes, die Egalisierung der Wahlkreise, soweit man am Mehrheitswahlsystem festgehalten, den Siegeszug des Verhältniswahlrechts und jetzt vor allem die weitgehende Egalisierung des wirtschaftlichen und sozialen Lebens. In diesem Zusammenhang scheint mir das Interventionsrecht das Vehikel zu sein, mit dessen Hilfe man versucht, die einmal begonnene radikalegalitäre Demokratisierung auf den nicht politischen Gebieten weiter zu treiben. Die diesem ProzeB innewohnende Dynamik und Eigengesetzlichkeit bedient sich der Formen der staatlichen Intervention, um ihre Ziele zu erreichen.

Damit sei zugleich noch auf etwas Weiteres hingewiesen. Die von Röpke, Hayek und anderen vertretene These, daß die weitgehende Planung und Lenkung, vor allem der Wirtschaft mit Hilfe der staatlichen Intervention oder gar ihrer Sozialisierung, die westeuropäischen Demokratien letzten Endes in totale Staaten transformiert, verzeichnet die Situation. Man mag mit dieser These persönlich sympathisieren. Realitätsgebunden ist dieser Neoliberalismus aber nicht. Denn in Wirklichkeit hängt der Bestand der heutigen westlichen Demokratien davon ab, ob es gelingt, die unentbehrlich gewordenen staatlichen Planungs- und Lenkungsmaßnahmen so zu gestalten, daß der liberale Grund- 
charakter der heutigen parteienstaatlichen Massendemokratie nicht in Frage gestellt wird.

Schüle-Heidelberg (Schlußwort): Bei der Fülle der Gesichtspunkte, die in der Diskussion vorgetragen wurden, ist es verständlicherweise nicht möglich, auf alle diese Fragen einzugehen. Ich bitte daher um Ihre Nachsicht, wenn ich nur auf diejenigen Punkte zu sprechen komme, von denen ich glaube, da $B$ sie eine besondere Beziehung zu meinem Referat haben oder die mir allgemein wichtig erscheinen.

Was mir zunächst an den weitgreifenden Darlegungen der beiden Herren aus Österreich und der Schweiz aufgefallen ist und Ihnen wahrscheinlich auch, das ist die internationale Parallelität in der grundsätzlichen Problemstellung, in den konkreten Formen der Intervention und ebenso in den verfassungsrechtlichen Fragen. Das mag bei Österreich zu einem Teil mit seiner jüngeren geschichtlichen Entwicklung zusammenhängen; bei der Schweiz ist das aber nicht so. Gleichwohl sehen wir, daß jedenfalls in diesen drei mitteleuropäischen Staaten eine Entwicklung festzustellen ist, die im Großen gesehen eine gewisse Gleichartigkeit aufweist. Eine wichtige prinzipielle Frage, die besonders von Herrn Kollegen Huber behandelt worden ist, ist die, ob man die Intervention heute noch als Ausnahme gegenüber dem sozusagen normalen Zustand der freien Wirtschaft betrachten darf. Der Ausdruck "Intervention" (er gefâllt mir gar nicht sehr) hat ja eine gewisse diskriminie ende Note, und wir müssen überlegen, ob das begründet ist. Sicher ist, wenn wir die Situation des ausgehenden I 9. Jahrhunderts ins Auge fassen, daß ihm damals zu Recht eine solche Note anhaftete. Ich glaube aber, da $B$ wir uns dazu durchringen müssen - insbesondere nach den Ausführungen unseres Kollegen Leibholz - , daB die staatliche Intervention gegenüber der Wirtschaft heute so etwas wie einen Normalbestandteil unserer gegenwärtigen demokratischen Verfassungsordnungen darstellt. Das ergibt sich aus der Tatsache, daß der heutige Staat gegenüber den außerordentlichen sozialen Problemen, verstärkt durch Kriegsfolgen und die allgemeine Unordnung, nicht mehr untätig zusehen kann, wie das früher einmal der Fall gewesen ist. Er hält es vielmehr für seine selbstverständliche Pflicht, hier und da und dort mit den ihm zur Verfügung stehenden Mitteln einzugreifen, und es sind wahrhaftig nicht wenige.

Herr Kollege Jellinek hat mir zu meiner großen Freude darin zugestimmt, daß man den Art. 2 Abs. (I) des Grundgesetzes nicht auch ausdehnen darf auf die Frage der wirtschaftlichen Freiheit. Die freie Entfaltung der Persönlichkeit ist nämlich etwas völlig anderes als die freie Entfaltung der geschäftlichen Tätigkeit. Diese aus dem Sinn der Begriffe geschöpfte Meinung wird durch die 
Stellung von Art. 2 Abs. (I) innerhalb der Grundrechte gestützt. Art. 2 folgt dem Art. $I$, in welchem die Unantastbarkeit der Würde des Menschen an die Spitze gestellt ist, und wenn Sie sich etwa den weiteren Gehalt von Art. 2 ansehen (Recht auf Leben, körperliche Unversehrtheit, Freiheit der Person), so dürfte dieses ebenfalls für die von mir dargelegte Ansicht sprechen. Herr Abendroth hat sich, wenn ich mich recht erinnere, gleichfalls in diesem Sinne geäußert, ebenso eine Anzahl weiterer Diskussionsredner.

Herr Klein hat eine Frage aufgeworfen, die mit dem eben Behandelten nahe zusammenhängt, nämlich, vereinfachend gesprochen, ob wir in Deutschland eigentlich eine freie Wirtschaft oder ob wir keine freie Wirtschaft haben? Meines Erachtens ist unser gegenwärtiges Wirtschaftssystem nicht wirklich frei, sondern wir haben eine Wirtschaft, die nur insoweit frei ist, als sie nicht staatlicher Intervention unterliegt. Welche Mittel und Möglichkeiten hierfür in Frage kommen, ist heute schon lang und breit auseinandergesetzt worden.

An den Ausführungen von Herrn Ipsen hat mich eines besonders interessiert, nämlich der Gedanke einer Art von allgemeiner öffentlich-rechtlicher Gewährleistung als Gegenstück zu den öffentlich-rechtlichen Verpflichtungen, denen die Wirtschaft im allgemeinen Interesse unterworfen ist. Das möchte ich noch durch ein Wort ergänzen. Nach meinem Urteil ist die Wirtschaft heute aus der privaten Sphäre herausgewachsen und im Grunde zu einer mehr oder minder öffentlichen Funktion geworden. Das mag Ihnen vielleicht seltsam erscheinen. Ich möchte nicht gerade behaupten, daß sie schon eine volle öffentliche Funktion darstellt, aber entscheidend ist, daß sie eben keine rein private Funktion mehr ist. Wer z. B. heute ein großes Unternehmen leitet, der steht derart im Gesamtzusammenhang des sozialen Lebens, seiner Mitmenschen, seiner Mitarbeiter, seiner Gemeinde usw., daß er sich den daraus entspringenden Pflichten gar nicht entziehen kann und etwa sagen könnte, das Schicksal seiner Bilanz sei ihm wichtiger als das Schicksal seiner Arbeiterschaft. Tatsächlich ist das auch so. - Mit dem Gedanken einer allgemeinen öffentlich-rechtlichen Gewährleistungspflicht ist ein sehr wichtiges Thema angeschnitten. In den ganzen Bewirtschaftungsanordnungen ist leider immer nur davon die Rede, was von der Wirtschaft getan, erfüllt und wie gelenkt werden soll, und fast nirgends auch davon, wie den Betroffenen dabei ein Rechtsschutz gewährt wird. Bei jeder Normierung dieser Art sollte ganz automatisch das Problem des Rechtsschutzes auftauchen; daran sollten diejenigen denken, denen die Aufgabe gestellt ist, Bewirtschaftungsanordnungen zu formulieren und zu erlassen.

Bei dem weiteren Thema, ebenfalls von Herm Ipsen berührt und in der Folge von Herrn Krüger ausführlich besprochen, näm- 
lich der staatlichen Finanzhilfe bzw. den staatlichen „Wohltaten" (um den Ausdruck von Herrn Krüger zu gebrauchen) bin ich der Meinung, daß scharf zu unterscheiden ist zwischen dem Verwaltungsakt der Gewährung und dessen sozusagen geschäftlicher Ausführung, d. h. der Ubernahme der Bürgschaft, der Hingabe des Darlehens usw. Gegen einen etwa ablehnenden Verwaltungsakt kann Verwaltungsklage erhoben werden, sofern die erforderlichen Voraussetzungen (subjektives öffentliches Recht und anderes) gegeben sind. Aber das Rechtsschutzproblem ist in diesem Zusammenhang nur dann richtig gestellt, wenn die "Wohltaten" unmittelbar von Behörden ausgehen. Ich habe heute morgen darzulegen versucht, daß, insbesondere auf Bundesebene, die Einschaltung von Kreditinstituten das Symptomatische an unserer ganzen neueren Entwicklung ist. Wenn aber nicht Verwaltungsbehörden, sondern Kreditinstitute die Entscheidung über die Gewährung z. B. von Darlehen treffen, so muß der übliche Weg des verwaltungsgerichtlichen Rechtsschutzes versagen. Hier taucht, weitergedacht, die Frage auf, wie den Kreditinstituten gegenüber ein Rechtsschutz im Falle von Ablehnungen erreicht werden kann.

Herr Naumann hat, ausgestattet mit vielseitigen Erfahrungen aus der Praxis, über Möglichkeiten einer eventuellen Reform des verwaltungsgericht lichen Schutzes gesprochen. In der Diskussion sind ja erfreulicherweise die Probleme des Rechtsschutzes sehr viel stärker hervorgetreten, als dieses Herrn Scheuner und mir in den Referaten möglich gewesen ist. Ich möchte hierzu eine höchst unjuristische, aber praktisch vielleicht richtige Bemerkung machen. Es ist mir bekannt, daB auch schon bisher, d. h. vor Errichtung des Bundesverwaltungsgerichtes, verwaltungsgerichtliche Möglichkeiten zur Anfechtung von Akten von Bundesverwaltungsbehörden vorhanden waren. Von der Praxis her gesehen bedarf es aber einer augenfälligen Zuständigkeitsnorm, d. h. einer solchen, an die man ohne weiteres denkt. Schwierige Zuständigkeitsfragen führen dazu, daß von der Wirtschaft gesagt wird: bis wir das überhaupt juristisch ermittelt und dann hinterher durchgepaukt haben, das kostet uns zuviel Mühe; und die können wir uns zeitlich, geldlich oder aus sonstigen Gründen gar nicht leisten. Ich halte es daher für einen großen Fortschritt, daß durch $\S 9$ des Gesetzes über das Bundesverwaltungsgericht, vor allem auf dem Gebiet der hoheitlichen Wirtschaftsverwaltung, eine eindeutige und, wie ich auch denke, augenfällige Zuständigkeitsnorm geschaffen worden ist. Wenn man außerdem noch durch eine ausgiebigere Richterbesetzung ein schnelleres Arbeiten der Verwaltungsgerichte erreichen könnte, so würde das nach meinem Urteil die Situation auf dem Gebiet des Verwaltungsrechtsschutzes der Wirtschaft sehr erleichtern. In diesem Zusammenhang ist mir, sowohl heute früh als auch besonders heute nachmittag, klar geworden, daß es ent- 
scheidend darauf ankommt, Rechtsbehelfe zu schaffen, die der Eigenart und der Interessenlage der Wirtschaft adäquat sind. Das mag eine allgemeine und wohl auch etwas billig erscheinende Formulierung sein, aber ich glaube, die Diskussion hat ergeben, da $B$ die bisherige Gestaltung des verwaltungsgerichtlichen Schutzes mit ihrer Abstellung auf den Verwaltungsakt im alten Sinne, auf die Verfügung, auf das subjektive öffentliche Recht usw. - da $B$ das alles heute nicht mehr ausreicht. Ich verstehe natürlich, da $B$ diesen Fragen bei der bisherigen Gestaltung des verwaltungsgerichtlichen Verfahrens noch nicht Rechnung getragen werden konnte. Aber als Ergebnis unserer Diskussion sollte es festgehalten, und es sollten bei der Verfahrensgerichtsordnung in Verwaltungssachen die zuvor dargelegten Gesichtspunkte berücksichtigt werden.

$\mathrm{Da} \beta$ die Möglichkeiten der abstrakten Normenkontrolle stärker ausgebildet werden müssen, erscheint mir sicher. In den Angelegenheiten der Bewirtschaftung steht die Form des Gesetzes und die Form der Verordnung derartig im Vordergrund, daB die Wirtschaft in den meisten Fällen ihre praftische Durchführung gar nicht erst abwarten kann. Schon mit dem Erlaß etwa einer Verordnung ist das Gravamen da. Man wird versuchen, es auszuräumen, und dafür gibt es in diesem Stadium nur die abstrakte Normenkontrolle.

Ein kleines "Steckenpferd" von mir möchte ich nochmals hervorheben. Die Verwaltungsbeschwerde ist, so primitiv sie unter Rechtsschutzgesichtspunkten erscheinen mag, doch eint ganz ausgezeichnete Einrichtung. Ich weiß selbst noch nicht, wie man die Verwaltungsbeschwerde vielleicht rechtlich noch besser ausbilden könnte. Aber in der Praxis ist es jedenfalls so, da $B$, vor allem wenn man es mit einer örtlich nahen Verwaltungsbehörd? zu tun hat, man zu ihr geht und ihr auseinandersetzt, was man selbst denkt und ihr klar zu machen versucht, daß und warum sie daneben gegriffen hat. In Bewirtschaftungsangelegenheiten sind die Verwaltungsbehörden auch gar nicht so uneinsichtig, vor allem, wenn man erst einmal Gegenvorstellungen mncht, dann eine Verwaltungsbeschwerde in Aussicht stellt und erst zuletzt mit dem schweren Geschütz der verwaltungsgerichtlichen Klage droht und sie am Ende auch einmal durchführt.

Herr Kollege Jellinek hat eine Frage gestellt wegen des Rechtsschutzes im Entwurf des deutschen Kartellgesetzes. Nach meinem Urteil bestehen gewisse Bedenken gegen die Ubertragung des Rechtsschutzes an Zivilgerichte. Der verwaltungsgerichtliche Schutz, früher beim Reichswirtschaftsgerichti, hat meines Erachtens gezeigt, daß der wirtschaftlich zumeist besser geschulte Verwaltungsrichter mit den Fragen des Kartellrechtes besser fertig wird als der Zivilrichter. Ich kenne die schwierigen organisatorischen und ver- 
fahrensmäßigen Uberlegungen, die in dem neuen Entwurf des deutschen Kartellgesetzes zu berücksichtigen waren, aber, allgemein gesprochen, bin ich der Meinung, da $B$ es im Prinzip zweckmäBiger wäre, man würde in Kartellsachen den Rechtsschutz durch Verwaltungsgerichte gewähren und nicht durch Gerichte der ordentlichen Gerichtsbarkeit. -

Meine Damen und Herren, dieses war das Wichtigste, was mir an den Diskussionsbeiträgen aufgefallen ist, und ich bitte um Entschuldigung, wenn ich darauf nur sehr kursorisch eingehen konnte. Abschließend möchte ich nur noch eine Bemerkung machen. Es ist bekanntlich im Bonner Grundgesetz davon Abstand genommen worden, einen Katalog von Wirtschaftsartikeln aufzunehmen. Man hat sich dazu aus dem einfachen Grunde entschlossen - Herr von Mangoldt hat uns das bestätigt - um nicht ,schlafende Hunde aufzuwecken" und damit die Beratungen im Parlamentarischen Rat mit einem weiteren sehr schwierigen Fragenkomplex zu belasten. Die Wirtschaft hat diese Auslassung seinerzeit begrüßt. Aber was mich persönlich betrifft, so habe ich noch ein zweites Herz in mir, nämlich das Herz des Verfassungsjuristen, und insoweit muß ich sagen, da $B$ das Fehlen von Wirtschaftsartikeln andererseits auch einen großen Nachteil hat. Wenn wir heute das Problem der staatlichen Intervention gegenüber der Wirtschaft kennengelernt und uns seine Mittel vor Augen geführt haben, so bleibt darüber hinaus noch ein ganz entscheidendes Problem übrig, nämlich die Frage nach dem verfassungstheoretischen Sinn der staatlichen Intervention und ebenso nach ihren rechtlichen Grenzen. Beides muß aus der hōheren Ebene, die Herr Leibholz uns in so bemerkenswerter Weise aufgezeigt hat, gelöst werden. Aber eine solche Lösung wird außerordentlich schwierig, wenn man versucht, sie mit den Begriffen des Verfassungsrechtes einzufangen und zu Papier zu bringen. Wir können feststellen, daß es eine sehr beachtliche und vielseitige Intervention des Staates gegenüber der Wirtschaft gibt und $\mathrm{daB}$ sie nach unserer geltenden Verfassung zulässig ist. Wo aber ihre Grenzen liegen, ist ungewiß. Es wird Aufgabe der Zukunft sein, entweder im Wege der gerichtlichen Praxis oder durch gesetzgeberische Einzelentscheidungen in Bezug auf die Grenzen der staatlichen Intervention die erforderliche Klarheit zu schaffen.

Scheuner-Bonn (Schlu\&wort): Man pflegt gewöhnlich am Schlusse einer Debatte auszusprechen, da 8 man sich durch die Diskussion bereichert fühlt, aber heute bezeugt es die Wahrheit, dies auszusprechen. Die Debatte ist heute auf einer ungewöhnlichen Höhe gestanden, weil sie in eine solche Fülle dringender und wichtiger Probleme hineingeführt hat, daB wir sie in keiner 
Weise haben erschöpfen können. Ich will mich daher in meinen abschließenden Bemerkungen auch mit einer Auswahl begnügen.

Zunächst möchte ich eingehen auf die Frage, die Herr Klein an mich gestellt hat. Sie ist zu einem Teil schon von Herrn Leibholz von einem sehr viel weiter ausgreifenden Gesichtspunkt aus beantwortet worden. Ich teile seine Auffassung, daB die zweifellos von bedeutender Gelehrsamkeit getragenen Auffassungen von Röpke und Hayek nicht dem wirklichen tieferen Zuge unserer Zeit entsprechen. Ich bin wie er der Utberzeugung, da $B$ das liberale Bild ein hohes und in gewissen Grundsätzen, soweit es nämlich die elementaren Grundwerte der Persönlichkeit enthält, bleibendes Bild darstellt. Aber für ein Massenzeitalter der abhängigen Menschen vermag es nicht mehr das Notwendige hinreichend auszusagen. Die Kritik hieran läuft schon durch das ganze I9. Jahrhundert, wo Anatole France ironisch von der Freiheit, unter den Bogen der Seinebrücken zu schlafen, gesprochen hat. Dieses etwas bittere Wort enthält eine Einwendung, die man doch nicht ganz überhören kann. Ich habe ferner in meinem Vortrag darauf hingewiesen: Freiheit können wir heute nicht mehr nur als Freiheit vom Staate verstehen. Zur Freiheit gehört nun auch die Sicherung der elementaren Lebensbedürfnisse. Als der Präsident Roose velt sein Wort von den vier Freiheiten aussprach, tat er einen Ausspruch, der ernste Anliegen und Bedürfnisse unseres Zeitalters zur Geltung brachte. Für den Arbeiter ist die Sorge um die Erhaltung seiner Arbeitskraft und der Schutz vor dem Alter wohl wichtiger geworden als das Eigentum oder manche der traditionellen Freiheiten. Dem ist allerdings eines hinzuzufügen:

Ich habe nicht ohne Absicht an den Beginn meines Referates jene Münchener Eingabe gestellt. Sie verrät uns eine Problematik des I9. Jahrhunderts. Viele Kreise haben in dem Durchdringen der hochliberalen Wirtschaftsfreiheit nicht unbedingt einen Gewinn gesehen. Wir können das Erbe des I9. Jahrhunderts nur dann würdigen, wenn wir uns seine nahe Verbindung mit der Zeit seit I750, mit der Ära des spätabsoluten Beamtenstaates und seiner Verwaltungsleistung vor Augen halten, die so viele unserer Grundanschauungen geprägt hat. Diese spätabsolute Periode war zweifellos von stärkeren sozialen Rücksichten bewegt als die ihr folgende des liberalen Denkens. Nicht mit Unrecht hat in diesem Zusammenhange Herr Merk auf Adolf Wagner hingewiesen; man darf hier auch den Namen Schmoller mitanfügen. Und man darf ferner hinweisen auf den berühmten preußischen Statistiker Hoffmann, dessen Werk über die Gewerbefreiheit von I84I von großem Einfluß auf die preußische Gewerbeordnung von I845, die Vorstufe der heutigen Gewerbeordnung, gewesen ist. Hoffmann, einer der Altersfreunde des Freiherrn vom Stein, hat gerade sehr deutlich auch die sozialen Probleme bei der Ein- 
führung der Gewerbefreiheit erkannt. Auf diese Komponente unserer Vergangenheit greift in manchem die moderne Entwicklung bei uns wieder zurück. Freilich tritt heute auch eine Erscheinung auf, die nicht ungefährlich ist. Es ist die Möglichkeit, daß sich in den Gruppen und Verbänden Mittelstellungen zwischen Individuum und Staat ausbilden, die den einzelnen in Abhängigkeit überführen. In der immer weiter greifenden Einordnung eines großen Teiles unserer Mitbürger in kollektive Zusammenhänge, in betriebliche Abhängigkeiten und Vorteile, schließlich auch in eine unleugbare geistige Massenformung liegen nicht unbedenkliche Tendenzen. Könnte sich etwa eine neue ständisch-feudalistische Machtbildung hier entwickeln? Das führt auf das Problem des übergeordneten, des ausgleichenden und sichernden Staates, der dem Individuum auch vor der Macht dieser Gruppen Schutz gewährt.

Wenn man mir die Gegenüberstellung von Zentralverwaltungswirtschaft und freier Marktwirtschaft entgegen gehalten hat, so muB ich bekennen, daB ich mit Absicht den Gebrauch dieser Worte vermieden habe. Ich kann mich der mit dieser modellartigen Kontrastierung arbeitenden Theorie nicht anschließen, weil sie das eigene Recht gerade des besonderen Typus unserer gegenwärtigen interventionistischen Wirtschaft mit partiellen Lenkungen leugnet.

Was die Kartellfreiheit anlangt, so gebe ich zu, daß die Frage, ob ein Vorgehen gegen Kartelle Schutz der Freiheit ist oder aber interventionistischer Eingriff, nicht logisch beantwortet werden kann, sondern eine Sache der Uberzeugung ist. Sie hängt mit dem soeben erwähnten Punkte zusammen. Ist man der Auffassung, $\mathrm{da} B$ allein die freie Marktwirtschaft eine natürliche Ordnung darstellt, dann gehört hierzu auch die Bekämpfung solcher Entwicklungen, die sie von innen her aufzulösen drohen. Das ist die in der Theorie von Eucken und Böhm vertretene These. Ich erkenne gern an, $\mathrm{da} B$ eine freiheitliche Wirtschaftsordnung in der Gegenwart, unzweifelhaft wirksame Kräfte entfaltet, die eine stark gebundene nicht aufzubringen vermag. Aber ich sehe in ihr kein naturgegebenes System. Daher sind für mich jene Eingriffe eine Intervention, in der man das Idealbild freien Wettbewerbes auch entgegen andersgerichteten Tendenzen der Wirtschaft verteidigt. Die Eingriffe zur Herstellung dieses Bildes idealen freien Wettbewerbes bergen große Gefahren in sich. Man könnte sich nämlich vorstellen, daß der zunächst gegen die Kartelle auftretende Staat allmählich daxu gelangt, sie doch als Ausnahmen zu genehmigen und schließlich sich mit ihnen teilweise verbündet. In jedem Falle aber wird eine staatliche Kartellbekämpfung zu fortwährenden neuen Einwirkungen und Umgestaltungen im Wirtschaftsablauf genötigt. 
Was die Frage von den Standards der Wirtschaftsverwaltung anlangt, die Herr Ipsen aufgeworfen hat, so scheinen mir seine Beispiele sehr glücklich gewählt und sehr bedeutsam. Es wird in der Tat notwendig sein, unsere Lehre von den Ermessensfehlern und von den Mängeln staatlicher Interventionen durch anschauliche, konkret gefaßte Standards und Muster zu beleben. Gerade die ausländische Rechtsprechung bietet uns höchst lehrreiche Beispiele der Herausarbeitung solcher HilfsmaBstäbe der Bewertung und Begrenzung staatlicher MaBnahmen unter dem Gesichtspunkt der VerhältnismäBigkeit oder der ,,reasonableness". Nur darf man, darin stimme ich Hern Abendroth zu, mit der hierdurch bewirkten Bindung des Gesetzgebers und der Verwaltung nicht zu weit gehen. Dem Wirtschaftenden darf der Staat ein gewisses Risiko überlassen, das von ihm zu tragen ist. Nur dort, wo der Staat selbst zur Ursache eines Risikos wird, wie in einem französischen Falle, wo er aus politisch-sozialen Rücksichten die weitere Fortführung einer Fabrik herbeiführt, die wegen Verlusten geschlossen werden soll und dadurch neue Verluste hervorruft, wird der Staat $z u$ einer Verantwortung herangezogen werden können ${ }^{\mathbf{1}}$ ). Hier liegt für uns die Anregung, unter Ausblick auf die so interessante und lebendige französische Theorie des risque exceptionnel, auch unsere Lehre der öffentlichrechtlichen Entschädigung weiterzuentwickeln.

Ob dagegen, wie Herr Ipsen meint, die Widerrufslehre mit ihren Konsequenzen ohne weiteres auf die Planänderung des Staates zu übertragen ist, ist mir zweifelhaft.

Zur Frage des Rechtsschutzes hat Herr Naumann sehr wertvolle Ergänzungen zu meinem Referate gebracht, für die ich ihm ganz besonders dankbar bin. Trotzdem bleibe ich bei meinen Thesen, dà $\mathrm{B}$ der Begriff des subjektiven Rechts als in gewissem Sinne veraltet angesehen werden kann. Er ist ein seinerzeit aus Ubernahme zivilrechtlicher Begriffsbildung aufgenommener $\mathrm{Be}$ griff, der seine Funktion erfüllt hat, heute aber keine klare und befriedigende Abgrenzung mehr gewährt. Viele der angeführten Rechtsmittel aus dem französischen Recht, in denen der einzelne einen Schutz gefunden hat, würden an der Handhabung des deutschen Rechts im Hinblick auf das subjektive Recht nicht durchgedrungen sein.

Ich darf das noch an einem in seiner Tatsächlichkeit farbigen Falle beleuchten. Es handelt sich um den Anspruch auf den Gemeingebrauch, der nach deutscher Auffassung - nur Herr Forsthoff nimmt einen abweichenden Standpunkt ein - keinen recht-

1) Société Boulanger et Cie. Conseil d'Etat Sirey 1948, 3, 2r. Die Haftung des Staates ergibt sich nicht aus faute, sondern aus dem Nachteil, den der Unternehmer erleidet und der nicht als "une chargo lui incombant normalement" angesehen wird. 
lichen Anspruch gewährt. Ein französischer Kunstschriftsteller hat wiederholt die Restaurationsarbeiten der französischen Verwaltung an der Kathedrale von Chartres fachlich als Verunstaltung kritisiert. Ich darf hinzufügen, die französischen Kathedralen sind seit der Trennung von Staat und Kirche und der Einziehung des Kirchengutes Staatseigentum, bleiben aber ihrer Widmung erhalten, also kirchlichen Zwecken weiter bestinumt. Als unser Autor eines Tages nach Chartres kommt und einen der Türme ersteigen will, bedeutet ihm der Wächter, ihm sei das Betreten des Turmes verboten, nur ihm, nicht anderen Leuten. Der empörte Besucher erhebt Klage, und nach sieben Jahren - inzwischen ist der zweite Weltkrieg über Frankreich hinweggegangen - entscheidet der Staatsrat, hebt das Verbot der Besteigung auf und billigt - ein seltener Fall im französischen Recht sogar dem Verletzten eine kleine Geldentschädigung zu. Denn das Verbot des Zutritts beruhte auf einer Weisung der ministeriellen Direktion der schönen Künste, die sich über die Kritiken des Schriftstellers geärgert hatte. Thre Entscheidung, dem Besucher den Zutritt zu denjenigen Teilen der Kathedrale, in denen kein Gottesdienst stattfindet - denn zu den Kulthandlungen muß natürlich der Besucher zugelassen werden - zu versagen, ist ungesetzlich ${ }^{2}$ ).

Ich möchte auch in einem zweiten Punkte bei meiner Ansicht beharren. Ich halte die Annahme des rechtlichen Interesses als Maßstab nicht aus dem Grunde für bedenklich, weil man damit einer Popularklage Vorschub leisten würde. Es ist durchaus möglich, auch hier eine feste Grenze zu finden. Ich möchte auch der Meinung sein, daB in bestimmten Fällen es angebracht wäre, auch Gruppen, die für ihre Mitglieder eintreten, als Klagberechtigte anzuerkennen. Ich halte den Vorschlag von Herrn Naumann, das gesetzlich auszusprechen, für wohl gangbar.

Ein anderes Problem hat Herr Krüger berührt. Er hat auf die mancherlei Gefahren hingewiesen, die aus einer häufigen An-

3) Carlier, Conseil d'Etat Sirey 1950, 3, 49. Inzwischen ist mir zu der kirchenrechtlichen Seite des Falles eine britische Entscheidung bekannt geworden, die die Frage des Zutritts nicht aus dem Gesichtspunkt des domaine public und des freien und gleichen Zugangs hierzu 16st, sondern aus religiősen und staatskirchlichen Gründen. Das Kapitel von Westminster verweist einen Fremdenführer aus der Kirche, der beim Gottesdienst mit einem Schilde „Cole's Sightseeing Tours Guide" herumgeht. Die MaBnahme wird gebilligt nicht wegen ungebührlichen Benehmens des Klägers, sondern deshalb, weil jeder Engländer zwar das Recht des Zutritts zu seiner Pfarrkirche hat, in der er noch heute verpflichtet ist, den Gottesdienst zu besuchen - es entsprechen sich also Pflicht zum Besuch des Kults und Zutrittsrecht zur eigenen Pfarrkirche -, aber die Westminsterkirche nicht Pfarrkirche, sondern eine besondere Kollegiatkirche ist, in der es keine Pfarrzugehörigen gibt. Vgl. Urteil von King's Bench in Cole v. P. C. (r936) 3 All E. R. ro7. 
wendung der Subventionen und anderer Förderungen erwachsen können. Zweifellos kann auf diesem Wege ein großer Einfluß erobert werden; gerade deshalb wird dies Mittel innerhalb unserer bundesstaatlichen Ordnung mit so großem Mißtrauen betrachtet, weil es dem Bunde hier Gelegenheit zu weitreichender Gewinnung von Einfluß geben könnte. Ich glaube, mit Verboten wird hier weniger zu gewinnen sein als mit rechtlicher Festlegung von Maßstäben und mit Aufsicht. Natürlich liegt in einer parlamentarischen Aufsicht auch die Gefahr, daB sie zu Tauschgeschäften untereinander führt, indem man seinen Freunden gegenseitig staatliche Hilfen zuwendet. In den Vereinigten Staaten ist dies sogenannte pork-barrel System nicht unbekannt.

Endlich eine Antwort auf die Frage einer umfassenden Planung, die Herr Abendroth aufgeworfen hat. Ich räume hier ein, daB ich gegenüber einer umfassenden nationalen Planung noch keinen ganz festen Standpunkt gewonnen habe. Man kann der Meinung sein, $\mathrm{daB}$ auch eine weitergreifende wirtschaftliche Planung noch nicht in ein System totaler Kontrolle der Wirtschaft hineinführt. Die totalitäre Wirtschaft, die unter dem Namen Zentralverwaltungswirtschaft hier als Schreckbild entgegengehalten wird, ruht doch in ihren so tief bedenklichen Erscheinungen nicht allein auf den wirtschaftlichen Ursachen. In ihr ist doch auch das Menschenbild zerstört, auf dem die Freiheit aufgebaut ist, sie überschreitet doch auch in ihrer Rechtsanschauung die Grenzen, die wir dem Staate ziehen. Ich möchte es daher für möglich halten, auch eine umfassendere Planung mit dem demokratischen Staate zu vereinen. Es gibt aber auch einen Punkt - das ist der richtige Kern in jener Lehre von den beiden extremen Möglichkeiten -, von dem ab das wirtschaftliche System voller Lenkung auch die rechtlichen und verfassungsrechtlichen Freiheiten verkürzt und erschüttert. Dann kann in der Tat eine Bindung am Arbeitsplatz, eine durch währungspolitische Maßregeln drohende Eigentumsumschichtung, eine Lähmung der wirtschaftlichen Energien eintreten. Im Zusammenhang hiermit steht die Frage der Monopole. Die Zulässigkeit von Finanzmonopolen steht nach dem Wortlaut des Grundgesetzes außer Zweifel. Andere Monopole halte ich für begrenzt statthaft. Der richtige Maßstab könnte vielleicht im Blick auf Art. 2 GG darin gefunden werden, da - von fiskalischen Motiven abgesehen - nur solche Monopole zulässig sind, wo die bestehende Ordnung mehrerer Unternehmen das vorhandene Bedürfnis nicht befriedigen kann und das öffentliche Interesse eine Zusammenfassung gebietet.

Zum Schluß noch einmal den aufriçhtigen Dank an alle Diskussionsredner. 